\title{
A Dialogue among Genres during the Late Eighteenth Century: Conjectural History and Travellers' Textual and Visual Representations of Cultures of the Near East and India
}

by

\section{Pamela M. Barber}

A thesis submitted to the Faculty of Graduate and Postdoctoral Affairs in partial fulfillment of the requirements for the degree of

\section{Doctor of Philosophy}

in

\section{Cultural Mediations}

\section{Carleton University}

Ottawa, Ontario 


\begin{abstract}
This dissertation explores the part played by historical frameworks of thought in the interpretation and representation of unfamiliar cultures. Examining works produced by British travellers to the Near East and India during the period of the Scottish Enlightenment, I argue that a significant and reciprocal relationship was found among the genres of historical writing and travellers' textual and visual representations of distant societies during the late eighteenth century. With social change accompanying rapid growth in commerce and global trade, ideas put forward in the new sub-genre of conjectural history served as a framework in the interpretation of all cultures, whether in Europe or in distant regions of the globe. While conjectural historians used the information provided by travellers in developing a new meta-narrative of history, travellers' representations in turn reflected the historical frameworks of the time. All aspects of societies could be discussed within the framework of stadial theory, including political structures and systems of jurisprudence, social structures, material culture, and architecture.
\end{abstract}

In addition, I argue that representations of distant societies were framed within the European aesthetic categories of central influence during the period, such as the sublime and the picturesque, while at the same time extending the subject matter typically associated with those categories. Further, an interplay of aesthetic and historical frameworks of thought is evident in late eighteenth-century representations of distant cultures.

This dissertation offers a close historicizing of a particular moment in Enlightenment thought in light of the many critiques put forward following the late 
eighteenth century concerning the assumptions, methodologies, and theories of the conjectural historians. The comparative method explored by conjectural historians, which encompassed observations spanning centuries as well as continents, led to a highly influential body of thought concerning the interconnections among economic, political, and social structures in societies. The differing types and degrees of distance characterizing the genres of historical writing and travellers' representations played a part in a dialogue of reciprocal reference, in which the close details of lived experience informed a removed, philosophical gaze as British travellers and conjectural historians attempted to mediate cultural distance. 


\section{Acknowledgements}

With much gratitude, I would like to acknowledge the invaluable support of my dissertation supervisor, Mark Salber Phillips. I have enjoyed our countless conversations throughout this project, and I have felt extremely fortunate knowing that I could count on his experience, perception, and judgment, not to mention his erudition and vast store of knowledge. I have appreciated his understanding that in a work of this scope, one must spend time exploring various approaches and avenues of research. His guidance in relation to some of these avenues, in addition to some of the ideas put forward in his own work, have played a central role in shaping this thesis.

I would also like to acknowledge the contributions of the members of my Committee, Danielle Kinsey and Julie Murray. The helpful recommendations that they offered, as well as our enjoyable conversations, were much appreciated.

In addition, I would like to acknowledge the stimulating and supportive atmosphere of the Institute for Comparative Studies in Literature, Art and Culture (ICSLAC) at Carleton University. Through the courses I have taken in the Ph.D. program, the talks I have attended, and the intellectual contribution of faculty from several disciplines, I have found encouragement in ICSLAC in pursuing a truly interdisciplinary approach to complex questions in cultural studies.

Lastly, I cannot end a section of acknowledgements without mentioning my son, Glen, with whom I have always shared lively conversations about any number of topics. Throughout every journey, he has been the centre of my world. 
Introduction 1

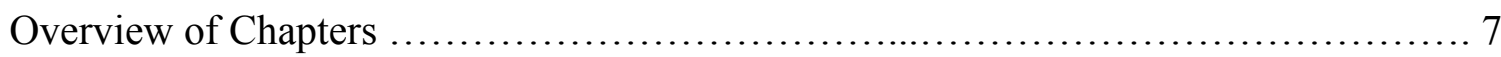

Critiques of, and Continuing Interest in, Conjectural History $\ldots \ldots \ldots \ldots \ldots \ldots \ldots \ldots \ldots \ldots \ldots$

Chapter One - Late Eighteenth-century Historical Frameworks of Thought ....... 27

New Historiographical Horizons of the Late Eighteenth Century $\ldots \ldots \ldots \ldots \ldots \ldots \ldots \ldots . \ldots 28$

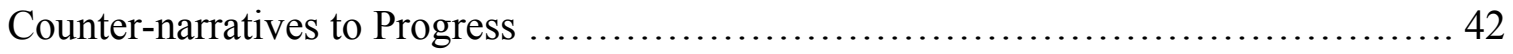

The Bookshelves of the Conjectural Historians: Sources of Information .............. 46

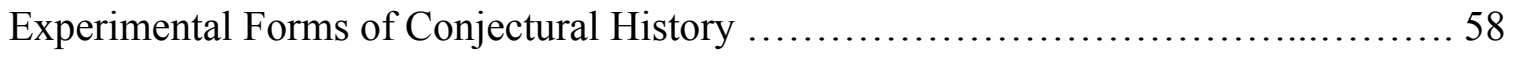

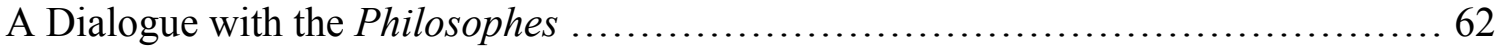

Anxieties regarding Change: Reflections of Edmund Burke ....................... 73

Chapter Two - Travellers' Representations during the Late Eighteenth Century: Epistemological Position among Genres ................................. 86

Stadial Ideas in Travellers' Representations of Cultures .......................... 89

Travellers' Representations in an Increasingly Commercial World ................. 96

Formal Structure: Immediacy and Questions of Subjectivity $\ldots \ldots \ldots \ldots \ldots \ldots \ldots \ldots \ldots \ldots \ldots$

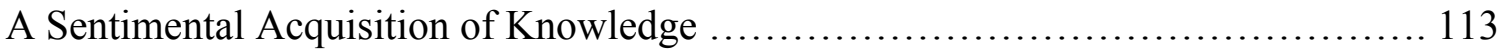

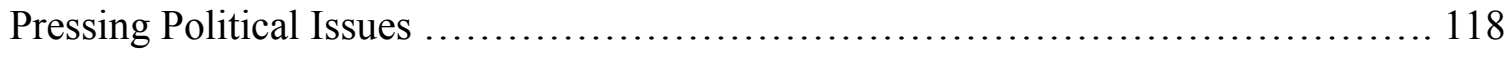

Chapter Three - Political and Social Structures in the Near East and India ...... 125 
Theories and Observations: The Near East

Private Property: Nomadic Tribes

The Power of Monarchs: The Ottoman Empire

Individual Rights: The Status of Women in Eastern Societies

William Robertson's Examination of Hindu Culture 146

James Mill: Another View within the Framework of Conjectural History 155

Chapter Four - Luxury Debates and the Material Culture of the East ........... 178

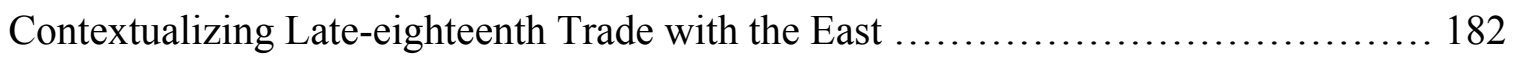

Commerce and Luxury in the View of David Hume ............................ 186

British Appreciation of the Material Culture of the East .......................... 190

Written Comments of Travellers and Conjectural Historians ................. 190

Acquisition ............................................................. 196

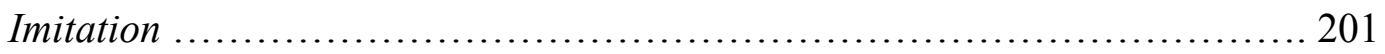

Visual Representation ............................................... 205

Diverse Modes of Expression of Conflicting Attitudes ........................... 216

Chapter Five - Depictions of Architecture and Scenes of Daily Life: Historical Meditations regarding Achievement and Decline .......................... 225

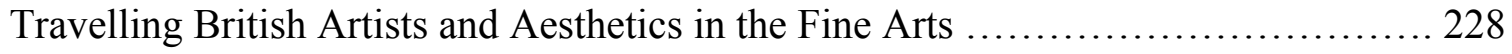

Architectural Encounters ................................................... 235

Classical Reference and Historical Allusion .................................. 238

Modes of Seeing: Aesthetic Categories and Depictions of Place ................... 243 


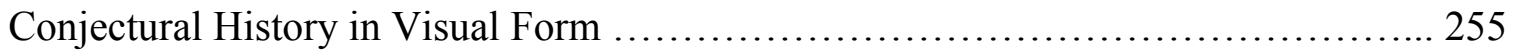

Perceptions of Decline: Musings regarding the Patterns of History .................... 265

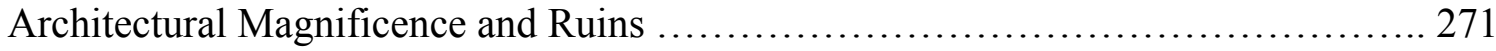

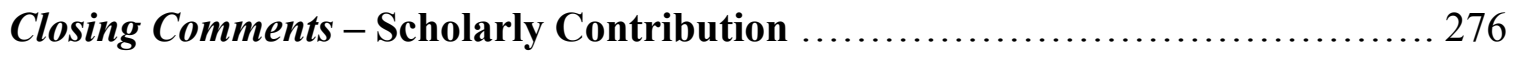

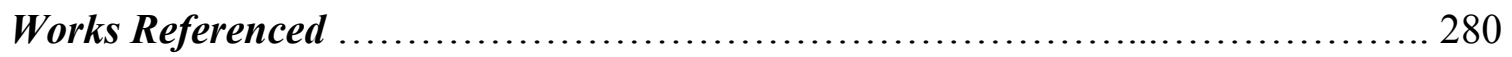




\section{Introduction}

Questions concerning the interpretation and representation of cultures, whether close to home or far away, comprise a vast subject that has ranged across countless genres and academic disciplines in various changing forms throughout the centuries. The frameworks of thought, and the conventions of writing and visual representation, involved in the study of cultures reflect their historical moment. The aim of this thesis is to explore one area within this exceedingly broad field by examining the epistemological frameworks involved in the interpretation of unfamiliar cultures.

More specifically, I will examine the role of historical frameworks of thought in travellers' cultural interpretations and representations during the late eighteenth century. Cultures at a great distance could indeed be unfamiliar during the early modern period, before the relative ease of travel, the availability of images through advances in technology, and the increasing hybridity of today's world. A significant and mutual challenge of interpretation could accompany the encounters that occurred with the expansion of global contact and trade.

Historical narratives provided a significant source of reference in the attempts of late eighteenth-century travellers to interpret distant cultures. Reciprocally, travellers' depictions of the details of everyday life in distant societies, in written accounts and visual representations, were viewed as a central source of evidence by philosophers and historians who were attempting to construct broad and general theoretical frameworks regarding the economic, political, and social aspects of cultures. A circular relationship

of mutual reference existed between the works of late eighteenth-century travellers and historians, and the genres of historical writing, travellers' written accounts, and visual 
representations of distant lands may each be more fully understood if considered in relation to the others. In particular, I will examine the interconnections among these genres in relation to the textual and visual representations of British travellers to the Near East and India.

Several historical narratives played a part in European representations of the East during the late eighteenth century. Accounts of the interactions between Europe and the East had for many centuries included narratives of both trade and conflict. In addition, Classical histories of the ancient civilizations of Egypt, Greece, and Rome and Biblical narratives continued to provide a central source of reference in late eighteenth-century writing. Further, philosophers and historians of the Scottish Enlightenment developed a new meta-narrative of history, in which they conjectured that all societies progress through similar stages of development. As well as providing information that was used in the development and substantiation of these new theoretical approaches in historical thought, travellers' written and visual depictions of distant societies mirrored, and in some instances complicated, the ideas being put forward in the works that came to be known as conjectural history.

An interplay of narratives characterizes the new forms of historical writing that emerged during the period of the Scottish Enlightenment, and the approach of referring to various historical narratives was echoed in travel writing of the period. Traditional chronological narratives concerning ancient as well as contemporary empires were interwoven within the broad meta-narrative of conjectural history. Classical texts were searched for information regarding the ancient cultures of Greece and Rome that could be used as a comparative reference in considerations of cultures, such as Hindu culture in 
India, that were viewed as having been similarly advanced in ancient times, and travellers to the Near East consulted the same texts for historical insight regarding the societies that had once existed around the sites and monuments of antiquity. Both travellers and historians turned to aspects of stadial theory in their attempts to interpret cultures in relation to which little traditional historical information was available. Threads of longstanding narratives of global trade and military encounter, Classical and Biblical references, and the ideas of conjectural history were intertwined to form the fabric of late eighteenth-century representations of the cultures of the Near East and India.

As discussed by Frank Palmeri, the approach of conjectural history could be used during the period in works that considered the development of societies in relation to stages that were defined according to various factors. Condorcet, for example, defined stages according to scientific and technological developments, but he noted that with the powers and interests of rulers and religious authorities, social progress did not always accompany each stage. David Hume examined typical stages in religious thought in societies, although he suggested that certain aspects of societies were no different and even more problematic with later forms of religion. In most conjectural histories of the Scottish Enlightenment, however, stages of development were defined according to differing economic structures of societies; in particular, matters relating to property formed one of the pillars of the stadial theory explored by the Scottish writers. Nonetheless, all aspects of societies could be considered within the framework of conjectural history in their works. A wide range of characteristics of societies were categorized according to developmental stages not only in activities relating to agriculture, the manufacture of goods, and commerce, but also politics and forms of 
government, the treatment of women, and the arts. Stadial theory provided the framework of late eighteenth-century European interpretations of cultures, whether of the East, the New World, or various nations within Europe.

India's cultures were of great interest during the period of the Scottish Enlightenment. While European exploration into the interior of Africa and contact with Australia increased later in the nineteenth century, British involvement in India expanded during the late eighteenth century, as European powers competed for control of trade with the subcontinent and other areas of the East. My aim in this thesis is not to specifically explore the aspects of hybridity, as discussed, for example, by Homi Bhabha, that may be suggested by travellers' representations of encounters with the societies of the Near East and India but rather to examine the role of historical thought in the process of forming interpretations of cultures that are unfamiliar. Curiosity played a significant part in encounters during the period of the expansion of the trade of the European East India Companies, and the complexity of the cultures of India indeed posed a considerable interpretive challenge to Europeans of the late eighteenth century. While information regarding the societies of the Near East and India during the late eighteenth century will necessarily inform this thesis, the historical frameworks of British perceptions of those cultures are the only direct object of study.

British perceptions of the cultures of the East often included generalizations, which is not surprising at a time in which travel was extremely difficult and limited for most people. Turkey, for example, was then referred to as the 'Orient' and was considered a distant destination, and until the expeditions of Napoleon, Egypt was still relatively unknown to most Europeans. Further, with the nature of theoretical thought 
and its goal of formulating abstractions from a myriad of specificities, conjectural historians similarly proposed generalizations regarding European societies.

Generalizations regarding all cultures, near and far, played a significant role in writing of the time, as philosophers and historians searched for new theories that could encompass all societies. As stated by P.J. Marshall, "to expect eighteenth-century scholars not to categorize or to generalize is to expect a great deal."

The Enlightenment is typically characterized as a period in which a shift from faith to reason occurred within European thought. In the emerging science of man, the use of empirical evidence, which formed the basis of the new scientific approach, was applied to the study of the structures of societies and the behaviour of individuals. While traditional historical writing presented chronological narratives describing significant events and the actions of statesmen, late eighteenth-century historical writing reflected the shift in focus, also evident in fictional writing of the time, to the manners and customs of societies both at home and abroad. Late eighteenth-century British historiography was characterized by innovative forms of historical writing that could accommodate this expanded focus, which included the general conditions of all segments of societies. The works of thinkers of the Scottish Enlightenment constituted a significant contribution to the nascent social sciences, providing some of the early groundwork in fields such as sociology, anthropology, and political and economic theory.

A dialogue is evident between traveller's representations and conjectural history during the late eighteenth century, in which the close details of the observations and lived experiences of the traveller were brought into the more removed and philosophical view

\footnotetext{
${ }^{1}$ Marshall 120.
} 
of conjectural historians in the attempt to bridge sometimes great cultural distance. Mark Salber Phillips points out that many types of distance may be at play to varying degrees of separation or closeness in historical representation. He proposes an expanded notion of historical distance that is "reconceived in light of the wider set of engagements that mediate our relations to the past, as well as of the full spectrum of distance-positions from near to far." ${ }^{2}$ The same types and varying degrees of distance may be involved in representations of societies across geographical and cultural distance as in representations of societies across temporal distance.

Travellers' detailed descriptions of the manners and customs of cultures across the globe reduced the sense of distance involved in British perceptions of faraway societies. For writers of the Scottish Enlightenment who had not travelled to the places to which they referred, travel accounts provided evidence from a close viewpoint. Phillips points out that distance in historical writing may vary with respect to intellectual positioning, and in this sense the work of conjectural historians represents a removed gaze over a vast general history of mankind. The position of philosophical distance in conjectural history was balanced by the close witnessing provided in the accounts of travellers. Whether attempting to bridge a temporal or cultural distance, it is the sense of reducing the distance inherent in the process of witnessing that may explain not only the extensive use of travellers' accounts in historical writing but also the immense popularity of the genre of travel writing during the late eighteenth century. In negotiating distances both between past and present and between culturally familiar and unfamiliar, historians and travellers turned to each other's writing as sources of information.

\footnotetext{
${ }^{2}$ On Historical Distance 14.
} 
In "Of Essay Writing," David Hume proposes a dialogue between the "learned," who pursue scholarly interests, and the "conversable," who prefer sociable "company and conversation." Hume questions the possibility of finding either "topics of conversation fit for the entertainment of rational creatures"4 without books, or useful works by philosophers "who never consulted experience in any of their reasonings, or who never searched for that experience, where alone it is to be found, in common life and conversation." ${ }^{5}$ In this thesis, I will underline and explore the interconnections among late eighteenth-century genres involved with cultural interpretation and representation that bring to life Hume's description of the possibilities that may arise with a dialogue between philosophy and lived experience. Not only did philosophers and historians of the Enlightenment avidly read travel writing, but the works of late eighteenth-century travellers indicate the significant extent to which their depictions of cultures were influenced by the theories being put forward at the time in Britain and Europe. Travellers' accounts often reflected the theoretical discourses of the time, and the political and social aspects of cultures being explored within the framework of stadial theory may be traced in travellers' representations of distant cultures.

\section{Overview of Chapters}

Within each chapter of the thesis, the focus is directed to a particular set of forms and ideas relating to the interpretation and representation of cultures during the late eighteenth century. The first two chapters will contextualize the genres of historical

\footnotetext{
${ }^{3}$ Hume. "Of Essay Writing." 1.

${ }^{4}$ Ibid.

${ }^{5}$ Ibid. 2.
} 
writing and travellers' textual and visual representations. Each of the following chapters will consider a different set of the aspects of societies that were typically considered within stadial theory. Like the dramatis personae of a play, the conjectural historians, travellers, and painters who will play a part in this thesis will make appearances on stage whenever particular components of their works inform the dialogue. Our cast of writers and artists will be gradually introduced, and by the end of the thesis, each character will likely seem like a familiar acquaintance to the reader.

Frameworks of thought exist within the specificity of historical moments. Ideas emerge gradually and for a myriad of tangible reasons. Historical circumstances continually change, and existing ideas change in consideration of new circumstances. Genres are shaped by the ideas of an historical moment, responding to the demands of their times. As I will examine in Chapter One, many factors played a part in lateeighteenth-century developments in historiography and particularly in the emergence of conjectural history. Along with the trends of the period in historical writing generally, I will consider the particular characteristics of the new sub-genre of conjectural history, including its assumptions and methodology and the sources of information on which conjectural historians based their theories. I will also examine the counter-narratives of the time to ideas of progress, and I will briefly consider the influence of the works of the philosophes of the European continent.

In Chapter Two, I will examine genres of travellers' textual and visual representations of distant societies within the literary landscape of the late eighteenth century more broadly. As well as providing information regarding different cultures that was used as evidence by conjectural historians, the ideas and tropes of stadial theory were 
reflected in travellers' representations of societies not only at a great distance but also closer to home. I will specifically examine the epistemological position of travellers' representations among other genres during the period. The challenges of cultural interpretation have typically fallen into the hands of novelists, historians, anthropologists, travellers, and visual artists, in works that raise significant epistemological questions regarding modes of access to knowledge of societies, the representation of this knowledge, and the discourses that influence the types of knowledge being provided.

In this chapter, I will consider questions of form in relation to subjectivity and sentiment. The formal structure of letter or journal entry that was typically used in travellers' accounts, whether genuine or adopted as literary device, greatly enhanced the sense of immediacy that added to the interest of travellers' depictions. A semblance of eye-witnessing in the use of first-person literary forms could lend believability to travellers' representations. At the same time, this subjectivity could also work against the credibility of an author's text. In addition, the affective aspects of travellers' encounters with distant societies were often recorded in their accounts. Travellers' anecdotes relating to personal encounters provided a source of information regarding the manners and customs of societies of the East, in some instances reflecting and at other times complicating some of the generalizations of the conjectural historians. Further, travellers' representations that were aimed at commercial appeal frequently included literary conventions that were popular at the time, such as the aesthetic categories commonly employed in descriptions of landscapes. Published travel writing often included political commentary that would be of interest to the British public in relation to contemporary events and debates. 
While the stadial theory set out in works of the Scottish Enlightenment was most often based on the economic organization of societies, with notions of property constituting the definitive factor of various stages of advancement, every aspect of a society could be drawn into its categorizations, including political and social structures and attitudes. Indeed, political theory and the stages of development of systems of jurisprudence were some of the central interests of thinkers of the Scottish Enlightenment, and this focus of the works of conjectural historians and travellers is explored in Chapter Three. Late eighteenth-century notions of what was then referred to as 'Oriental despotism' ${ }^{, 6}$ were commonly found in historical and travel writing of the period relating to the East. With emerging Enlightenment attitudes relating to liberty and equality, Eastern cultures were critiqued in relation to the tyranny of their political structures and the apparent lack of individual rights and freedoms. European writers frequently discussed the treatment of women as an example of the lack of individual liberty in Oriental societies.

These generalized critiques were found in representations of both the Ottoman Empire and the Mughal Empire. Conjectural historians and travellers associated notions of 'barbarity' not only with the economic and social structures of nomadic tribes but also

\footnotetext{
${ }^{6}$ Within recent discourses, terms such as the 'Orient' and 'Oriental despotism' have, likely due to the extensive influence of Edward Said's discussions of what he terms 'Orientalism,' fallen out of what is seen as acceptable usage. In late eighteenth-century usage, the 'Orient' simply signified an extensive geographical region east of the 'Occident' and carried no more connotations that today's usage of 'East' and 'West.' Similarly, the terms that were typically used within late eighteenth-century stadial theory, such as 'savage' and 'barbaric,' have also been seen as unacceptable following the emergence of postcolonial discourses. Such terms are nonetheless used throughout this thesis since they were the terms used during the period under consideration and any attempts to constantly bracket these terms would risk being both imprecise and excessively cumbersome within the context of discussing late eighteenth-century frameworks of thought.
} 
with the stage of political development exemplified in the tyranny of rulers in the East. John Logan's writing includes discussions of nomadic tribes as well as Oriental despotism, and Eyles Irwin's travel account includes descriptions of the desert tribes and the influence of the Ottoman empire in the Near East. With the growing involvement of the British in India, the Hindu and Mughal cultures of the subcontinent were of great interest, and both William Robertson and James Mill offer extensive discussions of the political structures, systems of jurisprudence, and social structures of Hindu societies in India.

Conjectural historians considered refinement in the arts and manufactures as an indication of a society's relative stage of advancement. In Chapter Four, I will explore British attitudes during the late eighteenth century in relation to the material culture of the East. Longstanding narratives of trade indicated that the goods of the material culture of the East had been eagerly sought since antiquity. The increase in global trade during the late eighteenth century resulted in an influx into Britain of goods from the East as well as from the Americas. British appreciation of the material culture of the East was evident in comments of travellers in their written accounts of their journeys as well as in discussions of conjectural historians. In addition to the acquisition by consumers in Britain of goods arriving from the East through trade, travellers typically collected fine goods of material culture along their journeys. As seen in the popularity of Turquerie and Chinoiserie, interest in the fashions of the East in clothing and domestic objects was evident throughout the early modern period. British manufacturers imitated Eastern design and tried to match not only the aesthetic qualities and workmanship of goods from the East but also Eastern abilities in the large-scale production of goods for varied markets. 
Elements of material culture of the East were vividly depicted in visual representations. In portraiture and conversation pieces of the time, travellers in the East sometimes donned local costume, and the attention of travelling artists was drawn to objects of material culture in their depictions of domestic scenes in the East.

Indeed, the evident appreciation of the material culture of the East during the late eighteenth century played a significant role in the luxury debates of the time, in which conjectural historians as well as others in the British public questioned the social effects of increasing global trade. Thinkers of the Scottish Enlightenment discussed the social benefits of commerce. At the same time, concerns with the effects of what was perceived as excessive luxury were expressed in various modes during the late eighteenth century, including the controversies of the time relating to nabobs.

Travellers' visual depictions of architecture in the Near East and India offer another important source of evidence of British appreciation of Eastern artistic achievement. In addition, instances of architectural cross-reference began to be seen in the British landscape. The focus of Chapter Five is directed to travellers' representations of architecture and scenes of daily life in the Near East and India. Visual observation plays a central role in the experience of a traveller who is encountering new landscapes and cultures for the first time. While continued time in a distant society may bring deeper understanding, travellers' interpretations of a culture are often based at least in part on the views to be seen on their routes. Further, travellers' depictions, in both textual and visual form, of distant societies similarly provided those at home with their first notions regarding unfamiliar areas of the world. 
Depictions of place were therefore not surprisingly a significant component of most accounts of late eighteenth-century travellers. Landscape, architecture, sites of historical significance, artistic achievements of antiquity, and scenes of everyday life were common subjects of travellers' written descriptions and visual representations. The visual evidence provided by travellers constituted one of the main sources of the perceptions of distant societies held by those in Britain who avidly read travellers' accounts and looked at the sketches, aquatints, and paintings of travelling artists.

As with the mutual influence between travellers' representations and historical thought, a reciprocal relationship existed between travellers' depictions and aesthetic theory of the late eighteenth century. Travellers' impressions of the views that they encountered played a central role in the definitions of the aesthetic categories of the sublime, the beautiful, and the picturesque that were set out during the late eighteenthcentury. In turn, European aesthetic conventions and ideas of the time were applied and expanded in depictions of the new landscapes and unfamiliar scenes of life being observed by late eighteenth-century travellers to distant regions of the globe.

Further, interconnections between historical and aesthetic modes of thought were in constant play within travellers' representations. Historical narratives pertaining to particular societies were suggested in travellers' depictions of structures of historical significance, such as palaces, temples, tombs, and forts. In addition, the Ottoman and Mughal Empires were perceived as being in decline during the late eighteenth century, and discussions of the causes, social effects, and material evidence of this supposed decline are found in the writing of conjectural historians and in the representations of travellers. The aesthetic of the sublime accompanied historical meditations regarding the 
cycles of civilizations in travellers' depictions of both architectural magnificence and ruins.

The ideas of conjectural historians were also explored in the use of the picturesque in travellers' textual and visual representations, with the manners and customs of distant societies being depicted within this aesthetic framework. Detailed depiction of groups of figures was typically included in the foreground of a picturesque sketch or painting, through which travelling artists provided ethnographical information in representations of scenes that depicted common daily activities in both urban and rural

areas. Stages of societies were suggested in visual representations of architecture and the occupations of everyday life.

\section{Critiques of, and Continuing Interest in, Conjectural History}

As underlined by George Stocking, an historicist approach is necessary to properly situate earlier thinking, and without doubt the tropes and ideas of stadial theory were pervasive in late eighteenth-century representations of cultures, forming a sub-text in much writing of the time. Further, hypotheses relating to similarities in the typical patterns of development that occur in different societies, as explored by the conjectural historians of the Scottish Enlightenment, did not altogether disappear following the late eighteenth century. Theories regarding the political and social effects of economic change were to continually reappear in various guises in several different fields.

Frank Palmeri points out the extensive influence of late eighteenth-century conjectural history in the emerging disciplines of the social sciences during the nineteenth century. Palmeri notes, for example, that although Karl Marx sets out a different 
grouping of stages of societies in his discussions, he "maintained and even intensified the focus on material forms of production and their relation to social, legal, religious, and cultural forms." ${ }^{77}$ In the mid-nineteenth century, a range of views were explored in the emerging discipline of anthropology, from discussions of race and theories of polygenism with an ahistorical focus on 'facts' to assumptions of monogenism and an approach that was historical and conjectural. During the following decades, the approaches of the late eighteenth-century conjectural historians were of central influence in works exploring theories of cultural evolution, such as, for example, Primitive Culture by E.B. Tylor, which was published in 1871. At the end of the nineteenth century, the focus again shifted, as Franz Boas and his students engaged instead in "detailed analysis of small preliterate societies and rejected the theory of cultural evolution generally." After the end of World War I, anthropologists such as Bronislaw Malinowski and Alfred RadcliffeBrown advocated "structural-functional analysis based on immersive study, by participant-observers, of a single people bound in a limited space." ${ }^{\prime 9}$ However, recognition of the theoretical insight that can be gained through comparative and historical studies of cultures has not been totally lost but rather has since reappeared in different forms in various fields as well as in anthropology itself.

Notions relating to relative stages of advancement among societies were also brought into the realm of political agenda, as the ideas of the conjectural historians were increasingly summoned throughout the nineteenth century in justifications of colonialism. The aim of bringing 'civilization' to remote societies, based on the view that European

\footnotetext{
${ }^{7}$ Palmeri 87.

${ }^{8}$ Ibid. 161.

${ }^{9}$ Ibid.
} 
societies were in a more advanced stage of development, was increasingly put forward in political rhetoric as being one of the goals of British policy with respect to its expanding empire. Depictions of Oriental despotism as barbaric, for example, indeed carried negative connotations within emerging political views of the Enlightenment.

Bernard Cohn has pointed out that British motivations in the acquisition of knowledge relating to India's cultures became increasingly entwined with the goals of colonial administration. Cohn discusses the accelerating drive to accumulate knowledge "to enable the British to classify, categorize, and bound the vast social world that was India so that it could be controlled."10 He states, "In coming to India, they [the British] . . invaded and conquered not only a territory but an epistemological space as well."11 Paul Keen notes the common use of a "colonizing metaphor" 12 that highlighted the expansion of knowledge along with territory, in which the collection of knowledge about remote cultures was represented as an expansion of "the borders of the republic of letters."13 Scholars have pointed out that throughout the nineteenth century, representations of India, as well as of other regions of the globe, were increasingly inflected by imperialist agendas. As the first period of curiosity was followed by greater familiarity and a growing history of colonial experience, with increasingly entangled political and economic involvements with distant colonies, a "more strident cultural chauvinism" ${ }^{14}$ became increasingly evident in British texts concerning remote cultures.

\footnotetext{
${ }^{10}$ Cohn 4.

11 Ibid.

${ }^{12}$ Keen 214.

13 Ibid. 209.

${ }^{14}$ Ibid. 233.
} 
In scholarship examining Western representations of cultures of the East, the arguments of Edward Said relating to Orientalism have, of course, been extremely influential. ${ }^{15}$ Drawing on Michel Foucault's discussions of the connections between knowledge and power, Said suggests that generalizations regarding distant cultures reflected Western self-perceptions, in which the West defined itself in relation to the East in terms that were used as justifications of imperialist aims, as much or more than actual aspects of the various cultures of the East. Said argues that exotic depictions of the East did not reflect the actual characteristics or the diversity of the societies to which generalizations were often applied.

Scholars have discussed the politics involved in the construction of the binaries of self and 'Other' that increasingly played a part in cultural representations during the colonial period. It must be noted, however, that the very notion of self and 'Other,' in the sense in which it is discussed in much postcolonial discourse, was foreign to the paradigm of late eighteenth-century thought. Self and perhaps 'self in earlier economic circumstances' would be a much better description of the thought of the conjectural historians. The Enlightenment belief in commonalities in human nature was the assumption underlying all of the political and social theories of the late eighteenthcentury conjectural historians. Stadial theory was based on the view that mankind is everywhere the same and that differences in societies relate only to the circumstances that have affected their stages of development. Supposedly scientific approaches in studies of characteristics related to race gathered force only later in the nineteenth century. The extent to which any commonalities may be assumed with respect to basic human nature

15 See Said's text Orientalism. New York: Vintage, 1979. 
and behavior in particular circumstances has, of course, also been extensively challenged in more recent academic approaches of cultural relativism. With the assumption of late eighteenth-century conjectural historians that all human beings share basic commonalities, their argument that each culture reflects a complex and continually changing set of effects of a myriad of circumstances generally precluded an essentializing view of cultures as being entities that reflect certain intrinsic, relatively enduring characteristics. While late eighteenth-century historians typically regarded the structures of various aspects of a society as being interconnected, this holistic view of cultures did not extend to notions of societies as organic cultural entities ${ }^{16}$ but rather as continually fluid communities whose characteristics were shaped in long trajectories of gradual change.

The temporal distancing of remote cultures involved in the stadial theory of the late eighteenth century proved to be extremely persistent in ethnographical studies. Johannes Fabian has criticized what he considers to be the underlying approach of temporal distancing in anthropology that is based on global power relationships and political agendas. Fabian points out the long persistence of a "denial of coevalness"17 in ethnological studies, which he states have been "affected by historically established relations of power and domination between the anthropologist's society and the one he studies." ${ }^{18}$ New approaches in historiography have, of course, continued to emerge since the period of the Scottish Enlightenment. The consideration of wider segments of

\footnotetext{
${ }^{16}$ As discussed by Palmeri, the view of the German writer Johann Gottfried Herder that each culture has a unique, organic character was less typical in some ways than the views of many of the late eighteenth-century conjectural historians.

${ }^{17}$ Fabian 28

${ }^{18}$ Ibid. 31.
} 
societies that increasingly appeared in the historical writing of the late eighteenth century has been further expanded by postcolonial scholars. The attempt to recover the voices of numerous groups not heard in political historical narratives is exemplified in the recent body of work relating to the history of South Asia that is referred to as Subaltern Studies. Ranajit Guha, for example, argues that the focus in the historiography of India has typically been directed to narratives relating to the oppositions and collaborations of elite political actors, both indigenous and British, with the significance and complexity of the role of the labouring population not being appropriately represented. ${ }^{19}$ Dipesh Chakrabarty points out the continuance of Enlightenment categories of thought and stadial narratives in relation to the political modernity of South Asia. He argues that while European traditions of thought, such as the ideas of Karl Marx, commonly form part of the intellectual landscape of previously colonized nations, the implications of the abstract categories put forward in European political thought do not adequately describe particular aspects of, for example, South Asian societies. ${ }^{20}$

As discussed by Palmeri, even during the nineteenth century, before the emergence of postcolonial discourses in the twentieth century, thinkers often "disavowed or attacked conjecture and speculation even as they engaged in conjectural historical modes of thinking and writing themselves." ${ }^{21}$ Palmeri explains, "In many cases, the author's silence about their debt to conjectural histories results from pressure to claim

${ }^{19}$ See, for example, Guha's essays "On Some Aspects of the Historiograpy of Colonial India" and "The Prose of Counter-Insurgency." Selected Subaltern Studies. Eds. Ranajit Guha and Gayatri Chakravorty Spivak. Oxford: Oxford University Press, 1988.

${ }^{20}$ See Chakrabarty's text Provincializing Europe: Postcolonial Thought and Historical Difference. Princeton, New Jersey, Princeton University Press, 2000.

${ }^{21}$ Palmeri 3. 
scientific authority and to avoid charges that they indulged in wild speculation." ${ }^{, 22}$ By the late nineteenth and the twentieth century, the Enlightenment reliance on reason was in itself increasingly challenged, as a result of emerging theoretical thought relating to the complexities of individual subjectivities as well as the more tangible atrocities that marked the history of the twentieth century.

There is no shortage, therefore, of rather formidable critiques standing in the background of any examination of the relationships between historical thought and travellers' representations of distant societies during the late eighteenth century. The framework of conjectural history has been discredited in postcolonial discourses, with the ideas of stadial theory being linked to, and therefore dismissed along with, the political agendas of imperialism. Postcolonial discourses constitute an important backdrop to any study relating to European perceptions of distant societies, and as is the case with most complex subjects, elements of validity are generally found in many different arguments. At the same time, not all, and certainly not the most basic and general, aspects of the role of historical frameworks in cultural interpretation and representation can be subsumed within the arguments of Orientalism and imperialism. With no denial of the validity of the criticisms of some of the uses of Enlightenment thought, or the strength of the motivations underlying those criticisms, the aim of this thesis is to examine, at the same time, an early phase during the early modern period in which events inspired the development of new economic, political, and social theory by some of the most brilliant thinkers of the time. The equation frequently put forward between the ideas of the

${ }^{22}$ Ibid. 13. 
conjectural historians and emerging imperialist agendas is too simplistically neat in much postcolonial discourse.

Thinkers of the late eighteenth century were presented with a vast puzzle relating to the characteristics of societies, and they turned to every source of information available to them in their attempts to develop frameworks of thought that could encompass observations literally spanning the globe. As intellectuals, their theorizing was far more disinterested than suggested in some postcolonial discourses. They equally sought to understand, and criticize the effects of, the processes of change that they were observing in their contemporary European societies. Writers of the time did not hesitate to point out the negative aspects of societies in an advanced stage of commercial development. In the works of late eighteenth-century conjectural historians, economic development was not simplistically conflated with cultural progress.

No-one can foresee future events, not even thinkers of the Scottish Enlightenment, and many aspects of their writing make it clear that they did not view the aims of their studies as being tied to the political agendas of imperialism. Rather, the late eighteenth century was a time of immense curiosity, as the intellectual field was in a sense blown wide open with the discoveries of travellers around the globe. The global interactions that ultimately led to European empires took place over centuries. Not only did notions of empire continually change, but the relationships between metropole and distant regions were always incredibly complex, consisting of countless variations around the globe and also within any particular region. Even late eighteenth-century politicians themselves could not predict the outcomes of European competition in global trade or the future extent of colonial expansion. As stated by Maya Jasanoff, the British Empire "had 
not come into being as a single 'project' plotted by London schemers; nor was it united by a homogeneous culture, ethnicity, or national identity."23

This thesis therefore seeks to add to a growing body of writing that asks only to complicate some of the equations adhered to in much postcolonial discourse. The processes of globalization studied in recent discourses of transnationalism, with a focus on the effects of migrations of people and commodities, ${ }^{24}$ are not entirely new, and some of the ideas of the conjectural historians are not without echoes in our contemporary world. Technological advancements have resulted in a period of increase in global connectedness, whether in trade, communications, migrations of people, or environmental effects, as rapid today as that witnessed by conjectural historians during the late eighteenth century. The march of technological development causes ongoing change in societies everywhere, and sadly much is lost in the process. Indeed, part of the pleasure in examining perceptions of cultures during the late eighteenth century is found in the glimpse that this affords of a world in which the characteristics of different cultures were more diverse and the appearances of all societies, whether in Europe or in the East, were in some ways perhaps also more visually beautiful, before the prevalence of the uniformity of cities of high-rise buildings, concrete, commercial signs, and traffic.

Societies struggle with the balance between cultural traditions and the effects of ever more alienating industrial development and the imbrication of all national economies within the global marketplace. Thinkers of the Scottish Enlightenment lived in an earlier period of the same process, and their writing continues to resonate today. Attempts to

23 Jasanoff 121.

${ }^{24}$ See, for example, Arjun Appadurai. Modernity at Large: Cultural Dimensions of Globalization. Minneapolis: University of Minnesota Press, 1996. 
find at least some room for academic consideration of works concerning some of the typical cultural effects of economic development independently of normative judgment are without doubt of value.

Palmeri notes that the use of conjecture, which was involved in the methodological approach of late eighteenth-century conjectural historians and was later criticized, continued in later social theory. He suggests that the value of conjecture has been too quickly dismissed, stating that "it is time to reevaluate the use of the term 'conjecture' as pejorative and to consider the necessary role that conjecture and inferentially grounded speculation still play not only in scientific hypotheses but also in theory and knowledge in the social sciences. ${ }^{, 25}$ Late eighteenth-century conjectural historians were not at all unaware of the limitations of conjecture, as seen in the explicit discussions of the value of conjecture despite its limitations in, for example, the writing of David Hume and Jean-Jacques Rousseau. Conjectural history opened up "a space for theory, for hypotheses, ${ }^{26}$ relating to the history of mankind outside of the providential explanations of religious narratives. The writing of the conjectural historians stands as a complex attempt to interpret distant cultures, in which factors such as environmental circumstances and religious views, for example, were extensively considered. With the comparative approach, spanning both centuries and continents, conjectural historians brought a distant, theorizing position to the study of cultures that continued in many branches of later social theory.

Within postcolonial discourses, earlier views of distant cultures are typically criticized as having been Eurocentric. Indeed, most areas of thought, including the

\footnotetext{
${ }^{25}$ Palmeri 17.

${ }^{26}$ Ibid. 14.
} 
interpretation and representation of cultures, are to some extent always inescapably circumscribed within the parameters of the bodies of thought existing within the culture of the thinker. However, these bodies of thought are not entirely static. Hans-Georg Gadamer discusses the hermeneutic circle within which a cultural language acquires its most basic significations. At the same time, Gadamer discusses the possibilities of encounters that result in expansions of understanding within cultural languages, which he refers to as a fusion of horizons. Mikhail Bakhtin discusses the dominance of hegemonic voices, but at the same time he notes the interplay of subordinate voices within the polyphony of a cultural language as well as the dialogic exchange with extraneous voices. To what extent the interpretation of an unfamiliar culture, as carried out by a thinker of any society, ever succeeds in a fusion of horizons or an extension of understanding through dialogic exchange may be questioned. Nonetheless, the works of late eighteenthcentury historians and travellers typically exhibit at least an extensive effort to acquire some degree of cultural understanding of distant societies.

The writing of late eighteenth-century conjectural historians and travellers reflects above all an intense interest in distant cultures. Global travel posed many difficulties and dangers during the late eighteenth century, and comments relating to shipwrecks, pirates, and illness are sprinkled throughout travel writing of the period. Despite the many challenges, a sense of wonder and curiosity typically characterizes the accounts of travellers during this time. Hermione Almeida and George Gilpin point out the openness of the first European artists to travel in India, drawing attention to a "brief and vibrant period" ${ }^{27}$ in which British artists in India "did not respond with deliberate limitation and

${ }^{27}$ Almeida and Gilpin viii. 
distance for what they saw but, rather, with delight and fascination for the new subjects, new vistas, new ideas, and new inspirations." 28

The genres of travellers' written accounts and visual representations responded to the wish of many in Britain to be able to picture distant societies in their imagination. In a period of accelerated expansion of global trade, merchants and administrators looked for information that would be helpful in negotiating their involvement with distant cultures. In addition, the detailed observations of distant societies provided by travellers comprised a central source of reference in the new sub-genre of conjectural history. Information regarding the cultural diversity to be found around the globe stood beside observations of significant social and political change in European societies, and philosophers and historians of the Scottish Enlightenment analyzed this growing wealth of evidence in developing general theories within the meta-narrative of conjectural history.

In turn, historical writing was viewed as a primary source of reference in the attempts of late eighteenth-century travellers to interpret what they were seeing. Travellers to the Near East and India referred to narratives of encounters accompanying the conflict and the trade of relatively recent centuries in addition to the narratives of ancient Classical texts and the Hebrew Bible. With little historical information being available regarding distant societies, travellers drew upon the ideas and terms of conjectural history in their cultural representations. A close and reciprocal relationship of reference exists between the genres of historical writing and travellers' textual and visual representations during the late eighteenth century, and aesthetic approaches of the time

\footnotetext{
${ }^{28}$ Ibid.
} 
were continually at play in travellers' depictions of place. David Hume's proposed dialogue between philosophy and lived experience was realized in the mutual reference of conjectural historians and travellers. In this dialogue, the differing types and degrees of distance that may characterize genres, as discussed by Mark Salber Phillips, resulted in a highly influential body of thought. In their representations of societies of the Near East and India, British historians, travellers, and artists attempted to mediate cultural distance during the period of the Scottish Enlightenment. 


\section{Chapter One}

\section{Late Eighteenth-century Historical Frameworks of Thought}

In this chapter, I will consider the wider context of British historiography of the late eighteenth century along with the circumstances, both within Britain and globally, that led to the emergence of the new sub-genre of conjectural history. The assumptions and methodological approaches of the conjectural historians will be discussed. I will consider counter-narratives of the time to ideas relating to the progress of societies, as found in the discussions of conjectural historians regarding the cycle of advancement and decline of civilizations that is seen repeatedly throughout history as well as their concerns with some aspects of commercialized societies. The sources of information upon which conjectural historians based their theories will be discussed, as well as other genres of writing that contributed to the body of historical representation during the late eighteenth century. I will consider the experimentation in form that accompanied the wider focus of conjectural history. The relationship of the Scottish Enlightenment with the philosophes of the European continent will be exemplified through a consideration of Montesquieu's The Spirit of the Laws and Rousseau's Discourse on the Origins and Foundations of Inequality among Men. Finally, I will end the chapter with the further contextualization provided by an examination of Edmund Burke's Reflections on the Revolution in France. As an influential contemporary text of political theory, Burke's work exhibits clearly the issues and concerns of the late eighteenth century relating to the political and social effects of economic change. Further, Burke's text demonstrates that the preoccupations found in works of conjectural history with the trajectories and the pace of historical 
change, and the causes of characteristics of structures of societies, both in European states and further away, were a pervasive element of texts of various genres during the period.

\section{New Historiographical Horizons of the Late Eighteenth Century}

During the late eighteenth century, Classical texts retained their position as an important component of education. Conjectural historians were well versed in the works

of ancient Greece and Rome and held a reverence for ancient authors and for the decorum of traditional historical narrative concerning the exploits of statesmen and political events. Mark Salber Phillips points out that while a political focus continued to be found in much historical writing of the late eighteenth century, Classical historical narrative no longer provided a sufficient model for British historiography. As the effects of becoming a modern, commercial society became increasingly apparent in Britain, new questions were raised in many areas of academic thought, and a vastly expanded set of subjects began to appear under the domain of historical writing. Along with the growing field of political economy, the social aspects of past and contemporary cultures were examined. Under the common phrase of 'manners and customs,' areas of private as well as public life were now considered appropriate areas of study. The domain of individual feeling was increasingly explored, with the inclusion of sentiment in writing of the period offering insight regarding the effects of historical and political events and of social change.

Instead of viewing social change as resulting from the innovations of visionary statesmen, political organizations and events began to be seen as continually emerging 
from the social conditions and the prevalent views of a society. In his Elements of the Philosophy of History, John Logan writes:

The arrangements and improvements which take place in human affairs result not from the efforts of individuals, but from a movement of the whole society. From want of this attention to this principle, History hath often degenerated into the panegyric of single men, and the worship of names. ${ }^{1}$

In his History of England, David Hume suggests the explanatory use of the study of manners and customs, inserting an Appendix in his chronological narrative "to make a pause: and to take a survey of the state of the kingdom, with regard to government, manners, finances, arms, trade, learning. Where a just notion is not formed of these particulars, history can be little instructive, and often will not be intelligible."2

Along with an increased circulation of currency and products of trade, global expansion brought information about remote cultures with very different modes of behaviour and structures of societies to those found in the states of Europe. At a time in which aristocratic power was increasingly challenged by social classes that were gradually acquiring more wealth, many late eighteenth-century thinkers examined questions regarding the rights of man and more egalitarian structures of government. Accounts of distant societies served as additional input in the re-evaluation of the domestic issues of European states. It was in this context of the uncharted parameters of a new world, both at home and abroad, that conjectural history became one of the central preoccupations of the Scottish Enlightenment.

\footnotetext{
${ }^{1}$ Elements 14.

${ }^{2}$ History of England Vol. V, 124.
} 
Encounters with remote societies led to the realization of the extraordinary diversity of human cultures, which in turn led to the interest in attempting to explain this diversity. Europeans had read the writing of travellers with great interest since the beginning of the expansion of global exploration. Accounts of early Spanish, Portuguese, and Dutch voyages included descriptions of encounters with very different societies, and European readers were fascinated with the range of information that these accounts provided, some of which could be quite fantastical. By the late eighteenth century, however, British involvement in faraway lands was rapidly increasing, and the accounts of merchants, administrative officials, and military officers became a matter of central interest to many in Britain. In addition to the need for information for the purposes of trade and administration, the extent and the causes of the cultural diversity being encountered around the globe presented a puzzle to British scholars of the time.

Thinkers of the Scottish Enlightenment were also interested in analyzing the changes occurring in many aspects of life in Britain. Philosophers and historians in Edinburgh and Glasgow, including Adam Ferguson, John Millar, Adam Smith, William Robertson, and Henry Home, Lord Kames, were surrounded by evidence that the manners and customs of societies may change according to economic circumstances. They witnessed the shift from an agriculturally to commercially based society that was experienced very rapidly in Scotland following its political union with England through the Act of Union of 1707. With the accelerated growth of commerce and global trade, they observed the acquisition of wealth by new segments of an increasingly urban society. In Samuel Johnson's account of his journey to Scotland in 1773, Journey to the Western Islands of Scotland, he describes "a nation, of which the commerce is hourly 
extending and the wealth increasing." 3 He states that "before the Union, the Scots had little trade and little money." Social changes accompanied the commercial activity, as could be seen in cities such as, for example, Edinburgh and Glasgow that were experiencing new prosperity. In addition, the ways of life of the Highland clans were disappearing. New laws set out "the prohibition of arms, and the change of dress" of the Highlanders, and Johnson observes:

There was perhaps never any change of national manners so quick, so great, and so general, as that which has operated in the Highlands . . . We came thither too late to see what we expected, a people of peculiar appearance, and a system of antiquated life. The clans retain little now of their original character, their ferocity of temper is softened, their military ardour is extinguished, their dignity of independence is depressed, their contempt of government subdued, and their reverence for their chiefs abated ... Their language is attacked on every side. Schools are erected, in which English only is taught ... Such is the effect of the late regulations, that a longer journey than to the Highlands must be taken by him whose curiosity pants for savage virtues and barbarous grandeur. ${ }^{6}$

Writers of the late eighteenth-century were interested in the manners and customs of European societies as well as of societies far away, and Johnson's words indicate the pervasiveness of the terms of stadial theory in writing of the time. Similar impressions are found in Tobias Smollett's novel The Expedition of Humphrey Clinker, in which his little band of fictional travellers describe growing urban centres in England and Scotland,

\footnotetext{
3 Johnson 4.

${ }^{4}$ Ibid. 7.

${ }^{5}$ Ibid. 46.

${ }^{6}$ Ibid.
} 
leisure activities of new social classes, and ancient superstitions of the clans in the Scottish Highlands.

Historians of the late eighteenth century were also presented with the widening application of the new scientific method. Throughout the period of the Enlightenment, the development of theories based on inference from empirical evidence increasingly took the place of explanations based on religious faith. This methodological approach, as explored, for example, in the philosophy of David Hume, was applied to the study of human behaviour and societies. Depictions of distant societies and observations of the changes in European societies supplied the empirical evidence in a process of conjecture that led to a body of nascent social theory. The convergence of the new method and the availability of new information resulted in the construction of a general theory regarding the development of societies that could encompass evidence of both cultural difference at a distance and cultural change at home.

A new science of man emerged during the Enlightenment. Attempts to develop new systems of thought that would replace the Scholastic edifice of earlier centuries stand as one of the salient features of the Enlightenment. Scholastic philosophers, such as Thomas Aquinas, had sought to reconcile the social theories of the philosophers of antiquity, as put forward by Aristotle, with the tenets that formed the basis of Christianity. Religious belief and social theories were challenged by the rational approaches that emerged in the seventeenth century. Thomas Hobbes and Hugo Grotius suggested new explanatory models of human social behaviour. As stated by Anthony Pagden, "by toppling the old Aristotelian idea of natural sociability, Hobbes had not merely demolished the Aristotelian-Thomist theological order; he had also banished any 
possibility of any mode of human interaction that was not based upon a crude calculation of interests," ${ }^{, 7}$ with little ground left that could theoretically support any ethical model of human behaviour in societies. During the eighteenth century, a new model of social theory began to emerge that was shaped by the "reasonings of the economists" ${ }^{\prime 8}$ in Scotland as well as by the philosophes of the European continent.

The attempt to apply approaches based on reason to all branches of knowledge formed one of the motives in the development of conjectural history. In their study of the societies of man, conjectural historians used a methodological approach that found its roots in the late seventeenth century. Sir Isaac Newton used observations of physical phenomena in his scientific method, and John Locke discussed the centrality of empirical observation in the formation of all types of knowledge. With the approach of developing theories by observation and inference being applied to individual human behavior as well as aspects of whole societies, the new science of man was in place, and thinkers of the Scottish Enlightenment were influential in this new area of study.

Edmund Burke's A Philosophical Enquiry into the Origin of our Ideas of the Sublime and Beautiful offers an example of the application of the new approach to matters of human behavior. Burke sets out aesthetic categorizations that are based on the responses that are commonly evoked in individuals through the characteristics of various subjects. Burke's proposed methodology reflects the language of logic and scientific method:

from a careful survey of the properties of things which we find by experience to influence those passions; and from a sober and attentive investigations of the laws of

\footnotetext{
${ }^{7}$ Pagden 67.

${ }^{8}$ Ibid. 42.
} 
nature, by which those properties are capable of affecting the body and thus of exciting our passions. If this could be done, it was imagined that the rules deductible from such an enquiry might be applied to the imitative arts. ${ }^{9}$

He states that the result is a text "proposing his notions as probable conjectures, not as things certain and indisputable." 10

David Hume's philosophical writing was of great influence on thinkers of the late eighteenth century. Hume explores the theoretical basis of the methodological approach adopted by the conjectural historians, which involved extrapolation from empirical evidence, in some of his works. The use of conjecture in relation to topics "where several ages have intervened, and only scattered lights are afforded us by ancient authors" ${ }^{11}$ is illustrated in his essay "Of the Populousness of Ancient Nations." Hume asks, "how can we pretend to calculate those [the populations] of ancient cities and states, where historians have left us such imperfect traces?"12 He proceeds by closely examining the works of ancient authors for relevant evidence, and then, in combination with observations of contemporary societies, he proposes various theories through the use of conjecture.

Through his examination of theological arguments regarding the existence of a divine entity in his Dialogues concerning Natural Religion, Hume demonstrates the limitations of basing conclusions on conjecture, although he admits its practical use in the functioning of society and in dispelling superstition. According to Hume, only concepts with which no contradiction is possible can be known with certainty, and while we may

\footnotetext{
${ }^{9}$ Burke A Philosophical Enquiry 1.

${ }^{10}$ Ibid. 2.

${ }^{11}$ Hume "Of the Populousness of Ancient Nations" 240.

12 Ibid. 225.
} 
believe causal relationships to be likely, they can never be proven. Hume denies the reasoning by which "[w]e always make inferences which presume that causal connections in nature are uniform."13 Thinkers of the Scottish Enlightenment explicitly acknowledge the probable aspect of their reasoning, with the use of the word 'conjecture' appearing frequently throughout their writing.

Philosophers and historians of the Scottish Enlightenment set out a stadial theory, in which they argued that all societies typically advance through similar stages. They defined these stages as corresponding to the differing economic organizations of societies: the least developed stage, referred to as the savage, occurred in the conditions of subsistence of the hunter/gatherer; the next stage, referred to as the barbaric, was seen in the ways of life of nomadic tribes; and the more advanced stages corresponded to agricultural and later commercial societies. The manners and customs that accompany each stage were extensively examined and categorized. All aspects of societies, including, for example, political structures, the treatment of women, and the arts, were categorized in relation to the proposed stages of development of societies.

Adam Smith introduces the four-stage division in his Lectures on Jurisprudence along with the thought that legislation is related to the economic stage of a society: it will be proper to observe that the regulations concerning them [matters relating to property] must vary considerably according to the state or age society is in at that time. There are four distinct states which mankind pass thro: $-\mathrm{I}^{\text {st }}$, the Age of

\footnotetext{
${ }^{13}$ Dialogues 14.
} 
Hunters; $2^{\text {dly }}$, the Age of Shepherds; $3^{\text {dly }}$, the Age of Agriculture; and $4^{\text {thly }}$, the Age of Commerce. $^{14}$

The same division of stages of economic development, as well as their connection with legislation in a society, is found in Montesquieu's The Spirit of the Laws, in which he suggests:

The laws are very closely related to the way that various peoples procure their subsistence. There must be a more extensive code of laws for a people attached to commerce and the sea than for a people satisfied to cultivate their lands. There must be a greater one for the latter than for a people who live by their herds. There must be a greater one for these last than for a people who live by hunting. ${ }^{15}$

Early economic theory, as put forward, for example, by Adam Smith, played a significant role in the new stadial theory. Ideas relating to property were central in the definition of the proposed stages of development. Notions of individual property did not, supposedly, play a role in the 'savage' stage of the hunter-gatherer. In the 'barbaric' stage, property consisted of only the herds and flocks of nomadic tribes. Property held more importance in the agricultural phases of societies and became ever more central and complex in later stages of manufacturing and commerce.

Stadial theory was based on the underlying assumption of commonalities with respect to basic human nature. John Logan states, "Man is one animal; and, where the same situations occur, human nature is the same." ${ }^{\prime 16}$ George Stocking notes that early thinkers most often assumed a common origin of all mankind and that extensive theories

\footnotetext{
${ }^{14}$ Smith Lectures on Jurisprudence 14.

${ }^{15}$ Montesquieu The Spirit of the Laws 289.

${ }^{16}$ Elements 17.
} 
of polygenism were not discussed until the nineteenth century. Similarly, characteristics of peoples were not generally considered specifically under the term 'race' until the nineteenth century. Obvious differences among peoples were sometimes discussed in texts of the Scottish Enlightenment in terms of questions regarding the effects of geography and climate. In his Sketches of the History of Man, Lord Kames, for example, includes an extended discussion regarding the characteristics of peoples in relation to climate. As stated by Stocking, the common view during the period was that Human nature was fundamentally the same in all times and places, and its development was governed by natural laws; man developed from his earliest state in a slow, unilinear evolutionary progress whose eventual goal was perfection and whose highest present manifestation was western European society. ${ }^{17}$

Conjectural historians asked not whether it was possible for all societies to progress to the level of economic advancement evident in Europe but rather why various cultures had remained in less developed states. The argument that all societies proceed through similar stages is expressed by Logan:

It is peculiar to the human race, that the species improves as well as the individual. Hence a noble field presents itself to the philosophical Historian, to trace the rise and progress of Society, and the history of Civilization. All nations have been rude before they were refined. The commencement of History is from the wood and the wilderness, mankind appear every where, at first, a weak and infant species; and the most celebrated nations trace back their origin to a few wandering tribes. ${ }^{18}$

\footnotetext{
${ }^{17}$ Stocking 26.

${ }^{18}$ Ibid. 18.
} 
Stadial theory formed a central component in the construction of a general historical framework that could be applied to all societies, which came to be known as universal or conjectural history.

With the premise that certain aspects of human nature are universal, philosophers and historians argued that differences among cultures are the result of varying circumstances. Conjectural historians extensively questioned the various factors that may be involved in the cultural diversity found throughout the globe. They recognized, for example, the significant part played by superstitions, religious beliefs, and structures of religious authority within various cultures. As we will examine in Chapter Three, late eighteenth-century writing concerning the cultures of the Near East and India commonly included discussions regarding Muslim and Hindu religious traditions and institutions.

As well as proposing theories concerning ancient periods in the history of mankind for which no documentary or material evidence was available, conjectural historians "attempted to investigate and speculatively explain transitions between major stages of periods of social history." ${ }^{, 19}$ In pondering the factors leading to transitions in stages of a society's development, conjectural historians recognized that "human beings establish and proceed through different social forms without intending or even realizing the consequences of their actions. ${ }^{20}$ As discussed by Frank Palmeri, the general view of late eighteenth-century conjectural historians was that new structures within societies are initially non-contractual. Adam Smith, for example, suggests that with feudal lords increasingly directing their resources to the acquisition of luxury goods rather than the

\footnotetext{
${ }^{19}$ Palmeri 25.

${ }^{20}$ Ibid. 18.
} 
support of their tenants, and manufacturers supplying the goods, a change in social structure gradually occurred that was not planned by either group.

Travellers' depictions of distant cultures were seen as providing information regarding various stages in the development of societies. Conjectural historians suggested that clues regarding the 'natural history of man' could be found in the conditions of supposedly less advanced societies, with the "extrapolation from the present backwards into the past." 21 While societies of many of the indigenous peoples of North America were often suggested to exemplify the state of savagery, as seen, for example, in Robertson's History of America, the nomadic tribes of Arabia and Egypt were often characterized as barbaric, as seen in Eyles Irwin's account of his travels through these regions. At the same time, some remote cultures were perceived as having declined from a state of advanced development, with the recognition that ancient civilizations that had flourished in India and in certain areas of Central and South America, as well as, of course, in Egypt, Greece, and Rome. In any case, aspects of all cultures were discussed in terms of their relative advancement within stadial theory. Robertson writes, "When compared with other parts of the New World, Mexico and Peru may be considered as polished states." 22 At the same time, Robertson notes that if compared to societies of Europe, "the inferiority of America in improvement will be conspicuous . . . The people of both the great empires in America, like the rude tribes around them, were totally unacquainted with the useful metals.",23

\footnotetext{
21 Marshall 93.

${ }^{22}$ History of America Third Vol., Book VII, p. 271.

${ }^{23}$ Ibid. 272.
} 
Conjectural historians suggested that the characteristics of remote cultures likely resembled the ancient inhabitants of Europe. Adam Ferguson, for example, argued that depictions of the indigenous peoples of the Americas offered clues in attempting to imagine the lives of Europeans in earlier times, stating that "the inhabitants of Britain, at the time of the first Roman invasions, resembled, in many things, the present natives of North America: they were ignorant of agriculture; they painted their bodies; and used for cloathing, the skins of beasts. ${ }^{24}$ Ferguson writes:

It is in their present condition that we are to behold, as in a mirrour, the features of our own progenitors; and from thence we are to draw our conclusions with respect to the influence of situations, in which we have reason to believe that our fathers were placed. What should distinguish a German or a Briton, in the habits of his mind or his body, in his manners or apprehensions, from an American, who, like him, with his bow and his dart, is left to traverse the forest; and in a like severe or variable climate, is obliged to subsist by the chace ${ }^{25}$

Late eighteenth-century travellers to the Near East and India frequently related the sense of stepping into the past, and in turn conjectural historians thought that travellers' descriptions of distant cultures offered clues regarding ancient societies.

P.G. Marshall discusses the various aims of historical scholarship relating to the Near East, stating that traditional historical studies involved the search for "new material ... to supplement existing textual authorities, the Bible and the classics of Greece and Rome. ${ }^{, 26}$ In addition, in constructing the early history of man, scholars attempted to

\footnotetext{
${ }^{24}$ Ferguson 75.

${ }^{25}$ Ibid. 80.

${ }^{26}$ Marshall 91.
} 
reconcile information regarding the antiquity of Asian civilizations to the chronology of events presented in the Bible and "to trace the sequence of diffusion from its point of origin. ${ }^{, 27}$ With increasing British involvement in India, some writers searched for evidence of the connections that had existed between Europe and the subcontinent in ancient times. In his essay "On the Gods of Greece, Italy, and India," Sir William Jones, a judge and gifted philologist with an interest in ancient Hindu culture, examined similarities in language and myth that may have suggested the cultural diffusion of antiquity.

Conjectural historians brought new questions to the study of ancient texts as they searched for information regarding cultures of antiquity. Classical texts concerning the histories of the civilizations of ancient Egypt, Greece, and Rome supplied a standard source of reference in various genres of late eighteenth-century writing. Conjectural historians turned to Classical texts as sources of information regarding various aspects of the social characteristics of ancient societies. Classical narratives were also of interest during the late eighteenth century in terms of the political lessons they offered regarding the development and decline of civilizations. In addition, the Hebrew Bible continued to hold its position of authority along with Classical narratives and provided a central source of citation in writing of the time. In his history of the structures of authority in societies, John Millar, for example, examined the Hebrew Bible for information relating to patriarchs of long ago.

J.W. Burrow notes that the conjectural historians of the Scottish Enlightenment anticipated "what came in the nineteenth century to be called the Comparative

${ }^{27}$ Ibid. 
Method," ${ }^{, 28}$ which assumed "similarities between the practices and beliefs of contemporary primitive or barbaric peoples and those recorded in the past history of civilization. ${ }^{29}$ In the approach of the comparative method, the observations used by conjectural historians to develop and substantiate their theories regarding the stages of development of societies were acquired from ancient writing of the Greeks and Romans and the Bible along with accounts of contemporary cultures that were regarded as being in various early stages of advancement.

\section{Counter-narratives to Progress}

Conjectural historians were interested in the decline of civilizations as well as their development. Conjectural historians recognized that the pattern in which one state acquires a particular set of advantages that allows it a position of dominance in a region of the globe for a certain period of time, following which a different state usurps that position, had been played out throughout history, and they sought to explain the general causes involved in the deterioration as well as the progress of civilizations. The decline of the ancient civilizations of Egypt, Greece, and Rome, for example, were of great interest to conjectural historians. Edward Gibbon's The History of the Decline and Fall of the Roman Empire was published in 1776, and conjectural historians contemplated the decline of civilizations not only of Classical antiquity but also of the East. Travellers often interpreted the impoverished social conditions that they encountered as being evidence of the decline of ancient civilizations, or of empires of the more recent past, in the Near East and India. British scholars of the late eighteenth century were aware of the

\footnotetext{
${ }^{28}$ Burrow 11.

${ }^{29}$ Ibid.
} 
early advancement of Muslim and Hindu cultures, as evident, for example, in achievements in architecture and astronomy, and they questioned what they viewed as a seeming absence of further development in certain aspects of some Eastern societies. As we will examine in Chapter Five, musings with respect to the common causes of decline recur throughout the writing of both travellers and conjectural historians.

Further, the notions of progress that accompanied many of the categorizations within stadial theory were tempered with the concerns of some of the conjectural historians regarding the losses on a social and individual level that are a result of the motivations and luxury found in modern commercial society. While stadial theory typically presented an overall narrative of progress, concerns regarding some of the effects of this progress also appeared in the writing of conjectural historians. As stated by Frank Palmeri, “The original formulators of modern social thought displayed little triumphal celebration of modern society." 30 Texts of the late eighteenth century included critiques of aspects of European societies as well as discussions of superior aspects of distant societies. Inherent in the theoretical approach of conjectural history was a critical stance from all societies, near and far.

In the Wealth of Nations, Adam Smith examines aspects of political economy in commercial stages of societies. He puts forward arguments regarding some of the economic advantages of, for example, the division of labour and an unregulated market that is allowed to follow natural laws of supply and demand. At the same time, however, Smith mourns the loss of rural values and traditions. Kathryn Sutherland suggests that “for all the economic buoyancy of Smith's commercial vision, the material progress it

\footnotetext{
${ }^{30}$ Palmeri 3.
} 
implies is attended by no corresponding moral advance ... Ultimately, Smith's is not an optimistic view." 31 Smith describes the mind-deadening effects of highly specialized labour and the advantages of country rather than city life. Smith writes that investment in the improvement of land seems to be as well secured as the nature of human affairs can admit of. The beauty of the country besides, the pleasures of a country life, the tranquillity of mind which it promises, and wherever the injustice of human laws does not disturb it, the independency which it really affords, have charms that more or less attract every body; and as to cultivate the ground was the original destination of man, so in every stage of his existence he seems to retains a predilection for this primitive employment. $^{32}$

Adam Ferguson's praise of certain superior aspects of the behaviour of people in supposedly less advanced societies also presented a counter-narrative to ideas of continual progress. Ferguson argues that the focus on personal gain in commercial societies weakens ties within a community, with a loss in values of, for example, loyalty, courage, and military valour. John Burrow points out that depictions of the "noble savage' often stood as a literary trope in discussions that reflected a concern with modern European society. An idealized concept of the 'noble savage' was summoned for the purposes of rhetorical stance and could be relatively removed from the empirical observations of ethnographical study. Burrow states that in many cases, "[ $[$ ] $]$ he Noble

\footnotetext{
${ }^{31}$ Sutherland xxxvi.

${ }^{32}$ Smith The Wealth of Nations Book 3, p. 229.
} 
Savage idea, in fact, was anchored only very lightly, if at all, in knowledge of actual primitive peoples."33

Lord Kames expresses concerns regarding the negative effects of increased luxury in societies:

In all times luxury has been the ruin of every state where it prevailed. Nations originally are poor and virtuous. They advance to industry, commerce, and perhaps to conquest and empire. But this state is never permanent: great opulence opens a wide door to indolence, sensuality, corruption, prostitution, perdition. ... In the savage state, man is almost all body, with a very small proportion of mind. In the maturity of civil society, he is complete both in mind and body. In a state of degeneracy by luxury and voluptuousness, he has neither mind nor body. ${ }^{34}$

Concerns of degeneration in aspects of European societies due to the attitudes and excessive luxury that accompany the growth of commerce often appeared in late eighteenth-century writing. At the same time, many thinkers of the Scottish Enlightenment argued that the growth of commerce and the exchange of products through foreign trade have beneficial effects on many aspects of societies. As we will examine in Chapter Four, the social effects of the flood of luxury goods into Britain with the expansion of global trade led to much debate during the late eighteenth century.

The idea of continual progress was further challenged by Thomas Malthus in his Essay on the Principle of Population, the first edition of which was published in 1798. Malthus was responding in part to Condorcet's vision of a future utopia, which was the final stage of development in societies imagined by Condorcet in Sketch for a Historical

\footnotetext{
${ }^{33}$ Burrow 5.

${ }^{34}$ Kames 333.
} 
Picture of the Progress of the Human Spirit, which was published in 1795. Malthus

argues that "an inescapable set of restraints, ${ }^{, 35}$ resulting from differing rates of increase of human population and agricultural production, would result instead in a continuing cyclical process in which times of prosperity and an increase in population would alternate with times of scarcity for many people caused by an excess of population growth. As discussed by Palmeri, ideas regarding a possible future stage of societies that would follow the continual growth that accompanies capitalism were to appear in the writing of several nineteenth-century thinkers, although in their thought, unchanging levels of material production in this future stage would not signify a lack of progress. John Stuart Mill, for example, envisioned "a more humane and equitable system"36 that is static in terms of growth in material production and allows improvement in other areas of life, such as in intellectual, artistic, and moral spheres of endeavour. Karl Marx and Friedrich Engels each conjectured regarding communal forms of societies in the ancient history of man and envisioned a future stage that would again be characterized by communal structures, such as in communism. As underlined by Palmeri, the works of these later writers exemplify, whatever the specific speculations they proposed, the continuation of the approach of the conjectural historians of the late eighteenth century.

\section{The Bookshelves of the Conjectural Historians: Sources of Information}

The eye-witness descriptions found in travel writing were viewed as a central source of information regarding various contemporary societies at a distance that had been unavailable to historians of earlier periods in which global exploration was more

\footnotetext{
${ }^{35}$ Palmeri 69.

${ }^{36}$ Ibid. 78.
} 
limited, and a countless number of references to travellers' accounts are found throughout the works of the conjectural historians. In The Origin of the Distinction of Ranks, John Millar offers a conjectural history of structures of authority in societies. Referring to ancient texts and the accounts of travellers, Millar provides a comparative and historical examination of the relationships between husbands and wives, fathers and children, masters and servants, chiefs and tribesmen, and sovereigns and citizens, and his text exemplifies both the methodology and the social focus of the works of the thinkers of the Scottish Enlightenment.

At the same time, conjectural historians were aware of the limitations of travel writing as a valid source of information. It was acknowledged that travellers could be mistaken or that their accounts could include exaggeration or even outright fabrication. Millar views travel writing as a valuable source of information and explains his solution to concerns with the issue of the credibility of travellers' accounts. He argues that while travellers are known either to be at times deceived or to misrepresent what they have experienced, the reader may compare the observations contained in numerous reports of many different travellers and ascertain the common observations that offer some measure of valid evidence:

Our information, therefore, with regard to the state of mankind in the rude parts of the world, is chiefly derived from the relations of travellers, whose character and situation in life, neither set them above the suspicion of being easily deceived, nor of endeavouring to misrepresent the facts which they have related. From the number, however, and the variety of those relations, they acquire, in many cases, a degree of authority, upon which we may depend with security, and to which the narration of any 
single person, how respectable soever, can have no pretension ... the reader has an opportunity of comparing their several descriptions, and from their agreement or disagreement is enabled to ascertain the credit that is due to them. ${ }^{37}$

While conjectural historians were careful in assigning epistemological value to individual travel accounts, travel writing as a body was extensively used in the development of their theories.

The use of travel writing as a source is exemplified continually throughout William Robertson's work An Historical disquisition concerning the knowledge which the ancients had of India. In all parts of his work, Robertson is not only meticulously careful to credit his sources but at the same time to extensively comment regarding the validity of many of the observations of the writers he cites or indeed the overall credibility of certain writers. Indeed, references to the reports of travellers, whether administrative or military officials, merchants, scholars, or adventurers, appear ubiquitously in Robertson's text. As was the case with James Mill when he wrote about India, Robertson had never travelled to the East himself, so that written sources, along with the visual representations provided by maps, drawings and paintings, were studied by him with a careful and supposedly objective academic distance. With the far more limited possibilities for travel in Robertson's time, armchair studies of foreign cultures were not at all an uncommon phenomenon. Nonetheless, with a far less extravagant attempt than that of James Mill to turn the limitations of his personal experience into an asset, Robertson similarly addresses the fact that he had never been to India in the Preface to his work, stating,

\footnotetext{
${ }^{37}$ Millar 90.
} 
I was so fully aware of the disadvantages under which I labored in undertaking to describe countries of which I had not any local knowledge, that I have been at the utmost pains to guard against any errors which this might occasion. I have consulted, with persevering industry, the works of all the authors I could procure, who have given any account of India. ${ }^{38}$

Robertson often uses the accounts of travellers of more recent periods to either verify or show the error of geographical statements of ancient writers. Further, Robertson suggests that the reports of contemporary travellers may provide descriptions of India during ancient times, stating that many customs in Indian society were retained despite a certain amount of cultural influence of foreign invaders.

Social aspects of ancient cultures often had to be pieced together by conjectural historians from passages in various ancient texts. With the focus of Classical historiography being upon statesmen and political events, historians had typically not recorded much information regarding the social conditions of ancient Greece and Rome. Millar points out the difficulty of obtaining proper materials for speculations of this nature. Historians of reputation have commonly overlooked the transactions of early ages, as not deserving to be remembered; and even in the history of later and more cultivated periods, they have been more solicitous to give an exact account of battles, and public negociations, than of the interior police and government of a country. ${ }^{39}$ Millar points out that the legislation in a society may serve as a source of cultural information, since laws typically reflect the manners and customs of a society. Millar

\footnotetext{
${ }^{38}$ Historical Disquisition vii.

${ }^{39}$ Millar 90.
} 
states that it is probable that the most respected legislators throughout history "were at great pains to accommodate their regulations to the situation of the people for whom they were intended" 40 and that they modified laws to "coincide with the prevailing opinions of the country.", 41

In the first part of Robertson's work, he presents a narrative describing the development of global trade in the ancient world. Robertson notes that since matters relating to commerce were not typically discussed by Classical writers as a topic in itself, it was necessary for him to construct his account of global trade in ancient times by looking for pieces of information in many different works:

as the operations of commerce, and the mode of regulating it, were little attended to in those states of antiquity, of whose transactions we have any accurate knowledge; their historians hardly enter into any detail concerning a subject of such subordinate importance in their political system, and it is mostly from brief hints, detached facts, and incidental observations, that we can gather information concerning it. ${ }^{42}$ Travellers' accounts, both ancient and contemporary, comprise a central source of the "brief hints, detached facts, and incidental observations" that are referenced in Robertson's text, and his work exemplifies the close dialogue between the two genres.

Johnson similarly discusses the scarcity of historical information regarding earlier structures of societies in Scotland. He refers to a Scottish historian who lived in the preceding century in which "the chiefs of clans had lost little of their influence ... and

\footnotetext{
${ }^{40}$ Millar 87.

${ }^{41}$ Ibid.

${ }^{42}$ Historical Disquisition 50.
} 
the feudal institutions operated upon life with their full force." ${ }^{43}$ Johnson states that while this historian might therefore have delighted his readers with many uncouth customs that are now disused, and wild opinions that prevail no longer ... The mode of life which was familiar to himself, he did not suppose unknown to others, nor imagined that he could give pleasure by telling that of which it was, in his little country, impossible to be ignorant. ${ }^{44}$ Further, often no written historical records were available at all relating to many newly encountered regions of the globe. While buildings, monuments, objects, and ruins remained as evidence of some ancient cultures that had been highly developed, such as, for example, India and Peru, conjectural historians noted that not even much material evidence of the past was available to provide information relating to the history of the indigenous peoples of the Americas.

Literary works of Eastern cultures could also play a part in British perceptions, as ancient texts of the Orient became available in translation. British scholars who were resident in India translated Sanskrit texts that contained the narratives and images, such as those of the Ramayana and the Bhagavad Gita, that were so central in ancient Hindu culture. In his discussion of Hindu society, the traveller George Forster reveals his familiarity and appreciation of some works of Hindu literature. He relates an episode of the Ramayana that he suggests gives hints about the status of women in ancient Indian culture. Forster argues that while fiction may present fanciful events and chronologies, it often supplies a wealth of indications of the actual manners and customs of the society in which it originated. The publication of the Arabian Nights was influential in the

\footnotetext{
${ }^{43}$ Johnson 52.

${ }^{44}$ Ibid.
} 
perceptions of the East in the imagination of many Europeans during the period, and Forster further states that even the Arabian Nights may provide some not totally fabricated ideas of Eastern societies: "The same use may be made of this story [the Ramayana], as that which is contained in the Arabian Nights entertainment, where amidst the olio of talismans, genii and devils, you are enabled to extract just representations of the manners and dispositions of the people." 45

Adam Ferguson similarly suggests the value of fiction in providing a view of the manners and customs of the societies of its authors. He states that Homer's epics may, with great justice, be cited to ascertain what were the conceptions and sentiments of the age in which they were composed, or to characterise the genius of that people, with whose imaginations they were blended, and by whom they were fondly rehearsed and admired. ${ }^{46}$

At the same time, he points out that the use of Homer's epics as sources of historical 'fact' is limited, stating, "It were absurd to quote the fable of the Iliad or the Odyssey ... as authorities in matter of fact relating to the history of mankind." ${ }^{, 47}$ Ferguson discusses the limits in attempting to obtain historical information regarding ancient states of societies from either conjecture based on nothing more than negations of modern conditions or on domestic fables which he states are "for most part, the mere conjectures or the fictions of subsequent ages; and even where at first they contained some

\footnotetext{
${ }^{45}$ Forster 82.

${ }^{46}$ Ferguson 77.

${ }^{47}$ Ibid. 76.
} 
resemblance of truth, they still vary with the imagination of those by whom they are transmitted, and in every generation receive a different form."48

As in the works of the conjectural historians of the late eighteenth century, the information to be found in travellers' accounts constituted a significant component of James Mill's extensive search of sources. Travellers to India held a wide range of professions, roles, and interests, and Mill refers to the works of, among others, Sir William Jones and Robert Orme, as well as George Forster, although misspelling his name, when he cites the Journey for Bengal to England by "[a]nother of our most instructive travellers, Mr. Foster."49 Accounts of travellers from the European continent were also available in England, and Mill refers to François Bernier, who had "spent a number of years in great favour at the court at Aurengzebe." ${ }^{50}$ Indeed, Mill argues that he could approach his subject with improved objectivity having never been to India. In the Preface to his work, Mill clearly anticipates and explicitly addresses the criticism that could, and has, been based on the fact that he had never visited the societies that he discusses. He states that he does not deny that useful knowledge is gained by being in India. ${ }^{51}$ However, he notes that histories are often written without their authors having been to the countries concerned:

Robertson, for example, never beheld America, though he composed its history. He never was either in Germany or Spain, yet he wrote the history of Charles the Fifth . . . Tacitus, though he never was in Germany, and was certainly not acquainted with the

\footnotetext{
48 Ibid.

${ }^{49}$ Mill Vol. 1, 130.

${ }^{50}$ Ibid. 244.

51 Ibid. xiii.
} 
language of our uncultivated ancestors, wrote the exquisite account of the manners of the Germans. ${ }^{52}$

Mill also makes the same argument made by Millar that if one looks at the accounts of "a sufficient number of witnesses, to leave no room for mistake from the partial or the erroneous statements which they may have separately made, ${ }^{, 53}$ one can acquire some sense of the actual circumstances of the society that they describe. With a position of distance, Mill argues that one is not affected by one's own "partial impressions.." ${ }^{, 4}$ Mill also notes that texts of many different genres were available that supply information:

The books, in which more or less of information respecting India might be expected to be found, were sufficiently numerous to compose a library. Some were books of History. Some contained philological, some antiquarian researches. A considerable number consisted of translations from the writings of the natives in the native tongues; others were books on the religion of the people of India; books on their laws; books on their sciences, manners, and arts. ${ }^{55}$

Like Robertson, Mill includes many comments regarding the sources that were available to him and also extensively cites his sources throughout his work. In any case, it must be acknowledged that the same distant view of cultures of the East equally characterized the works of writers of the Scottish Enlightenment.

Mill includes "antiquarian researches ${ }^{56}$ in his list of sources, and some mention should be made of the curious figure of the antiquarian, who also played a role, however

${ }^{52}$ Ibid.

${ }^{53}$ Ibid. xv.

${ }^{54}$ Ibid.

${ }_{56}^{55}$ Ibid. viii.

${ }^{56}$ Ibid. 
minor, on the historical stage of the late eighteenth century. The aim of antiquarianism was to preserve and to record. Antiquarians were typically viewed as having a specialized interest in collecting particular objects from the past, such as ancient coins, inscriptions, vases, statues, manuscripts, or whatever else caught their attention, and any subject could be chosen as the focus of an antiquarian text. The knowledge gained through the pursuits of antiquarians was often considered to be if not outright eccentric then at least of limited broad significance. However, Arnaldo Momigliano points out that an interest in matters set aside, as it were, from the traditional political focus of historical narrative could be found even among writers of much earlier centuries. He suggests that two streams of history had begun to emerge from the time of the Classical writers. Thucydides, for example, provided a political narrative of ancient Greece based on knowledge that he attained through his own involvement as an Athenian military general, and in a sense his writing reflects the approach of oral history in the Homeric tradition. In contrast, Herodotus presented a wider history of the Persians and Egyptians and used literary sources.

Within developments in late eighteenth-century historiography, with the increasingly social focus of narratives of political history, and indeed the broad considerations of all aspects of societies, including material culture, found in conjectural history, the two streams of history could begin to be found in works of some late eighteenth-century historians. Texts such as, for example, Robertson's work concerning trade with India and Hindu culture, were more inclusive of the types of subject matter in antiquarianism. Momigliano notes that the focus on material culture that often characterized the interests of antiquarians did not disappear but instead increasingly 
began to merge with other historiographical approaches in the nineteenth century, with the ultimate development of academic disciplines such as, for example, the history of art or architecture.

Historical representation could be found in a number of late eighteenth-century genres. With the social aspects of societies becoming more of a focus in historiography, related genres of writing were seen as providing valuable historical insight. At the same time, the "dignity of history" ${ }^{, 57}$ did not disappear among the proliferation and popularity of related genres. As pointed out by Phillips, genres of writing of the period defined themselves in relation to each other, and history typically retained an elevated position in a perceived hierarchy of epistemological value and studiousness of readership.

Novels of the time sometimes wove historical events into fictional plots. Sir Walter Scott's novel Waverley, Or, 'Tis Sixty Years Since is set during the Jacobite Rebellion and presents a close view of the disappearing ways of life of Highland society. The Jacobite Rebellion also makes a short appearance in Henry Fielding's novel The History of Tom Jones, a Foundling. More central in this work, however, are Fielding's portrayals of aspects of British society as he follows the adventures of his protagonist through villages, country roads, inns, and cities. In initial chapters of books of his novel, Fielding discusses aspects of the genres of history and romance in relation to his own 'History.' He states that his work will consider "Human Nature"58 and that "Man . . is the highest subject." ${ }^{59}$ The details of daily life that provide insight regarding the social conditions of a particular historical period were found in the many narrations of private

\footnotetext{
${ }^{57}$ Phillips Society and Sentiment 24.

${ }^{58}$ Fielding Tom Jones 24.

${ }^{59}$ Ibid. 325.
} 
'Lives' that were written during the period. While the protagonists could be fictional, as in the genre of the novel, the genres of biography and memoir narrating the lives of real people were also avidly read.

Embedded historical narratives were commonly found in the accounts of travellers, who sought historical knowledge in their attempts to interpret the cultures in which they found themselves. In A Journey through the Crimea to Constantinople, Lady Elizabeth Craven, for example, includes an extended passage offering a chronological history of Crimea since ancient times. In addition, passages narrating personal anecdotes that have been related to travellers by local inhabitants are embedded throughout their accounts and often provide valuable insights regarding the manners and customs of the societies they are visiting. Late eighteenth-century travellers' accounts constitute documents of contemporary historical representation; through travellers' descriptions of the political situations that they were witnessing, history was recorded as it was being made.

A significant source of historical information could also be provided in visual representations. History painting of the time increasingly reflected the social focus that was emerging in historical writing. Scenes involving all segments of society were increasingly considered to be appropriate subjects of history painting, and suggestions of the sentiments of the individuals portrayed in the scenes could be considered an important element of a work. As stated by Phillips, history painting began to "embrace its modern identity and sublimate its poetic and religious inheritance beneath a mantle of secular concerns. ${ }^{90}$ Relatively recent historical events were depicted as history painting

\footnotetext{
${ }^{60}$ On Historical Distance 156.
} 
"entered into an increasingly close engagement with the national histories of Europe." The painting Lord Cornwallis Receiving Tipu Sahib's Sons as Hostages at Seringapatam, 1793-4, by the Scottish painter Robert Home depicts a contemporary event in India. Home was the official war artist for the third Mysore War, and he includes himself in the painting, standing at the far left of the foreground holding a portfolio. As we will examine in Chapter Four, Tilly Kettle depicted, among other subjects, scenes that suggested the collaboration between some of the nawabs of northeast India and the British officials who were based in Bengal, such as the signing of a treaty or a meeting with troops appearing in the background.

As we will examine in Chapter Five, landscape painting offered a medium in which to present much information regarding distant cultures and ways of life. Within the aesthetic of the picturesque, the depiction of groups of figures in the foreground engaged in their typical daily activities provided ethnographic information. Depictions of architecture, whether of Ottoman palaces, Mughal mosques, Hindu temples, or the simple dwelling of the residents of a region, along with the Palladian villas of British officials serving in distant appointments, offered information about the cultural history of the various segments of society in the Near East and India. Visual representations of both architectural magnificence and ruins evoked mediations regarding the general cycle of the advancement and decline of civilizations.

\section{Experimental Forms of Conjectural History}

${ }^{61}$ Ibid. 158. 
Traditional historical writing generally consisted of chronological narratives concerning statesmen and political events rather than discussions of aspects of everyday life within a society. As discussed by Phillips, within the broadened scope of late eighteenth-century historiography, narratives of political history could reflect a wider social view encompassing various matters within more segments of societies. The works of the conjectural historians contributed to the wider domain of historical writing during the late eighteenth century. The expansion of subject area characteristic of late eighteenth-century historiography is particularly apparent in conjectural history with its attempt to describe the manners and customs that correspond to different stages of development in societies.

Phillips discusses the experimentation in form that accompanied the expansion of focus in late eighteenth-century British historiography. The forms used by conjectural historians as they sought to accommodate the new interests of history greatly varied, as may be exemplified by a few examples. William Robertson's An Historical Disquisition concerning the Knowledge which the Ancients had of India exemplifies a hybrid structure. The first portion of the work consists of a chronological history of global trade between Europe and the East and in particular the progression of commerce with India. This narrative is followed by an Appendix that consists of an ethnographical discussion of Hindu culture, with the title "Appendix, containing Observations on the Civil Policy the Laws and Judicial Proceedings - the Arts - the Sciences - and Religious Institutions of the Indians." In addition, both the narrative portion of the text and the Appendix are followed by an extensive set of "Notes and Illustrations" that not only expand or qualify particular statements but also reveal more of Robertson's sources. Robertson's text 
reflects the experimentation with formal structure that could accommodate the expanded scope of historical writing, with its new focus on customs and manners, while retaining a portion of chronological narrative that would continue to interest many readers. As discussed by Phillips, Robertson saved the continuity of narrative in his works by "incorporating a hierarchy of narrative and nonnarrative elements based in part on the needs of distinct audiences." ${ }^{62}$ Mill's History of British India also exhibits a hybrid structure of historical narrative and ethnological discussion; his text includes narrative sections in which periods of India's history are set out chronologically, sections discussing Hindu and Mughal culture, and sections discussing the history and administration of the East India Company.

John Logan's Elements of the Philosophy of History presents yet a different experiment in form. In the first section of his text, Logan introduces the new "Universal History" ${ }^{\prime 63}$ that he proposes to exemplify in his work, setting out a concise summary of stadial theory and pointing out the different focus of the new sub-genre of historical writing. In the following sections of his work, Logan uses a chronological narrative structure in which he examines the histories of ancient Greece and Rome in order to exemplify and explore the progress and decline of societies. Logan's plan was “to integrate theoretical history with conventional or narrative history by first setting out the philosophical principles of historical development in all societies and then focusing on the only three cases in which 'we behold mankind running the career of policy, from rudeness to refinement': ancient Greece, ancient Rome and Europe since the early

62 Society and Sentiment 91.

${ }^{63}$ Elements 3. 
fifteenth century." ${ }^{, 64}$ The existing text covers the history of ancient Greece and Rome, and the second volume, which would presumably have considered the history of Europe, never appeared.

In his Sketches of Man, Lord Kames organizes his work according to a wide range of subject areas, with chronological narrative disappearing altogether as a structuring strategy. The works of the conjectural historians were central in the emergence of a social and cultural focus in British historiography during the late eighteenth century. Historical writing was increasingly perceived as a genre that was concerned not only with the lives of statesmen and aristocrats but with the conditions of all segments of societies. The new focus enabled historians to search for a deeper understanding of events in history, since those events were no longer seen as simply the result of the innovations of a few exceptional individuals; rather, historical events were viewed as occurring in connection with the prevalent attitudes held within a society. With the inclusion of sentiment, the psychological effects of historical situations and events could be explored.

While much late eighteenth-century historical writing retained the form of chronological narrative and a predominately political focus, one of the valuable outcomes of the emergence of conjectural history was the possible inclusion of knowledge regarding all aspects of life within the domain of history. The range of subjects that were now seen as appropriate historical material was limitless, and could include, for example, aesthetic works of societies and aspects of the labour of farming or the lives of families. Using fuller pictures of societies in Europe as well as in remote regions of the globe,

${ }^{64}$ Ibid. xiii. 
conjectural historians were able to pursue a theoretical approach in which they produced works of significant influence in the emerging science of man.

\section{A Dialogue with the Philosophes}

Texts of the Scottish Enlightenment were to some extent in dialogue with works of the philosophes of the European continent that were published earlier in the eighteenth century, either extending some of their ideas or refuting others. As noted by Palmeri, the ideas and approaches of conjectural history "crossed and recrossed national boundaries," $" 65$ with these "transcultural exchanges . . . exerting influence and provoking critical and revisionary responses, producing a complex, multilayered, and multidirectional conversation." ${ }^{66}$ In this section, we will examine two texts of the philosophes that took part in this conversation: Montesquieu's work of political theory, De l'esprit des lois [The Spirit of the Laws], which was published in 1748, and JeanJacques Rousseau's Discours sur l'origine et les fondements de l'inégalité parmi les hommes [Discourse on the Origins and Foundations of Inequality among Men], which was published in 1755 .

In developing and substantiating his theories, Montesquieu refers to ancient histories and distant societies, with these references being as ubiquitous in his text as in the works of the Scottish writers. Montesquieu sets out theories regarding types of governments and the principles underlying each type. He defines three types of government:

\footnotetext{
${ }^{65}$ Ibid.11.

${ }^{66}$ Ibid. 12.
} 
republican government is that in which the people as a body, or only a part of the people, have sovereign power; monarchical government is that in which one alone governs, but by fixed and established laws; whereas, in despotic government, one alone, without law and without rule, draws everything along by his will and his caprices. $^{67}$

He states that a republican government is called a democracy when the people as a body have sovereign power and an aristocracy when sovereign power is "in the hands of a part of the people. ${ }^{\prime 68}$ Montesquieu suggests that many of the characteristics of governments may be explained through an examination of the effects of the principles underlying particular forms of government. He explores the many circumstances that may lead to particular forms of government in different societies, as well as the causes of a change of form of government in a society and the decline of a society that accompanies the corruption of the underlying principle of its government.

Montesquieu states that "[j]ust as there must be virtue in a republic and honour in a monarchy, there must be FEAR in a despotic government." ${ }^{, 69}$ Governments in the Near East and India were generally viewed as despotic in late eighteenth-century British thought, and various comments made by Montesquieu are echoed throughout discussions of conjectural historians relating to the structures of Eastern societies. Montesquieu notes, for example, that the power of religious authorities was the only check on the power of the ruling despot: "There is, however, one thing with which one can sometimes

\footnotetext{
${ }^{67}$ The Spirit of the Laws 10.

${ }^{68}$ Ibid.

${ }^{69}$ Ibid. 28.
} 
counter the prince's will: that is religion ... The laws of religion are part of a higher precept, because they apply to the prince as well as to the subjects.",70

Montesquieu assumes a distant, theoretical position in examining all societies, near and far, ancient and modern, and the conjectural historians of the Scottish Enlightenment are among his successors with respect to this stance. He discusses, for example, the effects of commerce and suggests that governments "of today speak to us only of manufacturing, commerce, finance, wealth, and even luxury.",71 At the same time, he suggests:

Certainly, when democracy is founded on commerce, it may very well happen that individuals have great wealth, yet that the mores are not corrupted. This is because the spirit of commerce brings with it the spirit of frugality, economy, moderation, work, wisdom, tranquillity, order, and rule. Thus, as long as this spirit continues to exist, the wealth it produces has no bad effect. ${ }^{72}$

Montesquieu offers interesting comments relating to luxury, drawing on a wide spectrum of evidence as in all of his explorations of issues. He suggests, for example, that luxury is discouraged in China because in order to feed the large population, everyone must work in the fields. ${ }^{73}$ With respect to the effect of the number of people in a community, in Europe or elsewhere, he states that " $[\mathrm{t}]$ he more men there are together, the more vain they are, and the more they feel arise within them the desire to call attention to themselves by small things." 74 The questions of the time are reflected in Montesquieu's

\footnotetext{
${ }^{70}$ Ibid. 29.

71 Ibid. 22.

72 Ibid. 48.

73 Ibid. 102.

${ }^{74}$ Ibid. 97.
} 
work, and thinkers of the Scottish Enlightenment explored his ideas with an expanded focus on economic theory.

In Montesquieu's fictional epistolary travel account Persian Letters, one of the Persian travellers states, "we even enjoy people's surprise when they discover we are quite polite, for the French do not suppose that our climate can produce civilized men." ${ }^{, 75}$ The degree to which climate influenced the characteristics of different cultures was a topic of much debate during the period. As stated by David Hume, "There are few questions more curious than this, or which will oftener occur in our inquiries concerning human affairs." ${ }^{76}$ Montesquieu was one of the early writers of the Enlightenment to consider the influence of climate, with a discussion of its effects included in The Spirit of the Laws, and he is often cited by late eighteenth-century writers when considering the effects of environment on societies. Lord Kames, for example, refers to "the celebrated Montesquieu, who is a great champion for the climate" opinion, that neither temper nor talents have much dependence on climate.",78 In his essay "Of National Characters," Hume refutes Montesquieu's theories regarding the influence of climate, and John Millar offers arguments that are similar to those of Hume:

How many nations are to be found, whose situation in point of climate is apparently similar, and, yet, whose character and political institutions are entirely opposite? ... The different manners of people in the same country, at different periods, are no less

\footnotetext{
${ }^{75}$ Persian Letters 59.

${ }^{76}$ Hume "Of National Characters" 115.

${ }^{77}$ Kames 39.

${ }^{78}$ Ibid. 40.
} 
remarkable, and afford evidence yet more satisfactory, that national character depends very little upon the immediate operation of climate. ${ }^{79}$

The word "immediate" in Millar's comments is significant. It must be noted that Montesquieu's arguments concerning the effects of climate extended to fuller discussions of the effects of the natural environment more broadly. Montesquieu discusses, for example, the fertility of the soil in relation to agriculture, as well as the relative isolation of societies in terms of natural borders such as seas and mountains. While the Scottish writers were typically in agreement regarding the limited cultural effects of climate, they certainly considered factors relating to the natural environment, such as the establishment of agricultural cultivation, in their theories relating to the cultural effects of economic structures of societies.

Both Montesquieu and the Scottish writers recognized the myriad of factors that may influence particular societies and express the idea that the institutions in a society gradually develop in response to all of those factors. Montesquieu points out that laws should be related to the physical aspect of the country ...; to the way of life of the peoples, be they plowmen, hunters, or herdsmen; they should relate to the degree of liberty that the constitution can sustain, to the religion of the inhabitants, their inclinations, their wealth, their number, their commerce, their mores and their manners. ${ }^{80}$

\footnotetext{
${ }^{79}$ Millar 89.

${ }^{80}$ Montesquieu The Spirit of the Laws 9.
} 
Indeed, Montesquieu suggests that the laws of a country "should be so appropriate to the people for whom they are made that it is very unlikely that the laws of one nations can suit another." 81

Echoing Montesquieu, Logan states, "The form of government, in every country, arises from the spirit and manners of the people." 82 Millar suggests that "[t]he institutions of a country, however imperfect and defective soever they may seem, are commonly suited to the state of the people by whom they been embraced," ${ }^{\prime 23}$ and he points out that for this reason, it is important to attempt to understand the causes underlying particular aspects of the structures of a society. He argues that "[i]n every system of law or government, the different parts have an intimate connection with each other" 84 and that "it is dangerous to tamper with the machine, unless we are previously acquainted with the several wheels and springs of which it is composed." ${ }^{, 85}$

Questions explored in the works of thinkers of the Scottish Enlightenment are similarly found in Rousseau's Discourse on the Origins and Foundations of Inequality among Men. The use of conjecture in discussions of the time concerning trajectories of development in societies is explicitly addressed by Rousseau in his Discourse. He notes that in his examination of the origins of inequality in societies, "One must not take the kind of research which we enter into as the pursuit of truths of history, but solely as

\footnotetext{
${ }^{81}$ Ibid. 8.

${ }^{82}$ Dissertation 22.

${ }^{83}$ Millar [Preface to the First Edition] 285.

${ }^{84}$ Ibid.

${ }^{85}$ Ibid.
} 
hypothetical and conditional reasonings. ${ }^{.86}$ At the same time, he points out the value of such reasonings even though they can proceed "only by means of conjecture," ${ }^{, 87}$ stating: beside the fact that those conjectures become rational when they are the most probable that can be inferred from the nature of things and constitute the only means one can have for discovering the truth, the conclusions I want to deduce from mine will not thereby be conjectural, since, on the basis of the principles I have established, it would be impossible to formulate any other system which would not yield the same results and from which I could not draw identical conclusions. ${ }^{88}$

Rousseau also discusses the sources of evidence that form the base of his conjectures, among which travellers' accounts are central. He notes that in pondering the characteristics of men, one may draw conclusions "[a]mong the men we know, either through our own acquaintance, or through historians or travellers." ${ }^{199}$ In discussing the apparently superior physical health of people who are not affected by aspects of contemporary European societies, for example, he notes, “Travellers' reports are full of examples of the strength and the vigour of men in barbarous and savage nations ... and as eyes are all that is needed to observe these things, there is no reason why we should not believe the testimony of eyewitnesses. ${ }^{.90}$ At the same time, Rousseau seems to suggest that since travellers' accounts provide information only through their own perceptions and frameworks of thought, their writing offers more than anything else a view of Europeans:

\footnotetext{
${ }^{86}$ Rousseau Discourse 78.

${ }^{87}$ Ibid. 107.

${ }^{88}$ Ibid.

${ }^{89}$ Ibid. 154.

${ }^{90}$ Ibid. 144.
} 
In the two or three centuries since the inhabitants of Europe have been flooding into other parts of the world, endlessly publishing new collections of voyages and travel, I am persuaded that we have come to know no other men except Europeans; moreover it appears from the ridiculous prejudices, which have not died out even among men of letters, that every author produces under the pompous name of the study of man nothing much more than a study of the men of his own country. ${ }^{91}$

Nonetheless, it is above all some of the assumptions and conclusions found in works relating to stages of development with which Rousseau is in disagreement in his text, as he similarly draws on travellers' descriptions of distant cultures in his general theories regarding societies.

Many of Rousseau's ideas are reflected in the works of the Scottish writers. He suggests that change occurs over long periods of time, noting "how many thousands of centuries must have been required for the progressive development within the human mind of all the operations of which it is capable." "92 Like Montesquieu, Rousseau acknowledges "the powerful effects of the diversity of environments" "93 among the causes of difference among societies. Rousseau notes "the variety which a thousand causes can produce and in fact have produced in the human species."94 Rousseau also suggests that the increasing global interconnectedness has led to less diversity among societies in different nations. In a comment that resonates in today's world, he states, “Today, when trade, travel and conquests bring various peoples closer together . . . one notices that

\footnotetext{
${ }^{91}$ Ibid. 159.

92 Ibid. 92.

${ }^{93}$ Ibid. 154.

94 Ibid.
} 
certain national differences have diminished." ${ }^{95}$ He states that more variation could be discussed "if one could have made sound observations in ancient times when various peoples' ways of life ... differed among themselves to a greater extent than do those of peoples today. $" 96$

Rousseau points out the central role played by notions of property in the characteristics of societies. He states, "The first man who, having enclosed a piece of land, thought of saying 'This is mine' and found people simple enough to believe him, was the true founder of civil society." ${ }^{, 97}$ Rousseau notes that "the idea of property ... was not formed all at once in the human mind. It was necessary for men to make much progress, to acquire much industry and knowledge, to transmit and increase it from age to age. ${ }^{98}$ Conjectural historians of the Scottish Enlightenment discussed both the benefits and the losses attending increasing commercialization of societies. Rousseau, however, concentrates on the destructive aspects of modern European societies in relation to what he refers to as the 'state of nature' of mankind. While the term 'noble savage' does not in fact appear in Rousseau's Discourse, his discussion regarding the superiority of certain characteristics of man in what he views as a pre-social state became a trope of much writing of the late eighteenth century.

Rousseau suggests that in the state of nature, man likely lived in relative isolation and that it may not be assumed that man is more social than any other animal. He notes that the construction of huts "introduced property of a sort from which perhaps even then

\footnotetext{
${ }^{95}$ Ibid.

${ }^{96}$ Ibid.

${ }^{97}$ Ibid. 109.

${ }^{98}$ Ibid.
} 
many quarrels and fights were born"99 and that development relating to commodities "was the first yoke they imposed on themselves, without thinking about it, and the first source of the evils they prepared for their descendants."

Like the texts of the Scottish Enlightenment, Rousseau's work is in dialogue with earlier works relating to the new science of man. Rousseau's theories, as set out in his Discourse, differ, for example, from those of Thomas Hobbes in some respects. Rousseau suggests that while man is not by nature more social than other animals, the sentiment of pity is natural to man as well as to some other species. According to Rousseau, the competition and resulting aggression found in gatherings of men unrestrained by the institutions of civil society, as described by Hobbes, are not found in the state of nature, in which men are "free and independent." ${ }^{\text {"101 }}$ Rousseau argues that man's propensity to seek advancement in various aspects of life have resulted in many supposed accomplishments and many negative changes in his character, referring to man's

faculty of self-improvement . . this distinguishing and almost unlimited faculty of man is the source of all his misfortunes; that it is this faculty which, by the action of time, drags man out of that original condition in which he would pass peaceful and innocent days; that it is this faculty, which, bringing to fruition over the centuries his insights and his errors, his vices and his virtues, makes man in the end a tyrant over himself and over nature. ${ }^{102}$

\footnotetext{
${ }^{99}$ Ibid. 112.

${ }^{100}$ Ibid. 113.

${ }^{101}$ Ibid. 119.

${ }^{102}$ Ibid. 88.
} 
Rousseau suggests that in addition to competition for commodities, "public esteem came to be prized ... and this was the first step towards inequality and at the same time towards vice ... there arose, on the one side, vanity and scorn, on the other, shame and envy ... fatal to happiness and innocence. ${ }^{103}$ Rousseau argues that corruption increases along with the continued development of societies, as "[t]he usurpations of the rich, the brigandage of the poor and the unbridled passions of everyone, stifling natural pity and the as yet feeble voice of justice, made men greedy, ambitious and bad." ${ }^{\text {104 }}$ Rousseau views despotism as being similar to the Hobbesian stage of development in which "everything is restored to the sole law of the strongest." 105

As well as questioning the benefits of more commercial societies, Rousseau questions some of the assumptions regarding human behavior in different stages of societies that are found in some works of conjectural history: "The philosophers who have examined the foundations of society have all felt it necessary to go back to the state of nature, but none of them has succeeded in getting there ... all these philosophers ... have transported into the state of nature concepts formed in society. They speak of savage man and they depict civilized man." ${ }^{\text {"106 }}$ According to Rousseau, "the savage lives within himself; social man lives always outside himself; he knows how to live only in the opinion of others," 107 and he suggests that "the soul and the human passions through imperceptible degeneration change, so to speak, their nature."108

\footnotetext{
103 Ibid. 114.

${ }^{104}$ Ibid. 120.

105 Ibid. 135.

${ }^{106}$ Ibid. 78.

${ }^{107}$ Ibid. 136.

${ }^{108}$ Ibid. 135.
} 
Rousseau's critique of contemporary European societies was of great political influence. While in the Discourse he presents a conjectural history of how societies developed, in The Social Contract he discusses how civil societies should be ideally established. In any case, along with earlier texts relating to the science of man, the works of both Montesquieu and Rousseau occupied a prominent position in the backdrop of the thought of the Scottish Enlightenment.

\section{Anxieties regarding Change: Reflections of Edmund Burke}

Edmund Burke's writing in response to the French Revolution exemplifies, within its consideration of a specific topic of great interest during the late eighteenth century, the reservations regarding change occurring in European societies that could be found in writing of the time. With the extensive discussions in Burke's work regarding the structures of societies and the processes of change with respect to those structures, his text exemplifies the pervasiveness of the interests of the conjectural historians in writing in other genres. Burke examines these questions through the prism of his own particular set of convictions, and in this sense his work offers an interesting counterpoint to the writing of his Scottish friends.

However extensive and noticeable the changes taking place in British society appeared to observers during the late eighteenth century, changes in France had become immediate and dramatic with the beginning of the Revolution. All of Europe watched intently as the longstanding structures of French society were overthrown by a new government that professed to be establishing innovative approaches based on the equal rights of all men. All real power was removed from the monarchy, church lands were 
confiscated, and the titles of nobility were abolished. The use of paper currency and public credit expanded within an economic system in which the value of all property could continually change according to speculation.

Burke expresses his concerns regarding the substantial changes occurring in the structures of French society in his Reflections on the Revolution in France. Many in Britain initially applauded the events in France as an historic advance in the rights of man. Indeed, from today's perspective, the French Revolution represents a moment of influential change in world history. However, as seen in many societies that go through revolutionary change, things often get worse before they get better, and transitions often involve much strife and bloodshed. Burke watched the destruction of the longstanding political and social structures of French society with horror as well as prophetic apprehension regarding the path in which events would unfold in France in the near future. Burke predicted "the excesses of infant liberty" 109 and stood as "the champion of existing institutions" ${ }^{\prime 10}$ in his text. His criticism and caution provoked much response from those in Britain with idealistic hope. Thomas Paine published The Rights of Man, and Sir James Mackintosh responded, with the passion of a young man, to Burke in his Vindiciae Gallicae, which was published in 1791. The text resulted in the immediate acclaim of Mackintosh's talents, and his work was praised by both Fox and Burke. While Paine's text was written "in an instinctively popular style," "111 Mackintosh responded to Burke on the same level of sophistication in argumentation.

\footnotetext{
${ }^{109}$ Mackintosh, Robert 56.

${ }^{110}$ Ibid. 57.

${ }^{111}$ Ibid.
} 
Reactions in Britain to Burke's arguments altered with time as those with initial enthusiasm for the Revolution in France witnessed the events of the Reign of Terror. Aside from either Burke's predictions of the phases through which the Revolution would proceed or the ultimate historical effects of the Revolution, the complexity and insight found in many of Burke's discussions of the interrelationships among structures of society and the processes and effects of systemic change in societies remain fascinating. In this respect, Burke shares the interest of the conjectural historians of his time in the causes of various characteristics of societies and in the close relationship between their economic and political structures. Conjectural historians considered all societies, near and far, in developing their theories, and Burke directs his inquiry to the causes of the characteristics of political aspects of French as well as British society.

Between the memory of the Glorious Revolution in the late seventeenth century in Britain and perceptions of the despotism in societies of the East with which Britain increasingly conducted trade, notions of tyranny were not terribly far from late eighteenth-century British minds. Burke is not opposed in principle to actions taken against tyranny, stating, "The punishment of real tyrants is a noble and awful act of justice." ${ }^{112}$ He supported the American Revolution on the basis of the claim of the colonies to a degree of political and commercial control in their affairs that was equal to that held by citizens within other states. However, Burke presents the differences between earlier revolts against tyranny in history and what he views as the violent and destructive aspects of the French Revolution. The political revolutions in England in the late seventeenth century had made it clear that no country is immune to the effects of

${ }^{112}$ Reflections 5. 
political upheaval. As pointed out by Conor Cruise O'Brien, Burke was an Irishman, with a Catholic mother and a father who supposedly assumed the Protestant faith in order to practise law, and so Burke would have been especially aware of the possibility of the political oppression of segments of society and the resulting dangers of revolt close to home. O'Brien suggests that Burke may have felt an inner struggle between the views and positions he assumed in his role in the Parliament in London and his emotional ties and empathy with the plight of the Catholics in Ireland, and he suggests that it is this inner dichotomy that is at play in the passion of Burke's rhetoric in the Reflections. In any case, Burke insists that there is no similarity, "either in the act or in the spirit of the proceeding" ${ }^{113}$ between recent events in France and the revolutions in England in the preceding century.

Burke frames his arguments within the form of a letter written to a young correspondent in Paris who has requested his views, with the resulting text being a work of brilliant political rhetoric, "a unique political work of art," 114 and not a work commonly associated with the genre of conjectural history. In fact, however, Burke's discussions of the underlying causes of particular structures of societies and processes of change with respect to those structures constitute a significant focus within the text, which in this sense may be viewed as sharing certain characteristics with the many highly divergent forms of the new speculative subgenre of historical writing. As discussed by Frank Palmeri, elements of conjectural history often formed a part of many works, not only of the late eighteenth century but also of the following centuries, that were associated with other genres. Palmeri attributes the lack of recognition of these elements

\footnotetext{
${ }^{113}$ Ibid. 184.

${ }^{114}$ O’Brien 73.
} 
in other texts in part to the "tendency to categorize all works as belonging to one genre" $" 115$ as well as to divergences from some of the ideas, such as the four-stage theory of social progress, that are commonly linked with the writing of the conjectural historians. In presenting his views of the basic characteristics of British society that he considers to have contributed to its political organization and attitudes, Burke's focus differs from that of many of the conjectural historians. He discusses the influence of chivalry in the history of European societies and gives credit to ideas "furnished from the wardrobe of a moral imagination ... to raise it [man's nature] to dignity in our own estimation."116 In his conjectural history of structures of authority in society, John Millar considers chivalry as one step in the long history of developments in European society. However, J.G.A. Pocock suggests that Burke extends the difference in his focus to the point of reversing the argument typically put forward by conjectural historians that economic development leads to a refinement of manners and new structures in civil society. According to Pocock, Burke suggests that "commerce is dependent on manners, and not the other way round." 117 Pocock notes that the treatment of Marie Antoinette "betokens the destruction of chivalric manners," 118 however much Burke's description of the tragic circumstances of the Queen is remarked upon as a highly sentimental expression in his text. In Burke's view, "religion is the basis of civil society." 119 Clearly of devout religious sensibilities, Burke attributes much influence to the prevalence of Christian moral views, referring to the Christian religion as "one great source of

\footnotetext{
115 Palmeri 6.

${ }^{116}$ Burke Reflections 171.

117 Pocock 199.

${ }^{118}$ Ibid.

${ }^{119}$ Burke Reflections 186.
} 
civilization amongst us." ${ }^{120}$ Conjectural historians acknowledged the significant part played by religion in societies, but they argued that certain general approaches in religious beliefs and structures, like other manners and customs, typically correspond with the stage of a society within stadial theory. Further, the power held by religious authorities within political structures of societies the East was a source of criticism in much writing of the time, as we will examine in Chapter Three.

Burke argues that "prejudices"121 are cherished in Britain and that it is much better to trust in a longstanding common stock of wisdom than in the reason of each individual. ${ }^{122}$ In Burke's view, good systems of government are necessarily complex and may only be achieved through "a slow and well-sustained progress . . From hence arises, not an excellence in simplicity, but one far superior, an excellence in composition." 123 Burke argues that a practical approach, informed by more than general philosophy, must be taken with political matters and that change to systems of government and law should be undertaken gradually and cautiously, through continuing addition to and amendment of centuries of legislation and through judicial precedent. He notes the central influence of the writing of the "literary cabal"124 in the recent political developments and suggests that even they might be surprised at the direct translation of

${ }^{120}$ Ibid.

${ }^{121}$ Ibid. 183.

${ }^{122}$ It should be noted that Burke's use of the word 'prejudice' anticipates Hans-Georg Gadamer's use of the word more than today's most common use of the word to signify a position of negative bias. Gadamer uses the word 'prejudice' to refer to an understanding of, for example, a term or practice, according to the longstanding ideas with which it is associated in a person's cultural language. This notion of prejudice of course applies not only to the signification of a particular word but to the understanding of various ideas and attitudes that form the building blocks, as it were, of the culture in which a person lives.

${ }^{123}$ Reflections 281.

${ }^{124}$ Ibid. 211. 
some of their satires and musings into sweeping political action. Upholding the rights of man in a society is not a simple matter but instead involves finely constructed balances with corresponding limitations of rights, and Burke underlines the amount of careful thought required "to form a free government; that is, to temper together these opposite elements of liberty and restraint in one consistent work."125 Burke notes, for example, "Liberty is always to be estimated perfect as property is rendered insecure." ${ }^{126}$ He refers to the writing of Jean Domat, author of Les Lois civiles dans leur ordre naturel, which was published in 1689, who "tells us, that the positive ascertainment of its [property's] limits, and its security from invasion, were among the causes for which civil society itself has been instituted,"127 and Burke condemns the National Assembly for its "contempt of this great fundamental part of natural law." ${ }^{128}$ Burke is disdainful of the claim of the revolutionaries in France that all of their actions are philosophically justified as furthering the rights of man. He states that in reality "the primitive rights of men undergo such a variety of refractions and reflections, that it becomes absurd to talk of them as if they continued in the simplicity of their original direction." ${ }^{129}$ Burke notes that the legislators of antiquity knew that they could not rely only on metaphysics: "They had to do with men, and they were obliged to study human nature. They had to do with citizens, and they were obliged to study the effects of those habits which are communicated by the circumstances of civil life."130 The word 'enlightenment' reappears throughout Burke's text in various discussions and is invariably used with a sarcastic tone, as Burke

\footnotetext{
${ }^{125}$ Ibid. 374.

${ }^{126}$ Ibid. 161.

${ }^{127}$ Ibid. 260.

128 Ibid.

${ }^{129}$ Ibid. 152.

${ }^{130}$ Ibid. 299.
} 
underlines his criticism of the philosophes. At the same time, Burke's argument that politicians must base their policies on observations of the behaviour of men in various actual circumstances echoes the empirical approach of the Enlightenment.

Burke's comments regarding the effects of the economic change in French society express various points of view similarly found in discussions of the time by conjectural historians and those in the British public. Burke is not against the prosperity in society that accompanies the expansion of trade and the increasing wealth of merchants, and he seems to share the views expressed by many at the time that commerce has beneficial effects. He does not deny that the longstanding institutions in France - the monarchy, the clergy, and the nobility - had faults. For example, he notes, "Those of the commons, who approached to or exceeded many of the nobility in point of wealth, were not fully admitted to the rank and estimation which wealth, in reason and good policy, ought to bestow in every country ... The two kinds of aristocracy were too punctiliously kept asunder." ${ }^{, 131}$ Rather, it is the approach taken by the new revolutionary government in France in the handling of public funds that is the source of his criticism. In particular, Burke is horrified by the confiscation, by the National Assembly in France, of lands traditionally held in France by the clergy and the nobility. ${ }^{132}$ He associates the use of paper currency with changes occurring in economic structures in France in relation to "landed property" and "monied property." 133 He states that the creation of a paper

${ }^{131}$ Ibid. 244.

${ }^{132}$ As pointed out by Pocock, Burke's discussions do not concern a "Marxist bourgeoisie" (199) but rather the difference between "a landowning class on the one hand and a debt-contracting government on the other" (200).

${ }^{133}$ Burke Reflections 210. 
currency is "founded on an eventual sale of the church lands" 134 and that "[s]o violent an outrage ... as this compulsory paper currency has seldom been exhibited by the alliance of bankruptcy and tyranny, at any time, or in any nation." ${ }^{, 135}$ As O'Brien notes, Burke foresaw that the system of "assignats, notes issued on the security of the church and crown lands confiscated to the state ... enriched a class of speculators." ${ }^{, 136}$ Burke states: France will be wholly governed by the agitators in corporations, by societies in the towns formed of directors of assignats, and trustees for the sale of church lands, attornies, agents, money-jobbers, speculators, and adventurers, composing an ignoble oligarchy founded on the destruction of the crown, the church, the nobility, and the people. Here end all of the deceitful dreams and visions of the equality and rights of men. ${ }^{137}$

He points out that the "truly melancholy part of the policy of systematically making a nation of gamesters is this; that tho' all are forced to play, few can understand the game; and fewer still are in a condition to avail themselves of the knowledge. The many must be the dupes of the few who conduct the machine of these speculations." ${ }^{138}$ Without doubt, Burke's comments at times appear extremely prescient when considering the effects of market crashes and the elite concentrations of wealth that have formed a feature of modern economies.

Burke points out the increase in mendicancy in Paris following the overthrow of the old systems. He suggests that population and wealth may be viewed as standards "by

\footnotetext{
${ }^{134}$ Ibid. 224.

${ }^{135}$ Ibid. 226.

${ }^{136}$ [Note 103] Reflections 391.

${ }^{137}$ Reflections 313.

${ }^{138}$ Ibid. 311.
} 
which we may judge whether, on the whole, a government be protective or destructive," ${ }^{\prime 139}$ and he notes that France enjoyed both an increasing population and relative opulence under the deposed government. He concludes that France's government was not "utterly unfit for all reformation"140 but rather "well deserved to have its excellencies heightened; its faults corrected; and its capacities improved into a British constitution." ${ }^{\prime 41}$ Burke points out that an absolute democracy is problematic and asks "Have these gentlemen never heard . . . of any thing between the despotism of the monarch and the despotism of the multitude? Have they never heard of a monarchy directed by laws . . . is it then impossible that a man may be found who . . shall prefer such a mixed and tempered government to either of the extremes . . . ?"142

Burke argues that with the traditional institutions of France, "the surplus product of the soil" "143 was put towards "the accumulation of vast libraries ... great collections of antient records, medals, and coins ... paintings and statues . . . grand monuments of the dead ... [and] collections of the specimens of nature." ${ }^{\text {"144 }}$ He recognizes the prevalence of new forms of expenditure in societies marked by increasing luxury and asks "Are the decorations of temples an expenditure less worthy a wise man than ribbons, and laces, and national cockades, and petits maisons, and petit soupers, and all the innumerable fopperies and follies in which opulence sports away the burthen of its superfluity?"145 Nonetheless, Burke affirms that liberties and rights to property are of greater importance

\footnotetext{
${ }^{139}$ Ibid. 233.

140 Ibid. 236.

${ }^{141}$ Ibid.

142 Ibid. 227.

${ }^{143}$ Ibid. 271.

${ }^{144}$ Ibid. 272.

${ }^{145}$ Ibid. 273.
} 
than criticism of seemingly transient and foolish uses of wealth, stating, "We tolerate even these ... We tolerate them, because property and liberty, to a degree, require that toleration. But why proscribe the other, and surely, in every point of view, the more laudable use of estates?"146

In the Reflections, Burke's discussions of the causes of, and the ongoing approaches required in, a civil society do not shy from practical complexity. Like the conjectural historians, Burke recognized the close connections between changes to economic structures and political change in societies. He did not necessarily agree in all ways with the order of cause and effect between economic and political change suggested by conjectural historians, and certainly he brought a different focus to the questions in some respects. In his view, religious beliefs play a significant role in shaping societies, and he suggests that there must be a connection between moral and governmental spheres in order to achieve just structures in a society. In addition, he held a reverent appreciation of the protections afforded by the checks and balances of power maintained in the British form of government as set out in its constitutional framework, and in his last comments before the two closing paragraphs of his very long letter, he reiterates that in England, "I think our happy situation owing to our constitution."147 To Burke, a constitutional framework represents the longstanding prejudices that shape the structures of a society and should be changed only very gradually in accord with the process of change in social attitudes. ${ }^{148}$

\footnotetext{
146 Ibid.

147 Ibid. 375.

${ }^{148}$ Britain's constitutional framework (and that of some of its former colonies, such as Canada) is not expressed in one document but rather in a set of pieces of legislative text, judicial precedent, and customary law. Nonetheless, this framework is typically referred
} 
In his text, Burke typically expresses his view of the advisable pace of political change in societies through discussions advocating respect for the accumulated wisdom of Britain's constitutional framework. Conjectural historians discussed the long trajectories of history in which political developments accompany gradual changes in manners and customs. They viewed political change as arising not from the actions of particular statesmen but in accompaniment with gradual change in the economic and social structures of a society. As stated by Phillips, late eighteenth-century historiography "entailed the revelation of the limits of political action and thus the need for historians to reconceptualize historical change within a broad narrative of social experience."149 While on opposite sides of the political debates at the beginning of the French Revolution, Sir James Mackintosh's appreciation of the astuteness of Burke's political writing continually increased over the years, and he later expressed agreement with Burke's views, "central to which was a firm commitment to a principle of gradualism and a consequent renunciation of any attempt to force the pace of historical change." ${ }^{150}$ Mackintosh shared Burke's view that political theory must be based on experience and cannot be a matter of speculation alone. In a letter written from India, Mackintosh states that Burke is typically praised most for his eloquence, in works that "profess to be speeches, or pamphlets, on the events of the time, and to have the temporary object of persuading, or dissuading, the public." ${ }^{151}$ Mackintosh argues that it

to as 'the Constitution,' as in Burke's text, and the components of this framework enable all other legislation as surely as if its principles were explicitly collected in one document.

${ }^{149}$ Phillips Society and Sentiment 220.

${ }^{150}$ Ibid. 228.

${ }^{151}$ Mackintosh 312. 
is in fact from these works with a supposed "transient interest"152 that one can gather the general instruction and consistent principles of political wisdom.

The tangible changes evident with economic development could indeed seem to be proceeding at a fast pace in British society during the late eighteenth century. In France, change in all aspects of society appeared to be occurring at an even more dramatic pace and may have seemed, to Burke, to be instigated by revolutionary philosophers and politicians. What Burke does not entertain is the idea that those revolutionary figures in France perhaps only appeared on the stage of France's history as a result of gradual economic change in French society over the preceding centuries, which increasingly challenged traditional structures of French society. In any case, whatever his political positions, Burke's work exemplifies one of the many texts in which are found similar preoccupations to those of the conjectural historians during the late eighteenth century.

${ }^{152}$ Ibid. 313. 


\section{Chapter Two}

\section{Travellers' Representations during the Late Eighteenth Century: Epistemological Position Among Genres}

While drawing on various traditions, genres of writing and visual representation reflect their historical specificity. Rather than being fixed entities, genres continually change as the aims of writers and artists are adjusted according to the needs and wishes of the audience of their time. As stated by Phillips, "genres are historical formations that mediate the communication of readers and writers." 1 The reading and viewing public of late eighteenth-century Britain had much curiosity regarding newly encountered distant cultures, and they sought the depictions of societies, both far away and closer to home, in various textual and written genres.

Readers in the late eighteenth century expected to find different styles of expressions and types of knowledge among the wide variety of genres in the new literary marketplace. Sources of knowledge from many disciplinary areas were valued in a public forum of literary discussion that was expanding rapidly with advancements in publishing, the proliferation of newspapers and journals, and the growth of a reading public. Along with travel accounts, novels offered a popular source of depictions of societies near and far, and indeed the degree of fiction involved in traveller's accounts of their journeys was always in question. Travellers' visual representations were subject to perhaps less suspicion in relation to the reality of the scenes depicted, even though additions and re-arrangements were a common practice among landscape painters of the

\footnotetext{
${ }^{1}$ Society and Sentiment 10.
} 
time. However, even without changes introduced by the artist with respect to the actual elements of a scene, affective response to landscape added a tone of subjectivity to visual representations.

The genres of travel writing and the novel each have a long and complex genealogy, and both continued to change in form and focus throughout, and after, the late eighteenth century. The emergence of the novel has been the subject of much scholarship. Percy Adams explores the roots of the novel in, for example, epic, romance, and picaresque traditions. The term 'romance' has, of course, its own history and appears in writing of the late eighteenth century in reference to earlier genres, such as chivalric romance, as well as to novels of the time, including works containing marvellous elements and Gothic novels. Travel often played a role in all of these genres.

Travel writing of the late eighteenth century included works of a great range of style and content, eluding strict generic definition and exemplifying the fluidity of generic borders of literature during the period. Paul Keen discusses the importance of viewing literature of the time more broadly as a "field of cultural production", in which all genres of writing were being shaped. Keen points out, for example, the "selfrepresentational strategies"3 that played a part in the increasing association of the term 'literature' with aesthetic expression that emerged in the late eighteenth and early nineteenth centuries.

Travellers' representations exhibited the same trends that were evident within the literary landscape more broadly. While epic dramas and romances narrating the exploits of gods, kings, and chivalric knights retained their places of honour on late eighteenth-

\footnotetext{
${ }^{2}$ Keen 17.

${ }^{3}$ Ibid. 19.
} 
century bookshelves, readers increasingly turned their attention to new novels that depicted the predicaments and sentiments that attended real lives in their contemporary society. Trends evident in fictional writing of the period similarly appeared in other genres of writing, including historical writing and travel writing. As we have seen, the inclusion of more segments of society in a fuller consideration of the social conditions underlying political change began to characterize late eighteenth-century British historiography, and other genres of writing were similarly more inclusive.

In this chapter, I will contextualize the genres of travellers' textual and visual representations in relation to other genres. The genre of the novel was continually increasing in popularity during the period and will therefore be the focus of my discussions of contemporary literary trends that were influential. Specifically, I will explore the epistemological contributions of the genres rather than a broad view of their late eighteenth-century generic definitions. Along with the tropes of travel and the depictions of societies that could be found in various genres, literary trends in styles of representation and range of focus were evident in the works of travellers as well as novelists. Formal structures, including the narrative convention of letter or journal, the inclusion of sentiment, the use of common aesthetic categories of the period, and an increasing focus on the social conditions of a wider range of society were seen in novels and in travellers' representations. The characteristics of late eighteenth-century genres will be examined specifically in relation to the types of knowledge that they were perceived as providing, as well as some of the reasons at the time for those perceptions. Information was acquired by writers through a variety of modes of encounter, filtered through various frameworks of interpretation, and represented using a number of 
techniques and forms. Despite the dubious epistemological value with which novels and travel accounts were sometimes credited, works of these genres were widely read. As we have seen in the discussions of conjectural historians, the exaggeration or even outright fabrication of travellers was well acknowledged at the time. Nonetheless, the first-hand witnessing found in travellers' representations was similarly sought by many in the British public, who were avidly reading travel accounts not only out of curiosity but also as a valuable source of information for those with administrative, scientific, or other specialized interests, however much they afterwards applied their discernment in their use of the observations contained in them.

Political issues of the time affected the knowledge to be found in works of both travellers and novelists. Political and social commentary were a common element in travellers' accounts. Along with depictions of the effects of the shift to increasingly industrialized and commercial societies, travellers and novelists often commented on domestic politics, and their writing reflected the influences of Britain's expanding global empire. Travellers involved with trade often included comments relating to the conditions of commerce in the regions that they visited. Further, particular interests of individual travellers, whether in botany, architecture, or any other subject, were often evident in their accounts. Travellers' representations and novels of the late eighteenth century offered depictions of societies both close to home and far away, and these works played a central role in providing knowledge to those in Britain as they tried to make sense of a changing world.

\section{Stadial Ideas in Travellers' Representations of Cultures}


Along with chronological historical narratives, travellers read visual signifiers of cultural histories, in the architecture, objects, and customs they see around them, noting indications of the historical diffusions that form part of the framework of their understanding of the society in which they find themselves. One may simply open any travel guide published today for an immediate indication of the ongoing importance of historical reference in the representation of cultures. With often little traditional historical information available regarding the events that had taken place in newly encountered areas of the world, travellers turned to the more general framework of conjectural history in their attempts to understand and depict what they were seeing. The ideas of the conjectural historians are reflected in travel writing of the period.

In works of late eighteenth-century conjectural history, all societies were characterized according to their stage of development, including not only remote cultures but also the societies of different European states and various areas within Britain. Whether in relation to the East, the Americas, or even various states of Europe or regional differences within those states, the terms and ideas of stadial theory are similarly pervasive in the representations of late eighteenth-century travellers. Travellers on the Grand Tour or visiting European states that were not generally included on its itinerary often commented on the relative stage of advancement of the societies they encountered. Mary Wollstonecraft's Letters Written During a Short Residence in Sweden, Norway and Denmark indicate that she was familiar with the work of conjectural historians, and she offers her opinions regarding the interpretations put forward by both historians and "writers of travels ... whose works have served as materials for the compliers of 
universal histories. ${ }^{24}$ Throughout her text, Wollstonecraft continually depicts

Scandinavian societies in terms of their stages of development, and her comments regarding some of the improvements that accompany advanced stages suggest that she shares the notions of progress underlying stadial theory. While noting many positive aspects of life in Norway, for example, she also writes that Norwegian culture is only just arriving to a stage of possessing "scientific knowledge" and "taste for literature," and she suggests that she would not find it entirely satisfying to spend all of her time in a place of "simplicity of manners."

While on the Grand Tour, James Boswell records his impressions of the advanced state of culture but lack of virtue in Italian society; he writes to Alexandre Deleyre:

Your ideas on the corruption of Italy have recurred to me many times. The worst is that in travelling there one becomes used to seeing people who think no more about the virtues of sensitive souls than an American savage thinks of the pleasures of civilised nations. The Italians as well as the savages appear to pass their time very agreeably. Why then reproach the former for not possessing elegant and sublime virtues, when we do not blame the savages for having neither brilliant ballets nor serious operas? ${ }^{7}$

Throughout his account, Boswell often complicates late eighteenth-century notions of progress. He extolls the less developed but more virtuous and heroic society of Corsica: Their poverty, I told them, might be remedied by a proper cultivation of their island and by engaging in a little commerce. But I bid them remember that they were much

\footnotetext{
${ }^{4}$ Wollstonecraft 29.

${ }^{5}$ Ibid. 38.

${ }^{6}$ Ibid. 57.

${ }^{7}$ Boswell 111.
} 
happier in their present state than in a state of refinement and vice, and that therefore they should beware of luxury. ${ }^{8}$

The philosophical gaze could be found in the accounts of some travellers as well as in the works of the conjectural historians.

Travellers to Greece, Italy, and the Near East were interested in seeing the lands that formed the setting of ancient narratives, carrying literary works and historical writing with them as guides. Along with the Classical ruins that they observed scattered throughout Ottoman lands, travellers noticed "the similarities between the ancients and the contemporary Ottomans in their manners and customs." ${ }^{.9}$ Nebahat Avcioğlu suggests that a commonly held view among travellers of the time was "that the Ottomans had inherited and preserved the cultural legacy of the ancients." ${ }^{10}$ In her examination of the European relationship with architecture of the Near East, she states that in various stylistic trajectories - from past to present, from West to East - "[t]he Turkish style of architecture always stood in the minds of European observers somewhere in between."

Travellers at times thought of scenes from texts of antiquity when viewing processions or performances of music or dance. During the late eighteenth century, the focus of European composers was shifting from the complex counterpoints of the Baroque to an exploration of the new formal structure of the Classical sonata and symphony. Travellers sometimes suggested that the music they encountered brought to mind an earlier stage, or at least a more pastoral mode, in the historical narrative of musical development. In a letter written to Alexander Pope during her travels in Turkey,

\footnotetext{
${ }^{8}$ Ibid. 170.

${ }^{9}$ Avcioğlu 121.

${ }^{10}$ Ibid.

${ }^{11}$ Ibid. 118.
} 
Lady Mary Wortley Montagu writes that some of the outdoor social gatherings that she observed evoked scenes described in literature, there not being one instrument of music among the Greek or Roman statues that is not to be found in the hands of the people of this country. The young Lads generrally divert themselves with making Girlands for their favourite Lambs, which I have often seen painted and adorn'd with flowers, lying at their feet while they sung or play'd. It is not that they ever read Romances, but these are the Ancient Amusements here. ${ }^{12}$ Styles of music and dance could evoke either the simplicity of ancient bucolic scenes or the spectacle of ancient celebrations and processions. While staying in Ghinnah, a town in Egypt, Eyles Irwin and his travelling companions witnessed what they found out the next day was a ceremony performed "on the first visible rise of the Nile,"13 writing: we were awakened from our first sleep by the sounds of tinkling instruments, accompanied by a chorus of female voices. I looked out of the window, and saw a band of thirty damsels at least, come tripping towards us, with measured paces, and animated gestures. The moon shone very bright, and we had a full view of them, from their entering the gate of our street, until they reached our house. Here they stopped, and spreading themselves in a circle before the door, renewed the dance and song with infinite spirit, and recalled to our minds the picture which is so fully given of these dancing females in holy writ. After they had favored us a few minutes with their lively performance, ... this joyous band quitted our quarter, and went, as the

\footnotetext{
${ }_{13}^{12}$ Montagu 332.

${ }^{13}$ Irwin 230.
} 
dying sounds informed us, to awaken the other slumberers of the town, to melody and joy! ${ }^{14}$

The differing tonalities, conventions, and forms of the music of the East could be relatively incomprehensible to Western ears. However, travellers' descriptions of the music they encountered, whether in the East or in rural festivities in European states, at times reflect ideas emerging within the framework of conjectural history.

Some travellers to the Near East were interested in visiting the sites referred to in Biblical narratives, as seen, for example, in the travel account of James Haynes. Haynes was employed as a clerk to a merchant involved in trade in the Levant, and he recorded his observations concerning not only trade but also the natural history of the regions through which he travelled as well as many aspects of the lives and customs of the local populations. He discusses, for example, the customs of the Copts in Egypt, noting, "The Coptis make a very splendid procession on their wedding days." ${ }^{15}$ He records his thoughts when visiting religious sites, stating to the reader, "you will not be surprised at my embracing so favourable an opportunity, to visit those sacred remains of antiquity." He relates that "my guide and I pursued our journey for Nazareth, the place where Christ was brought up, ${ }^{17}$ and he visits a synagogue that "has indeed the appearance to have been built many ages past, and may very probably be the same that Christ preached in." 18 However, Haynes at times expresses skepticism with respect to some aspects of his encounters and observations. He and his guide visit "a small building, which he assured

\footnotetext{
14 Ibid. 229.

${ }^{15}$ Haynes 49.

${ }^{16}$ Ibid. 117.

${ }^{17}$ Ibid. 133.

${ }^{18}$ Ibid. 147.
} 
me was the identical place where Joseph who was espoused to the blessed Virgin actually worked at his trade, ${ }^{19}$ and he describes a painting hung there of Joseph, Christ as a child, and Mary sitting in "an elegant modern made chair." ${ }^{20}$ He suggests "the absurdity of this piece ... Certainly it is very ridiculous, to place the Virgin Mary in a chair, in a country, where at the time she was living, it is more than probable, no such piece of domestic furniture was ever seen, and where the people then did, as most of them do at this time, sit in the same manner the Turks do." ${ }^{21}$ In listening to the stories of his guide, Haynes states, "as his relation of this matter was mixed with miracle, I soon grew tired of his superstition." 22 At the same time, Haynes does not hesitate to praise what he views as being of a more real piety than is sometimes found in European religious institutions. When staying with a Greek "Papas" in Cana [a town in Galilee referred to in the Bible], he writes, "The wish of possessing rich benefices, or soliciting for a bishoprick is not known to him; and the most chearful hospitality to strangers characterises his being, what I wish could be said of many, who occupy the holy function in England." ${ }^{23}$ He suggests that these priests exhibit what he imagines were the traits of those in the past, stating that "many of the Greek priests in the Holy Land are true types of their predecessors the Apostles; for they labour with their hands for the support of themselves and families, without thinking it any disgrace."24

As we shall examine in the following chapters, travellers to India also noted the similarities between what they observed and scenes from texts of antiquity, but in this

\footnotetext{
${ }^{19}$ Ibid.

${ }^{20}$ Ibid. 148.

21 Ibid.

${ }^{22}$ Ibid. 149.

${ }^{23}$ Ibid. 121.

${ }^{24}$ Ibid. 131.
} 
case the connections were based on what they imagined were common characteristics of ancient stages of civilizations.

\section{Travellers' Representations in an Increasingly Commercial World}

The social effects of increasing industrialization and commerce were a common focus of late eighteenth-century literature, during a period in which literature itself was acquiring an aspect of commodity in a market created by the rapid growth in publishing and a reading public. As stated by Keen, "commerce was felt by many to be a highly ambiguous force," 25 both "driving Europe's progress from feudal tyranny into an age of unprecedented liberty" 26 and at the same time having "morally enfeebling effects." 27 Wollstonecraft describes a town on the coast of Norway in which "[h]aving no employment but traffic, of which a contraband trade makes the basis of their profit, the coarsest feelings of honesty are quickly blunted ... there is a shrewdness in the character of these people, depraved by a sordid love of money which repels me."28

Contrasts between city and country were often discussed in relation to the effects of industrialization and commerce. In Tobias Smollett's novel The Expedition of Humphry Clinker, depictions of Britain's changing social order accompanying the shift in its economic structure are often placed in the letters of Matthew Bramble, in which he catalogues "the difference between my town grievances, and my country comforts." 29 Bramble's depictions of country life are idyllic and emphasize the importance of good

\footnotetext{
${ }^{25}$ Keen 225.

26 Ibid.

${ }^{27}$ Ibid.

${ }^{28}$ Wollstonecraft 65.

${ }^{29}$ Smollett 133.
} 
agricultural management. Ann Bermingham points out that landowners who "had a long tradition of participation in country affairs were dividing their time between their estates, London, and the continent. Wintering in London became the common practice of such families, with the result that when they did return to the country, they brought with them urban ideas and values." ${ }^{30}$ The results of this trend are depicted in Smollett's novel with Bramble's narration of the unfortunate consequences of the marriage of his friend Mr. Baynard. Bramble's depictions of city life are also extreme and express his disgust with the filth and the destructive effect of city life on social relationships; he notes that in London "All the people I see, are too much engrossed by schemes of interest or ambition, to have any room left for sentiment or friendship." ${ }^{\prime 31}$ Cities in Scotland, however, escape such a harsh review; Jery describes Glasgow as "an elegant and flourishing city"32 with which "my uncle is in raptures." 33 The relative merits of social aspects of city and country are less clear in Henry Fielding's novel The History of Tom Jones, a Foundling, in which vice as well as virtue is to be found in characters of both urban and rural societies.

Helenus Scott's novel The Adventures of a Rupee: Wherein are Interspersed Various Anecdotes Asiatic and European, which was published in 1782, exhibits the preoccupations with commerce that were common during a period of rapidly expanding global trade. Scott's novel assumes the form of an at times comical traveller's account in which the protagonist is a rupee, being passed from hand to hand along trade routes from India to England. The literary device of relating the adventures of an object in a

\footnotetext{
${ }^{30}$ Bermingham 75 .

${ }^{31}$ Smollett 138.

32 Ibid. 264.

${ }^{33}$ Ibid.
} 
commercial world is found in several works of the period, such as, for example, the novel Chrysal; or, The Adventures of a Guinea by Charles Johnstone, which was published in four volumes from 1760 to 1765 . Liz Bellamy points out that the episodic structure of these works, referred to as 'novels of circulation,' allows the depiction of "the full spectrum of social wealth and class" ${ }^{\text {"34 }}$ and is ideally suited to "a satiric portrayal of the nature of the modern world." ${ }^{35}$

Scott lived in India for thirty years while working as a physician for the East India Company. ${ }^{36}$ Scott's novel contains many statements extolling aspects of India's cultures, which, as suggested at times in comments overheard by the rupee, should be respected by Europeans engaged in trade in the subcontinent. Scott's novel includes depictions of well-known political figures. In an extended episode involving Hyder Ali, Scott writes that the ruler of Mysore had given "many proofs of great generalship and force of mind. ${ }^{37}$ With the limitless possibilities allowed by fiction, the rupee also spends time in the household of King George III and Queen Charlotte.

Various aspects of late eighteenth-century societies in both India and Britain are satirized in Scott's novel, including soldiers, criteria for the promotion of officials of the East India Company, and the practice of medicine. Along with the evils that often accompany commerce, religion sometimes receives his sharpest criticism. In the episode in which the rupee spends time with a fakir in India, Scott writes that the fakirs,

\footnotetext{
${ }^{34}$ Bellamy 121.

${ }^{35}$ Ibid. 126.

${ }^{36}$ Oxford Dictionary of National Biography.

${ }^{37}$ Scott 27.
} 
"somewhat like the Monks in Catholic countries, extort charity by a kind of religious robbery." 38

In Scott's work, the rupee gradually acquires an awareness of the miserliness, deceit, theft, poverty, and false associations of wealth with merit that may accompany commerce, and the tale often takes on the tone of moral fable. Like many writers of the time, Scott appeals to the reader's sentiment in anecdotes in which virtue is defined and rewarded, and the stories of visitors to a pawn shop in London give an early hint of scenes from the Victorian novels of Charles Dickens.

As well as describing the effects of commerce in societies in Britain and abroad, travel writing was a popular commodity in the literary marketplace. As well as bringing products from distant locations into Britain, expanding global trade gave rise to the encounters with remote cultures that provided the material of travel accounts. Travellers provided knowledge regarding a wide range of topics relating to foreign societies. The style and content of travel writing intended for possible publication often reflected contemporary literary fashions and perceived demands within a commercial society. Jeremy Black suggests that "published travel literature should be sharply differentiated from letters or journals never intended for publication, ${ }^{, 39}$ pointing out that there is a "major difference between writing for an intimate circle, and producing a work for a large anonymous market." ${ }^{40}$

The letters and journal entries written by Henrietta Clive during her travels in the south of India, as well as the travel journal of her daughter Charlie, remained in a

\footnotetext{
${ }^{38}$ Ibid. 11.

${ }^{39}$ Black vi.

${ }^{40}$ Ibid.
} 
collection of family papers in Wales until a selection of their writing was recently made available to a wider set of readers through the research of Nancy Shields. Henrietta had not only a persistent wish but also an extraordinary opportunity, as the wife of Edward Clive, Governor of what was then Madras, to travel extensively, undertaking an amazing journey of over a thousand miles around the south of India along with her two daughters and their Italian governess. Most of the letters that she wrote during her travels in India were addressed to her husband, along with a few close family members and friends, and their tone and contents indicate that she did not anticipate the possibility of their publication. In her letters, Henrietta does not appear to have had the aim of providing her correspondents with a broad historical or cultural overview of Indian society but rather of relating some of her immediate impressions of what she was seeing. Her writing is filled with updates regarding the weather, the daily status of her daughters' health, and her collection of plants, seeds, and trees that was continually growing due to her keen interest in botany. The family also collected other specimens of nature, such as shells and rocks, and along with the pets they had brought with them, they were accompanied by a growing menagerie. While men often exchanged weapons and sometimes jewels in the ceremony of gift-giving that went along with the encounters of travel, the hosts of Henrietta and her daughters throughout their journey would often give them animals as presents. As noted by Maya Jasanoff, "Lady Clive accepted the gift animals almost as a diplomatic obligation. She and her entourage constituted an embassy of sorts $-\mathrm{a}$ precursor to the quasi-royal governors' and viceroys' tours that would lumber through the princely states of Victorian India in gold-tasseled howdahs. ${ }^{\text {41 }}$ Henrietta's depictions of

\footnotetext{
${ }^{41}$ Jasanoff 189.
} 
various landscapes through which they travelled are often associated with practical matters of heat, rain, and agricultural cultivation rather than with states of the sublime or with the degree to which a view was picturesque. As noted by Black, popular literary conventions of the time, as well as evident aims of sustaining interest in narratives of experiences, were more commonly found in travel writing aimed at commercial appeal.

Henrietta shared the interest of many Europeans in the splendours of the East. Antoine Galland's translation of the Arabian Nights had appeared in the first few decades of the eighteenth century, and as with many travellers' accounts, Lady Mary Wortley Montagu's “Turkish Embassy Letters" being an often cited example, Henrietta describes some of her encounters in relation to the imagined scenes that were evoked by those tales. However, Henrietta's letters invariably assume a more realistic tone and make evident her interested awareness of the political events of the times. While Henrietta's letters and journal entries were not accessible as a published source of information during her time, her writing nonetheless exemplifies the first-hand witnessing that those in Britain sought in travellers' accounts of their journeys. Along with anecdotes regarding visits to Hindu and Muslim religious sites and festivals, candid descriptions of many political figures of the time, both European and Indian, appear throughout Henrietta's letters and journal entries, as in Scott's novel. She relates, for example, comments made by various officials with whom she was acquainted regarding the conflict with Tipu Sultan, as well as her own first-hand impressions of meeting Tipu Sultan's widows and the Rajahs of Mysore and Tanjore. Travellers' comments regarding political figures in India were of great interest to the British public at a time of increasing involvement with issues relating to the subcontinent. One particular segment of history of personal interest to Henrietta 
clearly influenced her travel itinerary; having been earlier captivated by the stories about India told by Robert Clive, who was Edward's father, Henrietta visited places to which he had been, carrying with her from England a copy of Robert Orme's work A History of the military transactions of the British nation in Indostan, which had been published a few decades earlier. The personal interests of individual travellers are revealed in their accounts of their journeys, as exemplified in Henrietta's focus on her family, botany, and the lives of contemporary political figures.

\section{Formal Structure: Immediacy and Questions of Subjectivity}

Most travel writing of the period consisted primarily of a first-person narrative relating the lived experience of the traveller. The form of letter or journal entry was a commonly used convention in travellers' accounts as well as in other genres of writing in order to lend a sense of immediacy to the narrative. In one of the letters to the Editor at the beginning of Samuel Richardson's novel Pamela, Or Virtue Rewarded, which was published in 1740, the advantages of epistolary form in revealing the inner feelings of the heroine are explicitly stated:

... (the Letters being written under the immediate impression of every Circumstance which occasioned them, and that by those who had a Right to know the fair Writer's most secret Thoughts) the several passions of the Mind must, of course, be more affectingly described, and Nature may be traced in her undisguised Inclinations with much more Propriety and Exactness, than can possibly be found in a Detail of Actions 
long past which are never recollected with the same Affections, Hopes, and Dreads, with which they were felt when they occurred. ${ }^{42}$

At the same time, the epistolary structure of Richardson's novel contributed to the controversy that followed its publication. Along with the challenges to aspects of British society, such as, for example, its class structure, that are posed by the novel, questions regarding the characters and their motivations arise in a form that reveals only one point of view through a narrator who may possibly be subject to self-deception or bias and who may be manipulating the text of a letter according to the anticipated readers of her letters. Richardson presented a work of psychological complexity that provoked dramatically varying interpretations and responses from readers. In An Apology for the Life of Mrs. Shamela Andrews, Henry Fielding offers a parody of Richardson's novel that constitutes a summary of many of the criticisms against it, including the potential artificiality of the epistolary form, as seen in, for example, the sheer amount of writing by Richardson's heroine.

The depiction of landscape was typically a significant component of travel writing during the late eighteenth century, and subjectivity could play a role in these depictions. Travellers' depictions of distant landscapes were of great interest to British readers at a time in which the possibilities of travel were more limited to many people than today. Descriptions of landscapes, often based on actual places, were similarly a standard element in novels. Several relationships between the individual and nature that were given expression during this period appear in the writing of Johann Wolfgang von Goethe, in The Sorrows of Young Werther, and of Jean-Jacques Rousseau, in Reveries of

\footnotetext{
${ }^{42}$ Richardson 5.
} 
the Solitary Walker. Goethe's epistolary novel tells the story of an exceedingly romantic young man, and Rousseau's set of essays consists of relatively resigned meditations looking back at his life, but the two protagonists share a concern with the limitations of formal logic as well as despair with supposedly rational worldly affairs and social structures, with each turning to nature as inspiration in the expression of more exalted systems of order.

Along with Richardson's Pamela, Goethe's work, which was published in 1774, was a very influential epistolary novel of the time. Goethe's use of the epistolary form in telling the story of Werther enables the full expression of the troubled young man's inner turmoil. Subjective states are suggested through the protagonist's words, written, as it were, straight from the heart, and the concern with which they are read by his friend Wilhelm. The extent to which Werther's states of mind are reflected in the depictions of his surroundings that frequently appear in his letters exemplify one commonly recurring relationship of the individual to the natural world during the period. Werther interprets nature not according to its material aspects but rather as an expression of a grand scheme that stands behind the visible world, with his depiction of this supposed scheme varying according to his emotional condition of the moment and ranging from a benevolent master plan to a devouring abyss.

While both Rousseau and Werther found contentment in a rural existence, separated from the affairs of the outside world, Rousseau retains the idyllic vision of nature that was lost to Werther following its spring blossoming. These two texts clearly exemplify the possibly highly subjective nature of the representations of 
landscapes that could be offered in writing of the period, an observation to be kept in mind when analyzing late eighteenth-century travellers' representations.

Through the epistolary structure of his novel The Expedition of Humphry Clinker, Tobias Smollett suggests the extent to which the perception of a place is dependent on its viewer. Smollett's fictional travel account presents the impressions of various cities and regions of Britain in letters written by Matthew Bramble and his sister, niece, nephew, and a family servant. Bramble becomes disgruntled with what he sees as the luxury and corruption of the popular destinations of travellers, writing that "Bath is become a mere sink of profligacy and extortion." ${ }^{, 43}$ In contrast, his niece Liddy writes that in London she is "dazzled and confounded with the variety of beauties that rushed all at once upon my eye." ${ }^{44}$ Nonetheless, while the epistolary form raised questions due to its subjectivity, it was at the same time ideally suited for the description of the details of daily life that could provide insight regarding the social conditions of societies; as attention was increasingly directed to the manners and customs of societies in many genres of late eighteenth-century writing, the common use of epistolary structure in writing of the period is not surprising. The eye-witnessing could lend a sense of credibility to the descriptions of societies found in the genre of travel writing. The factor of first-hand impression played a part in the views of conjectural historians regarding the evidentiary value of travellers' observations.

The representations of societies found in travel writing of the period comprise a body of early ethnography. In discussing later approaches in anthropology, Clifford Geertz explores the implication of the author in ethnographical accounts. Geertz argues

\footnotetext{
${ }^{43}$ Smollett 67.

${ }^{44}$ Ibid. 106.
} 
that the supposedly removed position of objective inquiry traditionally assumed by the anthropologist does not reflect the actual epistemological basis of ethnographic fieldwork, in which insight regarding the customs of other cultures is obtained through an inter-subjective process of encounter. Geertz suggests that ethnographic studies would be more properly considered using the techniques of literary analysis, bringing to the text the awareness of ethnographer as author. He states that while anthropologists have typically attempted, through a scientific stance, to distance themselves from the power asymmetries of the colonial encounters in which their discipline took shape, "the burden of authorship cannot be evaded, however heavy it may have grown."45

Relative degrees of objectivity and subjectivity in travel writing during various periods have been a subject of scholarly attention. Attempts at objective rigour are often suggested to have been more evident in seventeenth- and early eighteenth-century depictions of societies, becoming again more central in later periods as colonial administration sought a more systematized source of cultural information and as anthropology attempted to define its disciplinary borders. Jeremy Black notes that later eighteenth-century travel literature "generally moves from the supposedly objective to the frankly subjective." 46

Nonetheless, much supposedly objective observation may be found in late eighteenth-century accounts. Ingrid Horrocks discusses the view "that the final decades of the eighteenth century already saw a new and widely based emphasis on the subjective 'I' . . as opposed to the presentation of facts, ${ }^{, 47}$ with travel accounts of the time

\footnotetext{
${ }^{45}$ Geertz 140 .

${ }^{46}$ Black vii.

${ }^{47}$ Horrocks 2.
} 
narrating "an 'adventure of the self', first and foremost offering opportunities for selfexploration, self-discovery and self-staging." ${ }^{, 48}$ She points out that "[r]ecent scholarship suggests that this understanding has overemphasized a specifically literary branch of travel writing and in the process has misrepresented the vast majority of travelogues of the period." ${ }^{, 49}$ She notes that the work of some scholars suggests that readers at this point exhibited "little interest in the personality of the traveller, nor in the kind of interior exploration that has come to be associated with Romantic travel writing. This is especially noticeable ... in relation to texts which describe journeys further than the Continent, where the travelling self takes a distinct second place to the literal 'continent of information' available to the traveller." ${ }^{50}$

The wish to record 'factual information' of all types, whether pertaining to the natural history and geographical aspects of a region, the customs and manners of local cultures, the arts found in various cultures, or matters relating to commercial or military activities, is indeed apparent in the writing of travellers to the Near East and India. Antiquarian interests found expression in detailed and factual description of ancient structures and artefacts, philologists searched for knowledge of the languages and texts of antiquity, and surveyors and botanists provided information about the natural environments of various regions. James Haynes offers observations regarding a very wide range of subjects, including, among his many other interests, discussions of the local food and the birds and animals that he sees in the Near East. He carefully describes, for example, the habits of the four chameleons who lived in his room in Rosetta in Egypt,

\footnotetext{
${ }^{48}$ Ibid.

${ }^{49}$ Ibid.

${ }^{50}$ Ibid.
} 
and a diagram of a chameleon is provided with his account. James Forbes provided detailed visual representations of the flora and fauna that he observed during his travels in India, as seen, for example, in his depiction of a bird in the watercolour The Sultana: or Hoopoo, at Bombay, on a Sprig of the Citron Tree, c. 1765-8. The iconic banyan tree found in India was depicted by more than one travelling artist, as seen, for example, in Forbe's watercolour Indian Burr or Banyan Tree, 1779, as well as in the painting View of Cubbeer Burr, the Celebrated Banyan Tree, 1789, by James Wales, in which he records the pastimes of local residents in the shaded spaces offered under the wide expanse of the tree's branches. The fluidity of the disciplinary borders of the genre resulted in a great range of possible focus that depended on the personal interests of the individual traveller and at times the institutional aim that instigated the journey.

Architectural description was a common element of travel writing of the period, and those in Britain with an interest in architecture sought information regarding the style and construction techniques of buildings in foreign societies in the accounts of travellers. The careful descriptions and drawings found in many travellers' accounts often demonstrate the fine quality of the architectural observations that could be provided by non-specialists. Scholars have noted that "both verbal and visual information found in travelogues had a significant role on the developing epistemology of architecture in general. ${ }^{51}$ Sir Christopher Wren, for example, viewed Ottoman architecture as an important source of information in his studies of the construction of domes. Buildings, such as those designed by Sir William Chambers, often involved a synthesizing of the architectural descriptions found in travellers' accounts. Nebahat Avcioğlu points out that

${ }^{51}$ Avcioğlu 163. 
indeed the designs of buildings of the neo-Classical revival were informed by the descriptions provided by travellers on the Grand Tour. James Stuart and Nicholas Revett, for example, travelled to Greece and carefully depicted the ruins that they encountered in both picturesque views and measured drawings, which were presented in Antiquities of Athens, the first volume of which was published in 1762 . The "exploration of primary sources through travel and archaeology as undertaken by Stuart and Revett ${ }^{, 52}$ proved to be of great influence in British architecture. As stated by Spiro Kostof, during the period, the Classical world was examined "under closer scrutiny ... Visits to Classical sites, the measurement and systematic presentation of the monuments, and excavation broadened the visual spectrum of this revered antiquity and curbed the time-honored command of Vitruvius and his interpreters.

Stuart belonged to the Society of the Dilettanti and received commissions through the patronage of members of the Society, which was composed of gentlemen travellers who shared the project of promoting the influence of Classical architecture. Thomas Anson, for example, belonged to the Society and designed the gardens of his estate "with the intention of evoking his travels." ${ }^{, 54}$ In his gardens, Anson also included a Chinese House in memory of his younger brother Admiral Sir George Anson who had visited Canton. Sir William Chambers had visited China twice with the Swedish East India Company and had studied Chinese architecture. Avcioğlu notes that the architectural layout of the Vauxhall Gardens reflected travellers' perceptions of Topkapi Palace in Constantinople [Istanbul] and that the design of the Turkish Tent included among the

\footnotetext{
${ }^{52}$ Watkin 27.

${ }^{53}$ Kostof 549.

${ }^{54}$ Avcioğlu 147.
} 
building in the Gardens "held a close affinity" 55 with travellers' descriptions of Ottoman kiosks.

Travellers provided information regarding buildings of ancient significance in remote cultures, as seen, for example, in their careful depictions of the caves of Elephanta near Bombay [Mumbai] in India. In the painting Interior View of the principal Excavated Temple on the Island of Elephanta, 1785, James Wales depicts the view of the three-headed deity inside the caves, and James Forbes offers a close depiction of the same wall carving in his watercolour The Grand Altar-Piece ... in the Excavations at the Isle of Elephanta, 1774. Reflecting the consideration of a wider social spectrum that was found in late eighteenth-century genres of writing, travellers often described relatively ordinary buildings, such as houses of the common people, as well as the magnificence of Oriental palaces. James Haynes, for example, provides a detailed description of the typical houses in Tiberias [a city in Israel on the western shore of the Sea of Galilee]:

The houses in general are built with stone, and are flat at top; they consist of one large room, which is divided into two by a partition, the one of which is appropriated for following the different employments the inhabitants are engaged in, and the other to sleep in ... Those of the meanest people here are made in the form of a soldier's tent, and the materials they are built with consist only of sticks, canes, and a kind of clayey mud. $^{56}$

Avcioğlu notes that travellers' discussions increasingly placed "the practices of Ottoman architecture in their social and political context."

\footnotetext{
55 Ibid 106.

${ }^{56}$ Hynes 127.

${ }^{57}$ Avcioğlu 9.
} 
Along with the immense interest of those in Britain in the information offered by travellers, it was well acknowledged during the period that their accounts ranged from factual record to exaggeration or even the narration of totally fabricated experience, and that even with supposedly factual information, the traveller may possibly have misunderstood or been deceived. The concerns of Geertz do not involve doubts that later ethnologists are at least attempting to provide a factual representation of their fieldwork, and the extent to which late eighteenth-century readers questioned the connections, as examined by Geertz, between authorial subjectivity and the acquisition and representation of knowledge of other cultures is difficult to determine. However, at least in some tangible respects, late eighteenth-century readers were well aware of the centrality of the author when assigning credibility and epistemological value to travel accounts.

To address the issue of credibility, travellers' assurances of the veracity of their first-hand observations became a staple literary convention of the genre. Indeed, the very ubiquitousness of the inclusion of such assurances in the first pages of travel accounts perhaps diminished their intended effect. In any case, Haynes's comments in his Preface exhibit the typical elements found in travellers' testimonies of the truth of their accounts. He writes that "this little piece is not the production of compilation in a garret, but a description given by a person who has really visited the places treated of." ${ }^{, 58}$ As was common, his use of the epistolary form for his account supports his claim that the writing is "taken from copies of the real letters sent to his friend in England, while the several spots were actually under the inspection of, The Public's humble Servant, James

\footnotetext{
${ }^{58}$ Haynes iv.
} 
Haynes." ${ }^{59}$ Additional assurances are sometimes attached to descriptions of events that may have seemed particularly out of the ordinary to those in Britain. When later discussing a snake charmer, for example, Haynes writes, "the thing is so amazing, that had I not had occular demonstration of the fact, I would not presume to relate it to you. A sense of immediacy was also created in some literary works of the time by the imitation in the writing of a first-person narrator of theories that were receiving attention during the period regarding the processes of thought. John Locke had earlier discussed the association of ideas involved in man's thought processes, and Hume writes that "New opinions, new passions, new affections, new feelings arise, which continually diversify the mental scene, and produce in it the greatest variety, and most rapid succession imaginable." ${ }^{61}$ The succession of ideas in the mind is imitated in the style of continual digression in Laurence Sterne's novel The Life and Opinions of Tristram Shandy, Gentleman; indeed, both Tristram and the characters of his autobiography depart on digressions so often that it forms a central aspect of the structure of the novel. The sense of immediacy is increased by Sterne's use of a convention, which is also a common component of epistolary form, in which the narrator includes comments about the writing of his work as it is done. In one instance, for example, Tristram writes, "All my heroes are off my hands; - 'tis the first time I have had a moment to spare, - and I'll make use of it, and write my preface. ${ }^{.62}$

The use of the technique of digression is similarly common in travel writing. As well as the immediacy acquired through semblance with the thought process, digressions

\footnotetext{
${ }^{59}$ Ibid.

${ }^{60}$ Ibid. 67.

${ }^{61}$ Hume Dialogues Concerning Natural Religion 70.

${ }^{62}$ Sterne Tristram Shandy 149.
} 
allow the traveller to include commentary on subjects that supposedly just came to mind, whether relating to politics, art, history, agriculture, or any other of the manners and customs of the society being visited.

\section{A Sentimental Acquisition of Knowledge}

The depiction of inward states of feeling, commonly referred to during the late eighteenth century as sentiment, was increasingly found in many genres of writing. In her Letters Written During a short Residence in Sweden, Norway and Denmark, Mary Wollstonecraft depicts social aspects of Scandinavian life as well as the natural environment, but direct expressions of her inner feelings poignantly emerge in many passages of her text. Wollstonecraft states that she has decided to "permit my feelings to be my criterion. Whatever excites emotion has charms for me."63

Horrocks suggests that Wollstonecraft's reviews of travel writing reveal her own theories regarding the genre, which she puts into practice in her account of her travels in Scandinavia. In Wollstonecraft's view, the spontaneity and originality of an author's own impressions give interest to the text. Wollstonecraft "does not so much posit the traveller as the central object of enquiry, as suggest ways in which a travelling self could be used to engage readers. The specific travelling ' $\mathrm{I}$ ' in Wollstonecraft's account forms a constituent part of travel writing's wider later eighteenth-century aim of providing not just amusement, but information and instruction." ${ }^{, 64}$ During the period, the creation of lists of subjects into which a traveller should enquire were produced within the widening of the scientific approach to all aspects of societies and the recognition of the value of

\footnotetext{
${ }^{63}$ Wollstonecraft 58.

${ }^{64}$ Horrocks 3.
} 
empirical observation in distant regions of the globe. Reflecting this empirical approach, Wollstonecraft suggests that a traveller should have a particular focus of enquiry. Her travel account includes a social and political focus, with observations of aspects of social relations in Scandinavia being presented as "a measure of the stage the particular society she is travelling through has reached." ${ }^{, 65}$ Horrocks notes that Georg Forster, a naturalist on Cook's second voyage, ${ }^{66}$ similarly "privileged individual affective response, even in voyage narratives, arguing that it is necessary 'to be acquainted with the observer, before any use could be made of his observations ... This textual self must be used to create the amusement that will lead to instruction." 67

In his account of his travels on the Grand Tour, James Boswell records the many fluctuations of his moods. The Grand Tour was viewed as a component of cultural education during the period, and while there was a certain amount of variation in its itinerary, many particular sites of artistic and historical interest were commonly included along the route and were described in countless early guides and travel accounts. The letters and journal entries that form Boswell's account exemplify the possible experiences and adventures of privileged young men of the time while on the Grand Tour. As well as visiting sites of Roman antiquity, Boswell meets many of the well known political, intellectual, and artistic figures of the time, and his keen eye for observation results in an account that provides a vivid sense of life in certain segments of late eighteenth-century

\footnotetext{
${ }^{65}$ Ibid. 5.

${ }^{66}$ Georg (Johann Georg Adam) Forster was a naturalist and produced works of ethnology and travel writing relating to the voyage. Georg was accompanying his father, Johann Reinhold Forster, who was also a naturalist. Georg Forster is not to be confused with George Forster, who worked for the East India Company and travelled in India as well as other areas of Asia, writing an account of those travels as well as a work concerning Hindu culture that is considered throughout the chapters of this thesis.

${ }^{67}$ Ibid. 10.
} 
society. Information in Boswell's account is offered through the filter of his feelings in connection with the people or sites he is describing; in this sense, sentiment becomes an integral component of the knowledge provided by his account. Boswell's admiration of Pasquale de Paoli, for example, inspires his depiction of a faultless leader who is himself guided by sentiment; Boswell records Paoli's statement that "I act from sentiment, not from reasonings."

Late eighteenth-century writing from a first-person point of view could include depictions of the feelings of the author or of the people he or she encounters, as well as of the characters of embedded narratives. In his Lectures on Rhetoric and Belles Lettres, Adam Smith theorizes that more vivid impressions can be offered to readers through descriptions of the responses of spectators than through factual observation. As discussed by Phillips, this technique is exemplified in the witnessing of events of the French Revolution related by Helen Maria Williams in Letters Written in France. In her work, Williams includes an embedded narrative in which the sentimental story of one family serves as "a microcosm of the system of tyranny, domestic as well as public, from which France had been liberated by the Revolution." 99

In his fictional travel accounts in Volume VII of Tristram Shandy and in his novel A Sentimental journey through France and Italy, Laurence Sterne extends the use of sentiment to the point at which other aspects of knowledge are nothing more than an object of satire. He defines himself as a "Sentimental Traveller""70 and states that "both my travels and observations will be altogether of a different cast from any of my fore-

\footnotetext{
${ }^{68}$ Boswell 187.

${ }^{69}$ Society and Sentiment 95.

${ }^{70}$ Sterne A Sentimental Journey 35.
} 
runners. ${ }^{, 71}$ Sterne expresses his interest in understanding the feelings of the inhabitants of foreign cultures and suggests that the path to this knowledge is through personal encounter; he writes

But I could wish, continued I, to spy the nakedness of their hearts, and through the different disguises of customs, climates, and religion, find out what is good in them to fashion my own by - and therefore am I come. It is for this reason, Monsieur le Count, continued I, that I have not seen the Palais royal - nor the Luxembourg - nor the Façade of the Louvre - nor have attempted to swell the catalogues we have of pictures, statues, and churches - I conceive every fair being as a temple, and would rather enter in, and see the original drawings and loose sketches hung up in it, than the transfiguration of Raphael itself. ${ }^{72}$

Sterne satirizes the epistemological focus of much travel writing of the time, writing No; - I cannot stop a moment to give you the character of the people - their genius their manners- their customs - their laws - their religion - their government - their manufactures - their commerce - their finances; with all the resources and hidden springs which sustain them, and during all that time, making these things the entire subject of my enquiries and reflections. ${ }^{73}$

While the manners and customs of societies are included on his list of information to be excluded, it is above all the position of removed observation that is the object of Sterne's satire. In Sterne's view, sentiment provides the access to knowledge of different cultures.

71 Ibid.

${ }^{72}$ Ibid. 108.

${ }^{73}$ Sterne Tristram Shandy 403. 
One common source of sentiment in travel writing, as well as a common motivation to travel in the first place, during the period may here be noted. Tristram's wish to escape from death through the perpetual motion of travel offers a particularly frenetic example of the many journeys of the period in which travellers hoped to recuperate from a physical condition or to improve an emotional state. Indeed, the idea of the restorative effects of travel was so common at the time that some scholars have pointed out that works containing this theme constitute a popular subgenre of travel writing. While not all recuperating travellers so completely eschewed the traditional itineraries of historical and cultural sites as did Sterne's protagonists, the sentiments of the traveller typically played a central role in writing of this subgenre. As noted by Stephanie Russo, "the late eighteenth century saw the invention of the so-called 'health tourist', as invalids and hypochondriacs alike flocked to spas and other health resorts both at home and abroad seeking the latest fashionable cure for whatever ailed them." ${ }^{74}$ Scholars have suggested that "the practice of health tourism can be traced to the mideighteenth century," 75 noting "the 'discovery' of the seaside in the Western world from roughly 1750 onwards" ${ }^{\$ 76}$ and the increasing ability of individuals aside from aristocrats to travel. As conjectural historians debated the cultural effects of climate, the effects of climate on the health of individuals were also debated by physicians and writers of the time. Nonetheless, the health benefits of the warm climate of Italy and other states in southern Europe were frequently added to the historical and cultural attractions of Mediterranean regions. While Rome was sometimes associated with malaria, the British

\footnotetext{
${ }^{74}$ Russo 201.

${ }^{75}$ Ibid.

${ }^{76}$ Ibid.
} 
perception of the "restorative powers" of Naples was linked to more than its warm climate: "It is not warm air alone that will cure the ailing traveller in Naples: it is the whole experience of living within an environment that seems to be tethered more to the ancient past than to the industrialised present.",77

While the cause of the health concerns of the traveller in what Russo refers to as 'invalid travel writing' could be physical, it could in some cases be related to a "romantic disappointment.",78 The novel Corinne, or Italy by Germaine de Staël, which was published in 1807, offers a well-known example of the "sentimental suffering"79 of a traveller. Not surprisingly, works satirizing health tourism also began to appear among literary offerings, in which a common subject was "the corruption and vice that occurs at these supposed 'health spas'," ${ }^{80}$ as observed by Matthew Bramble in Smollett's novel.

Unfortunately, the risks to the health of those travelling to many distant regions of the globe such as India, which could begin even on the long voyages before arriving, were all too real at the time. Travellers' comments regarding the health of themselves and those around them are a recurring thread throughout their accounts, and rather than sentiment, these comments are often presented in a very matter-of-fact tone as the travellers seem to attempt to relegate their concern to simply an unavoidable aspect of distant journeys.

\section{Pressing Political Issues}

\footnotetext{
${ }^{77}$ Ibid. 208.

${ }^{78}$ Ibid. 205.

${ }^{79}$ Ibid.

${ }^{80}$ Ibid. 202.
} 
The body of late eighteenth-century literature contains no shortage of political commentary relating to domestic issues as well as those concerning foreign states. Black notes that travel writing published as journalism generally included "political statements or, at least, an ideological slant on what was reported and the way in which it was discussed." ${ }^{\prime 1}$ In The Journal of a Voyage to Lisbon, Henry Fielding describes his voyage along the coast of England, with his arrival in Lisbon being recorded only in the last couple pages of the work. Fielding's attention is almost exclusively directed to the social conditions he observes in British seaports as well as life on ships, and his text includes his observations of matters requiring attention in order to "lay open some of the grievances which demand the utmost regard of our legislature, as they affect the most valuable part of the king's subjects - those by whom the commerce of the nation is carried into execution." ${ }^{" 82}$

The French Revolution was, of course, of central interest to writers in Britain, as well as many other controversial issues of the time, such as slavery. With the early events of the French Revolution, "a widely extended impression existed, that a great political regeneration was at hand; and numbers of the best informed men in Europe, in general, looked forward to a grand and immediate improvement in the social institutions of the world." ${ }^{83}$ However, as events unfolded in the French Revolution, hope turned to despair on the part of many who watched. The influence of affective responses at various points, as well as the political issues raised, in witnessing the Revolution is seen throughout the writing of late eighteenth-century travellers. In the letters written by Sir

\footnotetext{
${ }^{81}$ Black vii.

${ }^{82}$ Fielding Voyage to Lisbon 49.

${ }^{83}$ Mackintosh, Robert 43.
} 
James Mackintosh during his residence in India, he expresses the ongoing effect of the Revolution with respect to his attitudes. He continued to read works relating to the events of those times throughout the following years, stating much later that the period, "horrible as it is, has a sort of personal interest to me; I heard and felt so much at the time, that I now feel almost as if I had been a party engaged." 84 As in much writing of the time, ideas relating to tyranny appear repeatedly in Mackintosh's writing, exemplifying the extensive influence of the French Revolution and the campaigns of Napoleon on the ideological formation of intellects during the late eighteenth century. In a letter written from Bombay, he states:

But can I be quite certain that the establishment of monarchical despotism in France, and the horrible effects of tyranny and imposture around me in this country, may not have driven my understanding once more to a point a little on the democratic side of the centre?" 85

Helen Maria Williams carefully crafts her criticism of Britain's involvement in the slave trade through a reference to a man in France who has proposed the abolition of the slave trade to the National Assembly . . But it is a sort of treason to the honour, the spirit, the generosity of Englishmen, to suppose that they will persevere in such conduct. Admitting, however, a supposition which it is painful to make; admitting that they should abide by this system of inhumanity, they will only retard, but will not finally prevent the abolition of slavery."

\footnotetext{
${ }^{84}$ Mackintosh, James 476.

${ }^{85}$ Ibid. 134.

${ }^{86}$ Williams 83.
} 
While in some cases discussed directly, specific political issues could also be referred to more obliquely in connection with more general comments regarding tyranny, equality, and the status of various segments of societies. Wollstonecraft suggests, for example, that "the inhabitants of Denmark and Norway are the least oppressed people of Europe" 87 and notes that they have a free press, in which they can "discuss French publications of the day." ${ }^{, 88}$

The implication of gender in the types of knowledge provided in writing of the period is, of course, a topic of much scholarly attention. The position of women's travel writing within the broader context of European imperialism has been considered within the great amount of research concerning the reflection of imperialist attitudes in travel writing of the colonial period. Some scholars suggest that being in a subordinate position of power within British society, women often stood at some remove from male colonizing agendas, while other scholars point out the inescapable framework of imperialism that is evident in women's writing. The different avenues of access to knowledge that were open to women and men, such as, for example, the harem and the battlefield, have been discussed. The extent to which women conformed, however much in pretence, to a gendered division in the types of knowledge that they were perceived as being capable of providing is discussed. In women's travel writing of the time, modest disclaimers of the author's knowledge often precede comments of particular insight in matters pertaining to, for example, politics or painting. To whatever degree claims regarding limitations in knowledge were feigned by individual writers, it must be noted that women generally had fewer educational opportunities than men at the time.

\footnotetext{
${ }^{87}$ Wollstonecraft 41.

${ }^{88}$ Ibid.
} 
Differences in the reading habits of women and men, as well as the discussions of these differences found in texts of the period, have been examined by scholars. The social position of women was a commonly discussed topic in writing of the time. While considered as one of the indices of the degree of advancement of a society, women in British society were not always perceived as being in a position of equality, and Wollstonecraft refers to the "dependent and oppressed state" ${ }^{\prime 99}$ of women in Europe. The extent, however, to which some of the basic epistemological approaches commonly taken by an individual engaged in the process of cultural interpretation vary with gender does not appear to be clear, much less definitive. In any case, my focus in this thesis with respect to gender issues is primarily directed to the discussions within stadial theory of the treatment of women in Eastern societies.

Women who accompanied their husbands or members of their family who had been appointed to diplomatic positions were typically in a position to acquire much awareness of political situations in distant societies. However, while some comments regarding the political dynamics that they were witnessing are at times included in their accounts, a certain reserve is often apparent in the writing of women who are in effect fulfilling diplomatic roles, as is seen, for example, in the letters of Lady Mary Wortley Montagu early in the eighteenth century, Lady Henrietta Clive towards the end of the century, and Emily Eden a few decades later. Addressed to her sister, Eden's letters often assume a candid tone and at times reveal the complex nature of her opinions, and her position as a woman, in relation to the imperial assumptions of the British at the time. Accompanying her brother as he fulfilled his responsibilities as Governor General, she

${ }^{89}$ Ibid. 33. 
was well aware of the intricacies of the political situations surrounding her. However, she refers to people only by initials and makes few directly political comments, perhaps intentionally employing a degree of reserve. The journey was not without serious dangers, whether due to thieves or military threats, and they witnessed scenes of misery among the local population, as occurred, for example, with the widespread drought and famine in the area around Agra. Such matters are briefly mentioned at times by Eden, along with the actions taken by their entourage in attempting to mitigate the damages of various situations to the limited extent possible, with a degree of stoicism that must have been required in witnessing distress. As we will examine in Chapter Five, it is the visual description of many of the buildings and people Eden observes that provides the central focus in her approach to her experiences in India.

While the power of the Ottoman Empire was perceived to be waning during the late eighteenth century, it retained control in several regions in the Near East and was still viewed, at least to a certain extent, as a threatening presence by European states. British diplomats travelled to Turkey, and its culture was of great interest to British readers. In her “Turkish Embassy Letters," Lady Mary Wortley Montagu offers her impressions of many aspects of life in Turkey, including some comments regarding political matters. She notes, for example, "The Government here is entirely in the hands of the Army ${ }^{90}$ In A Journey through the Crimea to Constantinople, Lady Elizabeth Craven also includes some political information. She describes, for example, the fears of the Greeks who are living in Constantinople under the Porte. As seen in the travel account of Eyles Irwin, which we will examine in Chapter Three, some travellers pondered the commercial

${ }^{90}$ Montagu 322. 
implications of the strategic position of the Near East with respect to trade with India. During the late eighteenth century, European states were competing for control of trade with India, and comments regarding the complex political dynamics involving Mughal and Hindu rulers in the subcontinent could be found in travel writing of the time, along with comments relating to the involvement of other European nations in South Asia. Lady Henrietta Clive, for example, expresses the common apprehension of the time regarding the extent of the advances of Napoleon and his armies.

As we shall examine in the next chapter, characteristics of British culture, including the views underlying it political structures, were often discussed in terms of contrasts with other societies, whether other states within Europe or more distant areas of the globe. In many instances, Britain was extolled as having relatively more enlightened thought and liberty, although comparisons also provided an opportunity to criticize aspects of British society. British travellers in Europe often commented on relatively smaller matters, such as in which country one found better food, post-chaises, inns, or sidewalks. Further, literature of the time often reveals a considerable amount of selfdefinition on the part of both England and Scotland in relation to each other. In The Expedition of Humphry Clinker, for example, Jery writes that Edinburgh "seems to be full of people: but their looks, their language, and their customs, are so different from ours, that I can hardly believe myself in Great Britain." 91

${ }^{91}$ Smollett 239. 


\section{Chapter Three}

\section{Political and Social Structures in the Near East and India}

The political structures of societies were of central interest in the works of the conjectural historians. Forms of government and systems of jurisprudence were extensively examined in relation to the economic structures of societies. In a statement that resonates with the title of Montesquieu's influential text of political theory, William Robertson suggests that a society's political structures and systems of jurisprudence are important indicators of its advancement: "In estimating the progress which any nation has made in civilization, the object that merits the greatest degree of attention, next to its political constitution, is the spirit of the laws and nature of the forms by which its judicial proceedings are regulated.",

Within British perceptions of political structures of Eastern societies, religious institutions were seen as playing a central part, whether in relation to Islamic societies under Ottoman and Mughal rule or in relation to Hindu societies in India. Social characteristics of Eastern cultures were considered within the complex interrelationships of the various political and religious structures of societies. In his essay "Of National Characters," Hume examines the question of why "each nation has a peculiar set of manners." He doubts that national characters are due to what he terms "physical causes," such as climate, and suggests that differences among nations are due to "moral causes," by which he means "all circumstances which are fitted to work on the mind as

\footnotetext{
${ }^{1}$ Historical Disquisition 270.

2 Hume "Of National Characters" 113.
} 
motives or reason, and which render a peculiar set of manners habitual to us." ${ }^{33}$ Hume includes "the nature of government" "when he lists examples of moral causes that influence societies.

Aspects of Eastern societies that repeatedly appear as the focus in late eighteenthcentury representations reflect the political concerns of the time relating to European states. Notions of individual rights provided a challenge to absolute monarchies and religious authority in Europe. At the same time, more democratic European systems were achieved only over time and with revolution and strife, and religious persecution continued throughout the period. The Inquisition was still part of the relatively recent history of Europe, as explored in Ann Radcliffe's Gothic novel The Italian, or the Confessional of the Black Penitents, which was published in 1797 . The inhumanity of the ongoing slave trade to the New World constituted a pressing political issue of the time in Britain. Preoccupations with emerging democratic notions with respect to individual rights, private property, freedom of religious thought, and limits to the power of monarchy are evident in late eighteenth-century writing. In addition, issues accompanying the growth of Britain's involvement in various regions of the globe, such as challenges in the administration of widespread regions, received increasing attention.

In this chapter, I will explore some works of conjectural historians and travellers in relation to their views of political and social structures of the Near East and India. I will first examine two texts in relation to European notions of Oriental despotism, in which structures of the East were perceived as exemplifying a barbaric stage of political development. In this respect, Eyles Irwin's account of his travels through the Near East

\footnotetext{
${ }^{3}$ Ibid.

${ }^{4}$ Ibid.
} 
reflects some of these notions in relation to Ottoman rule. His text also reflects notions of barbarity in terms of economic development, as exemplified in the social structures of nomadic tribes. Two works of John Logan, one discussing stadial theory and the other discussing Oriental despotism, offer succinct, to whatever extent unoriginal, expressions of British thought of the time with respect to these notions.

I will then consider William Robertson's examination of the political and social structures of Hindu culture in India. Robertson attempts to provide what in today's parlance could be termed a culturally relative examination of the organization of Hindu societies. He explicitly acknowledges certain British notions that would seem to be at variance with attitudes in Hindu culture and maintains at all times a non-judgmental position. I will then consider the work of James Mill in terms of the contrast of authorial view. Mill's work was published a few decades later than that of Robertson, and certain changes in British thought had begun to emerge in the early decades of the nineteenth century. Scholars have considered Mill's work in relation, for example, to utilitarianism. Nonetheless, Mill's work clearly builds on the approaches of late eighteenth-century conjectural history, and I will consider his work only in this context.

\section{Theories and Observations: The Near East}

Conjectural historians turned to the accounts of travellers for information regarding the political and social structures of Eastern societies, and travellers' writing reflected the theories of the time. This correspondence of ideas may be seen in the works of two relatively unknown writers of the late eighteenth century. In the academic years of 1780-81 and 1781-82, John Logan delivered a series of lectures in Edinburgh in which 
he presented the framework of stadial history followed by an exemplification of some of its notions in relation to ancient Greece and Rome. Logan's summary of his lectures was published in 1781 in the work Elements of the Philosophy of History. Richard Sher notes that the resulting work is a cross between "a substantive work of prose" and a course outline. In addition, William Creech, ${ }^{6}$ who was attending Logan's lectures, recorded and later published, in the work Dissertation on the Governments, Manners, and Spirit of Asia, the lecture in which Logan discussed the political structures of the East.

Logan was a minister of the Church of Scotland in South Leith, near Edinburgh. He had studied at the University of Edinburgh with Adam Ferguson, and Adam Smith was another of Logan's supporters. Logan hoped to obtain the civil history chair at the University after establishing his credentials in his series of lectures. However, while the lectures seem to have been well received, William Robertson, who was principal of the University, instead appointed William Tytler, a young lawyer who had the support of Lord Kames. Logan was prone to depression, and his drinking, along with two illegitimate children and even 'the perceived immorality of a Presbyterian minister's writing for the theatre," ${ }^{77}$ brought him a certain amount of disapproval in the puritanical Scotland of the time. Logan's life ended early, at the age of forty, after a period of time spent in London.

\footnotetext{
${ }^{5}$ Sher xi.

${ }^{6}$ An Advertisement, signed by "W.C." and presumably written by William Creech, precedes the text of the Dissertation. Creech was one year behind Logan at the University of Edinburgh. Along with ensuring that the text presents an accurate record of Logan's lecture, Creech suggests the timeliness of its publication given the British interest in India at the time.

${ }^{7}$ Sher xvii.
} 
In 1777, Eyles Irwin, an employee of the East India Company, travelled from India to England and wrote an account of the portion of his journey from Madras [Chennai] to Cairo. Irwin and his companions voyaged by ship to the Arabian coast and part way up the Red Sea, donned Arabian dress and crossed the Egyptian desert in camel caravans, and finished the last miles of their journey by boat on the Nile River. Irwin was born in Calcutta [Kolkata], the son of an Irish captain who was serving with the East India Company. Irwin was educated in England and then also joined the service of the East India Company. Having become caught up in a matter concerning the governor of Madras of the time, George Pigot, Irwin was suspended and left India early in 1777 to seek redress in England, beginning the journey that he describes in his account. On reaching England, Irwin discovered that he had already been reinstated in the East India Company. While in England, Irwin married the woman with whom he would have five children. He returned to India by an overland route, also writing an account of that journey. Irwin was successful in his career with the East India Company and spent most of his working life in the East, serving in India as well as in China for the final two years of his career. Beginning as a writer, he had advanced to become a merchant and superintendent of the lands and revenue in various districts of India. Irwin published several other works during his lifetime, including poetry and a play, which often had themes relating to the East. He was a member of the Royal Irish Academy. ${ }^{8}$

The terms and ideas found in Irwin's cultural representations closely correspond to the discussions of the time regarding stages of societies, as set out in Logan's text. The manners and customs of the nomadic tribes of the desert, and political rule under the

\footnotetext{
${ }^{8}$ Oxford Dictionary of National Biography.
} 
Ottoman Empire, are described as 'barbaric.' In addition, as we will examine in Chapter Five, Irwin's observations of ancient Egyptian ruins as well as unruly and impoverished social conditions in regions under control of the Ottoman Empire cause him to contemplate the common historical cycles of advancement and decline that were discussed by conjectural historians.

The travel account of Eyles Irwin documents the complexity of political dynamics in the Near East under the control of the Ottoman Empire during the late eighteenth century. His depictions of Arabian and Egyptian cultures reflect the stadial theory, as outlined in the writing of John Logan, that was being developed by European thinkers of the time. Irwin's comments illustrate notions of barbarity not only in relation to nomadic tribes without landed property but also in relation to the political situations that he observed during his journey. Issues of political concern in European states during the late eighteenth century are reflected in the aspects of the Oriental societies that are the focus of representations found in the writing of both travellers and conjectural historians. In these representations, the economic structures, political systems, and social customs of societies of the East are depicted within the stadial discourses of the time.

\section{Private Property: Nomadic Tribes}

The ideas of stadial theory that were being put forward during the period are set out in Logan's lectures. Richard Sher notes that Logan “borrows freely from Montesquieu and his Scottish teachers" and that "at times his borrowing from Ferguson

\footnotetext{
${ }^{9}$ Sher xii.
} 
reaches the point of plagiarism." ${ }^{\prime 10}$ However, whether or not Logan's text is "terribly original," $" 11$ it offers "an interesting formulation" 12 of the new conjectural history.

Conjectural historians of the Scottish Enlightenment typically viewed private property as not only an important individual right but also an indicator of the stage of development of a society. Consistent with the stadial theory being set out in the works of the Scottish writers, Logan defines the stage of barbarity as "[t]hat which takes place among barbarous tribes, who have adopted the idea of permanent possession in their flocks and herds; but who ... have no private property in land." ${ }^{, 13}$ He states, "Independent tribes, with a Chieftan or Prince, is the uniform description of a people in this state. ${ }^{, 14}$ Logan suggests that the barbarous state of nomadic tribes is a result of a lack of fertile agricultural land in a region:

We may observe, that men soonest unite in civilised society, and form regular government in the finest and most fertile climates ... A favourable situation invites to settlement; and turns a wandering tribe into a fixed community. Nothing but necessity; the bleakness of the climate, the barrenness of the earth, and want of the means of subsistence, compel mankind to submit to the wandering state, and roam from district to district ... In every fertile region of the earth we find cities and nations. ${ }^{15}$

\footnotetext{
${ }^{10}$ Ibid.

${ }^{11}$ Ibid. xiii.

12 Ibid.

${ }^{13}$ Elements 22

${ }^{14}$ Ibid. 23.

${ }^{15}$ Dissertation 19.
} 
Conjectural historians sought general theories that could encompass the structures of societies that were being encountered in all regions of the globe. In exemplifying the theories of the time regarding the influence of climate on societies, Logan continues:

The inhabitants of the Desert Arabia roam from region to region in tents ... Population and government held the same course in the New World as in the Old: while Chili and North America were perambulated by hunting tribes, who lived in a state of wildness and freedom, the richer and more fertile regions of Mexico and Peru were possessed by civilised nations. ${ }^{16}$

At the same time, Logan follows this observation in his Dissertation with the suggestion that extremely fertile areas encourage the indolence that was frequently associated with many societies of the East:

The extreme fertility of this continent [Asia] is no less favourable to despotic governments ... The most powerful motives to labour are withdrawn, where vegetation is the effect of the climate, and the earth almost spontaneously produces her fruits. The most fortunate countries are not the most favourable to the human genius ... The luxuriancy of the climate checks exertion; and the great facility of subsistence invites to indolence and sloth. The same sun also, which produces the fruits of the earth in vast abundance, enervates the people. The languor occasioned by a hot climate indisposes for action and inclines to ease. ${ }^{17}$

As discussed in Chapter One, Montesquieu's ideas regarding the cultural effects of environmental factors are echoed throughout the writing of thinkers of the Scottish Enlightenment, as exemplified by Logan's comments.

16 Ibid.

${ }^{17}$ Ibid. 21. 
Both the physical hardships and the roving tribes of the desert are described in Irwin's account. Irwin relates that "shaiks" often held the function of local chieftans, especially in the desert where they exacted money from travellers passing through their area. He writes that "it is customary for the caravan to pay a tribute to these chiefs, for a passage through their districts. They are only robbers of a larger growth, and openly set their protection to sale, to defend the traveller from the rapine of their tribes." ${ }^{, 18}$ Irwin relates that the thievery of "the banditti which infest the mountains of Upper Egypt" "19 was a constant threat not only to travellers but also to the inhabitants of local villages, an observation that supports Logan's suggestion that "Wandering tribes have no idea of a law of nations." ${ }^{20}$

Irwin despairs of the corruption of local politics. He describes the duplicitous scheming and "lust for lucre,"21 and at the same time the smooth eloquence and social manners, of the local dignitaries who were attempting to acquire all of the travellers' possessions and detaining them endlessly with supposed changes and delays of travel arrangements. In Ghinnah, a city on the banks of the Nile River, Irwin writes, "Though every request he made could only be construed into a demand, he never exceeded the bounds of good-breeding in the piratical visit; and it must be acknowledged that there never existed a more polite robber than the vizier of Ghinnah.,22

Assorted fees and custom tariffs were often required to be paid by those travelling through the Near East, in addition to the presents that were expected to be given during

\footnotetext{
${ }^{18}$ Irwin 139.

${ }^{19}$ Ibid. 123.

${ }^{20}$ Elements 25.

${ }^{21}$ Irwin 133.

${ }^{22}$ Ibid. 192.
} 
civilities with local dignitaries. Irwin's detailed daily journal entries indicate that these demands were never-ending and often exorbitant. He describes the great desire of officials for any of the goods being carried in the baggage of the travellers, whether shawls, jewels, silver pieces, clothes, or Indian handkerchiefs, a behaviour consistent with Logan's suggestion that "The desire of booty is the characteristic passion of the Barbarian." ${ }^{, 23}$ Irwin writes that weapons were highly valued in a society in which men were always armed, with ornate pistols being among the most coveted gifts taken from the travellers.

Irwin's depictions of the corruption of local governance and its lack of protection of the rights of citizens illustrate the notions of conjectural historians regarding barbarity in relation to politics. In discussing ancient Greece, Logan theorizes that barbarous states are characterized by

Independent tribes, without a fixed habitation; a chieftan deriving his power from the sword, yet controuled by inferior chiefs; wealth consisting in flocks and herds; military expeditions for plunder and glory; perpetual incursions and depredations of rival tribes; general disorder of society; giants and demigods, that is, oppressors, and those who redeemed the oppressed. ${ }^{24}$

At the same time, Irwin points out the 'honour among thieves' that the travellers encountered while being escorted through the desert by "a band of robbers." ${ }^{, 25}$ Irwin relates that the man who introduced them to the members of the caravan "made no scruple to acquaint us with the profession of the robbers; but added, that they had as

\footnotetext{
${ }^{23}$ Elements 25 .

${ }^{24}$ Ibid. 51.

${ }^{25}$ Irwin 298.
} 
much regard for their word as other people ... We might trust them implicitly, for the wild Arabs had never been known to break their faith on such occasions." ${ }^{26}$ After days of travelling together, Irwin praises the leader of the camel caravan:

In truth, the conscience of this robber is no less wonderful than his manners. He is easy of access, and yet carries a proper command over his party; and by his own example teaches them to be civil, and even obliging to us." 27

As is so often the case with travellers' accounts of the late eighteenth century, Irwin's depictions mirror but also complicate, or at least mitigate the stereotyping effect of, commonly held European views.

\section{The Power of Monarchs: The Ottoman Empire}

European history had been marked by struggles between religious and secular authority. Michael Curtis points out that some of the earliest uses of the term 'despotic' were in reference to the attempts of Popes to exercise power in opposition to monarchs of European states. $^{28}$ Late eighteenth-century writers discussed the central role played by religious authorities within political structures of societies of the East. Logan writes,

In Asia, the altar has always been joined to the throne, and a kind of theocracy has taken place. A government founded on religion is always despotic; the legislator is regarded as the messenger of Heaven; and he attains dominion over the mind, the most effectual engine of slavery that has ever been contrived. ${ }^{29}$

\footnotetext{
${ }^{26}$ Ibid. 299.

${ }^{27}$ Ibid. 313.

${ }^{28}$ Curtis 54.

${ }^{29}$ Dissertation 23.
} 
The powers of religious authorities were commonly criticized in discussions of Oriental despotism in writing of the time.

Late eighteenth-century writers note the significant part played by religion in social aspects of Eastern cultures. While Irwin does not hesitate to point out the value or beauty of various social customs that he witnesses, he disparages many of the influences of the Muslim faith in local societies. The passengers on the ship from India included many pilgrims on their journey to Mecca, and Irwin writes,

The abuse of reason in these useless undertakings, is the least evil to be complained of. They are such an encouragement to idleness, and so destructive to the welfare of a country, where thousands of the inhabitants are seduced from their families and habitations by a fanatic call, that we may consider their tolerations as one of the ruinous principles of a Mahometan government. ${ }^{30}$

James Haynes seems to share Irwin's view of the pilgrimages to Mecca. He relates that on the voyage from Smyrna in Turkey to Alexandria in Egypt, the captain's “principal freight were Turk pilgrims going to visit their impostor's tomb at Mecca. The cabin and steerage were full of these deluded people."31

The ruler of an Eastern state was often depicted as being above all law, with no balances or constraints to his total power aside from the role played by religious authorities. European writers often stressed that no council of nobles played a part in the political process and that all appointments were made according to the ruler's personal preferences. As described by Logan,

\footnotetext{
${ }^{30}$ Irwin 45.

${ }^{31}$ Haynes 32.
} 
One form of government hath prevailed in Asia from the earliest records of history to the present time. A despot, under the name of the Great King, or King of Kings, possessed supreme and unlimited power. His will is the law. The legislative, judicative, and executive powers are vested in his person: he is the active principle which exists in the centre of the machine, and gives life and motion to all its parts: power and authority are delegated from him: the viceroys and governors of provinces are of his nomination: judges who administer justice are of his appointment. His minister is the slave of his caprice or his pleasure. There is no check to a power which is not only arbitrary but absolute. The principle of despotic governments is fear. . A perpetual military power surrounding the palace ... summary and dreadful punishments; the frequent letting of blood; contribute to increase this fear and abasement. ${ }^{32}$

As pointed out by Marshall, the standard view of Oriental despotism was complicated, at least to some extent, by some writers during the period, such as Voltaire. ${ }^{33}$ The experience of the British in Bengal led Sir William Jones as well as some other scholars to suggest that criminal and civil law, including even certain rights to property, were provided by the law of Islam and that the Hindus also had an ancient legal system. Nonetheless, Logan's discussion of Oriental despotism was stereotypical of the views held by most British theorists of the time.

Discussions of good forms of government are, of course, found in the writing of the ancient Greeks, and the etymology of the word 'barbaric' may be traced back several centuries before the Enlightenment. Curtis notes that the term 'despotism' was

\footnotetext{
${ }^{32}$ Dissertation 10.

${ }^{33}$ Marshall 140.
} 
frequently used in the seventeenth and eighteenth centuries "to criticize absolute monarchical rule" in European states. ${ }^{34}$ However, for several centuries, tyranny was commonly exemplified by the Ottoman Empire in European writing. In her Turkish Embassy Letters, published earlier in the eighteenth century, Lady Mary Wortley Montagu offers her impressions of Turkish society and indicates her wish to dispel European misperceptions. However, she criticizes, in no uncertain terms, the despotic nature of government in Turkey, writing, "This reign has been bloody and avaritious., ${ }^{35}$ She writes, "Here is, indeed, a much greater appearance of Subjection than amongst us, ${ }^{, 36}$ and she describes the cruel treatment suffered by Turkish peasants under the authority of the janissaries.

In Mocha, the first city at which the travellers stopped on the Arabian coast, Irwin discusses the influence, however waning, of despotic Turkish rulers:

Mocha is under the authority of a governor, as the Imaun, who unites the offices of high-priest and king of Arabia Felix ... The Turks have lost the influence which they formerly possessed in this kingdom. They seem content, at present, to receive their proportion of the duties of the other provinces of Arabia, without pretending to exert the arbitrary sway, which marks their government in the districts that are more immediately within the reach of their arms. ${ }^{37}$

Irwin's account documents the complicated and uncertain division of powers between Turkish and Arab officials in the administration of regions that were under control of the Ottoman Empire. Marshall points out that by the end of the eighteenth century, it was

\footnotetext{
${ }^{34}$ Curtis 51.

${ }^{35}$ Montagu 359.

${ }^{36}$ Ibid. 322.

${ }^{37}$ Irwin 4.
} 
apparent that "the Ottoman system was at its most vulnerable in the outlying provinces . . . Egypt was regarded by Europeans as a province which was potentially very rich but which suffered even more than other parts of the empire from misgovernment as the Mamluke Beys struggled to reduce the power of the Ottoman representatives." ${ }^{38}$ James Haynes observes that "in Cairo, neither the Bashaw or any one of the twenty four Beys, care much about the Grand Seignior or his orders. ${ }^{39}$ In cities in Egypt in which Irwin and his companions were detained for periods of time, he observes the relationships between Turkish officials and local Arab shaiks. In Cosire, an Egyptian city on the coast of the Red Sea, Irwin writes, "The government of the district is undoubtedly in the hands of the shaik, who holds it from the mandate of the bey at Cairo ... But the ostensible dignity lies with the Turkish officer, who commands the fort of Cosire in the name of the bey, and is placed here as a spy on the conduct of the shaik." ${ }^{40}$ Irwin's comments exemplify Logan's suggestion that "[t]he eyes and ears of the King, as his officers are called, run over the earth." ${ }^{41}$

In describing his walk through the streets of Yambo [Yanbu' al Bahr OR Yanbu], another city on the Arabian coast, Irwin presents an instance of the reversal of the gaze of the European, with the non-European reciprocally regarding the foreigner with curiosity:

The first arrival of a Cherokee Indian in Europe, could not have begotten half the wonder that our appearance did here. If the commonalty of Europe are not more mannerly, they are at least better informed than the rude Arab. Bred up in utter ignorance of other countries, and bigoted to the prejudices of illiberal doctrines, he is

\footnotetext{
${ }^{38}$ Marshall 166.

${ }^{39}$ Haynes 100.

${ }^{40}$ Irwin 132.

${ }^{41}$ Dissertation 12.
} 
at a loss to account for the production of a Christian, whom his religion teaches him to hold in abhorrence and contempt. ${ }^{42}$

Along with his suggestion of some of the influences of the Muslim faith, Irwin's comparison clearly indicates his awareness of the intercultural encounters that were occurring throughout the globe during a time of expanding European exploration and trade.

The travel accounts of many merchants, as well as diplomats, during the late eighteenth century indicate the actual complexities of global politics in relation to the Near East either preceding or outside of the direct colonial involvement of European states. The Near East occupied a strategic position in the competition among European powers for the control of global trade. Vessels on the trade routes between Asia and Europe commonly stopped at ports on the shores of Arabia and Egypt. As an employee of the East India Company, Irwin's observations reflect British concerns with the challenges of traffic and commerce in the Near East during the late eighteenth century. In Mocha, Irwin notes,

The English are the only nation who have a resident here; and this is but a late regulation. The East India Company were accustomed to send a ship here every season; but now the coffee is transported on country bottoms to Bombay [Mumbai], from whence our Indiamen convey it to Europe. ${ }^{43}$

Irwin mentions the possibility of encountering pirates while sailing in the Red Sea as well as the Nile River. With his comments regarding the dangers of pirates, thieves in the desert, and being detained for long periods of time by officials in Arabia and Egypt,

\footnotetext{
${ }^{42}$ Irwin 48

${ }^{43}$ Ibid. 10.
} 
Irwin's account echoes the literary tradition of the many narratives of captivity written by Europeans who were taken captive along the Barbary Coast, an early example of which is found in Don Quixote, in which Cervantes includes a narrative of captivity based on his own experiences in Algiers. For several of the preceding centuries, the Ottoman Empire had been perceived as a significant military threat to Europe. Portions of southeastern Europe, including half of Hungary, were under Ottoman control following the siege of Vienna in 1529, and European fears of further Turkish military conquests did not begin to abate until the stalemate between Ottoman and Hapsburg forces ended with the second siege of Vienna in 1683. Trade continued between European and Turkish merchants, however, throughout all of this time. As stated by Bernard Lewis, "Neither excommunication nor more immediate penalties in this world ... were able to deter or even seriously limit the highly profitable traffic [from Europe to Turkey] in weapons.. ${ }^{, 44}$ James Haynes notes the presence of the establishment of European merchants at port cities in Turkey. At Smyrna, he notes, "The bay is very large, and in it are ships from all parts of Christendom and Turkey.... We have English houses established here; and the French and Italians many more." ${ }^{45}$ When he is later in Acre [a town in Israel on the Mediterranean Sea, at the north of the Bay of Haifa], he writes that it is "a sea-port town . .. The French have nine factors here, who all live in the same han our Consul does, and they carry on a pretty brisk trade. ${ }^{46}$ Christine Laidlaw discusses the trade that was carried out by merchants of the Levant Company, which continued throughout the eighteenth century while the commercial activities of the East India Company were

\footnotetext{
${ }^{44}$ Lewis 75.

${ }^{45}$ Haynes 30.

${ }^{46}$ Ibid. 157.
} 
expanding. Mehrdad Kia points out that before the development of coffee plantations in the West Indies posed significant competition to Ottoman control of the coffee trade, "European merchants purchased Yemeni coffee in Cairo, where the trade reached its zenith in the late 17 th and early 18 th centuries." 47

Following the French invasion of Egypt in 1798, the British formed certain alliances with the Ottoman Empire in order to counter advances of the French. While the control of the Ottoman Empire was seen as being increasingly challenged at the time of Irwin's journey, his depictions of the political situations that he encountered exemplify the many representations found in the writing of late eighteenth-century travellers that do not fit into a simple binary of imperialist West and subjugated East.

\section{Individual Rights: The Status of Women in Eastern Societies}

Criticisms of a lack of individual rights were central in European writing relating to Oriental political systems. Logan writes:

Sovereign and slave compose the only distinction of ranks in the East. An hereditary race of nobles arising as a barrier between prince and people has always been unknown. The inferior rank, born and bred in slavery, have no idea of another condition. Public spirit, liberty, independence, the rights of mankind, are names that have never been pronounced in the regions of Asia ... From fear and habit, not loyalty and affection, this passive obedience flows. ${ }^{48}$

Writers of the period typically associated despotism with the perceived lack of development in societies of the East. The supposed absence of rights to property in

\footnotetext{
${ }^{47} \mathrm{Kia} 238$.

${ }^{48}$ Dissertation 12.
} 
Oriental societies, in which all wealth belonged to the ruler, was often cited as one of the factors contributing to the stifling of ambition and creativity that prevents progress. European theorists viewed Eastern societies as unchanging. P.G. Marshall suggests that criticisms relating to the inequality seen in many aspects of life in Asian societies reflect emerging British theories regarding the necessity of individual development for social development, within societies that "rested on the solid basis of interlocking selfinterests. ${ }^{.49}$

European writers frequently discussed the treatment of women as an example of the lack of individual liberty in Oriental societies. As evident in the writing of Mary Wollstonecraft, the unequal position of women was still, at least for some, an issue in European societies. However, adherence to religious law rather than a political basis of individual rights resulted in what was viewed as the supposedly inferior position of women in Muslim societies. As stated by Logan,

Private life proceeds on the same maxims with public government; despotic power and domestic slavery always walk hand in hand. The father of a family is a despot; and a husband is the master of slaves ... If the cry of death is heard from the haram at night ... the laws give no redress; no appeal to justice issues from the haram. The seraglio and the empire are alike under the dominion of fear. $^{50}$

Logan's words echo Montesquieu's theory that "[e]ach man follows the spirit of the government and brings to his home what he sees established outside of it." ${ }^{, 51}$ While

\footnotetext{
${ }^{49}$ Marshall 145.

${ }^{50}$ Dissertation 15.

${ }^{51}$ The Spirit of the Laws 104.
} 
presenting an extended satire of European as much as Eastern societies, Montesquieu's Persian Letters, which was published anonymously in 1721, was influential with respect to European perceptions of the Orient. His fictional portrayal of attitudes relating to the harem is echoed in Logan's reference in his discussion of Eastern societies to "the cruel invention of eunuchs to guard the honour of women." 52

The harem was a topic of great interest in discussions of the time relating to Eastern societies. Women travellers sometimes had the opportunity of actually visiting a seraglio. As noted by James Haynes during his visit to Cairo, "the merchant's wife can be admitted into the Haraims, by which means she may sell them gold and silver lace, smelling bottles, embroidered stuffs and many other articles." ${ }^{, 53}$ Lady Mary Wortley Montagu's depictions provided a point of reference for the representations of travellers who followed. However, while struck by the beauty of the Turkish women and the interior spaces they inhabited, she observes, "In short, tis the Women's coffee house, where all the news of the Town is told, Scandal invented, etc." ${ }^{, 54}$ Further, she counters criticisms of the confinement of Turkish women by pointing out the ease and luxury of their lives:

Voyage-writers lament the miserable confinement of the Turkish Ladys, who are (perhaps) freer than any Ladys in the universe, and are the only Women in the world that lead a life of uninterrupted pleasure. ${ }^{55}$

In her account of her travels in Eastern Europe and the Near East in 1786, Lady Elizabeth Craven echoes Lady Mary's suggestion that the robes and veils of women in Oriental

\footnotetext{
${ }^{52}$ Dissertation 16

${ }^{53}$ Haynes 53.

${ }^{54}$ Montagu 313.

${ }^{55}$ Ibid. 406.
} 
societies afford them a certain degree of disguise and freedom. In her travels in India, Lady Henrietta Clive relates that the rooms of the seraglio in the palace of Tipu Sultan were not as exotic as in the European imagination:

I was terribly disappointed with the account of the zenana. I expected it to be like the seraglios of the Arabian Nights, but I am told it is only a number of small rooms not unlike the likes of a convent, where each lady lives in one room. I expected to have heard of fountains of marble spouting up rose water and of cushions of finest embroidery. ${ }^{56}$

The eye-witnessing recorded in the accounts of travellers offered realistic views of distant societies that could temper European perceptions that otherwise depended on little information and a great deal of imagination.

Having already spent extensive periods of his life in the East, Irwin's account indicates neither an initial awe of Oriental beauty and exoticism nor an unfamiliarity with Oriental customs. Nonetheless, as do many writers of the time, Irwin connects the treatment of women with issues of liberty more generally. He expresses sympathy with the veiled women whom he glimpses in the windows of buildings in which they were kept in confinement, a situation that resonates with that of the travellers who were themselves being detained. He notes that there is a certain amount of variation in customs among different societies in the East:

The women in Arabia are kept in much stricter confinement, than those of their religion in India. The females of rank are shut up in their apartments, and never stir abroad, except now and then, to accompany their husbands on an excursion to the

\footnotetext{
${ }^{56}$ Clive 90.
} 
vallies. They are vailed at these times from head to foot, and sent off upon horseback under cover of the night. ${ }^{57}$

However, as do some other travellers, Irwin complicates some of the common European judgments regarding the position of women in societies of the East, adding that "if female beauty be doomed to solitude in these rude parts, is not the liberty which is allowed it in more polished countries, too often the source of calamities more grievous than confinement . . ?" ${ }^{58} \mathrm{He}$ also points out that the seclusion of women is not practised to the same extent in all segments of particular Eastern societies:

To those of a lower degree, there is some deviation permitted from the severity of this custom. Though there are no public Hummums for the women to resort to as in Turkey, they are indulged with the freedom of visiting their neighbours, when the dusk of evening can skreen their persons from observation: for the thick vails in which their faces are buried, utterly preclude the possibility of distinguishing their features. $^{59}$

Travellers' opportunities to observe the details of daily life allowed them to recognize the complexities found in the cultures of distant societies, as in any culture, and their comments could at times counter European generalizations.

\section{William Robertson's Examination of Hindu Culture}

In examining the political and social structures of Hindu culture in India, William Robertson makes every attempt to be non-judgmental. In the closing lines of $A n$

\footnotetext{
${ }^{57}$ Irwin 9.

${ }^{58}$ Ibid.

59 Ibid.
} 
Historical Disquisition concerning the Knowledge which the Ancients had of India, he states his intention in having written the work:

If I might presume to hope that the description which I have given of the manners and institutions of the people of India could contribute in the smallest degree, and with the most remote influence, to render their character more respectable, and their condition more happy, I shall close my literary labours with the satisfaction of thinking that I have not lived or written in vain. ${ }^{60}$

While he explicitly acknowledges that Hindu customs are in certain respects discordant with British notions, he proceeds to attempt to explain the logic underlying the organization of Hindu society, and a negative assessment is not found in relation to any aspect of Hindu culture that he discusses. Geoffrey Carnall notes, for example, "the pertinacity of his openmindedness in the face of difference" ${ }^{\text {,61 }}$ that is evident in Robertson's arguments regarding the caste system. In any case, Robertson's approach results in an interesting discussion regarding the political and social structures of Hindu culture within what today would be described as an attempt to maintain a position of cultural relativism. We shall here look very closely at some of his arguments, since they reveal the issues that typically drew attention during the late eighteenth century as well as his approach of trying to find explanations for the most criticized aspects of Hindu societies.

Robertson suggests that the caste system is of central influence in the structures of Hindu societies in India. He describes the caste system as "the fundamental article in the

${ }^{60}$ Historical Disquisition 336.

${ }^{61}$ Carnall 214. 
system of their policy,"62 and he notes that for a person of the Hindu faith in India to do anything contrary to the caste system "would be deemed an act of most daring impiety.",63 Robertson acknowledges the discordance of the caste system with British notions of individual liberty, stating that "at first view" ${ }^{64}$ it would seem that the caste system "tends to circumscribe the operations of the human mind within a narrower sphere than nature has allotted to them." ${ }^{65}$ However, while admitting that in some instances the system would oppress the natural talents of an individual, Robertson states that this would be an exception within a system that is designed with the aim of the general functioning of society:

The regulations of Indian policy ... must necessarily, at some times, check genius in its career, and confine to the functions of an inferior cast, talent fitted to shine in an higher sphere. But the arrangements of civil government are made, not for what is extraordinary, but for what is common; not for the few, but for the many. ${ }^{66}$ Robertson does concur with the common British opinion that the chronologies suggested in significant Hindu texts were so absurd that basically no historical knowledge could be ascertained from Hindu sources. In discussing Hindu culture, the traveller George Forster, who will be introduced more fully in the following chapter, states:

The records of this ancient and extraordinary people, unfortunately for the learned of the present day, teem so profusely with fable, and abound throughout in such extravagant relations of the actions of their demi-gods, greatly similar in their feats to

\footnotetext{
${ }^{62}$ Historical Disquisition 258.

${ }^{63}$ Ibid. 259.

${ }^{64}$ Ibid.

${ }^{65}$ Ibid. 260.

${ }^{66}$ Ibid.
} 
the Bacchus, Hercules, and Theseus of the Greeks, that no rational or satisfactory conclusion can be drawn for any adjustment of chronology. ${ }^{67}$

Robertson states that one must turn to the writing of Classical authors for information regarding India in antiquity. Robertson suggests that the existence of kingdoms that "were powerful and prosperous" ${ }^{68}$ in ancient India is in itself an indication of India's advancement in antiquity. Reflecting the approach of stadial theory, he states that in early stages of "the progress of men in social life" communities," ${ }^{, 70}$ and he suggests that the "extensive states" ${ }^{, 71}$ in India "must have been a work of long time.. ${ }^{, 2}$ Robertson states that those states were monarchical rather than despotic. However, he suggests that it was not because of notions of rights similar to those in European states that the governments were not tyrannical, stating that "different principles" ${ }^{\text {"73 }}$ were underlying the checks to "the exercise of regal power." principles arose from the structure of the caste system, in which monarchs belonged to the second caste, "which is interested with the functions of government and exercise of war," ${ }^{, 75}$ and that they must be directed by the higher class of the Brahmins. The influence of Montesquieu is here, as in so many instances, apparent, in the terms used for types of government and in the notion that certain principles direct each type.

${ }^{67}$ Forster 21.

${ }^{68}$ Historical Disquisition 263.

${ }^{69}$ Ibid.

${ }^{70}$ Ibid.

${ }^{71}$ Ibid. 264.

72 Ibid.

${ }^{73}$ Ibid.

${ }^{74}$ Ibid.

75 Ibid. 
Robertson discusses the structures of Hindu societies in relation to land. He states that the sovereign is considered the sole proprietor "of all the land in his dominions."76 As we have seen, this characteristic of some governments of the East, with no-one aside from the ruler having any property rights, was seen as despotic by some writers. However, Robertson proceeds to suggest that a benevolent and functioning system accompanied the lack of ownership of land by individuals in India. He states that the lands were rented to the farmers and that "[a]s long as the husbandman continued to pay the established rent, he retained possession of the farm, which descended, like property, from father to son."77 Further, Robertson suggests that the caste system enabled other people in the society to wage war while the husbandmen continued to work in providing the source of subsistence in the society, stating that "[e]ven war did not interrupt his labours." Robertson then makes an intriguing comment, which surprisingly seems to carry a sarcastic tone that is rarely, if ever, found elsewhere in his writing:

These maxims and regulations of the ancient legislators of India have a near resemblance to the system of those ingenious modern speculators on political oeconomy, who represent the produce of land as the sole source of wealth in every country; and who consider the discovery of this principle, according to which they contend that the government of nations should be conducted, as one of the greatest efforts of human wisdom . . the most intelligent modern observers should celebrate the equity, the humanity, and mildness of Indian policy. ${ }^{78}$

\footnotetext{
76 Ibid. 266.

${ }^{77}$ Ibid. 267.

${ }^{78}$ Ibid. 268.
} 
Robertson seems to be suggesting that while modern thinkers may be very proud of their new theories, the Hindu people had figured out how to structure society successfully in antiquity.

Robertson points out that many aspects of what today would be termed infrastructure were in place in ancient India. He notes, for example, the management of "the Tanks, or public reservoirs of water," distances along important routes "to measure the road and direct travellers." ${ }^{80}$ Robertson points out the existence of "Choultries" ${ }^{\prime 1}$ and the care that was expended on behalf of travellers. He also notes that registers were kept of births and deaths in the society and that a system of weights and measures was used in public markets.

Europeans often expressed their impression of the immutability of Eastern societies. Robertson similarly notes "the permanence of its institutions ... neither the ferocious violence and illiberal fanaticism of its Mahomedan conquerors, not the power of its European masters, have effected any considerable alteration. ${ }^{, 82}$ Robertson states that the caste system, the system of renting land, and many of the practices of infrastructure still continued in his time. While some writers saw this fact as an indication of a lack of advancement since antiquity, Robertson gives a positive tone to the continuation of the same structures of society, which in his view could be seen as indicating the excellent functioning of the various systems.

As with every other aspect of Hindu culture, Robertson applies a stadial approach in his discussion of systems of jurisprudence in Hindu societies. He begins by describing

\footnotetext{
${ }^{79}$ Ibid. 269.

${ }^{80}$ Ibid.

${ }^{81}$ Ibid. 270.

${ }^{82}$ Ibid.
} 
the changes in approaches in solving legal disputes that typically occur in connection with the increasing complexity of economic structures of societies. Robertson states that in the early stage of this process of legal development, "the few disputes with respect to property which arise, are terminated by the interposition of the old men, or by the authority of the chiefs in every small tribe or community." Robertson suggests that with time, a body of unwritten customary law is gradually established:

[A]s controversies multiply, cases similar to such as have been formerly determined must recur, and the awards upon these grow gradually into precedents, which serve to regulate future judgments. This, long before the nature of property is defined by positive statutes, or any rules prescribed concerning the mode of acquiring or converting it, there is generally formed, in every state, a body of customary or common law.

Robertson suggests that Hindu societies had "no written laws" ${ }^{83}$ but that "justice was dispensed among them with great accuracy" according to consideration of "what had been formerly decided."

Robertson states that two compilations of Hindu law provided the most useful sources in his consideration of the topic, one having been instigated by "Akber," a Mughal emperor in the mid-sixteenth century, and the other by Warren Hastings. Robertson praises Akbar's view of the importance of understanding the customs and systems of jurisprudence of the Hindu societies falling under his rule, as well as the abilities of Akbar's vizier, Abul Fazel. He notes that the "brief compendium of Hindu

${ }^{83}$ Ibid. 271. 
jurisprudence" ${ }^{\prime 84}$ that was then published was "the first genuine communication of its principles to persons of a different religion." ${ }^{85}$

Robertson similarly praises Warren Hastings for his later efforts in codifying Hindu legal practices: “About two centuries afterwards, the illustrious example of Akber was imitated and surpassed by Mr. Hastings, the Governor General of the British Settlements in India." 86 He relates that Hastings brought together "the most eminent Pundits, or Brahmins learned in the laws" in Calcutta, and the resulting compilation of Hindu law "is undoubtedly, the most valuable and authentic elucidation of Indian policy and manners that has been hitherto communicated to Europe." 87

Robertson states that according to the Pundits, some of the writers of the ancient texts serving as sources had "lived several millions of years before their time." 88 Robertson admits that the extravagance of this chronology is best ignored, but he suggests that the fact that the texts were written in the ancient language of Sanskrit indicates that "the Hindus have in their possession treatises concerning the laws and jurisprudence of their country, of more remote antiquity than are to be found in any other nation." 89 Robertson then uses the framework of stadial theory to argue that whereas "[a]mong nations beginning to emerge from barbarism, the regulations of law are extremely simple," the Hindu system of law shows great refinement. He states that the laws are well arranged, numerous, comprehensive, and indicate "subtility of

\footnotetext{
${ }^{84}$ Ibid. 273.

${ }^{85}$ Ibid.

86 Ibid.

${ }^{87}$ Ibid.

88 Ibid.

${ }^{89}$ Ibid. 274.
} 
understanding. ${ }^{90}$ Robertson downplays aspects that one supposes may have been the subject of British criticism and suggests that, on the whole, Hindu law accords with a notion of universal, natural law. He states that "with a few exceptions occasioned by local prejudices and peculiar customs," Hindu law is "founded on the great and immutable principles of justice." ${ }^{.91}$

Indeed, Robertson suggests that the Hindu code of law represents "the jurisprudence of an enlightened and commercial people." ${ }^{92}$ He notes "a curious passage on the legal interest of money, and the limited rate of it in different cases, with an exception in regard to adventures at sea; an exception ... which commerce absolutely requires, though it was not before the reign of Charles I. that our English jurisprudence fully admitted it in respect of maritime contracts. ${ }^{, 93}$ Since within stadial theory, commerce was viewed as a characteristic of the most advanced stage of economic activity, Robertson's choice of an example of the refinement of Hindu law is significant in his argument that the Hindu code indicates a general advancement of certain aspects of Hindu societies.

The harshness of punishments for crimes set out in Hindu law was criticized by more than one writer of the time. Here again, however, Robertson presents this aspect of Hindu jurisprudence in a positive light, stating that "though the natives of India have been distinguished in every age for the humanity and mildness of their disposition, yet

\footnotetext{
${ }^{90}$ Ibid. 275.

${ }^{91}$ Ibid.

92 Ibid.

93 Ibid.
} 
such is the solicitude of their law-givers to preserve the order and tranquillity of society, that the punishments which they inflict on criminals, are . . extremely rigorous."94

\section{James Mill: A Different View within the Framework of Conjectural History}

James Mill's History of British India includes extensive discussions of Hindu, as well as Mughal, culture in India. He presents his impressions regarding the political and social characteristics of each of the cultures, as well as their achievements with respect to artistic, literary, and philosophical spheres of endeavor. At the time of the publication of Mill's work, certain changes in ideological context were beginning to emerge in Britain. As well as the influence of utilitarianism, attitudes regarding British involvement in India had begun the long trajectory, which would continue throughout the nineteenth century, of becoming increasingly imperialistic, and ideas of introducing liberal notions to the cultures of which Britain was assuming more extensive control were becoming more entrenched. Nonetheless, Mill's text reflects both the ideas and the innovative forms of conjectural history in relation to the interpretation of distant cultures, and I will examine his work only in this respect. In 1790, Mill began seven years of study at the University of Edinburgh, and he spent twelve years writing his History of British India before its publication from 1817 to 1818 . His work “shows clearly the influence exerted on Mill's intellectual outlook by his Scottish education."95 John Stuart Mill wrote of his father that

\footnotetext{
94 Ibid. 276.

${ }^{95}$ Winch "James Mill and India” 383.
} 
"as Brutus was called the last of the Romans, so was he the last of the eighteenth century.",96

The texts of Robertson and Mill comprise the two most significant early historical works relating to India attempted by British writers. Robertson's text concentrates on the history of European trade with India, and Mill stated that his text would provide the first comprehensive history of India of which he was aware. The texts present British attempts to interpret India's cultures during a period in which few texts with historical information relating to the subcontinent were available. Each author draws on the intellectual frameworks of the Scottish Enlightenment, and a close comparison of the two texts offers insight into both works.

Mill had a close association with Jeremy Bentham and was an advocate of theories of utilitarianism, and scholars have examined his work in this context. ${ }^{97}$ As discussed by Donald Winch, Mill brought the ideas of late eighteenth-century conjectural historians concerning the typical progress of societies together with the utilitarian notion that the maximization of benefit to society stands as a central measure of any government. The Scottish influence "provides a framework into which he [Mill] fitted ideas acquired later from Bentham and Ricardo; it not only survived the infusion of these later doctrines but gave them an extra dimension which was unique to Mill."98 In Mill's view, utilitarianism could be used as an approach within which it is possible to judge the relative advancement of a society:

\footnotetext{
${ }^{96}$ John Stuart Mill's Autobiography, p. 143, as quoted by Winch, "Biographical Sketch" 4.

${ }^{97}$ See, for example, Richard Stokes, The English Utilitarians and India. Oxford University Press, 1959.

${ }^{98}$ Winch "Biographical Sketch" 4.
} 
Exactly in proportion as Utility is the object of every pursuit, may we regard a nation as civilized. Exactly in proportion as its ingenuity is wasted on contemptible and mischievous objects, though it may be, in itself, an ingenuity of no ordinary kind, the nation may safely be denominated barbarous. ${ }^{99}$

Mill's text reflects the British interest of the time in exploring matters of ideal governance and administration in their rule in India. Writers of the time viewed India as a forum within which to attempt to put into practice model principles in governance, whether in administration or law, that they believed should also provide the frameworks for approaches in Britain. Conjectural history "provided a means by which certain practical lessons could be pressed home as to the effect of various institutions or policies on man's progress." ${ }^{100}$ Indeed, the contemporary view placed Mill's work within the radical range of the spectrum in the aim of advocating reform, both at home and in India.

Unlike Robertson, Mill shows no reservation in presenting his opinions in relation to the political and social structures of the cultures of India. The degrees to which the views of Robertson and Mill varied may be related to some extent to the political climate of the years in which the texts were written. Scholars have also noted that Robertson had been criticized for his extremely harsh depiction of the indigenous peoples of North America in his History of the Americas and suggest the possibility that the absence of any negative comment in relation to Hindu culture is in part in reaction to the criticism of his earlier work. In any case, what is most apparent in terms of the difference between the two works is the opposite approach taken by the two authors, with Robertson looking for

\footnotetext{
${ }^{99}$ Mill Vol. 1, 428.

${ }^{100}$ Winch "Biographical Sketch" 5.
} 
culturally relevant explanations whenever possible and Mill assuming a stance of criticism with respect to all societies, whether of India or Europe.

Indeed, Mill's work has almost invariably received severe criticism by scholars of recent times, as he offers no self-reflexive comments acknowledging the context of his point of view. However, he seems to be a writer who would have candidly recorded his opinions whatever the reaction at any time, at home or abroad, and in his work he also criticizes many aspects of British involvement in India with the aim of encouraging reform. As pointed out by Winch, Mill "was strongly opposed to the continuance of the Company's trading monopoly; he believed there to be a prima facie case against all monopolies."101 Mill noted that "since 1797 there had been no surplus after meeting the enormous expenses of government" ${ }^{102}$ in India, and he points out the need for military preparedness in the rule by foreigners of a country with an immense population and area as well as complications arising with political divisions among regions. At the same time, due to the extent of his concerns with respect to existing indigenous systems of governance in the subcontinent, "at no stage did he ever question the value of the Company as a instrument of government."103 As it happened, Mill's work was an immediate success and became the standard textbook at Haileybury, the college for servants of the East India Company.

Mill begins his work by presenting, in Book I, a chronological history of the development of British trade with India over the preceding couple of centuries. He discusses the rivalry that took place with the Portuguese and the Dutch, as well as the

\footnotetext{
${ }^{101}$ Winch "James Mill and India" 386.

${ }^{102}$ Mill Vol. 1, 387.

${ }^{103}$ Ibid. 383.
} 
history of the East India Company in terms of matters such as its charter and structures of financing. For the purpose of examining Mill's interpretation and representation of Hindu culture, my focus will be directed to Book II, "Of the Hindus."

Mill shares Robertson's view of the extravagance of the chronologies suggested in ancient Hindu texts. He describes the texts as "a maze of unnatural fictions" 104 and is not even convinced "that they at least contain a poetical or figurative delineation of real events."105 He states, "This people, indeed, are perfectly destitute of historical records," 106 noting that most of the works relate the exploits of gods and that there is no historical record, for example, of contact with Alexander the Great. In one of the countless comments that reveal Mill's propensity to criticize every culture, he states that the information offered in Classical texts is limited since the ancient Greeks "despised every foreign language."107 While not possible to ascertain the events of India's ancient political history, Mill states that fortunately, assisted by the research of modern Europeans, it has been possible to provide a picture of the manners and customs of the people of India, which, from "scattered hints contained in the writing of the ancient Greeks,"108 appear to have not changed since antiquity. Mill's comments reflect the central focus on manners and customs found in late eighteenth-century conjectural history:

how they lived together as members of the community, and of families; how they were arranged in societies; what arts they practiced, what tenets they believed, what

\footnotetext{
104 Ibid. 98.

105 Ibid.

${ }^{106}$ Ibid. 99.

${ }^{107}$ Ibid. 100.

${ }^{108}$ Ibid.
} 
manners they displayed; under what species of government they existed; and what character as human beings they possessed. This is by far the most useful and important part of history. ${ }^{109}$

Mill's work exemplifies the continuation of the expanded scope of late eighteenthcentury historiography with its inclusion of consideration of the broad social spectrum of societies. Like Robertson's Appendix to his Historical Disquisition, Mill’s Book II “On the Hindus" is divided into Chapters discussing various aspects of Hindu culture.

Both authors draw on the ideas of stadial theory put forward in the Scottish Enlightenment in framing their ethnological discussions. Mill typically introduces each of his discussions of aspects of Hindu culture with some passages of conjecture regarding the typical development in societies of the characteristic under consideration. In the Chapter "Classification and Distribution of the People," Mill begins by noting that structures of societies have little complication when countries are "overgrown with forest ... [and] the wretched inhabitants are reduced to all the hardships of the hunter's life." He suggests that more complex social organizations do not take shape until large groups of people are assembled together and that likely India arrived at these early stages of societies as early as any other culture. Mill states that because India's early institutions have seemed to be "distinguished by a durability so extraordinary"111 they "present a spectacle so instructive to those who wish to understand the human mind, and to trace the laws which, amid all the different from of civil society, invariably preside over its

\footnotetext{
${ }^{109}$ Ibid. 101.

${ }^{110}$ Ibid. 103.

${ }^{111}$ Ibid. 105.
} 
progress." ${ }^{112}$ Mill's comments indicate that he shares the view of the conjectural historians of the late eighteenth century that basic commonalities among peoples lead to common patterns of social development.

Mill states that a very gradual, slow process is involved in developing "a system of government and laws, ${ }^{, 113}$ in societies and that in the first steps of this process, institutions are founded on perceptions of divine authority. He states that in the early stages of societies, "men are perpetually haunted with the impression of superior powers," 114 and he states that this prevalence of superstition is used "to induce a people . . . to forego their boundless liberty, and submit to the curb of authority." ${ }^{, 15}$ Mill notes that every aspect of Hindu culture "is established by divine prescription" $" 116$ and that in this respect "[t]he leading institutions of the Hindus bear evidence that they were devised at a very remote period." $" 117$

Mill notes that the division of labour set out in the caste system was seen in other ancient societies, and in one of the countless footnotes exemplifying the vast range of sources used in conjectural history, he references Plato, Millar, Reynier, and Herodotus to substantiate his observation. ${ }^{118}$ Mill acknowledges that the caste system, "in the very simple state of society in which it must have been introduced, was a great step in improvement, $" 119$ which is the point that Robertson chooses to emphasize. However, Mill's concerns with the unbounded power held by the Brahmins and the extreme

\footnotetext{
112 Ibid.

${ }^{113}$ Ibid. 106.

${ }^{114}$ Ibid.

115 Ibid.

116 Ibid. 107.

${ }^{117}$ Ibid.

${ }^{118}$ Ibid. 109.

${ }^{119}$ Ibid. 118.
} 
inequality of the caste system recur throughout his discussions of various aspects of Hindu culture. The texts of Robertson and Mill exemplify the possible divergences in opinion that may be encompassed within the approach of conjectural history. Frank Palmeri notes "the flexibility of conjectural form, which can be used to express divergent and opposing political and ideological positions." $" 120$

Mill states that "[i]t is only in rude and ignorant times that men are so overwhelmed with the power of superstition as to pay unbounded veneration and obedience to those who artfully clothe themselves with the terrors of religion." ${ }^{121} \mathrm{He}$ notes that only the Brahmins are allowed to expound upon sacred texts. Throughout his work, Mill continually draws on "Halhed's code of Gentoo laws"122 as a significant source of information with respect to Hindu customs. Mill notes that under Hindu law, horrible punishments follow any form of disrespect to a Brahmin but "neither the life nor even the property of a Brahmen can be brought into danger by the most atrocious offences."123 He notes that Brahmins are exempt from taxes and that they must be given gifts that in total amount to a significant share of the wealth of India's inhabitants. Further, Mill points out that "it is incumbent on the king to employ them as his chief counsellors and ministers, and to be governed by their advice.",124

George Forster shares Mill's view with respect to the power of the Brahmins. Forster refers to

${ }^{120}$ Palmeri 36.

${ }^{121}$ Mill Vol. 1, 110.

122 Ibid. 111.

${ }^{123}$ Ibid. 112.

124 Ibid. 
preposterous and irreconcileably superstitious ceremonies which have been dragged by their doctors into the Hindoo system of worship; all of them tending to shackle the vulgar mind, and produce in it a slavish reverence for the tribe of Bramins. The privilege of reading the Baids and expounding its texts is only allowed to them ... By the sole investment of this singular authority, the priest is left at liberty to explain the original doctrine as may be the most conducive in consolidating his power and promoting the interests of his order. ${ }^{125}$

Forster, however, also suggests that there are some relatively positive features of Hinduism as a religion. He notes that at least "[t]hey do not admit of the infliction of eternal punishment, and shudder at the idea of a belief so disconsonant to the opinion which they have formed of the Supreme Being." ${ }^{, 126}$

In The Natural History of Religion, which was published in 1757, David Hume discusses typical patterns of development with respect to religious thought. Hume suggests that monotheism follows polytheism in the common sequence of religions in societies, noting that ideas concerning a central divine intelligence require a greater degree of philosophical abstraction than the more human traits typically identified with the various gods of polytheism. However, Hume argues that people are generally unable to act according to abstract ideas and that both forms of religion are characterized by similar motivations as well as by equal amounts of superstition and absurdity. Indeed, Hume suggests that many aspects of societies with polytheistic religions are less problematic than with monotheistic religions. Nonetheless, Hume expressed more skepticism regarding religion than most writers of his time; indeed, his Dialogues

\footnotetext{
${ }^{125}$ Forster 23.

${ }^{126}$ Ibid. 25.
} 
concerning Natural Religion were published only after his death. Arguments that the degree to which a religion is monotheistic is an indication of the state of the philosophical advancement of a culture are found among the range of views relating to religion that are found in works of the conjectural historians of the Scottish Enlightenment. Late eighteenth-century writers commonly suggested that superstition is more prevalent in societies that are in early stages of development, as echoed by Mill in his criticisms of the powers of religious authorities.

Some writers pointed out that ancient Hindu texts indicate that the concept of one deity was not absent from Hindu religious thought. William Robertson notes that as indicated in the writing of Abul Fazel as well as several Europeans who had travelled to India, such as Mr. Bernier and Mr. Wilkins, learned Brahmins had achieved progress in theology "as elevated their minds above the popular superstition, and led them to acknowledge and reverence one Supreme Being." ${ }^{127}$ However, Robertson further notes that the Brahmins did not dispel the beliefs of the "false religion" 128 followed by the body of the people, instead carrying on "a scheme of deceit" 129 and even presenting "every external appearance of reverence and devotion" ${ }^{\prime 130}$ to the popular deities. The popular representations of various divine figures in Hinduism were often perceived as a form of polytheism in late eighteenth-century writing. Forster notes that the Hindus "have been branded with the appellation of idolators, or adorers of many gods," 131 but he argues that the inclusion of various divine figures in Hindu practice serves a purpose in reaching

${ }^{127}$ Historical Disquisition 325.

${ }^{128}$ Ibid. 334.

${ }^{129}$ Ibid.

${ }^{130}$ Ibid.

${ }^{131}$ Forster 29. 
wide segments of society, stating, "Let this mode of offering up supplications or thanksgivings to the Supreme Being be dispassionately examined, and it may be seen, that a personification of the attributes of the Deity, is not unfitly adapted to the general comprehension." 132

Mill uses the approach of stadial theory to explain the choice of those in military roles as the second most powerful caste. He suggested that in early states of society, men are filled with fears of dangers "as well from nature as from his fellow men." ${ }^{\text {,133 }}$ While priests allay fears by procuring for men "the favour of the mysterious powers of nature," 134 soldiers are "the second object of his veneration and gratitude," ${ }^{, 135}$ since they prove "protection against the ravages of hostile men." 136

Some of Mill's most extreme criticism is directed to the degrading position of those in the lowest caste of Hindu society:

As much as the Brahmen is an object of intense veneration, so much is the Sudra [the lowest caste] an object of contemp, even of abhorrence, to the other classes of his countrymen. The business of the Sudra is servile labour, and their degradation inhuman. Not only is the most abject and groveling submission imposed upon them as a religious duty, but they are driven from their just and equal share in all the advantages of the social institution. ${ }^{137}$

Mill notes that under Hindu law, with each drop in level of caste, punishments for crime are more severe and more interest is charged on loans.

\footnotetext{
132 Ibid.

${ }^{133}$ Mill Vol. 1, 115.

134 Ibid.

${ }^{135}$ Ibid.

${ }^{136}$ Ibid.

${ }^{137}$ Ibid. 116.
} 
No marriage was allowed between different castes. However, Mill relates that "one of the few points in the antient history of India which we can ascertain by specific proof" ${ }^{138}$ is that during a period of the rule of a wicked king, laws were often violated, and a group of people with parents of different castes emerged. Referred to as the "Burren Sunker,"139 this group included "all manner of artisans and handicrafts,", for example, "one tribe of them being appointed weavers of cloth, another artificers in iron." Mill suggests that this constituted "the commencement of arts and manufactures" 142 in India, through which the "increasing wants of an improving society were provided for." ${ }^{\prime 43}$ The association of refinement of arts and manufactures with increasingly advanced stages of societies discussed by conjectural historians of the late eighteenth century is reflected in Mill's comments. He notes that "this is another important era in the history of Hindu society; and having reached this stage, it does not appear that it has made, or that it is capable of making, much further progress." $" 144$ In any case, Mill also notes that the treatment of, and employments open to, the children of parents of different castes depended on which two castes were involved, and he notes that "nothing can equal the disgust and insolence" towards the most abject within this ordering.

Mill discusses the political structures and systems of jurisprudence in Hindu societies in his Chapters "The Form of Government" and "The Laws." Mill's comments

${ }^{138}$ Ibid.
${ }^{139}$ Ibid.
${ }^{140}$ Ibid.
${ }^{141}$ Ibid.
${ }^{142}$ Ibid.
${ }^{143}$ Ibid.
${ }^{144}$ Ibid. 
reflect, as do Robertson's, the title of Montesquieu's work when he states that since a detailed analysis of Hindu jurisprudence would exceed the scope of his work, he will convey only "the character and the spirit of the Hindu laws." "145

Mill points out the power of the Brahmins in both the legislative function of government and the administration of justice. He states that since no laws are acknowledged aside from those set out in the ancient Hindu texts, the only scope which remains for legislation is confined within the limits of the interpretations which may be given to the holy text. The Brahmens, however, enjoy the undisputed prerogative of interpreting the divine oracles ... The power of legislation, therefore, exclusively belongs to the priesthood. ${ }^{146}$

Mill states that as set out in the sacred texts, the administration of justice was ostensibly under the authority the king. However, since the king was obligated to consult the Brahmins in all matters, he was effectively "the executive officer by whom the decisions of the Brahmens are carried into effect." ${ }^{, 147}$ Indeed, Mill suggests that the only reason that the Brahmens "did not invest themselves with the splendour of royalty" 148 was likely that they did not want the accompanying work and danger. With an echo, in part, of Montesquieu's discussions regarding the lack of energy of people in hot climates, Mill states that "to a people, over whom the love of repose exerts a wonderful sway, ... the toils and perils of the sword appeared to surpass the advantages with which it was attended." ${ }^{\prime 19}$ Nonetheless, Mill points out that the king still appeared to carry much

\footnotetext{
${ }^{145}$ Ibid. 133.

${ }^{146}$ Ibid. 130.

${ }^{147}$ Ibid. 131.

${ }^{148}$ Ibid.

${ }^{149}$ Ibid. 132.
} 
authority in Hindu society, by exhibiting "an external lustre, with which the eyes of uncultivated men are easily dazzled."150 Mill notes that while in European states, ministers are typically appointed for the different functions of government, governance in India was simply divided among regions, with a delegated tyrant for each.

Mill notes that with respect to Hindu law, "materials are abundant."151 He states that in the code of Hindu law, matters relating to justice are not distinct from matters relating to other aspects of life, such as "the doctrines and ceremonies of religion; the rules and practice of education; the institutions, duties, and customs of domestic life; the maxims of private morality, and even of domestic economy; the rules of government, of war, and of negotiation." ${ }^{, 152}$ He suggests that the result of this intermixing of matters is to confound the important distinction between those obligations which it is the duty of the magistrate to enforce, and those which ought to be left to the suggestions of selfinterest, and the sanctions of morality; it is to extend coercion, and the authority of the magistrate, over the greater part of human life, and to leave men no liberty even in their private and ordinary transactions. ${ }^{153}$

Just as the powers of religious authorities were seen as playing a central role within political structures of the East, the intermixture of matters of state and the mores and customs of private life was seen as characterizing systems of Hindu law.

Mill states that "the Institutes of Menu, the most celebrated perhaps of all the original compends of Hindu law, " $" 154$ are not structured according to a division between

\footnotetext{
${ }^{150}$ Ibid.

151 Ibid. 133.

${ }^{152}$ Ibid.

${ }^{153}$ Ibid.

${ }^{154}$ Ibid. 134.
} 
civil and criminal law. Nonetheless, Mill states that he will proceed by examining relevant sections of the Hindu code of law under the three divisions of civil, criminal, and judicial matters that are common in European approaches.

With respect to civil law, Mill points out that "property is the great subject."155 He notes that in the Hindu code, an extensive section regarding the obligations "between masters, and the servants who tend their cattle, is of so much importance, denoting a state of society approaching the pastoral." As found in the works of thinkers of the Scottish Enlightenment, Mill discusses the development of the law of inheritance. He notes that "[a] right of succession in the children suggests itself $\ldots$ at a very early period in the progress of civilization." He also notes that "it was the usual arrangement in early stages of society, for the different members of a family to live together; and to possess the property in common." 156

Mill similarly commences his discussion of criminal law with a passage drawing on the approach of stadial theory. He writes, "The misery and disorder which overspread human life, wherever self-defence rests wholly upon the individual, are the cause to which government owes its origin. To escape from these evils, men agree to transfer to the magistrate powers sufficient for the defence of all." ${ }^{157}$ However, Mill points out that the early motivation of this development was not a matter of "just and cool discernment" but rather the desire for revenge," found universally to characterize the penal code of a barbarous people; that of great

\footnotetext{
${ }^{55}$ Ibid. 137.

${ }^{156}$ Ibid. 145 .

157 Ibid. 150.

${ }^{158}$ Ibid. 151.
} 
severity; and that of retaliation." ${ }^{159}$ Mill's substantiation of this point with references to both ancient and distant cultures reflects the comparative method of conjectural history. He notes the cruelty of punishments set out in "[the] early laws of the Greeks and Romans" and the "the laws of Moses," as well as the "laws of the Egyptians" and the "barbarous punishments of the Chinese."160 Mill points out the hideously cruel punishments set out in Hindu law, and he notes Sir William Jones's agreement with the view that Hindu jurisprudence involved punishments that were "shocking to humanity." ${ }^{\text {161 }}$ Mill notes that within the goal of retaliation, "the punishment of crimes is chiefly measured by the resentment of the sufferer, ${ }^{, 162}$ and he notes this principle in the "Hebrew law of an eye for an eye, and a tooth for a tooth," 163 as well as in the law of the Romans and Egyptians.

Mill points out that the caste system is again a cause for criticism in relation to the criminal law. He notes that the most severe pecuniary fines are given to the lowest caste and therefore to those least able to afford them. However, Mill suggests that European law also exhibits some prejudices in favour of the higher classes of society, noting that more severe punishment for crimes against members of aristocratic classes "is found difficult to avoid even in high stages of civilization. At present, in the best governed countries in Europe, an injury done to a nobleman is deemed a crime of a deeper die, than a similar injury to a person of the lowest rank. ${ }^{" 164} \mathrm{He}$ notes that even if no distinction is set out in the laws, it is still carried out in practice, through, for example, the greater
${ }^{159}$ Ibid.
${ }^{160}$ Ibid.
161 Ibid. 152.
162 Ibid. 153.
${ }^{163}$ Ibid.
${ }^{164}$ Ibid. 156. 
"power of the nobleman to bring the offender to trial."165 In Mill's argument that punishment should be related not to the amount of suffering caused by the crime but to the severity necessary to ensure that people will not commit the crime, he expounds the principle of deterrence that proved to be central in British systems of criminal law. Sir William Jones was recognized as having admired many aspects of Hindu culture and having supported efforts to study existing customs in India. Mill notes that "[e]ven Sir William Jones is constrained to say that the punishments of the Hindus "are partial and fanciful, for some crimes dreadfully cruel, for others reprehensibly slight."

The lack of independence of judicial matters from the executive power is criticized by Mill. He suggests that as societies advance, judicial functions become separate from the ruler, but that "[ $\mathrm{t}] \mathrm{o}$ this pitch of civilization the Hindus had not attained."167 Mill notes that judgments were carried out, by the king or one of his regional delegates, in an area open to the public, and in a footnote he notes that this was also the case in the times of the Bible and in ancient Greece. In any case, the openness of court proceedings is of course also a characteristic of systems of European jurisprudence.

In discussing other aspects of judicial affairs, Mill directs his attention to the subject of evidence. He again begins with the approach of stadial theory, stating that "[p]rior to the general use of writing, the chief species of evidence . . is the speech of witnesses. It is this species which makes the principal figure in the laws of Hindustan to the present age."168 He notes that Hindu law sets out an extensive list of categories of people who many not serve as witnesses, which he suggests "affords a proof of the great

${ }^{165}$ Ibid.
${ }^{166}$ Ibid. 158.
${ }^{167}$ Ibid. 127.
${ }^{168}$ Ibid. 162. 
difficulty of obtaining true testimony ... a dreadful picture of the state of morality"169 in Hindu society. He states that the exclusion of various groups as possible witnesses is an example of "false refinement," relevant information. Mill notes that "full and satisfactory light may often be obtained from the worst sort of witnesses." ${ }^{171}$ He suggests that in the earliest stages of societies, judges, who would typically have been the chiefs in the society, would have likely questioned everyone in "the little community or family"172 and considered the relative value of different people as witnesses, and he points out that "[t]his is exactly the course, which true wisdom would recommend." 173 Mill further notes the influence of superstition in the process of valuation of testimony in Hindu law. He notes, for example, that if a witness gives a testimony and then within seven days experiences a misfortune, such as disease, fire, or the death of a relative, he is considered to gave been lying and is punished. Mill also points out the horrible and absurd tests of whether or not a person is guilty that are specified in Hindu law, and compares these to the "trials by ordeal in the dark ages of modern Europe." ${ }^{174}$

Mill discusses the development from unwritten, customary systems of law to those in which precedents are collected in writing. He suggests that customary law was the first development in the jurisprudence of societies and notes that its continuance is evident in European law. He states that although "[p]rior to the act of writing, laws can

\footnotetext{
${ }^{169}$ Ibid. 164.

${ }^{170}$ Ibid.

${ }^{171}$ Ibid. 165 .

${ }^{172}$ Ibid. 164.

${ }^{173}$ Ibid.

${ }^{174}$ Ibid. 167.
} 
have little accuracy of definition," ${ }^{175}$ nonetheless "the nations of modern Europe have allowed a great proportion of their laws to continue in the unwritten; that is the traditionary state ... of these nations, none have kept in that barbarous condition so great a proportion of their law as the English." ${ }^{176}$ However, he notes that in modern Europe, uncertainty of unwritten law is to some extent "circumscribed and limited, by the writing down of decisions." ${ }^{177}$ Mill notes that not only is the Hindu system of jurisprudence lacking a written record of judicial decisions, but those exercising the judicial function, being "the king and his Brahmens, or the Brahmens alone," 178 consider themselves "too powerful to be restrained by a regard to what others had done before them." ${ }^{\text {179 }}$ Finally, Mill notes that the definitions in Hindu law "are so far from excluding darkness and doubt, that they leave almost every thing indefinite and uncertain." 180

On a positive note, the issues of delay and expense increasingly characterizing the administration of justice in European systems, with their requirements of rules of procedure, were not a problem in the Hindu system of jurisprudence. Mill notes that in terms of efficiency, "the system of the Hindus displayed a degree of excellence ... far beyond what is exemplified in more enlightened countries."

Mill discusses various aspects of the social structures of Hindu society in his chapter titled "Manners," including education and the status of women. As did the conjectural historians of the late eighteenth century, Mill views the status of women as a

\footnotetext{
175 Ibid. 170.

${ }^{176}$ Ibid.

177 Ibid.

178 Ibid. 171.

${ }^{179}$ Ibid.

${ }^{180}$ Ibid. 169.

181 Ibid. 171.
} 
significant indicator of the relative advancement of a society, stating, "The condition of the women is one of the most remarkable circumstances in the manners of nations, and one of the most decisive criterion of the stage of society at which they have arrived." ${ }^{\prime 182}$ He argues that in early stages of civilization, women are typically "excluded from the inheritance of the family. Being condemned to severe and perpetual labour, they are themselves regarded as useful property." 183 He suggests that as a society "refines upon its enjoyments" 184 and increasingly values "the qualities of the mind," 185 the condition of women is "gradually improved, till they associate at last on equal terms with the men, and fill the place of voluntary and useful copartners." ${ }^{p 186}$

Mill states that "[a] state of dependence more strict and humiliating than that which is ordained for the weaker sex among the Hindus cannot easily be conceived." 187 He notes that in Hindu texts, women are represented as having a base nature that is lacking in virtue and that "at no time is a woman proper to be trusted with liberty." ${ }^{188}$ In a footnote, Mill quotes Halhed's code of Hindu law:

Women have six qualities; the first an inordinate desire for jewels and fine furniture, handsome clothes, and nice victuals; the second, immoderate lust; the third, violent anger; the fourth, deep resentment; the fifth, another person's good appears evil in their eyes; the sixth, they commit bad actions. ${ }^{189}$

\footnotetext{
182 Ibid. 293.

183 Ibid.

184 Ibid. 294.

185 Ibid.

${ }^{186}$ Ibid.

${ }^{187}$ Ibid. 294.

188 Ibid. 295.

${ }^{189}$ Ibid.
} 
Mill notes that women are viewed in Hindu law as being of "incompetence to bear witness" 190 in judicial proceedings.

Mill points out that women are "deprived of education"191 in Hindu society, echoing the observations of George Forster, who writes:

Conformably to the state of domestic subordination, in which Hindoo women are placed, it has been judged expedient to debar them from the use of letters. . . They urge, that a knowledge of literature would have an injurious tendency in drawing a woman from her household cares, and would conduce to give her a disrelish to those offices in which are centered the only satisfaction and amusement that she can with propriety and an observance of rectitude, partake of; and such is the force of custom, that a Hindoo woman would incur severe reproach were it known that she could read or write. $^{192}$

Forster notes that the "dancing girls, "193 on the other hand, are given education as well as "the protection and sanction of government."194

Mill states, "That remarkable proof of barbarity which we found among some of the rudest tribes, where the wife is unworthy to eat with her husband, prevails in Hindustan." "195 He notes that “[a]n almost unlimited power of rejection or divorce appears to be reserved to the husband ... But on the other had we have seen that no

\footnotetext{
190 Ibid. 296.

191 Ibid.

${ }^{192}$ Forster 62.

${ }^{193}$ Ibid. 63.

${ }^{194}$ Ibid. 64.

195 Mill Vol. 1, 296.
} 
species of barbarous treatment, not even desertion and sale, ever absolve the woman from her obligations to her lord." ${ }^{\prime 196}$

Mill notes that it is not certain whether the confinement of women was a Hindu custom or was adopted following the conquest of the Mughals. However, he notes that "as in general among the nations of Asia, ... it seems to have been the practice for every man, who possessed sufficient means, to keep his women guarded, in a state of seclusion." ${ }^{197}$ Mill notes the impossibility of this custom in the lower classes:

The law of seclusion is made only for the few. Among the jealous Ottomans themselves, the great body of the community must leave their women at large, because an indigent man can neither dispense with the useful services of his wife nor afford the cost of retaining her in confinement. ${ }^{198}$ Mill's comments are similar to those of Eyles Irwin regarding the variations found with respect to the confinement of women.

Mill's critiques of the inequalities at the foundation of the political and social structures of Hindu society are indeed scathing. In an article published in the Edinburgh Review in 1810, Mill states that "even the utmost abuse of European power is better, we are persuaded, than the most temperate exercise of Oriental despotism."199 Such comments have not surprisingly provoked much criticism of Mill's writing as being Eurocentric. However, the tone of Mill's criticisms appears to be motivated from an extreme indignation at what he perceived as the cruel oppression of the most abject in Hindu society. While critical of institutions in Hindu culture, Mill does not seem to have

\footnotetext{
${ }^{196}$ Ibid. 297.

${ }^{197}$ Ibid. 301.

${ }^{198}$ Ibid. 300 .

${ }^{199}$ As quoted by Winch, on p. 387, from the Edinburgh Review, January 1810, p. 171.
} 
any propensity at all to positions of superiority on any human level. In this respect, it is important to note that Mill also became increasingly radical in his writing regarding British political matters, in which "a marked sympathy is expressed for the situation of the poor" ${ }^{200}$ along with arguments in favour of the control of aristocratic power. In his "Essay on Government," for example, Mill makes "a case for democratic forms of government, based not on natural rights, but on the view that only under democracy could the selfish interest of rulers be made to coincide with those of the community at large."201 As stated by Winch, “Mill's belief in the idea of progress helps to explain his taste for sweeping generalisation and, to a certain extent, his dogmatism. He was constantly fortified in his pronouncements by the notion that history was on his side: the side of tolerance, freedom, reform, and above all, reason."202

${ }^{200}$ Winch "Biographical Sketch" 9, in reference to Mill's pamphlet "Commerce Defended," which was published in 1807.

${ }^{201}$ Winch "Biographical Sketch" 13.

202 Ibid. 6. 


\section{Chapter Four}

\section{Luxury Debates and the Material Culture of the East}

In this chapter, I will explore late eighteenth-century attitudes regarding the material culture of the East and the part played by those attitudes in British perceptions of the cultures of the Near East and India. Conjectural historians of the Scottish Enlightenment viewed artistic achievement and refinement in goods of material culture as an indication of the relative advancement of a society. Travellers described aspects of Oriental splendour in the courts of Mughal, Hindu, and Ottoman princes and collected fine objects of the material culture of the countries in which they were visiting. British consumers eagerly purchased objects of the material culture of the East that were arriving through global trade. Appreciation, on the part of travellers as well as those in Britain, of the aesthetic qualities and workmanship of the material culture of the East was clearly evident. Indeed, it was the enthusiasm of the British appreciation of the material culture of the East, and the increasingly apparent social effects of this enthusiasm, that contributed to the concerns underlying the luxury debates of the time. The conjectural historians discussed not only the benefits to society of refinement in the arts and manufactures but also the dangerous effects of excessive luxury. Late eighteenth-century attitudes occupied fluid positions along a spectrum in which the material culture of the East was viewed as indicative of either the relative advancement of the cultures of the Near East and India or the seeming decadence of those cultures.

As we have seen, observations of the changes in British society accompanying the growth of commerce were one impetus in the development of stadial theory. In this chapter, I will take a closer look at this commerce in relation to the East, by considering 
more tangibly what goods were involved and the attitudes in relation to these goods exhibited by both travellers and British consumers. Discussions relating to the cultural effects of expanding commerce appear throughout the works of the conjectural historians, in which they consider all aspects of daily life in societies in connection with wideranging theories; indeed, the material details of daily life constitute a significant source of the evidence on which they base their speculations. Similarly, in this chapter the cultural effects of increasing global trade during the late eighteenth century constitute the link among discussions of superficially disparate elements, drawing in various seemingly distinct spheres of observation and debate, tangible habits of domestic life, and modes of representation. My aim in this chapter is to point out the interconnections among responses, in intellectual, material, and artistic spheres of expression within late eighteenth-century Britain, to the increasing presence of the material culture of the East.

I will begin by contextualizing late eighteenth-century trade with the East. Attitudes towards Eastern material culture developed within a history of European global trade that goes back to antiquity. I will first situate late eighteenth-century trade within this history and examine the expansion of trade during the early modern period that provoked ambivalence regarding its social effects in Europe. I will argue that the increasing availability of objects of luxury led to a realization of the changing global relationships within which Britain's economy was becoming ever more imbricated.

I will next consider two essays by David Hume in which he addresses the questions of his time relating to the effects of economic change. Adam Smith held similar views to Hume with respect to the benefits of commerce in society, and while the wealth of insight offered in his works could equally well inform our discussions in this 
chapter, I will concentrate on a close reading of Hume's essays since they offer a succinct and direct summary of some of the concerns accompanying various aspects of the changes in British society with the increasingly tangible effects of the growth of global commerce.

The next section of the chapter is comprised of discussions of the various ways in which British appreciation of the aesthetic and technological aspects of the material culture of the East is evident. The breakdown within this section is primarily for clarity of consideration, since the subjects of the discussions would not have been distinctly separable in actual late eighteenth-century life. First, I will examine written discussions of impressions of Eastern material culture that are found in travellers' accounts of their journeys as well as in the works of conjectural historians. Second, I will argue that British enthusiasm was apparent in the acquisition of objects of Eastern material culture. In addition to the purchases by British consumers of the products arriving through global trade, travellers collected objects of the material culture of the areas they were visiting. Late eighteenth-century travellers occasionally mentioned particular acquisitions in their written accounts of their journeys, and nabobs often built substantial collections of great worth. Third, I will argue that British admiration of Eastern material culture was evident in various modes of imitation during the late eighteenth century. Here I will look at imitation in design and manufacturing. Fourth, I will examine the inclusion of elements of the material culture of the East in portraits and conversation pieces of the time. In these visual representations, British appreciation of the beauty of the material culture of the Near East and India found its perhaps most vivid expression. Dutch painting will make a recurring appearance throughout this chapter. The Dutch Republic was the pre- 
eminent European power preceding Britain with respect to global trade, and the paintings of the Dutch Golden Age play a significant part in the genealogies of visual representations that suggest European attitudes regarding the products of global trade and the attendant concerns with luxury.

In the final section of this chapter, I will look briefly at two examples of different modes in which the controversial attitudes regarding Britain's expanding trade with the East found expression. I will first consider the ambivalence of attitudes suggested in maritime paintings of the merchant vessels employed by the East India Company. I will then consider the controversy that was provoked in connection with nabobs, who sometimes acquired great wealth in India that they then ostentatiously displayed when they returned to Britain. Concerns arose with the challenge to existing social and political hierarchies that accompanied the new wealth arising from trade in the East. In comments, personal collections, and paintings, travellers revealed their appreciation of the beauty of the material culture of the East. When combined with travellers' descriptions of impoverished social conditions in some areas of the Near East and India and the extravagance and tyranny of Oriental rulers, conjectural historians attempted to explain why Eastern societies had clearly advanced in some ways and seemingly not in others. In any case, while societies of the East were at times perceived as barbaric with respect to political development, the refinement in Eastern material culture was not generally in question by those in Britain. If this admiration was not fully acknowledged in all late eighteenth-century texts concerning Eastern cultures, it was most certainly apparent in the vigorous trade for Eastern goods and in the attempts at imitation by British manufacturers. 


\section{Contextualizing Late Eighteenth-century Trade with the East}

Products of the East had traditionally been associated with luxury in European thought. As stated by William Robertson, "Not only the people contiguous to India, but remote nations, seem to have been acquainted, from time immemorial, with its commodities, and to have valued them so highly, that in order to procure them they undertook fatiguing, expensive, and dangerous journeys." ${ }^{1}$ European monarchs and aristocrats had acquired luxury goods from the East, some of which were carried great distances on overland routes such as the Silk Road, since ancient times. However, while not a new phenomenon, global trade greatly increased in the early modern period with improvements in maritime navigation, such as the invention of the compass. The Portuguese established areas of commercial encounter in Asia. In the seventeenth century, the new, independent Dutch Republic had taken the lead among all other European states with respect to global trade. The Dutch East India Company held a monopoly in the spice trade, which was a particularly important advantage since exclusive control was necessary in order to maintain the very delicate balance between the prices set and the demand for spices in the European market. The Dutch East India Company (VOC) was aggressive in "expanding its influence in the Indonesian Archipelago in an effort to control the spice trade. It attacked the Portuguese positions in Malacca, Ceylon and other places and used military force to exclude other nations from trade and shipping in areas that the VOC wanted to keep for itself.",

\footnotetext{
${ }^{1}$ Historical Disquisition 256.

${ }^{2}$ Gaastra 50.
} 
The Dutch East India Company established its centre in Batavia [Jakarta] and was involved in "a profitable intra-Asian trade network,"3 in which commodities such as silver and copper from Japan, silk from China, and textiles from India were traded along with spices and pepper among countries in Asia. Along with spices and pepper, the Dutch East India Company brought a great number of goods of material culture from the East to Europe. As pointed out by Maxine Berg, "Asian luxury goods were brought into Europe in unprecedented quantities by the seventeenth- and eighteenth-centuries." ${ }^{\circ}$ East India companies had been established by several European nations aside from the Dutch, including, for example, the British, the French, the Danish, and the Swedish.

In what is sometimes referred to as Britain's "Empire of the Seas," Britain's global trade also steadily increased during the early modern period. Indeed, three AngloDutch wars "in which commercial rivalry played a major part" were fought during the seventeenth century. Gaastra notes that following around 1680, commercial competition between the English and Dutch East India Companies was not marked by the conflicts that characterized the earlier portion of the seventeenth century. Following the Glorious Revolution, the English and the Dutch were allies, with France having become the common enemy, and the "theatre of European rivalry shifted to India." "While demand and profit did not diminish in the trade of spices and pepper, growth in the trade of textiles and tea offered space for both Companies. Britain recognized Dutch dominance in Indonesia, and the Dutch did not attempt to encroach on British holdings in India. During the last half of the eighteenth century, the British "took the lead in the European-

\footnotetext{
${ }^{3}$ Ibid. 51.

${ }^{4}$ Berg 20.

${ }^{5}$ Gaastra 51.

${ }^{6}$ Ibid. 50.
} 
Asian trade. It was during this period, more than ever before, that servants of both the companies were pursuing their own private fortunes and working closely together, no matter the national interests and Company policy.",

By the late eighteenth century, British trade had become increasingly tied with territorial acquisition in distant continents, as Britain engaged in wars with France in competition for trade monopolies. The nature of Britain's global relationships was gradually shifting into an "Empire of Conquest." This shift was accompanied by political considerations; with new British subjects at a distance, those in Britain viewed their increasing global involvement as the extension of British notions of liberal principles. Statesmen in the colonies on the Atlantic seaboard not surprisingly questioned this view, as they continued to be taxed without holding political representation in the British Parliament. The American Revolution constituted one of the new significant political pressures felt by those in Britain with their expanding global interests. In addition, outcry in the arena of domestic politics against British involvement in the slave trade was becoming more insistent. Concurrently, political concerns were taking shape in the other most important centre of British trade across the globe. The East India Company had begun as nothing more than a private corporation of merchants, given a charter of monopoly in British trade in all countries east of the Cape of Good Hope at the very end of the sixteenth century by Queen Elizabeth. To protect their commercial properties and interests, the Company had increasingly employed military troops, and in order to facilitate commercial activities, the Company had also become increasingly involved in administrative aspects of life in the Indian subcontinent. With stories of corruption and

\footnotetext{
${ }^{7}$ Ibid.
} 
unrestrained greed, many in Britain became concerned with the unsupervised political role played by the Company in South Asia. Guesses regarding the wealth of particular Company employees appeared in the public press, and the term 'nabob' was used pejoratively to refer to those who had acquired fortunes in the subcontinent by supposedly dubious means. The impeachment proceedings against Warren Hastings instigated by Edmund Burke served as a symbolic focus to these concerns. Ketaki Kushari Dyson states, "The fact that Burke played a prominent role in the impeachment of Warren Hastings is really a freakish trick of history" ${ }^{\prime 8}$ since the wish of both men was to conserve rather than destroy the cultural heritage of India. Nonetheless, to Burke and some others, British values seemed to be at stake. At the same time, no-one in Britain was questioning either the economic importance, or the strategic importance in terms of global politics, of its trade with distant continents. Adding the witnessing of the French Revolution across the Channel to all of this, the late eighteenth century was not without a certain amount of political and economic anxiety.

Indeed, the fact had become clear that Britain's economy had become irreversibly imbricated in a new, complex global model, which was increasingly characterized by direct interconnections, in terms of both commercial and political activity, among various areas of the world about which the British often knew very little. For example, Britain's decision that it would be impossible to repeal taxes on tea was based on consideration of the financial stability of the East India Company, which was in part dependent on the growing tea trade, and the frustration in the American colonies with this decision was given expression with the Boston Tea Party.

${ }^{8}$ Dyson 20. 
The Indian subcontinent had its own long and complicated political history and dynamics before the involvement of the British. The British role in these dynamics developed gradually, not all at once or in all areas of India, as the Company took part in alliances with various Indian princes in conflict with others. Developments in manufacturing and the growth of commerce, and the attendant social and political changes, in Britain had been similarly gradual and were not new in the late eighteenth century. However, these changes became accelerated with the increase in Britain's global trade. Expanded markets abroad were linked with the increased division of labour in manufacturing discussed by Adam Smith. Imports of both natural products and the objects of the material culture of distant societies flooded into Britain. Along with the growing supply of, and demand for, commodities from the Americas, products from India were increasingly seen in daily life in Britain. Taste for foreign goods expanded to consumers in all social classes, and the increasingly common appearance of these products in various aspects of daily life offered, as surely as the background objects in a conversation piece, tangible, material evidence of the changes occurring in British society. Questions regarding the benefits and drawbacks of these changes were endlessly analyzed and debated during the late eighteenth century.

\section{Commerce and Luxury in the View of David Hume}

David Hume turned his attention to the debates of the day in his essays. In "Of Commerce," Hume argues in favour of the benefits of efforts expended in the development of the arts and manufactures in a society. He states that occupations in a society may be divided into those of husbandmen and those of manufactures. He suggests that with time, improvements in the techniques of agriculture lead to a 
superfluity of rewards from the land, and that this superfluity is best directed to the arts and manufactures, stating that a habit of indolence prevails when the efforts of laborers are not motivated by rewards of commodities that increase their material comfort and enjoyment. Hume argues that the sovereign of a state always has the choice of directing the "superfluities of the land" towards "fleets and armies" when required in foreign engagements. As argued by Hume, "Trade and industry are really nothing but a stock of labour, which, in times of peace and tranquility, is employed for the ease and satisfaction of individuals, but in the exigencies of state, may in part be turned to public advantage."10 Hume then extends his argument to point out the benefits of foreign trade:

Foreign trade, by its imports, furnishes materials for new manufactures; and, by its exports, it produces labour in particular commodities, which could not be consumed at home. In short, a kingdom that has a large import and export, must abound more with industry, and that employed upon delicacies and luxuries, than a kingdom which rests contented with its native commodities. ${ }^{11}$

In An Inquiry into the Nature and Causes of the Wealth of Nations, Adam Smith explores the benefits of a free market in trade among nations.

While putting forward arguments regarding the benefits of commerce, conjectural historians considered at the same time the potential losses and damages to societies with increasing industrialization and trade. These concerns typically found expression in discussions regarding the dangers of excessive luxury. Hume begins his essay "Of

\footnotetext{
${ }^{9}$ Hume "Of Commerce" 157.

${ }^{10}$ Ibid. 162.

${ }^{11}$ Ibid.
} 
Refinement in the Arts" ${ }^{12}$ with the statement "Luxury is a word of uncertain signification, and may be taken in a good as well as in a bad sense." ${ }^{13}$ To Hume, the problem seems to be only one of excess in the pleasure of a luxurious product rather than in any inherent danger in the luxurious product in itself. He states, "These indulgences are only vices, when they are pursued at the expense of some virtue, as liberality or charity; in like manner as they are follies, when for them a man ruins his fortune, and reduces himself to want and beggary." ${ }^{14}$ With these proposed limits of luxury thus set out, Hume goes on to argue that the increase of luxury accompanying the refinement of the arts and manufactures is indeed of great benefit to a society. He states, "In times when industry and the arts flourish, men are kept in perpetual occupation, and enjoy, as their reward, the occupation itself, as well as those pleasures that are the fruit of their labour." ${ }^{, 15}$

Hume further suggests that the habits of industry that result in "refinements in the mechanical arts" ${ }^{\$ 16}$ lead to advancement in the liberal arts and in sociability in societies. He writes, "The same age which produces great philosophers and politicians, renowned generals and poets, usually abounds with skilful weavers, and ship-carpenters. ${ }^{.17}$ As in "Of Commerce," Hume argues that the energies motivated in the pursuit of luxury may be directed to the needs of the state when required, and he states that without the motivation supplied by the pleasure of commodities, men become indolent:

The increase and consumption of all the commodities, which serve to the ornament and pleasure of life, are advantages to society; because, at the same time that they

\footnotetext{
12 The title "Of Luxury" is used with the same essay in later editions.

${ }^{13}$ Hume "Of Refinement in the Arts" 167.

14 Ibid.

${ }^{15}$ Ibid. 168.

${ }^{16}$ Ibid. 169.

17 Ibid.
} 
multiply those innocent gratifications to individuals, they are a kind of storehouse of labour, which, in the exigencies of state, may be turned to public service. In a nation where there is no demand for such superfluities, men sink into indolence, lose all enjoyment of life, and are useless to the public, which cannot maintain its fleets and armies from the industry of such slothful members. ${ }^{18}$

Just as Warren Hastings had become the scapegoat of anxieties regarding the role being played by the East India Company in South Asia, so the material culture of the East became a tangible focus for the concerns of the British public regarding the changes in British society occurring with its expanding global entanglements. Hume specifically describes these concerns following his exposition of the benefits of refinement in the arts and manufactures, stating:

What has chiefly induced severe moralists to declaim against refinement in the arts, is the example of ancient Rome, which, joining to its poverty and rusticity virtue and public spirit, rose to such a surprising height of grandeur and liberty; but, having learned from its conquered provinces the Asiatic luxury, fell into every kind of corruption. ... All the Latin classics ... universally ascribe the ruin of their state to the arts and riches imported from the East. ${ }^{19}$

Indeed, we could find no clearer description of the concerns of the British public of the late eighteenth century regarding Britain's continuing entrenchment in the East and British desire for the objects of Eastern material culture.

However, Hume then refutes the validity of these concerns with the argument that it is not luxury but rather misgovernment that is the source of danger, whether in ancient

${ }^{18}$ Ibid. 170.
${ }^{19}$ Ibid. 173. 
Rome or in Eastern states. He writes, "But it would be easy to prove, that these writers mistook the cause of the disorders in the Roman state, and ascribed to luxury and the arts, what really proceeded from an ill-modelled government, and the unlimited extent of conquests. ${ }^{20}$ As we have seen, the enervating effects of luxury were often mentioned in relation to the courts of Eastern princes. However, according to Hume, it is tyranny and oppression, with luxury denied to all but the rulers, that are the real danger.

At the end of his essay concerning luxury, Hume states, "I thought this reasoning necessary, in order to give some light to a philosophical question, which has been much disputed in England." ${ }^{21}$ Similarly, a close reading of Hume's essays reveals the issues underlying late eighteenth-century concerns arising with the extensive importation of goods with increasing global trade.

\section{British Appreciation of the Material Culture of the East}

British appreciation of the aesthetic qualities and workmanship of the material culture of the Near East and India during the late eighteenth century was revealed in several interconnected spheres. Written comments of travellers and conjectural historians, acquisition carried out in the purchasing by British consumers and in the collecting of travellers, imitation in design and manufacturing, and inclusions of elements of material culture in visual representations all indicate late eighteenth-century British admiration for the products of the East.

\section{Written Comments of Travellers and Conjectural Historians}

\footnotetext{
${ }^{20}$ Ibid.

${ }^{21}$ Ibid. 177.
} 
Some travellers would at times record their impressions of particular aspects of the arts and material culture of the countries in which they found themselves. William Hodges, for example, includes in his written account of his travels in India an extensive digression in which he discusses the arts of the subcontinent, which we will examine in the next chapter. Similarly, conjectural historians included discussions of particular aspects of material culture in their consideration of various cultures around the globe. The texts of George Forster and William Robertson exemplify the close connections between the two genres, as the authors each discuss trade with India and the advancement of Hindu culture that they suggest is indicated by the material culture of the subcontinent.

The work Sketches of the mythology and customs of the Hindoos, most respectfully inscribed to the Honorable the Court of Directors of the East-India Company, by their dutiful servant by George Forster was published in 1785 and along with his account of his extensive travels in Asia, A Journey from Bengal to England, attracted considerable attention. As discussed by Ketaki Kushari Dyson, Forster was an inquisitive traveller and "an astute observer of human affairs" ${ }^{, 2}$ who was interested in all aspects of the societies that he encountered. She points out that his evident linguistic abilities were undoubtedly of great assistance to him in a remarkable overland journey, in which he often travelled in disguise, through North India, Kashmir, Afghanistan, Persia, the Caspian Sea, and Russia.

The opening words of the Sketches state that the text had been "extracted from private letters" ${ }^{23}$; while this may of course simply be a formal device, the work is comprised of two portions of supposed extracts, the first from a letter written at "Banaris"

\footnotetext{
${ }^{22}$ Dyson 142.

${ }^{23}$ Forster vii.
} 
[Varanasi] in 1782 and the second from a letter written at "Kachmire" in 1783. Forster's account provides examples of evidence discovered in his travels of ancient ties of commerce between India and Egypt. He writes that the "Egyptians and the Greeks in their commerce with India, thro' the channel of the Red Sea, have left, I am induced to believe, many tokens behind them of their connection with the Hindoos. ${ }^{24}$ He relates that coins of ancient Greece had been found near Benares and that some Egyptian and Greek artifacts are to be found in "the collection of a gentleman at Banaris." ${ }^{, 25}$ Forster states,

These circumstances are adverted to with some shew of evincing, that during the intercourse which existed between the natives of Egypt and of India, the former might have introduced into their country, with the rare and luxurious products of Hindustan, certain tenets and ceremonies of the Hindoo mythology. In considering of the tract by which these antiques were brought into India, I must not omit mentioning, that they might have found their way into that country in the cabinets of some of the Mussalman conquerors; who, in the more early period of their empire, were as warm and as enthusiastic admirers of Greek productions and literature as ever the Romans were. ${ }^{26}$

In his text, Forster mentions few written sources of the historical information on which he bases some of his conjectures. Forster states that his suggestions of a possible cultural diffusion of elements of Hinduism into Egypt have been made without "putting

${ }^{24}$ Ibid. 36.

${ }^{25}$ Ibid. 37.

${ }^{26}$ Ibid. 38. 
etymological proofs to the torture" ${ }^{, 7}$ or "the prepossessed determination of fabricating a system and adapting to it partial arguments, cautiously selected for its support" ${ }^{\prime 28}$; while a few writers may perhaps here come to mind, the reader is left to only guess to whose texts he may be referring in these statements. Further, Forster appears to anticipate the criticisms that could be directed at his work on the basis of its scarcity of academic reference. In the closing words of his Sketches, he writes, "The aforegoing opinions, my friend, I have freely given you, and I am to intreat, that you will as freely dissent and analyse them; taking such parts as may appear to you founded on reason and natural principles, and rejecting such as may seem vague or dictated by fancy."29

Strikingly similar points with respect to ancient trade and Hindu culture appear in the texts of Forster and of William Robertson, whose work An Historical Disquisition concerning the Knowledge which the Ancients had of India; and the Progress of Trade with that Country prior to the Discovery of the Passage to it by the Cape of Good Hope was published in 1791. Among the diversity of cultures found in the Indian subcontinent, each author directs the focus of his work to the achievements of Hindu society that have been in evidence since ancient times. Forster draws comparisons to the achievements of ancient Greece and Rome in recording some of his observations during his travels in India. Similarly, in discussing various aspects of Hindu culture, Robertson often makes comparisons to ancient Greek culture, which he uses as a relative measure of highly advanced ancient civilizations. Forster and Robertson each praise many aspects of the material culture of the subcontinent, including, for example, the craftsmanship of

\footnotetext{
${ }^{27}$ Ibid. 34.

${ }^{28}$ Ibid. 54.

${ }^{29}$ Ibid. 84.
} 
metalwork and textiles, which were much valued in the commerce of antiquity as well as in later centuries. Both authors draw associations between the specialization of various types of work and the caste system. Forster states, "Useful and elegant artisans, well skilled in their various trades, in the raising stupendous buildings, in the fabricating gold, silver, and the most delicate cotton cloths, and in the curious workmanship of precious stones and metals, all found ample encouragement in the exercise of their several professions." ${ }^{, 30}$ Robertson suggests that the "separation of professions" caste system reflects the need for technical expertise that accompanies the development of manufactures in a society.

The main narrative of Robertson's meticulously researched text offers a chronological history of global commerce in relation to the East. According to the Oxford Dictionary of National Biography, personal connections to India played a part in drawing Roberson's attention to the topic. In the early 1780s, Robertson was "intent on securing military commissions for his sons James and David, and by 1783 both were serving in India." 32 Robertson also had contact with various other people who served in India, including Robert Orme and James Rennell. Rennell's Memoir of a map of Hindoostan, which was first published in 1783, was "greatly admired by Robertson,"33 who was familiar with the 1788 edition of Rennell's work. John Logan's Dissertation on the Governments, Manners, and Spirit of Asia, which was published in 1787, had also received Robertson's attention. The commencement of the impeachment of Warren

\footnotetext{
${ }^{30}$ Ibid. 43.

${ }^{31}$ Ibid. 258.

${ }^{32}$ Oxford Dictionary of National Biography.

${ }^{33}$ Ibid.
} 
Hastings in 1788 added to the interest of Robertson, as well as of the general public, in Britain's increasing involvement in the subcontinent.

Robertson's narrative begins with the most ancient available records of trade with India and ends with the changes that arose with the discovery of a navigable route around the southern tip of Africa as well as the discovery of the Americas. Robertson surveys the various powers that had taken part in the commerce between East and West. He notes, for example, that among the causes of "the power and wealth of Venice ... its lucrative commerce with the East appeared to be by far the most considerable." Robertson considers detailed descriptions of specific routes of trade, both by ship and overland, technical issues influencing navigation and cartography, political aspects involved in the global competition for trade with India, the products being sought from the East, and the currencies offered in exchange.

Reflecting the stadial theory of the time, William Robertson notes, in his History of America, the continually increasing material sophistication that typically occurs in societies:

the disposition and manners of men are formed by their situation, and arise from the state of society in which they live. The moment that begins to vary, the character of a people must change. In proportion as it advances in improvement, their manners refine, their powers and talents are called forth. In every part of the earth the progress of man hath been nearly the same, and we can trace him in his career from the rude

\footnotetext{
${ }^{34}$ Historical Disquisition 131.
} 
simplicity of savage life, until he attains the industry, the arts, and the elegance of polished society. ${ }^{35}$

In the Appendix following his chronological narrative of ancient trade, Robertson examines various aspects of Hindu culture that he argues provide "evidence of the early and high civilization of the ancient Indians." ${ }^{, 36}$ Along with architecture, sculpture, literature, science, political and social structures, and religion, material culture comprises one of Robertson's categories. He argues that while most of the natural products of the East desired by Europeans, with the exception of pepper, were available from the Near East, it was "that high degree of perfection conspicuous in many of the Indian manufactures" ${ }^{37}$ that caused the "eagerness of all nations" ${ }^{\prime 38}$ to trade with India. He states that of "those productions of their ingenuity, which were the chief articles of their trade with foreign nations ... the labours of the Indian loom and needle have, in every age, been the most celebrated." ${ }^{39} \mathrm{He}$ writes, "The cotton manufactures of India seem anciently to have been as much admired as they are at present, not only for their delicate texture, but for the elegance with which some of them are embroidered, and the beautiful colour of the flowers with which others are adorned," 40 and he notes that India "has been distinguished for the number and excellence of the substances for dying various

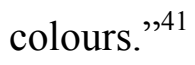

\section{Acquisition}

${ }^{35}$ History of America Vol. 2, p. 30.

${ }^{36}$ Historical Disquisition 311.

${ }^{37}$ Ibid. 261.

${ }^{38}$ Ibid. 257.

${ }^{39}$ Ibid.

${ }^{40}$ Ibid. 286.

${ }^{41}$ Ibid. 
The eager acquisition by consumers in Britain of the goods of the material culture of the East arriving through global trade is a clear indication of the appreciation on the part of the British public of the beauty of those goods. In addition to consumers' purchases, the collections of travellers offer another example of British admiration of Eastern arts and manufactures. Maya Jasanoff explores the "men and women who engaged with foreign cultures in tangible ways: as collectors of objects."42 Personal collections were acquired by individual travellers, whether diplomats, administrative officials, or soldiers. Collecting art was a common pursuit of travellers on the Grand Tour of Europe. With journeys to India, objects of Hindu art were typically collected by travellers who had a scholarly or antiquarian interest, such as Sir William Jones. The general propensity of travellers to collect, however, was typically directed in the East to acquisitions of fine products of material culture.

Emily Eden's comments in her letters written early in the nineteenth century while travelling through India, as well as her many purchases on that journey, indicate the continuation of appreciation of the material arts of the East, even as the political realities of British involvement in the subcontinent were changing. As did many late eighteenthcentury travellers, she continually collects shawls, writing to her sister, "I now say once more, as I have often said before, I really don't want any more shawls, but yet I do always when they come in my way."43 Eden's comments also exemplify the common British interest in acquiring goods of Chinese material culture. She writes, "We have forsaken the buying of shawls and trinkets, and have gone into the upholstery and

\footnotetext{
42 Jasanoff 5.

${ }^{43}$ Eden 197.
} 
furniture line; everything is done with a view to Kensington Gore. I have just been writing to C.E. for a few Chinese articles - a cabinet, and a table or so."44 The popularity of Chinoiserie continued until the mid-nineteenth century. However, following the Opium Wars between Britain and China, British interest in the material culture of the Far East was instead directed to Japan. ${ }^{45}$

Collections were also acquired within larger national or corporate aims, for example with the presentation of valuable gifts to royalty or the display of treasure in the London office of the East India Company. Jasanoff notes, "It was Napoleon in Egypt who most famously pushed the art of state-sponsored collecting to a new level, by bringing with him a corps of more than one hundred scholars, known as the savants, who would study Egypt in the army’s victorious wake." ${ }^{, 46}$ During the three years of French occupation, the savants gathered information and collections relating to both the natural history and culture of Egypt. As discussed by Holger Hoock, "The remains of ancient civilizations provided rich spoils for European imperial states engaged in wars of collecting."47 During the early nineteenth century, this rivalry became "increasingly important in the building of national museums," 48 such as the Louvre and the British Museum.

Collecting was a cross-cultural phenomenon during the late eighteenth century. Tipu Sultan, for example, "participated in the same tradition of royal collecting as his

\footnotetext{
${ }^{44}$ Ibid. 284.

${ }^{45}$ MacKenzie 73.

46 Jasanoff 124.

${ }^{47}$ Hoock 206.

${ }^{48}$ Ibid. 207.
} 
near-contemporary, Asaf ud-Daula." ${ }^{49}$ Along with Eastern treasures, his collection included the sort of European objects of both art and technological invention that would be similarly found in collections of wealthy Europeans during the Enlightenment. Unlike the infamous statue referred to as Tipu's Tiger (which depicts a British officer being attacked by a tiger), the "vast majority of Seringapatam objects attested, rather, to his aristocratic tastes and cultivations. ${ }^{, 50}$ Jasanoff points out that "these were rich, princely possession; they spoke of wealth, cultivation, and rank. Even Tipu's weapons were (and still are) admired by collectors for their technical sophistication, workmanship, and precious materials." ${ }^{, 51}$ While being "demonized for Asiatic cruelty",52 by the British, Tipu Sultan was also "like his British peers ... a connoisseur. His collection, neatly labeled and housed in a wing of the palace, was his refuge. ${ }^{.53}$ His library "consisted of over two thousand volumes in several languages..,54

Following the defeat of Tipu Sultan in Mysore, Seringapatam objects were collected not only by the soldiers who had played a part in the battle and administrative officials serving in India but also by wealthy members of society in Britain. Jasanoff argues that the Revolutionary-Napoleonic Wars resulted in a change in British attitudes to involvement in faraway regions of the globe. Military conquest of distant territories was seen as a necessary strategy in face of the threat of Napoleon's armies. Seringapatam objects sent back to Britain "worked primarily to promote the image of the Company as a

\footnotetext{
49 Jasanoff 184.

${ }^{50}$ Ibid. 179.

${ }^{51}$ Ibid. 183.

${ }^{52}$ Ibid.

${ }^{53}$ Ibid.

${ }^{54}$ Ibid. 184.
} 
ruler" ${ }^{, 55}$ in the subcontinent. With obvious symbolism, King George III was sent a piece of Tipu Sultan's gold throne. The drama of the defeat of Tipu Sultan caught the attention of the British during worrying times, and the British "avidly collected anything and everything associated with Tipu." ${ }^{, 56}$ Seringapatam objects "could soon be found scattered through the salons of Britain's elite," proudly displayed by Sir Walter Scott.

To Lady Henrietta Clive's avid collecting of plants and animals may be added her "enthusiastic appreciation" 58 of Seringapatam objects. The Clives acquired many objects that had belonged to Tipu Sultan, including swords that were "all elegantly chased, inscribed with Arabic calligraphy and covered in tiger motifs," ${ }^{, 59}$ slippers, a travelling bed, "a capacious, elaborate chintz tent,"60 and one of the jeweled, tiger-headed finials from his throne. As exemplified with British collections of Seringapatam objects, "[p]rincely objects brought British and Asian cultures of consumption together across the continental divide.",61

Lady Clive's Seringapatam collection belonged to a history relating to India with which her family had deep connections, going back to her father-in-law, Robert Clive. By the time Lady Clive returned to Britain, negative attitudes linked with nabobs had diminished. Instead, "being a part of the burgeoning history of British India was

${ }^{55}$ Ibid. 179.

${ }^{56}$ Ibid. 182.

${ }^{57}$ Ibid. 183.

${ }^{58}$ Ibid. 190.

${ }^{59}$ Ibid.

${ }^{60}$ Ibid.

${ }^{61}$ Ibid. 183. 
something to be celebrated and advertised." ${ }^{, 62}$ Tipu's tent appeared as a marquee at garden parties given by Lord and Lady Clive.

\section{Imitation}

Postcolonial discourses typically emphasize the imposition of various forms of European culture that took place within an unequal balance of global power. However, while European cultural imposition increased during the nineteenth century as European political control increasingly accompanied global commerce, recent scholars have pointed out that a more open curiosity regarding distant cultures characterized earlier centuries of expanding global trade. Indeed, the challenges of communicating with distant societies in order to carry out trade were at first immense and attempted by only the most adventurous of merchants. Initial encounters with the East were limited to various ports on coasts, where, over time, trading establishments, referred to as 'factories,' were established in the Near East and in Asia. In his history of trade with the East, William Robertson notes that it was only in the period more recent to his time that Europeans acquired direct knowledge of any areas of India further inland than certain of its coasts. All European trade with China was carried out through Canton, with foreign merchants not being allowed access to other areas of the country. One of the aims, for example, of the mission to Peking [Beijing] in 1792-1793 led by George Macartney was to obtain conditions for British trade in other ports in China, although the accomplishment of this goal proved to be unsuccessful.

${ }^{62}$ Ibid. 196. 
Recent scholars have turned their attention to "the intensity and multidirectionality of 'global' cultural flows during the eighteenth century.",63 Avcioğlu and Flood note that the "desire for appropriation consumption, and knowledge of "others" was not unique to the West."64 As discussed by John MacKenzie, relationships between East and West with respect to influence in the design of objects of material culture "had been a two-way process from the very beginnings of European contact with oriental design in the sixteenth and seventeenth centuries." ${ }^{, 65}$ European admiration of the material culture of the East was apparent in the great interest in Turquerie and Chinoiserie that emerged in those centuries. While a complex political relationship had long existed between European states and the Ottoman Empire, nonetheless, along with the trade that was continued throughout the centuries, a certain amount of diplomacy and definitely a great amount of mutual cultural interest took place between European states and those under Ottoman control. The goût turque in Europe found "expression in eighteenthcentury landscape architecture, painted interiors, furniture, decorative arts, and architecture."

Chinese producers adapted their designs for the lucrative European market, and Chinoiserie reflected European taste in styles according to European perceptions of the delicacy and refinement of the arts of China. Products in the Chinoiserie style, including porcelain, wallpapers, furniture, silverware, and fans, became extremely popular, and publications concerning Chinese design appeared in the mid-eighteenth century.

\footnotetext{
${ }^{63}$ Avcioğlu and Flood 32.

${ }^{64}$ Ibid. 8.

${ }^{65}$ MacKenzie 108.

${ }^{66}$ Avcioğlu and Flood 8.
} 
Products that were popular with the interest in Chinoiserie "became increasingly important in the 'private trade' of the employees of the East India Company."67

Of central importance in British commercial involvement in the East, however, was Britain's establishment of control of the trade in Indian textiles. With access to the array of fabrics produced in India, the East India Company was able to supply the entire range of demand in regions across the globe under British control, whether silks, printed chintzes, or plain cottons. The superiority of textiles and dyes produced in India was well acknowledged, and by the late eighteenth century, the woolen industry in Britain was being seriously affected. As with ceramics, European taste influenced designs produced in India.

The carpets of the East were viewed with particularly high esteem among the objects of material culture imported into Europe. The Near East was the source of many of the Oriental rugs that arrived in Europe. While Europeans strove to compete with certain products of the East, with rugs, "no one doubted that the quality of the eastern product could never be emulated." 68 The works of European painters during the early modern period make apparent their great interest in "the beauty of such carpets, the quality of their craftsmanship and materials, the complex and fascinating character of their designs and the technical challenge of rendering them in paint." ${ }^{69}$ This fascination is evident in paintings of the Dutch Golden Age, as seen in the several paintings by Vermeer in which an Oriental carpet draped over a table forms part of the domestic setting. In the painting Girl Reading a Letter at an Open Window, c. 1657, for example,

\footnotetext{
${ }^{67}$ MacKenzie 109.

${ }^{68}$ Ibid. 117.

${ }^{69}$ Ibid.
} 
Vermeer depicts not only the patterns but even the very texture of the carpet. The depiction of Oriental carpets continued throughout the following centuries to be a common feature of visual representations of interior scenes of life in both Europe and the East.

The enthusiasm of consumers for products of the East could not be missed by British manufacturers. By the late eighteenth century, the competition in the marketplace presented by Eastern goods was causing concern regarding the commercial viability of some domestic industries. Consumers were attracted to the style and the availability at relatively affordable prices of goods from the East that added pleasure and luxury to domestic life. British traders and manufacturers recognized the advances made in the East in the large-scale production of goods of material culture. If there is any truth in the saying that imitation is the most sincere form of flattery, then late eighteenth-century British attitudes were definitely not a matter of notions of superiority with respect to material culture. Motivated by the challenge of competing in both the domestic and global marketplace, recognition of Eastern advancement in material culture became a concentrated attempt on the part of British manufacturers to match Eastern capabilities in design and production for varied demands. As discussed by Maxine Berg, "Manufacturers and craftsmen sought to 'imitate' Eastern luxury ... They aspired to match Asian ability to produce and distribute a highly diverse range of goods for large urban and middling-class markets rights across the world."70 Throughout the eighteenth century, European manufacturers attempted to develop techniques that would allow them to match the success of the Chinese, and by the nineteenth century, ceramics were being

\footnotetext{
${ }^{70}$ Berg 20.
} 
mass produced in Britain for sale at home as well as for export to Asia. Manufacturing of course also continued in the East. Indeed, some historians have argued that the attempts to match Eastern capabilities of production in fine goods, such as Chinese porcelain and Indian fabrics, were a significant impetus in relation to the Industrial Revolution in Europe.

Travellers to India were often impressed with the architecture of ancient Hindu civilization and of the more recent Mughal Empire, and travellers to the Near East were similarly struck with the beauty of some of the architecture of the Ottoman Empire, such as Topkapi Palace in Constantinople. Travellers' depictions of the architecture of the East, along with instances in Britain of imitation of Eastern design in architecture, constitute further evidence of British appreciation of the refinement in arts and material culture found in societies of the Near East and India. We will consider British responses to the architecture of the East in the next chapter.

\section{Visual Representation}

It is in the realm of visual representation that late eighteenth-century travellers' admiration of the material culture of the Near East and India is most vividly suggested. In portraits and conversation pieces, whether of European or indigenous residents, the clothes, objects, and backdrops included in the paintings reflect the interest of travelling artists in recording the beauty of various aspects of the material culture of the East.

Travellers at times dressed in local costume for their portraits, or at least included a few elements of Eastern dress, such as a turban or shawl. If posing in European clothes, a few objects of the material culture of the East, or certain aspects of the natural or 
architectural background, served to narrate the Eastern aspect of the sitters' biographies. Just as various objects were traditionally included in European portraiture to indicate the interests or occupations of the sitters, donning local dress provided a way for travellers to narrate the global experiences of their lives that played a part in their identities.

Depictions of British travellers dressed in local costume or surrounded by elements of the culture they are visiting suggest their perceptions of the attractiveness of Eastern material culture as well as their desire to display their Eastern connections. In some conversation pieces, the inclusion of indigenous guests or servants in the paintings narrated the social circumstances of the lives of the sitters. Other conversation pieces depicted more official moments of interaction between Europeans and indigenous residents.

At the same time, travellers often dressed in local style during their daily activities in the East. In Alexandria, in Egypt, James Haynes notes, "As at Grand Cairo, no Frank wears his own country dress, Mr. F- H-, and myself have had our hair cut off, thrown aside our European garments, clothed ourselves like Turks, and in order to be quite compleat have been letting our whiskers grow ever since we left Smyrna.,"71 In some situations, wearing local costume could be helpful in terms of safety, as seen with the journey of Eyles Irwin through the deserts of Egypt. In other cases, certain elements of local fashion would be worn to show respect to the customs of local societies. However, travellers who spent much time in the East often adopted local dress simply as an acquired habit of daily life, undoubtedly indicating their appreciation of the beauty of the fabrics and the comfort of the fashions in climates very different from Britain. Irwin notes that donning Arabian dress helps "not only to avoid the inquisitive and illiberal

\footnotetext{
${ }^{71}$ Haynes 41.
} 
temper of the natives, but for the sake of coolness. The loose and light vestments of the oriental nations are admirably adapted to the nature of their climate; and the numerous folds of the muslin turban, are the best invented defence against the burning rays of a vertical sun." 72

Like elements of the East appearing on the canvas of a visual representation, donning elements of Eastern dress offered a mode of self-representation for travellers as they exhibited their expanded appreciation of Eastern fashion. Lady Mary Wortley Montagu's “Turkish Embassy Letters" had received much attention after being published in the mid-eighteenth century, and more than one painter depicted her in Turkish costume. With the popularity of Turquerie, even Europeans who had never been to the Near East sometimes donned elements of Turkish fashion for their portraits.

Tilly Kettle was the first British painter to arrive in India, in 1769, under the auspices of the East India Company. Kettle had tried to establish a career in London as a portrait painter, with a specialty in the genre of theatre portraits, in which an actor or actress was depicted in costume and the display of the painting would serve as publicity for a play being staged. With Sir Joshua Reynolds's success as a portrait painter and David Garrick's patronage of Johan Zoffany in the genre of theatre paintings, Kettle faced serious competition in London and viewed a sojourn in India as an opportunity to build his own reputation and fortune, as did many merchants and soldiers of the time. Kettle spent many years in India, indeed achieving his hopes of acquiring wealth and recognition, and his paintings exemplify both the attention to the material culture of the

\footnotetext{
${ }^{72}$ Irwin 123.
} 
East that is so evident in the works of artists in India as well as the motives of the sitters and patrons involved.

During the early years of his employment with the East India Company, Kettle sent some of his paintings to London to be exhibited, where they were received with much interest. Almeida and Gilpin point out the theatrical aspects of these paintings and suggest that these works reflect some of the viewpoints that either would have been officially supported by the Company or that would have been common in the British imagination of the East. During the late eighteenth century, officials of the Company were building alliances with various Indian regional rulers within the complex political dynamics playing out in the subcontinent as regional Mughal princes came into conflict with the Mughal Emperor in Delhi. Important alliances were strengthened in the area of Oudh to the west of Bengal, with the Mughal ruler Shuja ud-Daula, who had his court in Faizabad, and upon his death with his son Asaf ud-Daula, who moved the court to Lucknow. In the painting Shuja-ud-daula, Nawab of Oudh, and four sons with General Barker and military officers, 1772, Kettle depicts this collaboration, however staged the composition appears with the group all standing facing the artist. In his portrait of Mahammad Ali Khan, 1770, Kettle depicts the elaborate fabrics and the strings of pearls worn by the nobleman, who is standing in a pose of seeming majesty and dignity, with a direct gaze at the artist and his long, curved sword at his side. Almeida and Gilpin argue that Kettle's portrait would have resonated within British perceptions of both the opulence and the tyranny of Eastern rulers. While this may be true, it must be noted that similar opulence could be found in contemporary portraits of British nobility, as seen, for example, in the portrait of King George III, 1761-1762, from the studio of Allan Ramsay, 
in which the monarch is clothed in embroidered, gold fabric, draped in ermine, and standing on an Oriental rug. Swords were a highly valued possession in the East, often being elaborately decorated, and were not an unusual object to be held by a person holding rule. Swords were similarly found in portraits of British officials who held military roles, as seen in the 1781 portrait of then Captain Horatio Nelson by John Francis Rigaud. In contrast, in Kettle's depiction of Shah Alam, Mughal Emperor, reviewing the 3rd Brigade of the East India Company's troops at Allahabad, c. 1781, the Mughal ruler is depicted sitting with a hookah beside him. The hookah was a rather ubiquitous object in conversation pieces set in the East, and while Kettle's imagined scene in this painting again underscores the political cooperation between the East India Company and various Indian rulers, it may also have underlined the British perception of the lethargy associated with Eastern pleasures of the senses.

Kettle also sent to London a painting of an imagined scene in which a Hindu widow says her farewells to her relatives before carrying out the ritual of sati, a practice that was a common topic of horror in British perceptions of India. Interestingly, Eyles Irwin, who was an acquaintance of Kettle in Madras, sent a poem to London for publication at the same time in which he extolls the dignity and loyalty of the Hindu wife, characteristics also suggested in Kettle's portrayal of the scene.

Lucknow was a centre of vibrant cosmopolitanism during the late decades of the eighteenth century. Having no interest in matters of politics, Asaf ud-Daula immediately capitulated military and administrative control to the East India Company and expended all of his resources in creating an environment in which the arts flourished, even though some argued that his pursuit of pleasure reached the point of excess and decadence. Elite 
social circles in Lucknow consisted of people from India, Europe, and other regions of the East. Eclectic collections were built by the Nawab as well as by many European residents of Lucknow, such as Antoine Polier, Claude Martin, and Benoit de Boigne, with the wealth accumulated from trade; whether illuminated manuscripts of the East or European paintings and inventions, extensive collections stood as extraordinary Enlightenment cabinets of curiosity. European expertise in architecture and engineering was combined with Eastern styles in the construction of palaces.

Kettle spent several years in Lucknow, and his paintings exhibit the richness of the material culture in the domestic lives of those living there. Artists travelling in India were attracted to the architecture of Lucknow; both Kettle and, later, Johan Zoffany visited Polier's palace, named 'Polierganj,' which was built in a Persian architectural style, and William Hodges depicted the residence, named 'Farhat Baksh,' of Claude Martin in View of a House Built by Col. Claude Martin at Lucknow, Bengal, 1790. In Kettle's painting Colonel Antoine Polier watching a nautch, c. 1780, he depicts Polier living the life of a Mughal prince with all of the adornments. Polier is dressed in the fashion of the East, with his Indian wife sitting not far away, and graceful Eastern architectural forms are seen in the garden in the background.

When Kettle later moved to Calcutta, the reputation as a painter that he had established in Lucknow helped him to achieve success in painting portraits of British officials in that city, such as his portrait of Warren Hastings, c. 1775. Hastings believed that it was important to learn as much as possible about the cultures of India in the attempt to fulfill a role of administration while carrying out trade in the subcontinent. $\mathrm{He}$ founded the Asiatic Society, appointing Sir William Jones as one of its first members, 
and commissioned studies concerning Hindu and Muslim frameworks of legal thought and practice. Arthur William Devis's portrait of Sir William Jones, c. 1793, exemplifies the inclusion of objects of Eastern culture in portraits of Europeans living in India. Jones is depicted sitting beside a table on which is found a statue of Ganesh, the beloved Hindu deity with the head of an elephant.

Many paintings of domestic scenes in the Near East and India have indeed been so full of sumptuous detail of the material culture of the East that they have raised many critiques, both in the late eighteenth century and also later in postcolonial discourses. Postcolonial scholars have argued that the artists exaggerated the exotic elements of scenes in order to offer European viewers fantasized images that either constructed or affirmed their imagined ideas of the East, to the point that little, if any, reality could be associated with their representations. This by now well familiar argument, which draws, of course, on the discussions of Edward Said, is often associated with nineteenth-century paintings, such as those by Jean-Auguste-Dominique Ingres.

The depiction of costumes of the East already had a long tradition in European portraiture by the late eighteenth century. Rembrandt, for example, included elements of Eastern dress in depictions of contemporary characters as well as of Biblical scenes. In discussing Rembrandt's painting of The reconciliation of David and Absalom, 1642, E.H. Gombrich states:

When Rembrandt was reading the Old Testament, and tried to see the kings and patriarchs of the Holy Land in his mind's eye, he thought of the Orientals he had seen in the busy port of Amsterdam. That is why he dressed David like an Indian or Turk with a big turban, and gave Absalom a curved Oriental Sword. His painter's eye was 
attracted by the splendour of these costumes, and by the chance they gave him of showing the play of light on the precious fabric, and the sparkle of gold and jewellery. ${ }^{73}$

Gombrich notes that in Rembrandt's etching of Christ preaching, c. 1652, he has turned to his own city for models. Rembrandt lived for a long time in the Jewish quarter of Amsterdam, and he studied the appearance and dress of local residents "so as to introduce them into his sacred stories."74 Emmanuel Starcky notes Rembrandt's "attraction towards oriental exoticism, ${ }^{, 75}$ as evident in his portrait of a Man in Oriental Costume, 1633. Dressed similarly to King Belshazzar in Rembrandt's painting of a dramatic Old Testament scene, Belshazzar's Feast, 1635, the man wears a bejewelled turban and a cloak of rich, gold fabric. Nonetheless, the pose and features of the figure suggest a rugged vigour, contrary to any European perceptions of Eastern indolent sensuality.

To whatever extent exoticism parted from reality in late eighteenth-century paintings, it must be noted that attention to similar elements, such as fabrics and background objects, was typical within the tradition of European portraiture. Late eighteenth-century interest in such elements in representations of the East was certainly not entirely a matter of exoticism. In any case, during the late eighteenth century it was the luxury of the East, as depicted in visual representations and as imagined within British perceptions, that formed the basis of the common critiques. The conflicted attitudes of Europeans to the luxury of the material culture of the East had been long apparent in European painting. In Dutch still life paintings of the seventeenth century,

\footnotetext{
${ }^{73}$ Gombrich 424.

${ }^{74}$ Ibid. 427.

${ }^{75}$ Starcky 64.
} 
collections of exotic goods are typically included. Pepper, citrus fruits, pieces of silver, and exotic flowers are common inclusions in the set of products for consumption or decoration found on the table. At the same time, the theme of vanitas is also a common feature of the genre, with its moral of the impermanence and relative lack of worth of worldly pleasures. This moral fell within frameworks of religious thought in states of northern Europe in the early modern period, as did criticisms of the rich adornments found in the institutions of the Catholic faith in Rome. European concern with luxury had a long historical basis and simply became of more central and immediate concern by the late eighteenth century with the flood of products being imported with global trade.

Paintings of women of the Near East and India, and particularly those of women either dancing or lounging in the harem, are typically seen as having played a significant part in relation to British perceptions of Eastern excess with respect to sensual aspects of life, and certainly in relation to later postcolonial critiques of exoticized fanatasy. British perceptions of the sensuality of women in India were indeed common during the late eighteenth century. Sir William Jones specifically considered these perceptions, studying "the role of the female in Hindu mythology" "76 and the link between "cosmic sensuality and creation." ${ }^{, 77}$ At the same time, Almeida and Gilpin point out that during the late eighteenth century, the consorts of high-ranking British officers and traders in the subcontinent, referred to as bibis, were often princesses of Indian royal families and that "these arrangements were more than just domestic and personal ones: they constituted alliances between a reigning nawab and a powerful Company representative that

\footnotetext{
${ }^{76}$ Almeida and Gilpin 81.

${ }^{77}$ Ibid.
} 
promoted the political and economic interests of each party." ${ }^{, 78}$ These women were often well educated, and they provided interpretation of local languages as well as "guidance as to the nuances of regional culture and the politics of the particular nawab's court.",79 With British men commonly spending many years in India, they often regarded their bibis and the children they had with them with the affection and respect typical of close familial relationships.

As such, Almeida and Gilpin argue that late eighteenth-century visual portraits of bibis and conversation pieces of these interracial families depict not only the perceived sensuality of Indian women but also their empowerment as influential figures in the lives of the British men with whom they lived. Depictions of domestic settings in which women and other members of the household engage in some routine activity or intimate conversation during some moment of daily life also find a tradition in paintings of the Dutch Golden Age. Nonetheless, during the late eighteenth century, portraits of English women "by artists like Gainsborough and Romney ... show the subjects seated stiffly in a formal pose, holding in their hands some girlish sign of innocence or womanly sign of domesticity. ${ }^{" 80}$ Without doubt, depictions of bibis were far more sensual, often showing the subject "at rest and informally lounging against cushions on a divan or a oriental carpet, poses derived from representations of the figure of Venus in Italian Renaissance paintings. ${ }^{\prime 81}$ Francesco Renaldi trained at the Royal Academy and worked in India from 1786 until 1796. His painting of a Muslim lady reclining, 1789, portrays not only the sensuality of the woman but also the play of light filtering through the latticed screen on

\footnotetext{
78 Ibid.

${ }^{79}$ Ibid. 83.

${ }^{80}$ Ibid. 84.

${ }^{81}$ Ibid.
} 
the fabrics, rug, and objects in her surroundings. Thomas Hickey's painting of an Indian lady, perhaps “Jemdanee', bibi of William Hickey, 1787 depicts “a pensive figure of dignity and beauty" tranquility," 83 and the portrait captures William Hickey's "attachment and respect for his bibi." ${ }^{84}$ James Wales, an artist working in Bombay and Poona, depicted Beebee Amber Kooer, bibi of Sir Charles Warre Malet, 1792, a princess of the Maratha rulers "who held sway over much of west and central India, and who were also important allies of the Company." 85 In 1790, Malet had "successfully negotiated a treaty with the Maratha prince Peshwa Madhu Rao Narayan against Tipu Sultan."86 Almeida and Gilpin suggest that in Charles Smith's portrait of an Indian lady, perhaps the bibi of John Wombwell, 1786, "the representation of the princess - reputed to be from the court of the Moghul Emperor in Delhi - is a regal one." 87

Johan Zoffany's painting of The Palmer family, 1786 (formerly attributed to Francesco Renaldi), depicts a scene of "domestic bliss and interracial harmony." 88 However, such living arrangements were later prevented by the laws put forward by Governor General Cornwallis banning interracial relationships. According to Almeida and Gilpin, "No intimate or empowered portraits of Indian bibis can be found dating after the 1790 s. $" 89$

\footnotetext{
82 Ibid. 85.

${ }^{83}$ Ibid.

${ }^{84}$ Ibid.

${ }^{85}$ Ibid. 83.

86 Ibid.

${ }^{87}$ Ibid. 85.

${ }^{88}$ Ibid. 87.

${ }^{89}$ Ibid. 84.
} 
To whatever extent late eighteenth-century portraits of bibis indicate the emotions of the British men with whom they lived, the attention of travelling artists to the beauty of the carpets, fabrics, jewels, and other objects that were common in the domestic settings of the lives of these women indicate, unequivocally, British appreciation of the beauty of Eastern material culture. The sensuality of both the women and the interior scenes may indeed have supported British perceptions of the indolence of Eastern excess. Nonetheless, critical assessments during the late eighteenth century were clearly not based on either a perceived lack of refinement in the material culture of the East or on concerns regarding a lack of reality in exotic images, as expressed in postcolonial critiques. Rather, if anything, it was the abundance of temptations of the material culture of the East that was the source of late eighteenth-century concerns.

\section{Diverse Modes of Expression of Conflicting Attitudes}

The conflicting attitudes of the late eighteenth century regarding increasing trade with the East found expression in various diverse modes of expression. This ambivalence may be seen in two examples: the first in visual representations of the ships employed in the operations of the East India Company, and the second in the controversies relating to nabobs.

Geoff Quilley points out the emergence not only of the East India Company as "the pulse of the commercial life of the nation" $" 90$ but also "a deeper association of its

commercial function and character with the perceived identity of the nation at large." ${ }^{.11}$ He states that given "the central ideological place of navigation generally in the

\footnotetext{
${ }^{90}$ Quilley “Signs of Commerce" 183.

${ }^{91}$ Ibid.
} 
conceptualization of British national identity" ${ }^{92}$ and the fundamental role of shipping in the operations of the Company, images of East Indiamen could suggest various positions within the significant debates of the time relating to Britain's expanding commerce. $\mathrm{He}$ notes:

In no small measure the promotion of the East India Company was achieved through visual culture: painting, prints, architecture, sculpture, illustrated books and scholarly works, maps, medals, and virtually every other type of visual artefact produced during the eighteenth century ... And it is clear that, from the rebuilding and pictorial decoration of the Leadenhall Street offices in the 1720s, the directors were aware of the value of the visual in presenting the Company as the product of Shaftesburian civilized politeness rather than that of a Mandevillean rapacity. ${ }^{93}$

Quilley argues that 'ship portraits,' which were produced in great number from the 1750 s on, in some cases evoked views of the beneficial aspects of commerce in societies, and the positive role played by the Company in this civilizing process, and in other cases suggested the destructive effects that could accompany motivations of profit and luxury. Quilley notes that paintings of East Indiamen were "overwhelmingly celebratory and commemorative," ${ }^{94}$ depicting the maiden voyages of "conspicuously large vessels, ${ }^{, 95}$ such as the Hindustan, which was to be used in the rapidly developing trade with China. Paintings of merchant vessels, which were often reproduced as prints, were typically produced by "academically untrained artists ... who had usually had direct

\footnotetext{
92 Ibid. 185.

${ }^{93}$ Ibid. 184.

${ }^{94}$ Ibid. 187.

${ }^{95}$ Ibid.
} 
experience of working on board ship."96 Quilley notes that these works "tend to follow a clear compositional formula, deriving from Dutch seventeenth-century prototypes, but greatly simplified in the treatment of space and light." 97 He states that these images "show a stylistic uniformity which, in its reductive lack of ostentation and its documentary character is far removed" 98 from some of the Dutch paintings and that the images "instead show a closer resemblance to the shipboard practice of coastal profiling, a practice in which officers were routinely trained." 99 At a time when the East India Company was facing corruption scandals, the "consistently plain unornamented and transparent style"100 of the images of the merchant vessels may have offered "an affirmation that the represented vessels are engaged in open, honest plain dealing,"101 as seen, for example, in the Portrait of an East Indiaman Sailing from Madras by Richard Dodd.

At the same time, "in the iconography of shipwreck of the period, wrecks of East Indiamen figure very prominently." "102 The loss of the Halsewell, in which the commander drowned with his two daughters instead of saving himself, was the subject of several literary narratives and paintings of the time. Quilley points out that these works included not only praises of heroic self-sacrifice but also reminders "of the fatal effects of excessive commercial ambition, particularly through contact with the luxurious east." Both Richard Dodd's image of the party before sailing and Robert Smirke's sentimental

\footnotetext{
${ }^{96}$ Ibid. 186.

${ }^{97}$ Ibid.

${ }^{98}$ Ibid.

99 Ibid.

${ }^{100}$ Ibid. 193.

${ }^{101}$ Ibid.

102 Ibid. 194.

${ }^{103}$ Ibid. 195.
} 
depiction of the family group during the disaster in his painting The Halsewell East Indiaman carry visual warnings of the dangers of the lure of commercial fortune in India.

Conflicting attitudes towards increasing trade with India also found expression during the late eighteenth century in the controversies relating to nabobs. As discussed by Tillman Nechtman, the appearance in the British landscape of the imitation of South Asian architectural design, as seen in some of the homes built by nabobs who had returned from India, caused a certain amount of concern and criticism at the time. With wealth acquired during their time in the East, nabobs were able to buy estates traditionally owned by the landed aristocracy when they returned to Britain. Robert Clive, for example, purchased the Claremont estate from the Duchess of Newcastle in 1769. The incorporation of Eastern "architectural flourishes" 104 in the design of the homes that they had constructed clearly indicates that along with their fortunes, they had acquired an appreciation of the beauty of various architectural forms in India. In 1793, James Forbes, for example, included an octagonal temple in the gardens of his estate, surrounded by a group of Hindu statues that he brought back from India. In 1787, Warren Hastings "purchased his family's ancestral estate at Daylesford and commissioned Samuel Pepys Cockerell, the architect to the Company, to design a new main house."105 The design included "a large dome, derived from Islamic architectural influences, over the central entry hall ... [and] a conservatory with eastern-styled windows."

\footnotetext{
${ }^{104}$ Nechtman 166.

105 Ibid. 167.

${ }^{106}$ Ibid.
} 
garden follies based on South Asian themes." ${ }^{107}$ Further, the interiors of nabobs' homes were "often filled with markers of their lives in South Asia,"108 even if they lived in houses constructed in the Georgian or neo-Classical architectural styles that were popular at the time in Britain. In addition, nabobs introduced a demand in Britain for the foods, such as curries, of South Asia that they missed.

Even exotic animals were being brought into Britain from remote regions of the globe. By the late eighteenth century, British monarchs opened the menagerie at the Tower of London "as an early zoo," 109 and George Stubbs painted a zebra that had been give to Queen Charlotte by the East India Company. A painting by Stubbs of an Indian yak hung in Hastings's office in his Daylesford estate.

Land was traditionally the source of both wealth and political influence in Britain. Indeed, it was necessary to own an estate in order to qualify for a seat in Parliament. Nechtman suggests that within the traditional British view of the value of land, plantation owners who had built fortunes in the West Indies were viewed with less suspicion than nabobs who had acquired wealth in India through sometimes seemingly more dubious means in trade. Nabobs commonly transferred their wealth back to Britain in the form of diamonds. Diamonds given by nabobs to Queen Charlotte were seen as attempts to gain royal influence. Critics viewed nabobs as "being able to eschew traditional patterns of social organization with their imperial wealth." 110

References to the social changes occurring with the new wealth of returning nabobs became a common inclusion in novels. In Smollet's novel The Expedition of

${ }^{107}$ Ibid.

${ }^{108}$ Ibid. 168

${ }^{109}$ Ibid. 176.

${ }^{110}$ Nechtman 118. 
Humphry Clinker, Matthew Bramble's description of the situation of his unfortunate friend, Mr. Baynard, takes on the tone of moral fable. With the hope of resolving his personal debts, Mr. Baynard enters into "a prudent marriage" " with a woman whose "fortune came by an uncle, who had died in the East-Indies." ${ }^{112}$ Mrs. Baynard's interests are entirely directed to matching the ostentation of her neighbours in the country:

All these three ladies have at this time the same number of horses, carriages, and servants in and out of livery; the same variety of dress; the same quantity of plate and china; the like ornaments in furniture; and in their entertainments they endeavour to exceed one another in the variety, delicacy, and expence of their dishes. ${ }^{113}$ Through his wife's extravagance, Mr. Baynard is drawn into ever-increasing debt and despair, and Smollett satirizes the centrality of fashion in the desires of newly wealthy consumers.

Nabobs provided a tangible, observable focus for the anxieties felt at the time by those in Britain who were becoming aware of the increasing imbrication of nation and empire. Britain's economy could no longer be viewed independently of global markets. Demand continually increased for the goods from distant regions of the globe that were becoming part of everyday life in Britain. Urban centers were expanding, prices were soaring, and domestic manufacturers of certain products were challenged. In short, Britain's economy, as seen very clearly by thinkers of the Scottish Enlightenment, had shifted to a new model of industrialization, consumerism, and globalization. Britain's traditional social structures were changing with this shift. Those in manufacturing and

\footnotetext{
111 Smollett 286.

112 Ibid.

113 Ibid. 294.
} 
trade were acquiring wealth, whether in Britain or in distant regions under British control, and through this wealth were also acquiring political influence.

It was evident that nabobs had grown fond of many aspects of the cultures of South Asia. As stated by Nechtman, "a Company employee could not recount his own biography without including the subcontinent; it was a fundamental piece of his identity, and Indian commodities . . . served as markers of this braided narrative."114 Nechtman argues that the hybridized identity of nabobs was viewed as a challenge to domestic notions of British identity. It became clear that not only was it possible for Britain to influence culture in distant regions, but British domestic culture would also be changed in the process.

According to Nechtman, this possibility of mutual influence raised questions and concerns within the framework of stadial theory. If cultures in India were formed within the characteristics of the environment in South Asia, then the British in India, as seemed to be the case with the nabobs, could become culturally more similar to South Asians. Nechtman argues that since justifications for imperialism were linked to notions of cultural difference with, and more specifically superiority to, distant societies, a more fluid concept of cultural identity was seen as being problematic.

Arguments based on ideas of European superiority were put forward by those in Britain with political interests more commonly in the nineteenth century. It must be noted that the conjectural historians of the late eighteenth century were far more politically disinterested than the later political uses of their theories might seem to suggest. An equation between the development of stadial theory and justifications of

\footnotetext{
${ }^{114}$ Nechtman 71.
} 
imperialist political agendas is far too neat and lacking in recognition of the philosophical, removed stance that characterizes the sub-genre of conjectural history. Thinkers of the Scottish Enlightenment were exploring questions concerning long trajectories of cultural change in societies, including changes in overarching political attitudes and systems. With stadial theory being based on a notion of universal commonalities in basic human nature and not difference, the idea that the environment of South Asia could similarly affect, in the long term, the cultural characteristics of any group of people was primarily a subject of intellectual interest for the conjectural historians. Their focus was not on personality changes of individuals over the years of their lives but rather the changes that typically occur in societies over centuries. Further, conjectural historians did not take a simple view of India as a less advanced society but rather as a civilization that was highly developed in ancient times, as were several other cultures, including ancient Egypt, Greece, Rome, Peru, and China. Conjectural historians were interested in the common patterns and causes not only of progress but also of the decline of civilizations.

Conjectural historians and pamphleteers of political criticism and social satire were examining societies from differing positions of distance, covering a range from philosophical disinterest to daily involvement. However, from any position in this range, questions concerning luxury were central in late eighteenth-century thought. Domestic critics of nabobs saw the flood of products of Eastern luxury as a threat to British ways of life. Conjectural historians argued that the increased consumption of luxury products was one feature of a new globalized economic model that resulted in various changes in social and political structures. Whether luxury is typically beneficial or ultimately destructive 
of a culture, be it ancient Rome or contemporary Britain, was one of the questions

explored by Hume in his essays, in which he exemplifies his proposed dialogue between the worlds of philosophy and daily life. 


\section{Chapter Five}

\section{Depictions of Architecture and Scenes of Daily Life:}

\section{Historical Meditations regarding Achievement and Decline}

During the early modern period, travellers' visual impressions of newly encountered societies formed one of the bases of their perceptions regarding remote cultures. The views passing in front of the eyes of travellers, whether of geographical landscape, architecture, or street scenes, provided one of their central sources of information regarding distant societies. In turn, visual representations of these views offered impressions of distant societies to those in Britain. Depictions of place, whether urban, rural, or uninhabited by man, were a common element of most late eighteenthcentury travel accounts. Before the invention of photography, travellers' visual representations, through pictures in words or through drawings and paintings, supplied the only impressions of remote places available to many late eighteenth-century readers, and these representations both reflected and influenced the aesthetics of the period.

Many of the early depictions of landscapes in distant societies of the East were provided by military officers who had been trained as draughtsmen, and their works indicate the interest of the time in recording topographical information. At the same time, the visual representations produced by travellers typically indicate the influence of the aesthetic frameworks that the travellers had inescapably carried with them when they set out from home. In this chapter, I will explore the relationships between European aesthetics and visual representations of remote societies. As well as Edmund Burke's discussions of the emotions evoked by the sublime and the beautiful, Gilpin's notions of 
the picturesque were extremely influential. Situating travellers' depictions within the general context of landscape representation during the late eighteenth century offers much insight regarding the information that they were attempting to transmit through their work.

Travellers often recorded their impressions of visually stepping back in time in the East. Various connotations could be suggested through references to Classical beauty, or the pastoral tranquility of rural scenes, or chivalric splendour, or monumental ruins of ancient achievement. Notions of idyllic pasts were at times evoked through references to literary utopias, whether of the Golden Age and lost Arcadia or the Garden of Eden, in late eighteenth-century travellers' representations of societies in which residents lived in close connection with their natural surroundings; while these tropes were most commonly found in representations of the indigenous peoples of the Americas, they are also found, for example, in Hodge's impressions of the peoples of the South Seas Islands. The various common sources of reference to the past offered a fluid set of allusions in the attempts of late eighteenth-century to relate their perceptions of distant societies.

Historical ideas were often suggested in landscape painting of the period. Classical references were a common element in late eighteenth-century painting, in which they were seen as lending a sense of dignity to the subject of a portrait painting or an association of artistic achievement to the society being depicted in a landscape painting. Richard Wilson was one of the foremost British landscape painters of the time, and allusions to the history of ancient Rome, as well as Wales, are included in his representations of contemporary landscapes. William Hodges was also primarily a 
landscape painter and was influenced by Wilson. Hodges travelled to the South Seas and later to India, recording his impressions of the subcontinent in his written account Travels in India, during the years $1780,1781,1782, \& 1783$, which was published in 1793. As one of the first professional European artists to travel in India and produce depictions of the subcontinent in both text and visual form, Hodges's works offer insight into the vision of the late eighteenth-century traveller.

Depictions of the dress and daily activities of local residents reflected the interest of the time in ethnographical depiction. The aesthetic of the picturesque was extended in visual representations of distant societies to offer information regarding the groups of figures depicted in the foreground. Travellers often commented regarding the 'picturesque' appearance of groups of indigenous residents, as seen in the letters of Emily Eden, who also painted many portraits during her travels in India, as well as in the written account of Hodges.

Preoccupations with the decline of civilizations were found in the writing of both conjectural historians and travellers during the period. In his travels through the Near East, Eyles Irwin ponders the evidence of the decline of the ancient civilization of Egypt, and John Logan discusses the advancement and decline of several cultures of antiquity. Hodges states that a traveller's first impressions and the novelty of views of a different place do not last and "the traveller is lost in the philosopher." Hodges's depictions of Mughal ruins were linked to historical meditations that were typical of British thought of the time and expressed through the aesthetic approach of the sublime. Writers and artists continually encountered material evidence of the past during their travels in the Near East

\footnotetext{
${ }^{1}$ Hodges iv.
} 
and India, and their representations of distant societies were often closely connected with not only chronological narratives of particular empires but also the broader contemporary frameworks of historical thought relating to the cycles of advancement and decline of civilizations more generally.

\section{Travelling British Artists and Aesthetics in the Fine Arts}

John MacKenzie notes the commonly made distinction between the applied arts and the fine arts in British attitudes towards the arts of the East, stating that "[w]hile Europeans were prepared to acknowledge the influence of 'crafts' and of the decorative arts from the earliest days of commercial contact with the East, they always maintained the outright superiority of western sculpture and painting." ${ }^{2}$ While adaptations of Eastern design in goods for domestic use were extremely popular in Europe, "pre-eminence in sculpture was hallowed by the great classical precedents" ${ }^{3}$ in the Western tradition. European artists who travelled to distant regions of the globe brought with them their notions regarding aesthetic approaches and established genres of European painting. Eastern aesthetic conventions were generally of little influence in the representational techniques employed by European artists travelling in Asia during the late eighteenth century; as stated by Giles Tillotson, "British artists in India were never much influenced by indigenous artistic traditions." ${ }^{\text {" }}$ While both Mughal and Hindu representations of architectural sites, for example, used many points of view in attempting to depict the plan of the site as a whole along with the conceptual meanings of this plan, European

\footnotetext{
${ }^{2}$ MacKenzie 105.

${ }^{3}$ Ibid.

${ }^{4}$ Tillotson "The Indian Picturesque" 149.
} 
representations invariably depicted buildings and ruins from one particular point of view and in a particular light. ${ }^{5}$ Indeed, Tillotson states that the European aesthetics of their time influenced their way of seeing, with their representations of distant landscapes and cultures reflecting "an inescapable artistic vision."

Emily Eden's comments reveal that there could at times be a mutual lack of understanding of the visual aesthetics of the other's culture. She notes that while she was sketching one of the rajahs, "One of his native painters was sketching G., and if my drawing looked as odd to him as his did to me, he must have formed a mean idea of the arts in England. They put full eyes into a profile, and give hardly any shade." ${ }^{, 7}$ However, in other instances her comments indicate the amount of mutual appreciation and exchange that could occur between British and Indian artists, as when she writes:

I have had two Delhi miniature painters here, translating two of my sketches into ivory, and I never saw anything so perfect as their copy of Runjeet Singh. Azim, the painter, is almost a genius; except that he knows no perspective ... He is quite mad about some of my sketches, and as all miniatures of well-known characters sell well, he has determined to get hold of my book.... Their miniatures are so soft and beautiful. $^{8}$

Similarly, Hodges suggests that many Mughal miniature paintings "are highly beautiful in composition and in delicacy of colour." ${ }^{9}$ Hodges had a great interest in the artistic traditions of the cultures he encountered. His own paintings, however, support

\footnotetext{
${ }^{5}$ See Tillotson, "Hodges and Indian architecture."

${ }^{6}$ Ibid. 151.

${ }^{7}$ Eden 228.

${ }^{8}$ Ibid. 264.

${ }^{9}$ Hodges 152 .
} 
Tillotson's view of the limited influence of Eastern aesthetic approaches in the work of travelling artists.

Beaulieu and Roberts argue that the extent of cross-cultural interaction involved in Western representation of Oriental subjects has received insufficient scholarly attention. Eden's letters reveal the mutual interest involved in intercultural encounters during the period. Eden points out that many of the local people were very pleased to sit for their portraits; she writes, "I thought when we were at Nabun that an old man, a sort of prime minister of the rajah's, would make an good drawing, and I told him so; and today he arrived, having made two marches to have the picture drawn."10 The man gave Eden a matchlock, and she gave him a watch in return ; she relates that "While Captain L.E. was gone to fetch the watch, the old man took the opportunity to question my jemadar about our habits, and I understood enough of the language to make out that he was asking how many times we eat in the day."11 Eden's comments point out that the interest in the manners and customs of others was not only European.

Hodges began his journeys having already achieved a mastery of the techniques and conventions of European painting. Hodges apprenticed with Richard Wilson, and following Hodges's attainment of at least a certain amount of recognition for his own works, he was chosen (following complications preventing the first choice of Johann Zoffany) to accompany Captain James Cook on his second voyage to the South Pacific in 1772. By the time Hodges travelled to India under the patronage of William Hastings and the East India Company in 1780, Hodges's reputation as a painter of remote landscapes had been established.

\footnotetext{
${ }^{10}$ Eden 245 .

${ }^{11}$ Ibid. 246
} 
Hodges states that while British involvement in India had naturally created much curiosity regarding that country, other than some information with respect to its laws, religion, and the Mughal government, little was known of "the face of the country, of its arts." ${ }^{\prime 2}$ As found so commonly in travel accounts of the period, Hodges begins his written account with the claim that his intention is to provide "a few plain observations, noted down upon the spot, in the simple garb of truth, without the smallest embellishment from fiction, or from fancy." ${ }^{\prime 13}$ Hodges clearly sees himself primarily as an artist; he includes a disclaimer regarding his abilities as a writer, stating that it is in his drawings that "I appear in my proper professional character." ${ }^{14}$ In the written account of his journey, Hodges underlines that artists visiting distant societies should attempt to portray the true nature of what they see:

A painter for such pursuits ought necessarily to be endowed with three great qualities; a perfect knowledge of his art, and with powers to execute readily and correctly; judgment to chuse his subjects; and fancy to combine and dispose them to advantage. ... but the imagination must be under the strict guidance of cool judgment, or we shall have fanciful representations instead of the truth, which, above all, must be the object of such researches. Every thing has a particular character, and certainly it is the finding out the real and natural character which is required; for should a painter be possessed of the talents of a Raphael, and were he to represent a Chinese with the

\footnotetext{
${ }^{12}$ Hodges iii.

${ }^{13}$ Ibid. iv.

${ }^{14}$ Ibid. v.
} 
beauty of a Grecian character and form, however, excellent his work might be, it would still have no pretentions to reputation as characteristical of that nation. ${ }^{15}$ Nonetheless, as we will examine in this chapter, Hodges's paintings reflect the aesthetic approaches of his time. As well as aspects of the sublime and picturesque, his paintings at times include Classical allusions. At the same time, since Hodges's works brought some of the earliest images of the South Seas and India to a European audience, his paintings served to further extend the association of these aesthetic categories with new subject matter.

At the time of Hodges's travels to the South Seas, there existed a hierarchy of established genres of European painting. History painting was considered the most noble of the genres, just as historical writing was held in a position of honour above other genres of writing during the period. Portraiture was also respected, with no shortage of portraits of those who held positions of public notice or who were wealthy enough to commission their own portraits, and some of the first artists to travel to India made their incomes by painting portraits and conversation pieces of British officials and their families in residence there. While landscape painting was the focus of several masters in the seventeenth century, the genre was developing and had not yet attained the consideration accorded to history painting and portraiture. While the British nobility often commissioned depictions of their country estates, these works generally fell to topographical draughtsmen, an area in which Hodges had proven his competence.

Nonetheless, having apprenticed with Wilson, Hodges had been influenced by one of the leading landscape painters of the day, and Hodges's body of work clearly suggests

${ }^{15}$ Ibid. 155. 
his own devotion to the genre. Few portraits are found in Hodges's oeuvre, and of these, his portrait of Captain Cook and his portrait of Omai (who had been brought to England from Huahine, one of the Society Islands) are among the most notable. Similarly, Hodges produced few history paintings in the traditional sense of the genre, aside from three works depicting a few eventful encounters with inhabitants of islands in the South Seas when Captain Cook and some of his sailors were attempting to land. These works share in the innovation seen in the history painting of other artists of the time with their depiction of contemporary events. Benjamin West, for example, was influential in the expansion of subject matter in the domain of history painting, with works such as The Death of General Wolfe, 1770.

The priority given by Hodges to the genre of landscape painting was undoubtedly not the result of a lack of subject matter in India for history painting. When travelling under the escort of the military in the subcontinent, Hodges was a close witness to conflicts with Mughal rulers. Indeed, in his written account, Hodges at times records his interest in observing military manoeuvres, such as when he describes the cavalry who were continually manifesting their dexterity, in the oriental manner, by setting off their horses in full speed, firing behind, as if pursued by an enemy, and then instantaneously stopping, and flying back with the same velocity as they advanced ... Their adroitness in the management of their horses is, indeed, wonderful. ${ }^{16}$ However, most often Hodges disparages the effects of war, on one occasion writing: my route was scarcely fixed, when I was interrupted by the great scourge of human nature, the great enemy of the arts, war ... driving the peaceful husbandman from his

\footnotetext{
${ }^{16}$ Hodges 130 .
} 
plow, and the manufacturer from his loom ... I was a melancholy witness to its effects. $^{17}$

Hodges's landscape paintings extended the genre to depict remote cultures, and his paintings comprise some of the earliest works in the genre of ethnographic depiction. As such, Hodges was one of the first artists to give visual form to the ideas being put forward with the emergence of conjectural history during the late eighteenth century. Hodges's paintings were seen in the halls of the Admiralty and in the exhibition space of the Royal Academy, and several aquatints made from his paintings were published under the title Select Views of India after he had returned to England. In the closing paragraph of his written account, Hodges suggests that there would be great value in artists travelling to other areas of India:

Many other tours in that interesting country might be undertaken by the enterprising artist. We know that the whole coast of Malabar possesses picturesque beauty equal to any country on earth; and how valuable would be the representation of that scenery, whether as a natural object, or as connected with the history of the country, and the manners of the people? Pictures are collected from their value as specimens of human excellence and genius exercised in a fine art; and justly are they so: but I cannot help thinking, that they would rise still higher in estimation, were they connected with the history of the various countries, and did they faithfully represent the manners of mankind. ${ }^{18}$

Hodges did not live to make another journey to India, but his comments clearly indicate that he shared the common late eighteenth-century interest in manners and customs.

\footnotetext{
${ }^{17}$ Ibid. 5.

${ }^{18}$ Hodges 155 .
} 


\section{Architectural Encounters}

Travellers to the Near East and India often described the magnificence of some of the architecture and the beauty of the mosaics and gardens with which it was adorned. As we have seen in Chapter Four, the admiration of nabobs for the architecture of South Asia was apparent in some of their homes and gardens. At the same time, John MacKenzie suggests that unlike the design and production of objects of material culture in the East, Eastern architectural design was of "little fundamental influence"19 on European architecture, being limited to a certain amount of "eclectic experimentation.",20 He notes that examples of architectural cross-reference began to be seen in various instances, most notably in "the architecture of leisure.",21 Features commonly found in Chinese gardens, such as bridges and latticework, were incorporated into English gardens and were seen as being well suited to the late eighteenth-century "picturesque and irregular",22 style of landscape design. In keeping with the interest of the time in ancient civilizations, certain elements of ancient Egyptian architecture, such as obelisks, also appeared in British parks. Discussions in Britain concerning both the practical and ideological appropriateness of Eastern architectural forms in a very different climate and social setting accompanied British interest in Eastern architectural design.

Nebahat Avcioğlu argues that a more serious interest in Eastern architectural design was involved in European approaches than is commonly acknowledged by scholars. She notes, for example, that scholars have often been dismissive of the

\footnotetext{
${ }^{19}$ MacKenzie 73.

${ }^{20}$ Ibid. 71.

${ }^{21}$ Ibid.

${ }^{22}$ Ibid. 76.
} 
significance of the projects of Vauxhall and Kew Gardens, describing them simply as examples of frivolous, flimsy, exotic fantasy aimed to offer entertainment within the emerging public sphere. Avcioğlu states, "Understanding of Eastern-inspired architecture in Western Europe will only be possible when the inseparable bond between exoticism and frivolity is abandoned." ${ }^{23}$ She points out that a close examination of the political and social context of the Vauxhall and Kew Gardens reveals that they were carefully designed, based on attentive readings of travellers' depictions of distant architecture, and that they were in fact princely gardens that resonated with the political views and aspirations of their royal patron, Frederick, the Prince of Wales, and his family. Avcioğlu suggests that existing scholarship downplays the impact of Turkish culture on Europe during the period, dismissing exoticism as being "culturally inconsequential." 24 She underlines that cultures are dynamic and that the art and architecture of European states, such as, for example, Britain and France, have always been shaped by different cultures. As stated by Avcioğlu, "It is time to acknowledge eighteenth-century 'exoticism' on its own terms" ${ }^{25}$ with an attempt to "comprehend the intellectual, cultural and political momentum by which it came into being."26

Avcioğlu points out the political connotations of many of the buildings constructed in the Vauxhall and Kew Gardens. While the London entrepreneur Jonathan Tyres leased and managed the grounds of the Vauxhall Gardens, Frederick was the landlord of the grounds and took an active interest in the project. Frederick was in a position of succession to the British throne, and Avcioğlu notes the royal iconography of,

${ }^{23}$ Avcioğlu 142.

${ }^{24}$ Ibid. 4.

${ }^{25}$ Ibid. 174.

26 Ibid. 
for example, the Turkish Tent. The Ottoman kiosk was "a metonym of the Turkish palace" ${ }^{27}$ and a symbol of "royal sociability." ${ }^{28}$ The price of admission to the Vauxhall Gardens was kept to a minimum, and the princely project of a public garden suggested "the possibility of an interconnection between a future monarch and 'ordinary' people." 29

Although Frederick died before the completion of the construction of Kew Gardens, his vision for the Gardens was continued by his wife, Augusta. The plan of Kew Gardens corresponds to a hopeful period with respect to Frederick's future influence in improving the political situation in Britain, following the considerable amount of dissatisfaction with the government of Walpole during the reign of Frederick's father, King George II. Avcioğlu argues that the inclusion of the Turkish Mosque among the buildings of the Kew Gardens symbolizes Frederick's view of religious tolerance. In addition, the Temple of Bellona, the Roman goddess of war, and the Temple of Victory reflect British optimism following successes during the Seven Years' War with France. MacKenzie notes that instances of imitation of the architecture of the East could at times be "wildly syncretic," ${ }^{30}$ with elements from different areas of the East being at times freely combined, for example, among the structures within one park or even among the architectural and decorative elements of one building. At Kew Gardens, for example, buildings in Classical, Gothic, Chinese, Moorish, and Ottoman styles were all found around the periphery of the Gardens. Scholars have noted that the use of architectural styles of various cultures reflects the increasingly global view of Britain at the time. Interestingly, no buildings in the styles of architecture found in India were found among

${ }^{27}$ Ibid. 146.

${ }^{28}$ Ibid. 127.

${ }^{29}$ Ibid. 119.

${ }^{30}$ MacKenzie 76. 
the collection of styles in Kew Gardens, which could be seen as refuting the conflation of the appearance of various examples of world architecture with a simplistically imperialist vision. Avcioğlu notes that travellers often described scenes in the Near East in which Classical ruins stood near Ottoman buildings and notes that "to find the Turkish Mosque at Kew in the vicinity of a Greek temple or a Roman aqueduct" ${ }^{31}$ is not totally a matter of "fictive fabrication." 32 Above all, however, the juxtaposition of various distant architectural styles implies a recognition of the commensurability of architectural achievement among different cultures. Chambers "was preoccupied with the ideas of the universal validity of architecture as a sign of civilization.",33 Within his view of "the relative worth of foreign architecture," ${ }^{34}$ the project at Kew was "legitimate in architectural terms. ${ }^{, 35}$ In the painting Composition: Hindu and Moslem Architecture, 1799, Thomas Daniell's placement of depictions of a Hindu temple and the Taj Mahal within the same scene may similarly suggest recognition of the commensurable architectural achievement of the two cultures of the Indian subcontinent.

\section{Classical Reference and Historical Allusion}

One of the sites included in Frederick's plan did not end up being completed: the project of Mount Parnassus was to include a pairing of portrait busts of ancients and moderns, with each pairing being symbolic of attributes of excellence in different fields. Classical references were similarly a common convention in painting of the late

\footnotetext{
${ }^{31}$ Avcioğlu 168.

32 Ibid.

33 Ibid. 163.

${ }^{34}$ Ibid. 151.

${ }^{35}$ Ibid.
} 
eighteenth century. As well as their persistence as standards of artistic beauty in European culture, Classical references were often used to add a sense of the timeless and heroic to the subject being depicted. As discussed by Beth Fowkes Tobin, Sir Joshua Reynolds often included references to Classical sculpture through the poses of the subjects of his portraiture, including the flowing clothes of ancient Greece and Rome. Reynolds used these references as "a form of citation" $" 36$ that would lend dignity to the portrait and its subject. Tobin suggests that the nationalist narrative of Britain's growing empire played a part in Reynolds's use of Classical references that evoke the "empire building and military conquests of Greece and Rome. ${ }^{, 37}$

At the same time, the inclusion of exotic elements in paintings with settings in distant societies performed a distancing effect in itself. Tobin discusses "the distancing effect requisite for the heroic," 38 noting Edgar Wind's suggestion that "distance lends dignity",39 and his reference to Racine's comment that "[d]istance of country compensates in some sort for nearness of time: for people do not distinguish between that which is ... a thousand years, and that which is a thousand miles away from them." ${ }^{40}$ Tobin points out that multiple dimensions of time and place were common in depictions of distant societies during the period and discusses the "erasure of temporal and spatial differences ${ }^{\text {} 41}$ that may to some extent result. Classical references are found in Hodges's works, and it is possible that in attempting to depict the grandeur of ancient Hindu and of Mughal culture, Hodges included those references as a way of suggesting a level of

\footnotetext{
${ }^{36}$ Tobin 209.

${ }^{37}$ Ibid. 218.

38 Ibid. 221.

${ }^{39}$ Ibid.

${ }^{40}$ Ibid.

${ }^{41}$ Ibid. 217.
} 
advancement of civilizations in India that was comparable to that of civilizations that were viewed as being part of the Classical heritage of European cultures. Phillips discusses the manipulations of many types of distance in historical representation, and Hodges may have referred to ancient Greece and Rome in order to bring India's cultures into a more understandable sphere for Europeans. Styles of architecture and dress, religious icons, and even the plant life appearing in paintings of exotic locations comprised signifiers of cultures and climates very different from Europe, and along with news of different languages, literary heritage, systems of belief, and social structures, Europeans were aware of their great cultural distance from many regions of the globe.

As we have seen, some scholars attempted to show links between the ancient cultures of Europe and India that arose from the movement of peoples or from contact through trade. William Jones, for example, directed his exceptional linguistic abilities to ancient texts and suggested that similarities in language and myth reflect connections between various cultures of antiquity, and William Robertson discussed the encounters that had accompanied global commerce in ancient times. Hodges occasionally points out particular aesthetic similarities between East and West, such as with a column that he sees in Benares [Varanasi]. More often, however, Hodges suggests general similarities in appearance according to his imagination of Classical subjects, as seen, for example, in the dress of women in India:

To a painter's mind, the fine antique figures never fail to present themselves, when he observes a beautiful female form ascending these steps from the river, with wet 
drapery, which perfectly displays the whole person, and with vases on their heads, carrying water to the temples. ${ }^{42}$

Visual similarities among ancient cultures were often suggested in travellers' depictions of India and the Near East, as the views in front of travellers' eyes evoked scenes from Classical literature in their imagination. When relating their impressions of distant cultures, late eighteenth-century travellers frequently referred to texts of antiquity. References and allusions to Classical narratives appear ubiquitously as a source of comparison with respect to the ancient advancement of some Eastern cultures. Hodges clearly indicates that he appreciates the achievements of remote cultures and does not agree that the works of ancient Greece and Rome should be considered universal standards:

That the Grecian Architecture comprises all that is excellent in the art, I cannot help considering as a doctrine, which is in itself as erroneous and servile, as in its consequences it is destructive of every hope of improvement. Architecture undoubtedly should, and must be adapted, to all the climates and countries which mankind inhabit, and is variously, more than any other art, influenced and modified by the nature of the climate and materials, as well as by the habits and pursuits of the inhabitants ... why should we admire it [Classical architecture] in an exclusive manner; or blind to the majesty, boldness, and magnificence of the Egyptian, Hindoo, Moorish, and Gothic, as admirable wonders of architecture, unmercifully blame and despise them, because they are more various in their forms, and not reducible to the precise rules of the Greek hut, prototype, and column? or because in smaller parts,

\footnotetext{
${ }^{42}$ Hodges 33.
} 
perhaps accidentally familiar, their proportions are different from those to which we are become familiar by habit. ${ }^{43}$

Hodges displays the openness to Indian culture that was common with late eighteenthcentury travellers to remote regions.

As seen in the works of Richard Wilson, landscape paintings of the period often presented evocations of the past, whether of antiquity or of relatively recent centuries. In Caenarfon Castle, c. 1745, for example, Wilson removed contemporary elements from the view. Even though Caenarfon was at the time a thriving town with a busy port, Wilson's painting depicts the castle as a ruin in a tranquil setting, underlining the presence of the history of past centuries in the contemporary landscape. At other times, Wilson added antiquities to contemporary views, as with the fragments of Classical sculpture included in Rome from the Villa Madama, 1753. In picturesque landscapes of India and the Near East, artists similarly adjusted the vistas they were seeing, adding trees and ruins and re-arranging aspects of the view. With the inclusion of ruins in the serene pastoral landscape Tomb and distant View of the Rajmahal Hills, 1781, for example, Hodges's painting echoes the Arcadian themes evoked in works of the seventeenthcentury masters Claude Lorrain and Nicolas Poussin. John MacKenzie suggests that in reaction to the rapid change occurring in European societies with increasing industrialization, artists often evoked a sense of timelessness in visual representations of the East. Depictions of scenes in the East could offer a sort of "history painting in a

\footnotetext{
${ }^{43}$ Ibid. 64.
} 
modern setting," ${ }^{44}$ with elements of the hunt and horsemanship, for example, evoking ideas of medieval chivalry.

During the late eighteenth century, historical narratives and ideas were suggested in visual representations as well as in the prose descriptions of landscapes, architecture, and scenes of life that were a staple of travellers' written accounts. Depictions of place and historical meditation were commonly intertwined.

\section{Modes of Seeing: Aesthetic Categories and Depictions of Place}

John MacKenzie notes that many of the artists who depicted distant regions of the globe "were topographical, architectural or taxonomic artists, illustrating landscape, exotic structures, and botanical or zoological specimens."45 Often amateurs, these artists worked in "a tradition of scientific draughtsmanship"

colouring. " 47 Francis Swain Ward, for example, pursued a military career with the East India Company and produced topographical paintings such as Mausoleum at Outatori near Trichinopoly, c. 1788. A few decades later, Colonel Robert Smith served as a military engineer, and his painting The Kila Kona Masjid, Purana Qila, Delhi, 1823, exhibits the continuation of a topographical quality in depictions of architecture of the subcontinent. Romita Ray notes that military officials often saw landscapes not seen by many Europeans in India. Visual representations of landscapes were "integral to civil engineering projects and military surveillance, with military officials preferring sketches

\footnotetext{
${ }^{44}$ MacKenzie 58.

${ }^{45}$ Ibid. 52.

${ }^{46}$ Ibid.

${ }^{47}$ Ibid.
} 
to written reports as more accurate and revealing records." 48 She notes that in the curricula at military colleges during the period, the "mastery of watercolour techniques"49 was taught along with the skills of "precision-oriented draughtsmanship."50

The popularity among the British aristocracy of commissioning visual representations of their country estates contributed to the British tradition of draughtsmanship and landscape painting. The genre of 'house-portraits' emerged in the late seventeenth century, with paintings depicting a bird's-eye view of the entire estate (a point of view that interestingly has some affinity with the depictions of Mughal and Hindu palaces and their grounds by artists of India). The painting Wollaton Hall and Park, Nottinghamshire, 1697, by Jan Siberechts, for example, includes a great amount of detailed information about the estate, including the depiction of the four parterres with rows of small citrus trees in pots, the greenhouse, the area of lawn for sport and exercise, the kitchen garden, and even the area to lay out laundry to dry and bleach in the sun.

During his training at the Royal Academy, Thomas Daniell had studied the engravings of Andrea Palladio, the Italian Renaissance architect, as well as of the contemporary Roman architect Giovanni Piranesi. The engravings of these architects offered accurate and detailed depictions of buildings, exemplifying "the verisimilitude that was conventional" ${ }^{\prime 51}$ in engravings depicting architecture. In Britain, Thomas specialized in the branch of landscape painting that depicted country estates and their surroundings. Thomas and his nephew William Daniell produced many visual representations of landscape and architecture during their travels in India from 1786 until

\footnotetext{
${ }^{48}$ Ray 10.

${ }^{49}$ Ibid.

50 Ibid.

${ }^{51}$ Almeida and Gilpin 183.
} 
1794. In Thomas's painting Jami Masjid, Delhi, 1811, for example, much architectural information is provided with respect to the famous mosque. Indeed, as pointed out by Almeida and Gilpin, on their journeys through India the Daniells carried with them tools typically used by British cartographers in order to ensure a high level of accuracy in their representations. While Hodges had produced free-hand, on-site sketches when encountering a view, the Daniells first recorded some of the specifics of the landscape using a camera obscura. In addition, they used a perambulator to acquire measures of distance that were helpful in improving the accuracy of their depictions of a view. The Daniells were highly praised by many contemporaries for the precision and reliability of their representations. They were the first British artists to travel to the foothills of the Himalayas and the source of the Ganges River, and James Rennell later used some of their sketches to make some corrections with respect to that region in his work Memoir of a map of Hindoostan for the third edition published in 1793.

New aesthetic approaches of the late eighteenth century increasingly influenced visual representations of architecture and landscape. The innovative approaches of Richard Wilson in visual representations of landed estates are seen in his painting Tabley House, Cheshire, ca. 1764-1765, in which the house appears at the left in the depiction of the surrounding countryside. The composition of the painting Malvern House, Warwickshire, ca. 1820, by John Constable, one of the most influential landscape painters of the following decades, echoes Wilson's transformation of the house portrait. Indeed, as discussed by Robin Simon, "European landscape painting was transformed in the second half of the eighteenth century," 52 and Wilson "was at the heart of this

\footnotetext{
${ }^{52}$ Simon 1.
} 
transformation. ${ }^{, 53}$ Earlier landscape representations included either relatively mechanical topographical depictions or 'invented' compositions considered more worthy of creative artists. Wilson's “most significant and original achievement lay in his powerful interpretations of specific locations, ${ }^{" 54}$ producing landscape paintings that were "devoted to the accurate and emotive depiction of the natural world." 55 Wilson was "unusually specific about local conditions, ${ }^{, 56}$ depicting the light and atmospheric conditions seen in locations at a specific hour of the day, and his legacy in this respect is seen in the later works of Turner, Constable, and French Impressionism. In his painting Holt Bridge on the River Dee, ca. 1761-62, for example, Wilson "actually tells us about the weather as it might be in that place at a particular time of day."

Wilson had relatives in the north of Wales with whom he sometimes stayed following the time he spent in Italy, and he "discovered new vistas that changed the priorities and possibilities of landscape painting - and, by extension, recreational travel forever." ${ }^{, 58}$ With paintings such as Snowdon from Llyn Nantille, ca. 1765-67, Wilson's work contributed to a new "aesthetic appreciation of those wilder parts of the natural world that hitherto had been ignored.. ${ }^{, 59}$

Attitudes of the time in relation to nature must be taken into consideration when analyzing the aesthetic approaches employed in travellers' depictions of place during the late eighteenth century. Global exploration had intensified an interest in natural history,

${ }^{53}$ Ibid.

${ }^{54}$ Ibid. 12.

${ }_{56}^{55}$ Ibid.

${ }^{56}$ Ibid.

${ }^{57}$ Ibid. 30 .

${ }^{58}$ Ibid. 26.

${ }^{59}$ Ibid. 24. 
and the geological formations, plants, and animals existing in various climates and regions were endlessly classified and noted. The development of the scientific method was put to use in the observation, cultivation and plundering of nature. ${ }^{60}$ At the same time, many writers responded to this flurry of the activity of coldly studying the material aspects of the natural world with a renewed appreciation of the aesthetic and mystical aspects of the natural wonders in front of their eyes. The investigation of nature according to rules of rationality was often replaced by the depiction of its power to affect the sensibility of the observer. Landscapes and sites were described using the aesthetic terms of the sublime, the beautiful, and the picturesque, which acquired relatively specific and differentiated meaning and were summoned ubiquitously in late eighteenthcentury representations of various subjects. The emotional responses associated with particular aesthetic categories were frequently extended to states of metaphysical contemplation, and entities constructed by man rather than nature, such as architecture, Milton's poetry, or realms of philosophical thought, were also described using these terms. Late eighteenth-century aesthetic categories became a standard trope in travellers' representations as well as in writing of other genres during the period.

Indeed, travel played a central role in the development of the various aesthetic categories within late eighteenth-century aesthetic theory. In A Philosophical Enquiry into the Origin of our Ideas of the Sublime and Beautiful, Edmund Burke proposes an aesthetic categorization according to the differing sets of responses typically invoked in observers of a subject. Burke defines the sublime as involving reactions of awe or terror, as invoked by a subject of great magnificence or possible danger, and he defines the

\footnotetext{
${ }^{60}$ See, for example, Beth Fowkes Tobin, Colonizing Nature: The Tropics in British Arts and Letters, 1760-1820. Philadelphia: University of Pennsylvania Press, 2005.
} 
beautiful as involving the gentle and soothing effect of viewing subjects that seem pleasing and non-threatening. The relationship of reciprocal reference that is found between conjectural history and travellers' depictions of distant societies during the period is similarly found between late eighteenth-century aesthetic theory and travellers' representations of landscapes, architecture, and other subjects that they encountered along their journeys. While the beautiful was associated with pastoral landscapes, the sublime was associated with views of mountains, ominous and dark skies, and monumental architecture or ruins. Artists travelled to some of the more wild areas of the British Isles and to the Alps in continental Europe with these aesthetic categories in mind.

In her novel The Italian, Ann Radcliffe describes the reactions of her heroine who in her captivity finds a room with a view, in this case of mountains:

To Ellena, whose mind was capable of being highly elevated, or sweetly soothed, by scenes of nature, the discovery of this little turret was an important circumstance. Hither she could come, and her soul, refreshed by the views it afforded, would acquire strength to bear her, with equanimity, through the persecutions that might await her. Here, gazing upon the stupendous imagery around her, looking, as it were, beyond the awful veil which obscures the features of the Deity, and conceals Him from the eyes of his creatures; dwelling as with a present God in the midst of his sublime works; with a mind thus elevated, how insignificant would appear to her the transactions and the sufferings of this world! ${ }^{61}$

Wollstonecraft continually describes the landscapes of Scandinavia in terms of late eighteenth-century aesthetic categories, including countless sublime views of "wild

\footnotetext{
${ }^{61}$ Radcliffe 106.
} 
grandeur" ${ }^{\prime 2}$ and the "peaceful composure" of picturesque bays. The feelings inspired by views of landscape are a central component of Wollstonecraft's depictions; she writes, "Nature is the nurse of sentiment."

References to the sublime are found in Hodges's written account of his travels in India, and sometimes in connection with objects of view that would be new to most British readers. Hodges travelled under military escort due to the conflicts of the time between the British and Mughal rulers in the north of India, and in watching the movement of the army he writes:

To these I may add the majestic movements of the elephants; not only of those which carried the great men, but of those with the heavy baggage. The appearance, indeed, of the whole army, with the camels, artillery and baggage cattle, formed a scene highly gratifying to the mind, entirely new to a European, of singular variety, and even sublime. ${ }^{64}$

The aesthetic of the sublime is found even more commonly in Hodges's paintings. In Mrs Hastings near the Rocks of Colgong, 1790, for example, Hodges depicts a particularly dangerous passage in the three-day trip along the Ganges made by Hasting's wife in order to be with him when he was ill. The submerged rocks and rapids of this point in the immense river are described in Hodges's text, and the painting suggests the fear of those on the boat. With this subject matter and the effects of light with the dramatic sky, the painting closely fits the European aesthetic of the sublime. The sublime is also found in some of Hodges's depictions of Mughal ruins. In this case, however, the

\footnotetext{
${ }^{62}$ Wollstonecraft 27.

${ }^{63}$ Ibid. 35.

${ }^{64}$ Hodges 130 .
} 
aesthetics of the sublime evoke complex ruminations on the transience of empire. The appearance of the sublime in Hodges's works exemplifies the expansion of subject matter within European aesthetic categories that was occurring with travellers' representations of distant societies during the late eighteenth century.

Almeida and Gilpin suggest that connotations of the aesthetic of the sublime became increasingly threatening in Britain within the political climate accompanying events such as the French Revolution. Along with the association of the aesthetic with sites such as the Alps of the European continent, a wish for reason and order decreased the appeal of the type of feelings evoked by the sublime with its association of "spectacular, overwhelming, and transporting experiences." ${ }^{.65}$ Indeed, in 1790, "at a moment of great public anxiety" ${ }^{\prime 66}$ in Britain, the aesthetic of the sublime was renounced by Joshua Reynolds. In any case, the aesthetic of the picturesque increasingly took centre stage as the "visual framework of choice" ${ }^{\natural 7}$ in travellers" representations.

In his Observations of the River Wye, William Gilpin presents a unique and single-minded framework through which a traveller may observe and represent the region she or he is visiting. Gilpin's text is in the form of a written account of his journey along the Wye River and is illustrated with his sketches. Gilpin is solely interested in the scenes offered by nature, and particularly in their relation to the aesthetics of landscape painting. He includes basically no comments regarding the aspects of social life that he must necessarily have witnessed in the Wye Valley, and he mentions almost nothing of historical interest regarding any of the sites on his route. As stated by Phillips, Gilpin's

\footnotetext{
${ }^{65}$ Almeida and Gilpin 190.

${ }^{66}$ Ibid. 189.

${ }^{67}$ Ray 4.
} 
work reveals "no desire to fuse historical memory and visual impression to evoke the unique experience of place ... In short, picturesque beauty and historical interest remain separate categories." ${ }^{\prime 68}$ Phillips suggests that "[t]he more, in fact a ruin becomes a part of nature - the more it can be seen simply as a physical object removed from human time the freer he is to respond on his favourite aesthetic grounds. ${ }^{, 69}$ Gilpin's comments in a few passages regarding the visual effects of industry similarly exhibit that elements introduced into a scene by man have interest to Gilpin only in terms of their effect on the picturesque scenes offered by nature.

Rather, Gilpin defines an aesthetic notion of the picturesque, a category that could be added to Burke's definitions of the sublime and the beautiful and that was to become extremely influential in textual and visual representations. Gilpin's definition of the picturesque, in its most simple terms, is what would be suited to a painting. This definition is more fully elaborated in his text as he comments on technical matters of, for example, placement within the range from foreground to background, detail, and colour. He reveres nature as the master designer and archetype of all visual representation, and yet he continually shows what would need to be adjusted in nature's vistas to make a better painting. He also includes some intriguing passages in which he assesses literary depictions of settings using the same principles. In a critique of John Dyer's poetic description of "Dinevawr" [Dinefwr or Dynevor] Castle, Gilpin writes:

his distances, I observed, are all in confusion; and it is not easy to separate them from his foreground ... Transgressions of this kind are common in descriptive poetry. Innumerable instances might be collected from much better poems, than Grongar-hill.

${ }_{69}^{68}$ Society and Sentiment 334.

${ }^{69}$ Ibid. 335. 
But I mention only the inaccuracies of an author, who, as a painter, should at least have observed the most obvious principles of his art. - With how much more picturesque beauty does Milton introduce a distant castle $\ldots{ }^{70}$

Gilpin's accounts of his various travels in Britain resulted in a new industry of picturesque tourists with his accounts in hand. The itinerary of Gilpin's tour of the Wye Valley in 1770 included Tintern Abbey. In discussing its effect in terms of the rules of the picturesque, Gilpin suggests that in the view of the Abbey from a distance a number of gabel-ends hurt the eye with their regularity ... A mallet judiciously used (but who durst use it?) might be of service in fracturing some of them; particularly those of the cross isles, which are not only disagreeable in themselves, but confound the perspective. ${ }^{71}$

Tintern Abbey was to reappear in later representations. As portrayals of the sublime acquired even greater overtones in both literature and the visual arts, the ruin inspired William Wordsworth's reflections on phases of his life and was luminously depicted in paintings by J.M.W. Turner.

While rapidly gaining prevalence during the last decades of the eighteenth century following the publication of Gilpin's text, the development of the aesthetic approach of the picturesque in Britain had begun earlier in the century. Works of painters, such as Thomas Gainsborough and Richard Wilson, showed the influence of the seventeenthcentury artists Claude Lorrain, Salvator Rosa, and Gaspard Dughet (Poussin), as well as Dutch painters such as Jacob van Ruisdael. Gaspard Dughet, who was the brother of the wife of the painter Nicolas Poussin and was often referred to as Poussin, devoted himself

\footnotetext{
${ }^{70}$ Gilpin 60 .

${ }^{71}$ Ibid. 33.
} 
to landscape painting, in particular of the countryside around Rome. Nicolas Poussin produced mostly history paintings, which sometimes have a landscape element. Nicolas's two paintings with the title Et in Arcadia ego, depicting shepherds around a tomb, are also referenced by some of Hodges's paintings, with Mughal ruins in pastoral scenes, as well as a funeral bier in the background of 'Tahiti Revisited', 1776. However, the aesthetic of the picturesque was more significantly influenced by Gaspard.

The writing of aesthetic theorists propagated notions of the picturesque in its application to landscape gardening. As stated by E.H. Gombrich, Claude selected only such motifs as he considered worthy of a place in a dreamlike vision of the past, and he dipped it all in a golden light or a silvery air which appear to transfigure the whole scene. . . for nearly a century after his death travellers used to judge a piece of real scenery according to his standards . . Rich Englishmen went even further and decided to model the pieces of nature they called their own, the gardens of their estates, on Claude's dreams of beauty. ${ }^{72}$

Claude's influence on Hodges is suggested by some general similarities in composition between, for example, Hodges's Tomb and distant View of the Rajmahal Hills, 1781, and Claude's Landscape with sacrifice to Apollo, 1662-3. Both works offer "a nostalgic vision of a land of serene beauty,"73 with distant hills in shimmering light, one tree sloping darkly across the pastoral scene, ruins, and small figures in the foreground. However, while Claude's painting evokes life as it may have been in Rome's ancient past, Hodges's painting depicts a scene in which evidence of past glory forms part of the contemporary landscape, with a small portion of a ruin appearing at the far side of the

\footnotetext{
${ }^{72}$ Gombrich 396.

${ }^{73}$ Ibid. 419.
} 
foreground of a contemporary view in which a shepherd sits by the ruin and a flock of sheep is seen grazing in the middle ground. Hodges's paintings present new subject matter within the European aesthetic of the picturesque.

Ann Bermingham points out that relationships between man and nature involved in the aesthetics of the depiction of landscape carried political resonance during the late eighteenth century. Bermingham discusses the ways in which landscape painting, as well as landscape gardening, reflected public response to the loss of uncultivated countryside. Along with the encroachment upon agricultural land accompanying industrialization and the increasing concentration of population in urban centres, the practice of enclosure precipitated the loss of natural landscapes. Idyllic depictions of rural life appeared in both literature and painting, in which a romanticized view dims the impoverished conditions of many inhabitants of villages. In her Recollections of a Tour made in Scotland, Dorothy Wordsworth writes:

There were several woodman's huts, which, with some scattered fir trees, and others in irregular knots, that made a delicious murmuring in the wind, added greatly to the romantic effect of the scene. They were built in the form of a cone from the ground, like savages' huts, the door being just large enough for a man to enter with stooping. Straw beds were raised on logs of wood, tools lying about, and a forked bough of a tree was generally suspended from the roof in the middle to hang a kettle upon. It was a place that might have been just visited by new settlers. I thought of Ruth [the heroine of William Wordsworth's poem "Ruth"] and her dreams of romantic love. ${ }^{74}$

\footnotetext{
${ }^{74}$ Wordsworth 88.
} 
In addition, Spiro Kostof suggests that with the period being characterized by challenges to traditional institutions of authority, certain political connotations accompanied the more free and natural aesthetic of the picturesque in English gardens, which "broke the tyranny of single-minded axes, geometric paths, the clipped hedge." ${ }^{, 75}$ The picturesque employed "free and irregular forms, rough textures, indefinite rhythms, the evocative ruin, the quaint mill.."76

Burke's definition of the aesthetic category of the beautiful could be associated with scenes of pastoral beauty, as found at times in picturesque landscape representations. As is common with descriptive categorizations, they are not always distinctly separate, and elements of more than one aesthetic could be combined in one painting. Nonetheless, within the ideas of conjectural history that were pervasive during the late eighteenth century, the sublime was often used to depict both the magnificence of architectural achievement and the decline suggested by ruins, the picturesque was often used in depicting ethnographic types within a landscape, and the beautiful often evoked the pastoral stage of societies.

\section{Conjectural History in Visual Form}

The scenes that present themselves to the eyes of travellers typically offer many clues regarding the cultural history of a region, whether through architecture, iconic and religious symbols, dress, or manners and customs. The 're-presentation' of the visual aspects of a society by travelling artists similarly offers cultural and historical information to those in their societies at home. With little historical information available

\footnotetext{
${ }^{75}$ Kostof 548 .

${ }^{76}$ Ibid. 549.
} 
regarding many distant societies during the late eighteenth century, the cultural meanings of visual observations could be difficult to decipher, and conjectural history provided a more general historical framework of reference for travelling artists in their attempts to interpret what they were seeing.

The manners and customs of distant societies could be depicted by travellers through the use of the picturesque in new settings. In a picturesque representation of a landscape, details were typically included in the foreground that were thought to catch the interest of the viewer and draw the eye into the scene. Within the broad definition of what would be most pleasing in the composition of a painting, the picturesque approach generally included "a good depth of field, preferably divisible into three grounds, ... a variety of line and form, and often some intricate detail in the foreground. ${ }^{77}$ Travellers provided ethnographic information in groups of figures included in the foreground that recorded details regarding the dress of local inhabitants and common activities in their daily lives. Travellers also turned to the he aesthetic of the picturesque in written ethnographic depiction. In their written accounts, travellers at times described the appearance groups of local inhabitants as picturesque.

Tobin points out that while the aim of portraiture is to depict the individuality of the sitter, using elements of setting and objects that signify the occupations and interests of that person, ethnographic depiction, in contrast, is concerned with portraying types. Tobin suggests that within the interest during the period in classifying specimens from around the world, ethnographic depiction constituted another project of taxonomy. Emphasis in ethnographic depiction was typically placed on surface appearances, such as

${ }^{77}$ Tillotson "The Indian Picturesque" 142. 
detailed depictions of the dress of the groups of people being portrayed, as well as the activities in which those people are engaged in the painting. Ethnographic paintings could "contain elements akin to English 'genre' paintings,",78 with there being "an ethnographic quality to these images of England's working classes." ${ }^{.79}$ Influenced by seventeenth-century Dutch genre painting, British genre painting of the late eighteenth century depicted scenes of everyday life. In some cases, genre painting could involve a crossover with pastoral landscape to elevate the lives of peasants and farm workers, as seen, for example, in the painting Reapers, 1795, by George Stubbs. George Chinnery travelled to India, and produced what may be described as genre scenes of life in the subcontinent, including rural areas as seen in his painting View in Southern India, with a Warrior Outside His Hut, ca. 1815.

In providing images of remote cultures that were previously unknown to Europeans, Hodges's work was influential in developing both frameworks of European social and historical thought and genres of ethnographic representation. Hodges's encounters with societies in remote regions of the globe led to his portrayals of what were then viewed by Europeans as less advanced cultures.

Hodges often uses the term 'picturesque' in his written travel account. He sometimes describes his observations of the people of India and their activities as picturesque. In seeing some women carrying lamps to tombs, he writes that "the effect, considered in a picturesque light, is highly beautiful; with that of sentiment, it is delightful. ${ }^{, 80}$ In observing groups of people along a road, including sepoys, merchants,

\footnotetext{
${ }^{78}$ Tobin 140.

${ }^{79}$ Ibid. 142.

${ }^{80}$ Hodges 28 .
} 
people baking their bread, and "various fakirs, with a more than savage appearance,", Hodges writes,

It is extremely pleasant to observe the variety of travellers that are to be met with on the road ... On the whole, I must say, that the simplicity and primitive appearance of these groups delighted me ... Sometimes whole families may be seen travelling up and down the country, forming most beautiful picturesque groups ... These are certainly valuable subjects for the painter. ${ }^{82}$

The words used in Hodges's comments suggest his familiarity with the terms of the stadial history that was being proposed and developed at the time by thinkers of the Scottish Enlightenment.

Hodges's images of Tahiti provide insight into his engagement with the stages of development of societies being conjectured by late eighteenth-century thinkers as well as his use of the aesthetic of the picturesque to transmit his ideas in this respect. Hodges clearly shared the feeling of his companions on the voyage that they had stumbled upon a lost Arcadia, and his paintings of scenes in Tahiti offer a portrayal of idyllic existence in a lush and innocent world. Hodges's works depict pastimes that may be perceived to be accompanied with less stress and more pleasure than the occupations of residents in modern Europe. The indigenous inhabitants are depicted swimming and fishing in locations of exquisite tropical light and vegetation, as in paintings such as 'Tahiti Revisited', 1776, and A View of Matavai Bay in the Island of Otaheite [Tahiti], 1776. Hodges records the beauty of craftsmanship of the boats in Tahiti, as in, for example, his painting The War-Boats of the island of Otaheite, and the Society Islands, with a View of

\footnotetext{
${ }^{81}$ Ibid. 31.

82 Ibid.
} 
part of the Harbour of Ohameneno [Haamanino], in the island of Ulietea [Raiatea], one of the Society islands, 1777. As discussed by David Bindman, in Hodges's paintings, Tahitian societies are suggested to be peaceful, collaborative, and well functioning. Hodges's paintings seem to support the suggestion that was made by Johann Reinhold Forster, who was a naturalist on the voyage, that Tahitian societies were at a more advanced stage of development than what he would expect to find in the 'savage' societies of North America. However, the travellers also encountered societies in the South Seas that they saw as being at a less developed stage of civilization. The Malakulans, for example, were perceived to be less advanced, as seems to be reflected in Hodges's painting Landing at Mallicolo [Malakula], one of the New Hebrides, c. 1776.

Hodges's depictions of the inhabitants of the South Seas sometimes carry Classical allusions. The depiction of the physical condition of individuals in paintings during the late eighteenth century could suggest not only the effects of climate on the characteristics of different cultures, which, as we have seen, were much debated during the period, but also the relative health of individuals. William Hogarth, for example, suggests the harmful effects on individuals of an excessive consumption of gin in his print Gin Lane, 1751. The Classical beauty of the human form, as seen in Hodges's depictions of the inhabitants of the South Seas, at times suggested the beneficial effects of warm climates as well as the absence of the acquisition of the vices of excessive luxury that attend commercialized societies.

The figures in Hodges's landscape paintings are typically too small for the depiction of individuality; in attempting to portray types, the people in Hodges's paintings are often in groups, and what is most noticeable is their dress and the activities 
in which they are involved. As stated by Bindman, landscape paintings depict not specific events, as seen in the genre of history painting, but rather "the continuum of daily life, ${ }^{, 83}$ and Hodges's figures appear as a natural part of the landscape. In Hodges's works, the genre of landscape painting is extended through the exotic locations and the ethnographic information being provided.

With his visual representations of India, Hodges continued the approaches that he had begun to develop during his voyage in the South Seas in which he produced his first works portraying remote cultures. Hodges's painting A Group of Temples at Deogarh, Santal Parganas, Bihar, 1782, exemplifies the ethnographic depiction that is found in many of his paintings of architectural sites in India. In the painting, the dress and activities of the groups of people around the Hindu temples are a significant aspect of the work. Figures in Hodges's landscape paintings provided information regarding customs that were typical in the cultures found in the area of the particular scene. At the same time, in India, Hodges was seeing cultures that had been highly advanced in various spheres of endeavour in earlier centuries, and the focus of most of his paintings is a structure of either Mughal of Hindu architectural significance, whether still in contemporary use or in ruin.

Hodges spent time in Calcutta when he had newly arrived in India and observed the vibrant intermingling of indigenous and British culture. He states, The mixture of European and Asiatic manners, which may be observed in Calcutta, is curious: - coaches, phaetons, single horse chaises, with the pallankeens and hackeries of the natives - the passing ceremonies of the Hindoos - the different appearances of

${ }^{83}$ Bindman 25. 
the fakirs - form a sight perhaps more novel and extraordinary than any city in the world can present to a stranger. ${ }^{84}$

In the paintings View of Calcutta from Garden House Road, c. 1781, and Natives drawing Water from Pond with Warren Hastings' House at Alipur [just south of Calcutta] in the Distance, 1781, for example, Hodges suggests a juxtaposition of ancient and modern, reflecting the ideas of stadial theory through the depiction of the supposedly differing stages of development found among the cultures of the city. Within the same view, Hodges depicts the neo-Classical architecture of newly constructed buildings and British ships in the harbour, suggesting the expanding commerce of a modern stage of economic development, and the simple huts and customs of the indigenous people. As suggested by Natasha Eaton, Hodges portrays not the 'Other' but rather the juxtaposition of two different stages of civilization.

Thomas and William Daniell also began their sojourn in India with time spent in Calcutta. Over a two-year period, Thomas produced the twelve aquatints Views of Calcutta. During this time, the changes occurring following the appointment of Governor General Cornwallis became increasingly noticeable, and in the last few aquatints of the series, Thomas places the focus on 'British Calcutta.' However, in the earlier aquatints, Thomas depicts the vibrant diversity of street life in Calcutta with its intermingling of cultures. As in Hodges's representations of Calcutta, the contrast between old and new is depicted in Thomas's works. In the aquatints The Old Fort Ghaut, 1787, and The New Buildings at Chouringhee, 1787, for example, Thomas depicts British architecture and ships indicating modern, commercial advancement along with the

\footnotetext{
${ }^{84}$ Hodges 16.
} 
traditional ways of life of local inhabitants, with the busy activities along roads depicting the mix of cultures involved in the functioning of the thriving metropolis.

Romita Ray points out the different focus in representations of Benares [Varanasi]. Instead of the diversity of Calcutta, the ancient cultures of the subcontinent were emphasized in depictions of Benares. Ray notes that not only was Benares considered the most holy site of pilgrimage in Hindu culture, the Ganges River was "a vital artery that facilitated the movement of a wide variety of commodities between the old market towns and bazaars dotting the plains through which it flowed." ${ }^{„ 85}$ There had in fact been a steady increase in the number of Europeans in the area, who were living just outside the centre of Benares, but it was the famous shoreline of the city that was depicted instead of the increasing interaction of cultures in the area. In the painting The Ghats of Benares, 1787, for example, Hodges depicts figures at the water's edge carrying out traditional activities at the ghats near a temple. In the painting $A$ View of Benares, 1781, Hodges depicts a seventeenth-century mosque, which was considered to be symbolic of Mughal incursions into the sacred city of Hindu culture. George Forster relates that the mosque was said to be "erected by the order of Aurungzebe, on the foundation of an ancient Hindoo temple" as a disgraceful record of a foreign yoke. ${ }^{87}$ Ray points out that in Hodges's painting the mosque appears older than it was at the time, exemplifying a key strategy of the picturesque "to convey a significant passage of time." 88

\footnotetext{
${ }^{85}$ Ray 29.

${ }^{86}$ Forster 4.

${ }^{87}$ Ibid. 5.

${ }^{88}$ Ibid. 33.
} 
Emily Eden's letters describing her extensive travels in the north of India reveal the central role of visual impression in travellers' perceptions of distant societies as well as the great interest of some travellers in recording their impressions through the production of visual representations. While Eden's journey took place in the first decades of the nineteenth century, the aesthetic framework of her textual descriptions as well as her sketches and paintings is clearly rooted in the ideas of the picturesque that took form during the late eighteenth century. Eden's letters indicate that sketching was a continual activity for her throughout her journey. Her comments reveal her artistic tendencies; she writes, "I love hills, but I have discovered by deep reflection that we are such artificial animals, that the recollections of art are much more pleasing and stronger in my mind than those of nature. ${ }^{~} 89$ While Eden at times notes the beauty of various buildings that she sees, one of her greatest interests is in the costumes and appearances of various groups of people in India. Rather than landscape, it is the picturesque aspect of groups of people in themselves that continually draws Eden's attention. In attending a military review she observes "thousands of Runjeet's followers all dressed in yellow or red satin, with quantities of their led horses trapped in gold and silver tissues, and all of them sparkling with jewels . . I really never saw so dazzling a sight." ${ }^{90}$ She praises the military skills of the Sikhs, stating, "It is a sad blow to our vanities!"91 She notes that "[t]he sun was up and shining on them [the cavalry], and I suppose there was not one who would not have made the fortune of a painter." ${ }^{92}$ She describes what strikes her as the extraordinary appearance of a group of Afghans whom she encounters in Lahore: "He

\footnotetext{
${ }^{89}$ Eden 146.

${ }^{90}$ Ibid. 205.

${ }^{91}$ Ibid. 209.

92 Ibid. 213.
} 
and his sons and followers were rather picturesque, with their enormous coarse turbans and cloth gaberdines, and great jack-boots, amongst all those jewelled Sikhs.",93

Nigel Leask discusses various relationships of the picturesque to visual representations of India, and of these, he notes a self-protective distancing effect that was often effected by a picturesque view. In discussing Emma Robert's literary depictions of India, for example, Leask writes, "The achievement of picturesque distance . . is illustrated in her 'birds-eye view' of Benares [Varanasi]: looking down at the bustling city from a minaret, 'the hum of the busy multitude below is scarcely heard'."94 Eden's extremely visual approach in recording her observations on a journey that was physically difficult and at times dangerous may at times be a chosen method of coping. For example, at one point she describes the alarming violence and plundering habitually carried out by a group of people close by, and then she abruptly ends the paragraph with the sentence, "They are very picturesque."

Romita Ray similarly suggests that travellers turned to familiar aesthetic frameworks in an attempt to stabilize the disorientation involved in their encounters with distant cultures. Travellers' experiences could include not only visual delight but also troubling experiences and observations. Ray notes that the creation of picturesque representations often occurred within "risky engagements with one's surroundings,",96 involving observations that could seem incomprehensible and that had the "capacity to

\footnotetext{
93 Ibid. 224.

${ }^{94}$ Leask 225.

${ }^{95}$ Eden 230.

${ }^{96}$ Ray 6.
} 
unsettle emotions. ${ }^{.97}$ Ray underlines the physical presence of the traveller in the experience, stating that

any study of the picturesque has to be released from the tight polarities of centermetropole, and relocated instead in the horizons it shored up for view, with the colonial spectator as an active participant in the rhythms of local life, not some detached viewer sequestered away with pots of paint, sketchbooks, and paintbrushes. $^{98}$

The mobility of the traveller was central in the "fluid optical experience" captured through the aesthetic of the picturesque, in encounters with endless variation of views in different regions of the globe. Ray suggests that while framed within a traditional European aesthetic of landscape painting, picturesque representations "were outstanding in the freshness of their observations." 100

\section{Perceptions of Decline: Musings regarding the Patterns of History}

Thinkers of the Scottish Enlightenment were as interested in the decline of civilizations as in their development. Travellers encountered architectural ruins of the ancient cultures of regions of the Near East and India and similarly pondered the cycles of civilizations.

John Logan discusses some of the cultures that were influential before the period in which the Grecian states extended their power:

\footnotetext{
97 Ibid.

${ }^{98}$ Ibid. 7.

${ }^{99}$ Ibid. 4.

${ }^{100}$ Ibid.
} 
The Egyptians were the first civilized people of the world. The banks of the Nile gave birth to the arts and sciences. Here the first efforts of genius were disclosed, and specimens exhibited in the arts, which the Greeks were to admire, and to perfect into models for mankind. The wisdom of the Egyptians was the admiration of all antiquity. Their institutions, laws, and religious rites, passed into Greece. ${ }^{101}$

The flourishing of the arts in ancient Greece was considered by Logan to be an important element of the development of societies:

It was reserved to Greece to strike out elegant forms, and introduce refinement and taste. From this native country of the Muses, the strain of literature, both in ancient and modern times, is derived. The Greeks set the first example of perfection in the arts. $^{102}$

Logan attempts to explain not only the development but also the downfalls of the ancient cultures of Greece and Rome, and he points to the tyranny and indolence that contributed to the decline of Roman societies.

Ruins of antiquity inspire Eyles Irwin to similarly eulogize the achievements of ancient Egyptian culture: "The parent of science! The nurse of heroes! And the monument, alas! Of decayed greatness! Too severe, O Egypt! Has been thy lot; too severe an example dost thou afford of the instability of human glory." 103 Irwin suggests that aside from spoken eloquence, the cultures of late eighteenth-century Arabia and Egypt exhibited a diminished interest in literary pursuits:

\footnotetext{
${ }^{101}$ Elements 29.

102 Ibid. 89.

${ }^{103}$ Irwin 120.
} 
Books are entirely neglected by them, except those of a religious turn; and which are more calculated to infuse the gloom of superstition into the mind of a Musselman, than to afford amusement. Poetry itself, which seems to have sprung from the pastoral regions of Arabia, is no longer courted nor acknowledged by this degenerate race. ${ }^{104}$

The ruins of villages and ancient monuments caused travellers to speculate regarding the patterns of prosperity and decline commonly affecting societies. Irwin notes that several once flourishing towns in Egypt had fallen into a ruinous state due to either their diminishing importance in routes of trade or the thievery of local desert tribes. He records that on the route to Ghinnah, "we passed by the ruins of a large village, which our guides tell us has long been abandoned, on account of robbers, who were continually plundering the property of the inhabitants." 105 With travellers in Egypt often "painting a melancholy picture of oppression and poverty," ${ }^{106}$ the Ottoman Empire was perceived by many late eighteenth-century writers as being in decline. In Cosire, Irwin writes, "as the power of the Turks began to decline in these parts, commerce failed apace; the inhabitants of this populous city removed by degrees to the more fertile banks of the Nile, and have left it a prey to poverty and desolation." ${ }^{\prime 107}$ In Constantinople, Lady Elizabeth Craven writes that the Sultan is "totally unable to quell the interested little intrigues of his ministers, and direct the interior policy of his cabinet or empire ... The body of

\footnotetext{
${ }^{104}$ Irwin 124.

105 Ibid. 176.

${ }^{106}$ Marshall 166.

${ }^{107}$ Irwin 138.
} 
Janissaries sometimes make a revolt - several governors of provinces or Pashas have revolted at one time.",108

Some recent scholars have raised questions relating to the characteristics and time frames of the decline of the Ottoman Empire, arguing that within general discussions by European writers during certain periods regarding decline in cultures in the East, the continuing power and influence of the Ottoman Empire was not acknowledged. Scholars point out, for example, that just as revolts were taking place in regions under Ottoman control, such as Egypt, revolts were at the same time occurring in Britain's colonies on the Atlantic seaboard. It must be noted, however, that not only did Britain indeed lose its colonies in the United States following the American Revolution, but that the British Empire as a whole was nonetheless in a phase of early expansion due to its increasing involvement in India. Indications of the decline of the Mughal Empire by the late eighteenth century are perhaps less in question. While still holding much power in India, regional Mughal rulers were in conflict with each other, and the British formed alliances with various Mughal sultans as well as Hindu rajahs as the East India Company became more involved in the changing political dynamics of the subcontinent.

Scholars also point out that the production of Oriental carpets, finely woven shawls, and embroidered textiles continued during the late eighteenth century. It must be noted, however, that these exquisite products of the material culture of the East were typically produced through demanding personal labour. Similarly, outstanding examples of Classical and Oriental architecture had often been accomplished through the labour of the most poor segments of society. Adam Ferguson notes that "[i]n the midst of our

${ }^{108}$ Craven 240. 
encomiums bestowed on the Greeks and the Romans, ${ }^{, 109}$ it is not always remembered that the advancements of Classical antiquity were accomplished by slaves within societies of extreme inequity. In any case, regardless of the extent to which inequalities within various cultures of antiquity and of the East were discussed, observations of the seemingly increasingly impoverished social conditions among local populations in various regions of the Near East and India were typically interpreted by late eighteenthcentury writers as evidence of a decline from earlier heights of achievement and levels of prosperity.

In late eighteenth-century writing, attempts to explain what was viewed as a decline or a lack of advancement in some aspects of societies of the Near East and India are found along with acknowledgements of the achievement that was evident in other aspects of those societies. During the period of the Scottish Enlightenment, the Islamic world under control of the Ottoman and Mughal Empires stretched from the shores of the Atlantic Ocean in Morocco, through North Africa and the Near East, to southwest Asia. Many European writers acknowledged earlier achievements of Islamic societies. Muslim scholars of the Near East were recognized as having been more advanced in many fields, such as mathematics and science, in earlier centuries than their European counterparts, with many Classical texts having been translated into Arabic long before they were accessible in Europe. With Britain's growing involvement in India, the Mughal Empire was of great interest during the late eighteenth century, and many aspects of Mughal culture in India were praised by European writers.

${ }^{109}$ Ferguson 176. 
Travellers in India observed evidence of the achievements of ancient Hindu civilization, as seen, for example, in astronomical sites and temples adorned with intricate sculptures, as well as the splendour of the Mughal palaces and mosques that had been constructed in centuries of the relatively more recent past. The perceived decline of empires of the East was often attributed by both travellers and conjectural historians of the late eighteenth century to the excessive luxury and the corruption of Oriental despots. Travellers to both Turkey and India recorded the opulence of the courts of rulers along with the miserable conditions of the people. In referring to an earlier Mughal ruler, Akbar, whose accomplishments were praised by Hodges as well as by Warren Hastings, William Robertson writes:

He is one of the few sovereigns intitled to the appellation both of Great and Good, and the only one of Mahomedan race, whose mind appears to have risen so far above all the illiberal prejudices of that fanatical religion in which he was educated, as to be capable of forming a plan worthy of a monarch who loved his people, and was solicitous to render them happy. ${ }^{110}$

Robertson's comments reveal his negative opinion of most of the Mughal rulers in India relative to the outstanding qualities of Akbar.

As we have seen in Chapter Four, David Hume attributes the decline of empires in the East to misgovernment. In his essay 'Of National Characters,' Hume notes the destructive effect of tyrannical governments on the arts, stating, "As poverty and hard labour debase the minds of the common people, and render them unfit for any science and ingenious profession, so, where any government becomes very oppressive to all its

${ }^{110}$ Historical Disquisition 272. 
subjects, it must have a proportional effect on their temper and genius, and must banish all the liberal arts from among them."111

\section{Architectural Magnificence and Ruins}

The landscape representations produced by late eighteenth-century travellers in India evoked their musings regarding the cycle of advancement and decline of civilizations seen repeatedly throughout history. Travellers perceived the magnificence and the ruins of buildings of ancient Hindu civilization and of the Mughal Empire as presenting architectural evidence of this cycle.

As we have seen, varying views of the Hindu and Mughal cultures of the subcontinent could be found in the writing of conjectural historians. William Robertson highly praises the achievements of ancient Hindu culture, but the few comments that he makes regarding Mughal culture are generally disparaging of the tyranny and oppression of the Mughal Empire. James Mill, on the other hand, praises the achievements of Mughal culture and is critical of aspects of Hindu society, such as the caste system and the influence of the Brahmins. Hodges's comments in his written account indicate that he finds artistic achievements worthy of praise in both cultures. In his written account, he expresses his admiration of different aspects of both Mughal and Hindu architecture and sculpture. He notes that with respect to "the ornamental parts of architecture,"112 some of the sculptures adorning Hindu buildings "are very highly to be commended for the beauty of the execution; they may, indeed, be said to be very finely drawn, and cut

${ }^{111}$ Hume "Of National Characters" 114.

112 Hodges 152. 
with a peculiar sharpness." ${ }^{113}$ He suggests that the "amazing monuments" $" 114$ found in India "prove the Mussulman conquerors, to have been well acquainted with the principles of architecture." ${ }^{, 15}$ Hodges was extremely impressed with the Taj Mahal, writing, "The effect is such as, I confess, I never experienced from any work of art. The fine materials, the beautiful forms, and the symmetry of the whole, with the judicious choice of situation, far surpasses any thing I ever beheld."

Hodges refers to the Mughal Empire as "the greatest and the richest empire, perhaps, of which the human annals can produce an instance, and which was adorned with many really great characters in politics and in arms. ${ }^{, 117}$ In his written account, Hodges states, "It is not my business to enter into the question respecting the rights of the government in different countries and those of the governed. Facts are my object, and such alone as fell within the limited and confined sphere of my notice." ${ }^{\prime 18}$ His text contains neither praise nor criticism relating to British involvement in India. It is possible that a certain amount of reserve may have seemed appropriate in his view, given that his journey to the South Seas was under the auspices of the Admiralty and his journey to India was under the patronage of Hastings and the East India Company. Hodges's journeys were unavoidably, as stated by Geoff Quilley, “intimately connected with the rise of empire." $" 119$

\footnotetext{
${ }^{113}$ Ibid.

${ }^{114}$ Ibid.

115 Ibid.

${ }^{116}$ Ibid. 126.

${ }^{117}$ Ibid. 151

118 Ibid. 48

${ }^{119}$ Quilley "William Hodges, artist of empire" 1.
} 
The political comments that are found in Hodges's written account relate, for the most part, to the social conditions that he views in his travels. Hodges attributes the miserable living conditions of the people to the luxury and tyranny of recent rulers:

The private luxury and vices of the Mussulman princes too frequently reduce them to a state of real poverty, even with large revenues; and too often they delegate to artful, designing, and avaricious characters, the management and concerns of the state, and become virtually the plunderers instead of the parents of their subjects. ${ }^{120}$ Hodges's comments reflect the discussions of the time relating to notions of Oriental despotism. With his appreciation, at the same time, of some of the achievements of the Mughal Empire, the social conditions that he was witnessing seemed to serve as evidence of a decline in the Mughal Empire. Warren Hastings shared Hodges's views of some of the earlier achievements of Mughal rulers. As discussed by Natasha Eaton, Hastings tried to achieve a structure of administration of the East India Company that would retain some of the best principles put forward by earlier Mughal rulers, in particular Akbar, in combination with British principles of governance, in a hybrid approach referred to as enlightened or benevolent despotism. In any case, Hodges was clearly affected by the poverty of the people that he was observing in his travels. He often relates his sense of melancholy in viewing Mughal ruins and some of the areas that he views in his travels. The dark and brooding atmosphere of paintings such as $A$ View of a Mosque at Mounheer [Maner], c. 1781, may suggest some of Hodges's reflections of the time. Hodges's paintings of Mughal architecture include many depictions of sites in ruin, and his

${ }^{120}$ Hodges 103. 
ruminations in relation to the state of the Mughal Empire, in both textual and visual form, constitute another aspect of the reflection of conjectural history in his works.

Hodges's final exhibit in England was dedicated to the theme of war and peace. Ever critical of the effects of war, Hodges's depictions of peace are associated with landscapes of thriving pastoral scenes. Natasha Eaton argues that just as Hodges's landscapes of the English countryside suggest the peaceful continuity of traditions under British governance, his depictions of Bengal suggest that the area is thriving under British administration. In his written account, Hodges notes:

Where there is neatness in the cultivation of the land, and that land tilled to the utmost of its boundaries, it may reasonably be supposed that the government is the protector and not the oppressor of the people. Throughout the kingdom of Bengal it appears highly flourishing in tillage of every kind, and abounding in cattle. The villages are neat and clean, and filled with swarms of people. ${ }^{121}$

As well as paintings of pastoral landscapes in Bengal, Hodges's aquatint $A$ Farmyard in the Kingdom of Bengal, 1786, depicts a peaceful rural scene of people, animals, and farm buildings.

Along with creating an association of European aesthetic approaches such as the sublime and the picturesque with new subject matter, Hodges experimented with new techniques in painting. In the effort to depict tropical light during his voyage to the South Seas, and likely influenced by Richard Wilson and perhaps by the company of sailors and geographers who were keenly interested in atmospheric conditions, Hodges attempted to produce paintings with an en plein air effect. Although developed extensively by later

${ }^{121}$ Ibid. 17. 
artists, critics of Hodges's time were not always approving of these new techniques. In addition, the application of existing European aesthetics to subject matter that appeared very strange and unfamiliar to a British audience also caused criticism of Hodges's paintings. The impeachment of his patron may have played a part in the lack of favour Hodges found with British critics, and Hodges's works have only recently begun to acquire the recognition that is appropriate to his contribution to late eighteenth-century thought. In extending the genre of landscape painting to serve as ethnographic depiction, Hodges was one of the first artists to give visual form to the new conjectural history of the late eighteenth century. In addition, Hodges's works present his engagement with a specific portion of the narrative of India's history and reflect the preoccupations of the conjectural historians regarding cycles of progress and decline. 


\section{Closing Comments}

\section{Scholarly Contribution}

In a world in which images of distant cultures make a constant appearance in news reports, on Internet sites, and in films, and in which global connections through trade, communications, and the ease of air travel contribute to increasing hybridity in all societies, one may question whether the interpretation and representation of unfamiliar cultures is a subject of current concern. However, that question is simply answered with an even cursory glance at today's equally evident challenges in achieving reciprocal understanding among the world's cultures and at the serious political implications involved with the representations of societies. While certain products of commercial modernity now appear almost everywhere, cultural differences still play a part in the global geo-political sphere as well among various communities within nations. With the degree of unfamiliarity involved in encounters accompanying an early phase in the expansion of global trade, the late eighteenth century offers a valuable forum in which to examine some of the basic epistemological processes involved in the interpretation of cultures and in the conventions of cultural representation. With the assumption of basic commonalities in human nature, late eighteenth-century conjectural historians explored the myriad of circumstances that contribute to cultural diversity.

Two interconnected levels of arguments are put forward in this thesis. On one level, the thesis closely examines the sub-genre of late eighteenth-century conjectural history in light of the many critiques since that period in relation to the assumptions, methodologies, and theories of the conjectural historians. As demonstrated by Frank 
Palmeri, the influence of late eighteenth-century conjectural history has, despite the many critiques, been both extensive and continually recurring in many fields, and the works of thinkers of the Scottish Enlightenment stand as a significant moment in the narrative of intellectual history. Scholarly discussions of Enlightenment thought range from postcolonial despair to the view that Enlightenment thinkers set out the entire basis of modern society. The truth is likely somewhere between those two poles, and this thesis presents a close historicizing of a particular period of Enlightenment thought in order to arrive at a more nuanced and realistic assessment. I turn my focus specifically to the works of the Scottish Enlightenment in relation to interpretations and representations of one area of the globe as a way of exploring the sources of this thought. The period of focus in this thesis is intentionally specifically delimited to only the decades of the late eighteenth century. Consideration is given to the influence of earlier thought, as well as to the later influence and critiques of late eighteenth-century conjectural history. However, my direct examination of conjectural history ends around the beginning of the nineteenth century. The Near East and India provide the case study of my project of historicization, and changing circumstances around the turn of the century triggered the beginning of a long trajectory of shifts in the attitudes reflected in representations of India. As we have seen, the goals of Britain's foreign policy with respect to distant regions became increasingly territorial, in part due to the acceleration of European global competition resulting from the aggressive advances of Napoleon and his armies. Along with the emergence of structures of a state-funded military supported by continuously expanding industrial and labour bases, state-driven collecting increasingly played a part 
in the cultural competition that accompanied political realities. In short, the period under my consideration ends with the British capture of Seringapatam in India.

On another level, the thesis explores the role of historical frameworks of thought in the process of cultural interpretation and representation. The examination of the interconnections among works produced by historians and travellers is an area that has not been extensively explored and is a contribution to existing scholarship relating to travel literature as well as to historical writing. The role of the information provided by travellers in works of the new sub-genre of conjectural history during the late eighteenthcentury is a topic that is referred to in many scholarly texts but forms the central investigation of very few. This thesis explores and underlines the significant and reciprocal relationship among the genres of historical writing and travellers' textual and visual representations. Not only did the first-hand observations of distant societies provided by travellers inform the theories being developed by conjectural historians, but travellers' interpretations and representations in turn reflected the historical frameworks of the time. In addition, I examine the aesthetic frameworks of thought involved in late eighteenth-century travellers' representations of distant societies. The examination of the interplay of aesthetic and historical frameworks in relation to representations of unfamiliar cultures is a further scholarly contribution of this thesis. The relationships among the genres involved in late eighteenth-century cultural interpretation and representation exhibit the part played by the differing positions of distance that characterize each genre. The dialogue between philosophy and lived experience discussed by David Hume and the varying types and degrees of distance in genres of 
representation discussed by Mark Salber Phillips are exemplified in the relationship among the works of late eighteenth-century conjectural historians and travellers. 


\section{Works Referenced}

\section{Primary Sources}

Boswell, James. Boswell on the Grand Tour: Italy, Corsica, and France, 1765-1766. London: William Heinemann Ltd., 1955.

Burke, Edmund. A Philosophical Enquiry into the Origin of our Ideas of the Sublime and Beautiful. Oxford: Oxford University Press, 1990. [1757]

Burke, Edmund. Reflections on the Revolution in France and on the Proceedings in Certain Societies in London Relative to that Event. Ed. Conor Cruise O'Brien. London: Penguin Books, 2004. [1790]

Clive, Henrietta. Birds of Passage: Henrietta Clive's Travels in South India, 1798-1801. Ed. Nancy Shields. London: Eland, 2009.

Craven, Elizabeth, Lady. A Journey through the Crimea to Constantinople in a Series of Letters from the Right Honourable Elizabeth Lady Craven, to His Serene Highness the Margrave of Brandenbourg, Anspach and Bareith. Written in the Year M DCC LXXXVI [1786]. ECCO. [London, 1789]

Eden, Emily. Up the Country: Letters written to her Sister from The Upper Provinces of India. London: Virago Press, 1983.

Fielding, Henry. The History of Tom Jones, a Foundling. London: Penguin, 1985. [1749]

Fielding, Henry. The Journal of a Voyage to Lisbon. Dodo Press. [1755]

Fielding, Henry. An Apology for the Life of Mrs. Shamela Andrews. London: Penguin, 1999. [1741]

Ferguson, Adam. An Essay on the History of Civil Society. Cambridge, U.K.: Cambridge University Press, 1995. [1767]

Forster, George. Sketches of the mythology and customs of the Hindoos, most respectfully inscribed to the Honorable the Court of Directors of the East-India Company, by their dutiful servant, George Forster. ECCO. [London, 1785]

Gilpin, William. Observations on the River Wye and several parts of South Wales, etc. relative chiefly to Picturesque Beauty; made in the summer of the year 1770. Richmond, Surrey, England: Richmond Publishing Co., 1973. [1782] 
Goethe, Johann Wolfgang, von. Die Leiden des jungen Werthers. [The Sorrows of Young Werther.] London: Penguin, 1989. [1774]

Haynes, James. Travels in several parts of Turkey, Egypt, and the Holy Land, by James Haynes, late clerk to an eminent merchant in Grand Cairo. ECCO. [London, $1744]$

Hodges, William. Travels in India, during the years 1780, 1781, 1782, \& 1783. ECCO. [London, 1793]

Home, Henry, Lord Kames. Sketches of the History of Man. Indianapolis: Liberty Fund, 2007. [1788]

Hume, David. Dialogues concerning Natural Religion. London: Penguin, 1990. [1779]

Hume, David. "Of Commerce." Selected Essays. Oxford: Oxford University Press, 2008.

Hume, David. "Of Essay Writing." Selected Essays. Oxford: Oxford University Press, 2008.

Hume, David. "Of National Characters." Selected Essays. Oxford: Oxford University Press, 2008.

Hume, David. "Of Refinement in the Arts." Selected Essays. Oxford: Oxford University Press, 2008.

Hume, David. "Of the Populousness of Ancient Nations." Selected Essays. Oxford: Oxford University Press, 2008.

Hume, David. The History of England. Indianapolis: Liberty Fund, 1983. [1778]

Hume, David. "The Natural History of Religion." Principal Writings on Religion including Dialogues Concerning Natural Religion and The Natural History of Religion. Ed. J.C.A. Gaskin. New York: Oxford University Press, 1993. [1757]

Irwin, Eyles. A Series of adventures in the course of a voyage up the Red-Sea, on the coasts of Arabia and Egypt: and of a route through the desarts of Thebais, hitherto unknown to the European traveller, in the year M.DCC.LXXVII, in the service of the Honourable The East-India Company. ECCO. [London: Printed for J. Dodsley, Pall-Mall, 1780]

Johnson, Samuel. A Journey to the Western Islands of Scotland. Oxford: Clarendon Press, 1985. [1775] 
Jones, William. "On the Gods of Greece, Italy, and India." The British Discovery of Hinduism in the Eighteenth Century. Ed. P.J. Marshall. Cambridge University Press, 1970.

Logan, John. Dissertation on the Governments, Manners, and Spirit of Asia. Introduction by Richard Sher. Bristol, England: Thoemmes Press, 1995. [London, 1787]

Logan, John. Elements of the Philosophy of History. Part First. Introduction by Richard Sher. Bristol, England: Thoemmes Press, 1995. [Edinburgh, 1781]

Mackintosh, James, Sir. Memoirs of the Life of Sir James Mackintosh. Volume I. Second Edition. Ed. Robert James Mackintosh. Kessinger Publishing. [London: Edward Moxon, Dover Street, 1836.]

Mackintosh, Robert James. Memoirs of the Life of Sir James Mackintosh. Volume I. Second Edition. Kessinger Publishing. [London: Edward Moxon, Dover Street, 1836.]

Mill, James. The History of British India. Cambridge: Cambridge University Press, 2010. [1817]

Millar, John. The Origin of the Distinction of Ranks: Or, An Inquiry into the Circumstances Which Give Rise to Influence and Authority, in the Different Members of Society. Indianapolis, Indiana: Liberty Fund, Inc., 2006. [1771]

Montagu, Mary Wortley, Lady. "Turkish Embassy Letters." The Complete Letters of Lady Mary Wortley Montagu. Volume I, 1708-1720. Ed. Robert Halsband. Oxford University Press, 1965.

Montesquieu. Persian Letters. Trans. Margaret Mauldon. New York: Oxford University Press, 2008. [1721]

Montesquieu. The Spirit of the Laws. Eds. Anne M. Cohler, Basia C. Miller, and Harold S. Stone. Cambridge: Cambridge University Press, 1989. [1748]

Orme, Robert. A history of the military transactions of the British nation in Indostan, from the year MDCCXLV [1745]. To which is prefixed A dissertation on the establishments made by Mahomedan conquerors in Indostan. ECCO. Print Editions. [1763 (vol. 1), 1778 (vol. 2)]

Radcliffe, Ann. The Italian. London: Penguin, 2004. [1797]

Richardson, Samuel. Pamela: Or, Virtue Rewarded. Oxford: Oxford University Press, 2001. [1740] 
Robertson, William. An Historical Disquisition concerning the Knowledge which the Ancients had of India; and the Progress of Trade with that Country prior to the Discovery of the Passage to it by the Cape of Good Hope. ECCO. [London, 1791]

Robertson, William. History of America. ECCO. Print Editions. [1777]

Rousseau, Jean-Jacques. Discours sur l'origine et les fondements de l'inégalité parmi les hommes. [Discourse on the Origins and Foundations of Inequality among Men.] Trans. Maurice Cranston. London: Penguin, 1984. [1755]

Rousseau, Jean-Jacques. Les Rêveries du promeneur solitaire. [Reveries of the Solitary Walker.] Trans. by Peter France. London: Penguin, 1979. [1782]

Scott, Helenus. The Adventures of a Rupee. Wherein are Interspersed Various Anecdotes Asiatic and European. ECCO. [1782]

Scott, Walter, Sir. Waverley; Or, 'Tis Sixty Years Since. London: Penguin, 1972. [1814]

Smith, Adam. An Inquiry into the Nature and Causes of the Wealth of Nations. Intro. by Kathryn Sutherland. Oxford: Oxford University Press, 1993. [1776]

Smith, Adam. Lectures on Jurisprudence. Indianapolis: Liberty Fund. Oxford University Press, 1978.

Smith, Adam. Lectures on Rhetoric and Belles Lettres. Ed. J.C. Bryce. Oxford University Press, 1983.

Smollett, Tobias. The Expedition of Humphry Clinker. London: Penguin, 2008. [1771]

Sterne, Laurence. A Sentimental Journey through France and Italy. By Mr. Yorick. Ed. Graham Petrie. Intro. A. Alvarez. London: Penguin, 1967. [1768]

Sterne, Laurence. The Life and Opinions of Tristram Shandy, Gentleman. Oxford: Oxford University Press, 2009. [1759-67]

Williams, Helen Maria. Letters Written in France. Peterborough, Ontario: Broadview Press, 2001. [1790]

Wollstonecraft, Mary. Letters Written During a Short Residence in Sweden, Norway and Denmark in 1796. London: Centaur Press, 2004. [1796]

Wordsworth, Dorothy. Recollections of a Tour Made in Scotland, A.D. 1803. New Haven: Yale University Press, 1997. [1874]

[ECCO: Eighteenth Century Collections Online (Gale)] 


\section{Secondary Sources}

Adams, Percy. Travel Literature and the Evolution of the Novel. Lexington, Kentucky: The University Press of Kentucky, 1983.

Almeida, Hermione de and George H. Gilpin. Indian Renaissance: British Romantic Art and the Prospect of India. Aldershot, England: Ashgate Publishing, 2005.

Avcioğlu, Nebahat. Turquerie and the Politics of Representation, 1728-1876. Farnham, Surrey, England: Ashgate Publishing, 2011.

Avcioğlu, Nebahat and Finbarr Barry Flood. "Introduction." Globalizing Cultures: Art and Mobility in the Eighteenth Century. Washington: Smithsonian. Ars Orientalis. Vol. 39.

Beaulieu, Jill and Mary Roberts, eds. Orientalism's Interlocutors: Painting, Architecture, Photography. Durham: Duke University Press, 2002.

Bellamy, Liz. Commerce, Morality and the Eighteenth-century Novel. Cambridge, U.K.: Cambridge University Press, 1998.

Berg, Maxine. Luxury and Pleasure in Eighteenth-Century Britain. New York: Oxford University Press, 2005.

Bermingham, Ann. Landscape and Ideology: The English Rustic Tradition, 1740-1860. Berkeley: University of California Press, 1986.

Bindman, David. "'Philanthropy seems natural to mankind': Hodges and Captain Cook's second voyage to the South Seas." William Hodges, 1744-1797: the Art of Exploration. Eds. Geoff Quilley and John Bonehill. London: National Maritime Museum, 2004.

Black, Jeremy. The British Abroad: The Grand Tour in the Eighteenth Century. Stroud, Gloucestershire: The History Press, 2003.

Burrow, J.W. Evolution and Society: A Study in Victorian Social Theory. Cambridge, U.K.: Cambridge University Press, 1966.

Carnall, Geoffrey. "Robertson and contemporary images of India." William Robertson and the expansion of empire. Ed. Stewart J. Brown. New York: Cambridge University Press, 1997.

Cohn, Bernard. Colonialism and its Forms of Knowledge: The British in India. Princeton, New Jersey: Princeton University Press, 1996. 
Curtis, Michael. Orientalism and Islam: European Thinkers on Oriental Despotism in the Middle East and India. New York: Cambridge University Press, 2009.

Dyson, Ketaki Kushari. A Various Universe: A Study of the Journals and Memoirs of British Men and Women in the Indian Subcontinent 1765-1856. New Delhi: Oxford University Press, 2002.

Eaton, Natasha. "Hodges's visual genealogy for colonial India, 1780-95." William Hodges, 1744-1797: the Art of Exploration. Eds. Geoff Quilley and John Bonehill. London: National Maritime Museum, 2004.

Fabian, Johannes. Time and the Other: How Anthropology Makes its Object. New York: Columbia University Press, 1983.

Gaastra, Femme S. "War, Competition and Collaboration: Relations between the English and Dutch East India Company in the Seventeenth and Eighteenth Centuries." The Worlds of the East India Company. Eds. H.V. Bowen, Margarette Lincoln, Nigel Rigby. Woodbridge, Suffolk, U.K.: Boydell Press, 2002.

Geertz, Clifford. Works and Lives: The Anthropologist as Author. Stanford, California: Stanford University Press, 1988.

Gombrich, E.H. The Story of Art. London: Phaidon Press, 1995.

Hoock, Holger. Empires of the Imagination: Politics, War, and the Arts in the British World, 1750 - 1850. London: Profile Books, 2010.

Horrocks, Ingrid. 'Creating an 'insinuating interest': Mary Wollstonecraft's travel reviews and A Short Residence." Studies in Travel Writing. Vol. 19, No. 1. February 2015. Routledge. p. 1-15.

Jasanoff, Maya. Edge of Empire: Lives, Culture, and Conquest in the East, 1750 - 1850. New York: Vintage Books, 2005.

Keen, Paul. The Crisis of Literature in the 1790s: Print Culture and the Public Sphere. Cambridge, U.K.: Cambridge University Press, 1999.

Kia, Mehrdad. Daily Life in the Ottoman Empire. Santa Barbara, California: Greenwood, 2011.

Kostof, Spiro. A History of Architecture: Settings and Rituals. Oxford: Oxford University Press, 1995.

Laidlaw, Christine. The British in the Levant: Trade and Perceptions of the Ottoman Empire in the Eighteenth Century. London: Tauris, 2010. 
Leask, Nigel. Curiosity and the Aesthetics of Travel Writing, 1770-1840: 'From an Antique Land.' New York: Oxford University Press, 2002.

Lewis, Bernard. Islam and the West. New York: Oxford University Press, 1993.

MacKenzie, John M. Orientalism: History, Theory and the Arts. Manchester, U.K.: Manchester University Press, 1995.

Marshall, P.J. and Glyndwr Williams. The Great Map of Mankind: British Perceptions of the World in the Age of Enlightenment. London: J.M. Dent \& Sons Ltd, 1982.

Momigliano, Arnaldo. "Ancient History and the Antiquarian." Studies in Historiography. London: Weidenfeld and Nicolson, 1966.

Nechtman, Tillman W. Nabobs: Empire and Identity in Eighteenth-Century Britain. Cambridge University Press, 2010.

O'Brien, Conor Cruise. "Introduction." Reflections on the Revolution in France and on the Proceedings in Certain Societies in London Relative to that Event. London: Penguin Books, 2004.

Pagden, Anthony. The Enlightenment: And Why It Still Matters. New York: Random House, 2013.

Palmeri, Frank. State of Nature, Stages of Society: Enlightenment Conjectural History and Modern Social Discourse. New York: Columbia University Press, 2016.

Phillips, Mark Salber. On Historical Distance. New Haven: Yale University Press, 2013.

Phillips, Mark Salber. Society and Sentiment: Genres of Historical Writing in Britain, 1740-1820. Princeton, New Jersey: Princeton University Press, 2000.

Pocock, J.G.A. Virtue, Commerce, and History: Essays on Political Thought and History, Chiefly in the Eighteenth Century. New York: Cambridge University Press, 1985.

Quilley, Geoff. "Signs of Commerce: The East India Company and the Patronage of Eighteenth-Century British Art." The Worlds of the East India Company. Eds. H.V. Bowen, Margarette Lincoln, Nigel Rigby. Woodbridge, Suffolk, U.K.: Boydell Press, 2002.

Quilley, Geoff. "William Hodges, artist of empire." William Hodges, 1744-1797: the Art of Exploration. Eds. Geoff Quilley and John Bonehill. London: National Maritime Museum, 2004. 
Ray, Romita. Under the Banyan Tree: Relocating the Picturesque in British India. New Haven: Yale University Press, 2013.

Russo, Stephanie. "“The writer died at Autun in her 26th year': genre, health tourism and Anna Jameson's Dairy of an Ennuyée." Studies in Travel Writing. Vol. 20, No.

2. June 2016. Routledge. p. 200-213.

Sher, Richard. "Introduction." John Logan. Elements of the Philosophy of History. Part First. Bristol, England: Thoemmes Press, 1995.

Simon, Robin. "Richard Wilson, Rome, and the Transformation of European Landscape Painting." Richard Wilson and the Transformation of European Landscape Painting. Eds. Martin Postle and Robin Simon. Yale University Press, 2014.

Starcky, Emmanuel. Rembrandt. New York: Portland House, 1990.

Stocking, George W. Race, Culture, and Evolution: Essays in the History of Anthropology. New York: The Free Press, 1968.

Sutherland, Kathryn. "Introduction." Adam Smith. An Inquiry into the Nature and Causes of the Wealth of Nations. Oxford: Oxford University Press, 1993.

Tillotson, Giles. "Hodges and Indian architecture." William Hodges, 1744-1797: the Art of Exploration. Eds. Geoff Quilley and John Bonehill. London: National Maritime Museum, 2004.

Tillotson, Giles. "The Indian Picturesque: Images of India in British Landscape Painting 1780-1880." The Raj: India and the British 1600-1947. Ed. C.A. Bayly. London: National Portrait Gallery Publications.

Tobin, Beth Fowkes. Picturing Imperial Power: Colonial Subjects in Eighteenth-century British Painting. Durham: Duke University Press, 1999.

Watkin, David. "Stuart and Revett: The Myth of Greece and its Afterlife." James "Athenian" Stuart, 1713-1788: The Rediscovery of Antiquity. Ed. Susan Weber Soros. New Haven: Yale University Press, 2006.

Winch, Donald. "Biographical Sketch.” James Mill. Selected Economic Writings. New Jersey: Transaction Publishers, 2006.

Winch, Donald. "James Mill and India." James Mill. Selected Economic Writings. New Jersey: Transaction Publishers, 2006. 